\title{
ANALYTICAL SELECTION
}

\author{
OF MARKETABLE
}

SAHP SYSTEMS

\author{
FINAL REPORT \\ FOR THE PERIOD \\ September 30, 1977 - December 31, 1979
}

William Kahan

January 1980

Work Performed Under Contract EG-77-C-03-1467

THE SINGER COMPANY

286 Eldridge Road

Fairfield, New Jersey 07006 


\section{DISCLAIMER}

This report was prepared as an account of work sponsored by an agency of the United States Government. Neither the United States Government nor any agency Thereof, nor any of their employees, makes any warranty, express or implied, or assumes any legal liability or responsibility for the accuracy, completeness, or usefulness of any information, apparatus, product, or process disclosed, or represents that its use would not infringe privately owned rights. Reference herein to any specific commercial product, process, or service by trade name, trademark, manufacturer, or otherwise does not necessarily constitute or imply its endorsement, recommendation, or favoring by the United States Government or any agency thereof. The views and opinions of authors expressed herein do not necessarily state or reflect those of the United States Government or any agency thereof. 


\section{DISCLAIMER}

Portions of this document may be illegible in electronic image products. Images are produced from the best available original document. 


\section{ANALYTICAL SELECTION}

OF MARKETABLE

SAHP SYSTEMS

FINAL REPQBT

FOR THE PERIOD

September 30, 1977 - December 31, 1979

William Kahan
January 1980

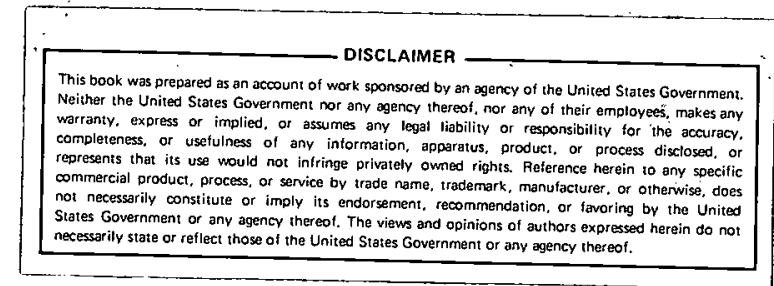

THE SINGËR COMPANY

286 Eldridge Road

Fairfield, New Jersey 07006

Prepared for

THE U. S. DEPARTMENT OF ENERGY

SOLAR HEATING RESEARCH AND DEVELOPMENT BRANCH

OFFICE OF CONSERVATION AND SOLAR APPLICATION

Under Contract EG-77-C-03-1467 


\section{NOTICE}

This report was prepared as an account of work sponsored by an agency of the United States Government. Neither the United States nor any agency thereof. nor any of their employees, makes any warranty, expressed or implied, or assumes any legal liability or responsibility for any third party's use or the results of such use of any information, apparatus, product or process disclosed in this report, or represents that its use by such third party would not infringe privately owned rights. 


\section{ABSTRACT}

For the effective marketing of energy conserving heating systems which have high initial costs, such as the solar assisted heat pump (SAHP). it is imperative to identify those climatic regions, load profiles, and system characteristics for which such systems are economically promising. This report summarizes efforts to develop a quick and efficient means of performing this identification. These efforts were separated into two distinct studies, a marketing study and a techinical study of five energy conserving systems; a stand-alone heat pump, a stand-alone solar energy system, and a series, a parallel, and a dual source SAHP system.

- One of the primary results of the marketing study was the identification of the portion of the HVAC market (i.e... the load profile and the U.S. regions) into which the initial marketing thrust of these systems should be concentrated. In addition, several factors which influence the sales of these systems were identified.

The technical study concentrated on the development and use of an analytical model of each of the systems. This model was designed to quickly "size", In a specific climatic region, the system components for an economic optimum; i.e.. for a minimum life cycle cost. Then the one energy conserving system which has the lowest life cycle cost, and thus the best potential, can be identified.

It was found that, at present costs of electricity. the air-to-air heat pump has the lowest life cycle cost and hence is considered most marketable. At significantly higher electricity costs, the series SAHP system is the most marketable one because it has the lowest life cycle cost of the five energy conserving systems studied. 


\section{TABLE OF CONTENTS}

SECTION

PAGE

I

EXECUTIVE SUMMARY

6

T-1.

TECHNICAL INTRODUCTION \& SUMMARY

21

$\mathrm{T}-2$

TECHNICAL PAPERS

26

$\mathrm{T}-3$

TECHNICAL CONCLUSIONS

M-1

MARKETING INTRODUGTION

M-2

ENGINEERING OF SELECTED SAHP SYSTEMS

82

M-3

HVAC SYSTEM COMPONENT \& INSTALLATION COSTS

M-4

SINGLE FAMILY HVAC MARKET CHARACTERISTICS

116

M-5

LCC ANALYSIS IN SELECTED CITIES

134

M-6

CORRELATION ANALYSIS

REFERENCES

APPENDDX 1

APPENDIX 2

ADDENDUM

170 


\section{EXECUTIVE SUMMARY}

\section{PURPOSE}

This report presents final data, information, and conclusions developed by the singer company on the marketability of Solar Assisted Heat Pump (SAHP) heating systems in the course of its work under Department of Energy contract No. EG77-C-03-1467.

\section{$\underline{\text { SCOPE }}$}

The study had for its basis two premises and one question... ... Solar heating systems are energy-conserving.

... Heat pump heating systems are energy-conserving.

... How can these two systems best be combined into a Solar Assisted Heat Pump (SAHP) system to conserve energy more effectively? o

- The scope of the study was, then, to...

... examine the ways in which the two systems could be combined and optimized

... compare the SAHP system energy and economic perform- . ance with conventional systems

... determine the marketability of such a system

\section{WORK ORGANIZATION}

The work of the study was organized into two major sections... ... Technical. Section

... Marketing section

The work of each of these sections was conducted in parallel to optimize the use of the planned time-period. However, both sections were under the direct supervision of the Principal Investigator so that specific preliminary market data and information required by the Technical section would be furnished at the appropriate times.

This report is also organized into a Technical section and a Marketing section. 


\section{TECHNICAL SECTION}

The work of the Technical section of this study was performed by Renee C. Estes, William Kahan, and Michael C. Lendemer under the supervision of the Principal Investigator.

Three types of SAHP systems were identified and investigated in the Technical Section...

... dual-source SAHP system

... parallel SAHP system

... series SAHP system

Through an Analytical Model developed for this study, the three SAHP systems were optimized for the best collector and storage capacity and then compared, on a life cycle cost (LCC) basis, with ...

... all-electric heating system ..

... stand-alone air-to-air heat pump system

... stand-alone solar heating system

The comparison among these systems is based on the premise that the system with the lowest LCC would normally be the most marketable. This premise implies that most buyers perceive the value of higher initial cost in return for longer-term benefits; however, in the past, buyers have not shown this characteristic and have favored lower first cost instead. Despite this, the premise is used here because, without it, the substantially higher initial cost of solar and SAHP systems could not even be considered. In any event, it is believed that buyers will become more LCCconscious when and if faced with large energy cost in-: creases above the general inflation rate.

The results of the Analytical Model clearly show that, of the active solar systems studied, a SAHP system is by far more economically attractive than a stand-alone solar system in the foreseeable future.

However, the results also demonstrated that active solar systems in single family residential applications are not economically competitive with the stand-alone air-to-air heat pump and that large changes in their initial cost would be required to make them competitive. 
The 1979 average cost of residential electricity in the United states is $5 \mathrm{c} / \mathrm{kWh}$. The following table shows the electricity cost, expressed in 1979 constant dollars, that would be required for the active solar systems studied to have a LCC equal to that of an air-to-air heat pump in New York City:

Electricity Rate Required for LCC Equal to Air-to-Air Heat Pump

Solar system Type

Solar Assisted Heat Pump

Stand-Alone solar

(1)

\&/kWh

13

36

(1)

\section{Constant Dollars}

Figure 1.1 shows in more detail the results of the analytical Model analysis for a New York City type climate. In this figure, the ordinate gives, instead of the total ICC of a system, an equivalent quantity, the AUC. This is the annual cost of owning and operating the system, expressed in 1979 dollars. For each competing system, the figure shows the AUC as a function of $C_{F}$, the cost of fuel at the time the system is installed. At very low values of $C_{F}$, as are typical of gas at present (equivalent to approximately $1 \mathrm{c} / \mathrm{kWh}$ at $50 \%$ utilization). conventional fuel burning systems have the lowest AUC (lowest LCC), even if they are only $50 \%$ seasonally efficient. At today's cost of electricity, the electrically driven system with the lowest AUC and hence the most marketable one, is the air-to-air heat pump. Among systems installed when costs of electricity are significantly higher than $5 \mathrm{c} / \mathrm{kWh}$, the system with the lowest AUC (lowest LCC) is the series SAHP. 


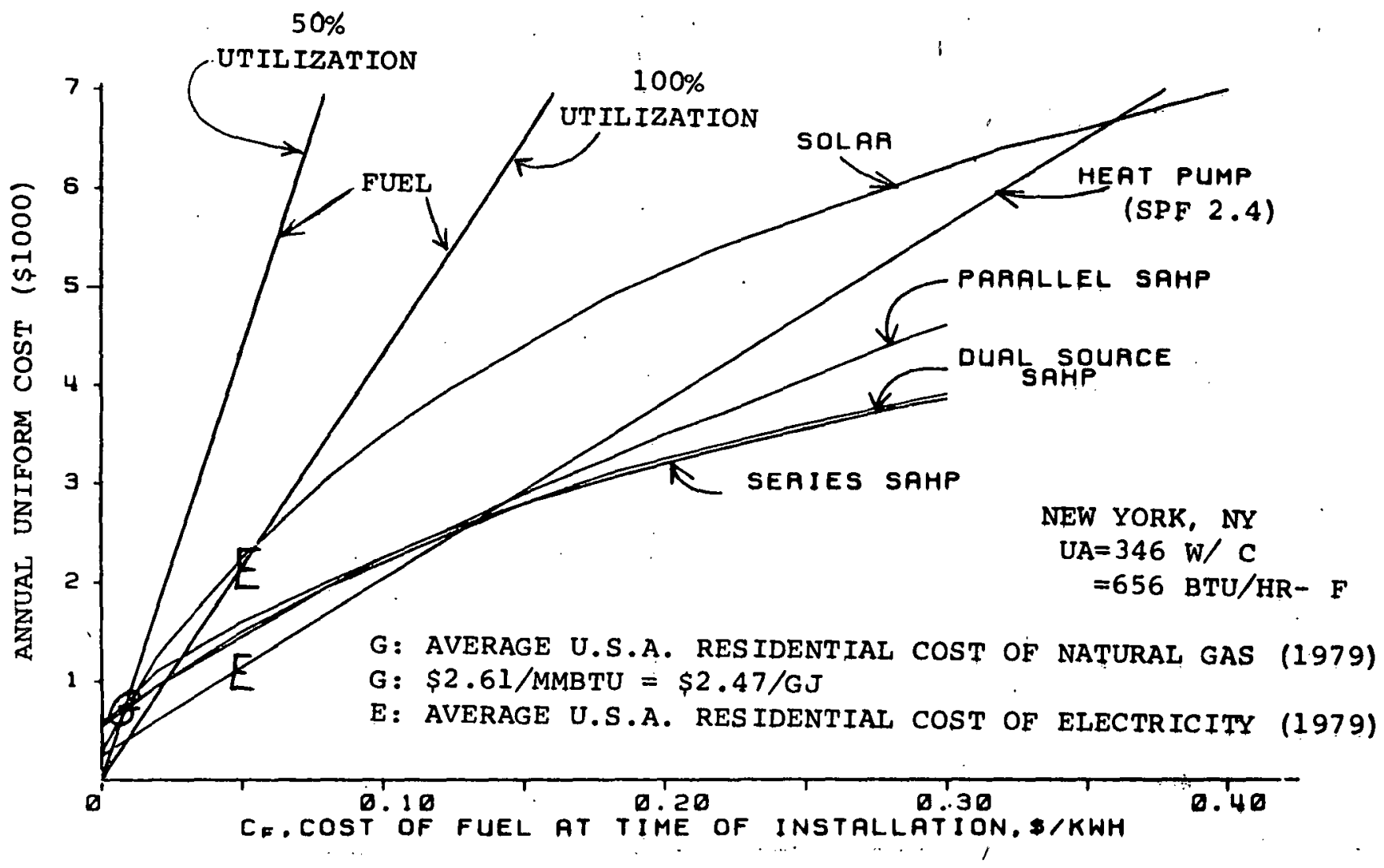

FIGURE 1.1 - Comparison of Competing space Heating systems

The figure shows the Annual Uniform cost (AUC), in 1979 dollars, of heating a single family house in a New York city type climate as a function of $C_{F}$, the cost of fuel at the $t$ ime the system is installed. The AUC is the annual cost of owning and operating the system and is directly related to the total life cycle cost (LCC). For the assumption used here (annual worth of money = 0.02 above inflation, system lifetime $=15$ years), each $\$ 1000$ of the present value of the LCC is equivalent to $\$ 77.83$ of AUC. Where appropriate, the collector area and storage volume have been sized at each value of $C_{F}$ to minimize the AUC of the system. The symbols $\mathrm{E}$ and $\mathrm{G}$ have been located at positions corresponding to their present values of $C_{F}$. 
These results were based on certain key economic assumptions:

- Fuel Escalation Rate- 0.045 above inflation for gas, oil, and electricity

- Worth of Money

- 0.02 above inflation

- System Life

- 15 years

Lower fuel escalation rates, as commonly predicted for electricity, would favor conventional over solar energy systems. Similarly, higher values for the worth of money, corresponding to past consumer buying preferences, would also favor conventional over solar energy systems.

In addition, because the analyses were performed to assess the marketability of SAHP systems to be developed in the future, it was assumed that two of the major components of the systems had cost and/or performance characteristics which are not available today but which may be available in the future. Accordingly, the moderate efficiency collector used in analysis, which has a $63 \%$ efficiency intercept where the difference between the collector fluid temperature and the outdoor ambient temperature is zero and an efficiency slope of $-100 \% /\left({ }^{\circ} \Delta \mathrm{F} \mathrm{ft} \mathrm{ft}^{2} / \mathrm{Btuh}\right)$, was assumed to cost $6 \$ \mathrm{ft}^{2}$. fully installed. This price is only a small fracti on of the price of fully installed collectors that are commonly available. Furthermore, the collector assumed in this analysis has a better Btu per dollar performance ratio than those in the market today.

In addition, it was assumed that a high efficiency heat pump would be available for $\$ 3,000$. This heat pump, when used as a stand-alone unit, would exhibit-a seasonal performance factor (SPF) in New York City of 2.4 as indicated in Figure 1.1. For comparison, current stand-alone heat pumps typically cost approximately $\$ 2,000$ and have SPF's of approximately 2 .

Because the results showed such an unfavorable position for SAHP systems, further analysis were performed for the climates of Charleston, SC, Nashville, TN, Madison, WI, and Santa Maria, CA with one favorable change in assumption, namely that... 
...the heat pump whose stand-alone seasonal performance factor is 2.4 would be available for use in the SAHP system, but only current conventional heat plimps with seasonal performance factors ranging from 1.75 to 2.25 would be available for stand-alone use. The $\$ 3,000$ cost for the stand-alone units was retained, however.

Figure 1.2 shows the result of the Analytical Model analys is for New York City with this revised assumption. The electricity cost, expressed in 1979 constant dollars, that would be required for the active solar systems studied to have a LCC equal to that of an air-to-air heat pump in New, York city would be:

$$
\begin{aligned}
& \text { Solar System Type } \quad \xi / k w h^{(1)} \\
& \text { Solar Assisted Heat Pump } 7 \\
& \text { Stand=Alone dolap...... } 23 \\
& \text { (1) } 1979 \text { Constant Dollars }
\end{aligned}
$$

This additional assumption considerably changes the economic relationship between the three SAHP systems and the stand-alone heat pump. Even though the 1979 national average electricity rate was $5 \mathrm{c} / \mathrm{kwh}$, there are some regions of the U.S. (with a New York City type climate) where the current rate for electricity is almost $7 \mathrm{c} / \mathrm{kwh}$. The results indicate then that the series SAHP systems, with their improved, yet unavailable components, have a potential for being marketable in these areas today (assuming, of course, that natural gas is not available). In reality, however, to be marketable, the AUC of a SAHP system has to be significantly below that of the air-to-air heat pump because...

...consumer buying preferences are influenced to a great degree by initial cost, and the initial cost of a standalone pump is much less than that of a solar assisted heat pump.

...many of the assumptions used to generate Figure 1.2 are biased, at least partially, in favor of the solar energy system. Thus, for example, the moderate efficiency, lowcost collector used in the analys is is not available today and is unlikely to become available unless substantial 


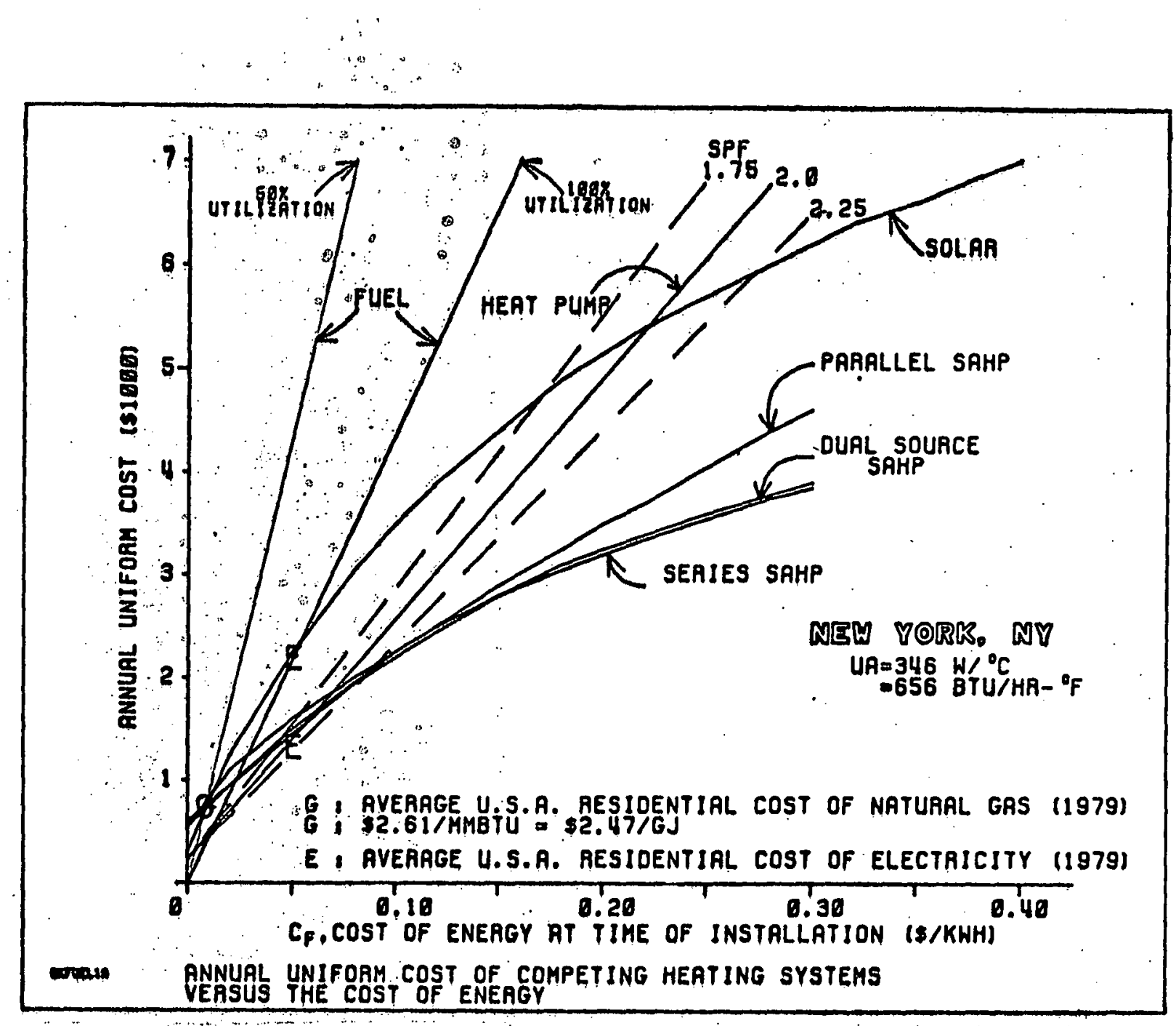

Figure 1.2 - Comparison of Competing Space Heat Systems

The flgure shows the Annual Uniform Cost (AUC), in 1979 dollars, of heating a single family house in a New York City type climate as a function of $C_{F}$, the cost of fuel at the time the system is installed. The AUC is the annual cost of owning and operating the system and is directly related to the total life cycle cost (LCC). For the assumptions used here (annual worth of money $=0.02$ above inflation, fuel escalation rate $=0.045$ above inflation; system lifetime $=15$ years), each $\$ 1,000$ of the present value of the LCC is equivalent to $\$ 77.83$ of AUC. Where appropriate, the collector area and storage volume have been sized at each value of $C_{F}$ to minimize the AUC of the system. 
scientific and/or manufacturing breakthrough occur.

...it is unlikely that the extra $\$ 1,000$ (of 1979 constant dollars) tacked on to the price of the stand-alone heat pump of Figure 1.2 will result in no performance improvement, as is assumed here.

...most observers feel that electricity costs will escalate more slowly than fossil fuel costs, say 0.025 above inflation instead of the 0.045 above inflation used here, because only about one-third of a utility's cost is for fuel, the balance consisting of items not expected to escalate faster, in the aggregate, than inflation. Thus, the use of 0.045 escalation above inflation for all three energy sources is highly favorable, and probably unrealistic for SAHP systems.

Note too, that the use of a 0.025 escalation rate above inflation for electricity raises to $10 \mathrm{k} / \mathrm{kwh}$ in 1979 constant dollars the cost of electricity (at system installation time) at which active solar energy systems have a LCC equal to that of an air-to-air heat pump.

The results of the analyses show that this significant difference between SAHP and heat pump occurs when the cost of electricity (in 1979 dollars) becomes appreciably higher than $7 \xi / \mathrm{kwh}$. This may take many years. For example, an increase to only 10 \&/kwh (in 1979 dollars) from the $7 \xi / \mathrm{kwh}$ electricity rates currently prevalent in some regions would take 8 years at an annual fuel escalation rate of 0.045 (above inflation); and 14 years at a 0.025 rate. The lower escalation rate of 0.025 will produce equal LCC for SAHP and heat pump systems at approximately $10 \% / \mathrm{kwh}$. Therefore, not only is equality of LCC between SAHP and heat pump systems 14 years into the future at the assumed rate of 0.025 , but also it would be many years after that before SAHP would achieve a significant LCC advantage.

These results, even with assumptions biased in favor of active solar energy, lead not only to the conclusion that solar assisted heating systems are not economically competitive with air-toair heat pump systems at this time, but also that hugh changes would be required to make them competitive. 
Accordingly, manufacturers cannot discern directions of investment in development or marketing that could be productive within a normal planning period of 5 to 7 years.

The absolute values of the parameters used in the analysis assumptions do not effect the results and conclusions as much as the relationships between these parameter values do. Therefore, if large scale changes in these relationships occur --
for example...

... if electricity rates should begin to escalate much faster than the worth of money .. if the worth of money should undergo a prólonged fall
below inflation

... if radical cost reductions in collectors and storage should
occur

...if techńologies fundamentally different from those studied come to light (one example is ground coupling)

or other unforeseen large-scale changes take place, then it is recommended that this study be reopened. Such a need is not

1 foreseen, however, for several years.

\section{MARKETING SECTION}

The work of the Marketing Section of this study was performed by Robert P. Shapess, Marketing Analyst, under the supervision of William Kahan, Principal Investigator, and general direction, as Singer Company's Climate Smith, Vice President, Planning of the Singer's subcontractor, Control Division. Also, ITC/Solar, Section.

The major scope and sequence of the marketing work included:

...SAHP system application engineering

... SAHP system costs

...Single Family Home HVAC Market characteristics 


\section{...Life Cycle cost Analysis}

...Correlation Analysis

Each of these has been developed into a chapter in the marketing section of the report.

\section{SAHP System Engineering}

In the HVAC industry, application engineering is commonly a marketing function and, accordingly, system application engineering was performed as part of the work of the marketing section of this study by Mr. Shapess.

The prime thrust of the Technical section centered around its development and use of an Analytical Model. The basic function of the Analytical Model was to identify the combination of system type and climate region in which SAHP systems would have lower LCC than competing space heating systems. To accomplish this identification in a cost effective manner. the Model empioyed simple, generic systems to represent SAHP and competing systems... These systems were chosen because they are amenable to rapid elosed form mathematical solution. However, after the model identifies $\mathrm{SAH}$ system and climate in which it is marketable, two additional steps must be taken: one, design a number of engineered systems that correspond to . the generic "Winner"; and then, two, simulate the performance of these engineered systems in order to asses, in detail, their performance and methods by which they can be improved.

The design of engineered systems was begun in parallel with the development of the Analytical Model. As the engineered systems were designed, checks were made to insure that they could be simulated by TRNSYS, an accepted HVAC-solar simulation model. These engineered systems were to represent the best of which solar heating is now capable, but were also to be sufficiently within the working knowledge of manufacturers, builders, and installing contractors that components could be selected by model number and realistic installation costs obtained.

A substantial review of systems and system performance resulted in the selection of a series over a parallel configuration for solar assisted heat pumps. The following four systems utilizing the series configuration were designed... 
...Air-to-Air Heat Pump with Air Solar collectors and Rock storage

...Water-to-Air Heat Pump with Air Solar Collectors and Liquid Storage

...Water-to-Air Heat Pump with Iiquid Solar collectors and Liguid storage

...Air-to-Air Heat Pump with Liquid Solar Collectors and Liquid Storage

These systems were developed while simultaneously subjecting them to field appraisals and cost data to provide feedback.

\section{SAHP System Costs}

Although an early reguirement of the Analytical Model was performance information in order to optimize component parameters -- specifically collector capacity and storage capacity - cost was also an element of the optimization.

Accordingly; cost data were compiled for the four different types of solar assisted heat pump systems described above and were provided for work with the Analytical Model.

Cost collection activities were then expanded into conventional systems in order to be able to evaluate SAHP system LCC's in comparison with various types of conventional systems.

\section{Single Family Home HVAC Market characteristics}

The single family home market was the focus of the study because of its very large size, its very large potential for energy conservation, and its 'relatively uniform characteristics -- all when compared with any other building type.

As a result of engineering, cost, and other inputs up to this time, it was determined to establish the heat pump as a Reference system in the marketing analysis, in order to provide a basis for comparison of SAHP systems. 
This was done for several reasons...

...Competitive with Conventional systems

Heat pumps are competitve with conventional systems in many areas, and are increasingly considered "conventional" by the HVAC industry in their prime areas of application.

\section{...Competitive with SAHP systems}

A SAHP system, by definition, includes a heat pump, and therefore its comparison with a heat pump is appropriate to determine if the cost increment of the solar assist will support itself economically. The comparison is made particularly appropriate because assumptions of future electricity costs affect the two systems in similar ways and thus reduce sencitivity to the accuracy of such projections. Accordingly, HVAC market data were collected for the 50 states in order to cover all regions and to establish a data base for the comparison of SAHP LCC to Heat Pump LCC. The data base included conventional gas, oil, and electrically heated homes in order to establish the degree of competitiveness of heat pump systems.

The data base was utilized to develop typical annual home heating costs for each state for conventional systems using gas, oil, electric resistance, and heat pump as the system type. This information was then used in the LCC analyses which followed.

Generally, the results show favorable gas heating costs, thus supporting its popular usage. In contradistinction, however, where heat pump energy costs for heating were favorable, it did not necessarily correlate with high heat pump sales.

\section{Life Cycle costs}

As was stated previously, it was a basic premise of the study that a system of heating must have a competitive LCC in order to be considered marketable, even though consumers 
have not previously shown a significant propensity to choose systems with low LCC's if such choices require high initial investments.

It was necessary to develop a rationale for heat pump sales in order to further rationalize how and where heat pump sales in a solar assist mode would be marketable. Accordingly, early LCC's were developed manually to compare heat pump systems with other conventional systems using gas, oil, and electric resistance, pending comparisons of the heat pump with SAHP with the Analytical Model.

While the data on single family homes were developed on a state basis to provide a regional overview, a parallel effort focussed more narrowly on selected cities because significant variations occur in some states in items such as climate, fuel availability, and fuel price. Accordingly, LCC analyses were done for Fort Worth, TX, Dallas, TX, and Madison, WI. In no case was the incidence of heat pump sales consistent with either energy cost or life cycle cost.

Although some sources of data indicated heat pump sales would rise in their areas, this information was not considered sufficiently definitive for use here.

As a result, a correlation analysis was undertaken to determine how heat pump sales can be better rationalized as a preparatory means of predicting SAHP system sales.

\section{Correlation Analysis}

Several successive trials at a Multiple correlation Analysis were made.

The final analysis achieved a rather significant 0.85 correlation coefficient. The factors included in the analysis were...

.. Ratio of Annual Heating Load to Annual cooling Load reflecting the heat pump's (and therefore, SAHP's) basic function of cooling

...Air Conditioning Sales - again, reflecting the heat 
pump's basic cooling function

...Heating Energy Costs

- gas

- 0 il

- heat pümp

... Number of Single Family Home construction starts

... Number of Existing Homes

... New Gas Heating Services - reflecting the availability or unavailability, of gas as a heating fuel.

At a 0.85 correlation, these are clearly key factors in heat pump sales.

\section{DOMESTIC HOT WATER HEATING ADDENDUM}

The primary work of the SAHP marketability study centered on life cycle cost analyses, comparisons, and correlations of total space heating systems. In addition to these, an ancillary study of solar energy domestic hot water heating systems was begun. The purpose of this study was to assess, via the Analytical Model Program, the effect of collector tilt on the systems' Iife cycle cost. The results of this study showed that the energy savings accrued when changing the collector tilt from vertical to that of the latitude justifies an incremental installation cost of approximately $\$ 7$ per square foot in New York, NY climates and approximately $\$ 4$ per square foot in Fort worth. TX climates.

\section{SUMMARY}

As was indicated in the Technical section, the completed Analytical Model clearly demonstrated that series SAHP systems are the most promising of all active solar energy systems considered. Yet they are not, at this time. competitive with heat pump systems and large favorable changes in initial system cost, unfavorable changes in electricity cost, or the unpredictable entrance of unknown factors would be required to make them so. 
At the same time, however, the competitiveness of the heat pump system against other systems and fuel sources was demonstrated more clearly than has previously been the case.

Further trials on the Multiple correlation Analysis, above, to determine if there are other factors that significantly correlate with heat pump sales, and/or to establish a weighting for each of the factors used might be useful in knowing where and how to more effectively market such systems.

Finally, the heat pump is being recognized as an energy-conserving device and, accordingly, is being considered by congress as a candidate for a 15 percent (up to $\$ 2,000$ ) tax credit for residences. This is an appropriate, practical action in the light of this study. 


\section{INTRODUCTION}

The prime thrust of the Technical section centers around the development and use of an Analytical Model. This model was developed as an alternative to TRNSYS, an existing and recognized HVAC-solar simulation model, in order to optimize performance versus life cycle cost of SAHP and competing conventional systems in different climatic regions. The Analytical Model was programmed to "hunt" through many alternatives to find the economical optimum, using very simple, generic system types. These generic systems were to be made more specific at a later point in the project.

TRNSYS would have required a set of specific inputs for each alternative and would have produced much more detailed and specific results at much greater expense and time, especially in the early phases of optimization. The Analytical Model was more efficient and was validated with TRNSYS; the results of a definitive system analyzed by one were similar to results analyzed by the other.

\section{Analytical Model}

The Analytical Model was developed and programmed to run on a minicomputer as a self-contained package requiring the user to specify the system to be analyzed. The four major aspects of the model are discussed below. They are: systems, weather, economics, and input parameter.

1. Systems. To assess the marketability of SAHP systems, their cost and performance had to be compared to those of competing systems. Accordingly; the Analytical Model was developed to include six generic system types. They are:

$$
\begin{aligned}
& \text {-Stand-alone heat pump } \\
& \text {-Stand-alone solar energy } \\
& \text {-Series SAHP : }
\end{aligned}
$$


-Dual source SAHP

-All electric (load)

Paper 3 of the next chapter discusses the programming economies used in the modeling of these different systems.

2. Weather. The Analytical Model also includes insolation and ambient temperature data for $26 \mathrm{U} . \mathrm{S}$. cities. These were derived from TMY weather data as discussed in Paper 3 of the next chapter.

3. Economics. In this program, marketability was identified with low life cycle cost. Therefore, the model used economic parameters selected by the user to derive the present value of the Iife cycle cost of each system analyzed. For convenience, this cost was presented as an Annual Uniform cost of owning and operating the system over its life time.

4. Input Parameters. An interactive computer program was used to implement the Analytical Model. The program asks the user to identify system type. location, season, etc. and then calculate the resulting thermal and economic performance.

Approximately 40 input parameters are needed to specify a system completely. They include:

-Collector parameters, such as area, tilt, efficiency, and cost per unit area

-Storage parameters, such as volume, insulation, external temperature, and cost per unit volume

- Heat pump parameters, such as fraction of ideal (carnot) COP, and assorted temperature drops

-Load parameters, such as indoor temperature, UA value, and domestic hot water usage 
-Economic parameters, such as system lifetime, present cost of fuel, and annual worth of money.

For user convenience, the program assumes all parameters for a given system type to be equal to those specified in the previous analysis of that generic system. The user must only specify parameters that are different from the ones used previously.

Economically optimized Systems

The major advantage of the Analytical Model program was its speed. A thermal and economic analysis of the annual performance of a typical system took less than 2 minutes. This fast response enables a user to vary a given parameter, such as collector area, over a wide range and select the parameter value that minimizes life cycle cost.

As discussed in Paper 3 of the following chapter, competing solar heating systems were designed so that each has economically optimum values of collector area and storage volume. These optimized systems were then compared, and the one with the lowest life cycle cost was selected as the most marketable one.

\section{Results}

If natural (regulated) gas is not available, the most cost effective space heating system at present costs of electricity is the air-to-air heat pump. At higher fuel prices, the geries SAHP system has the lowest life cycle cost. As discussed in the final chapter of this section of the report, these results were found to hold true in five U.S. climate regions. That chapter discusses these results and the conclusions drawn from them in detail.

\section{Accuracy}

The results of the Analytical Model program are subject to two sources of error: errors in thermal analysis and errors in the values of the economic parameters used in the analysis.

The thermal calculations of the Model were verified against TRNSYS. It was found that the Model gives results that are generally within 10\% of those given by TRNSYS. This margin of error 
is within the range of values that would result from running TRNSYS using any of several accepted methods for averaging weather data.

In this, as in all similar studies, the accuracy of the results obtained from the Analytical Model is determined alsmost entirely by the correstness of the economic assumptions. These are clearIy stated in the technical papers and the reader is cautioned to review them carefully to assess the validity of the conclusions drawn from the Analytical Model studies. However, the results of this study are valid over wide ranges of input assumptions, particularly for the five-year future time frame of interest to manufacturers. This is especially true for changes in input parameters that maintain a relatively stable difference between the annual fuel escalation rate and the annual worth of money.

Paper 1 of the next chapter discusses in detail the sensitivity of the results to changes in the assumed values of the economic parameters.

Further Research

Topics for further research include:

-system life cycle cost sensitivity to collector price/performance

-development of superior algorithyms for control of dual source SAHP systems

-construction of an analytical model of a ground coupled heat pump to assess its capabilities and limitations.

These topics are discussed in more detail at the end of chapter T-3 of the technical part of this report.

Marketing studies

Two efforts proceeded in parallel with the development and use of the Analytical Model. One was the design of engineered systems; the other was a study of the single family residential HVAC market in the U.S. 
The purpose of the first of these efforts was to design SAHP systems that could incorporate the principal generic characteristics that the Analytical Model demonstrated to be favorable; these more definitive systems could, in turn, be simulated by TRNSYS for performance and thus optimized. The engineered systems were flexible for simulation purposes by the liberal use of schematic valves and dampers in order to determine the best of which solar heating is now capable; at the same time, they were kept sufficiently within the working knowledge of manufacturers, builders, and Installing contractors so that components could be specified by model number for performance data and for the securing of realistic installation costs.

The second effort conducted in parallel with the development of the Analytical Model was a study of the characteristics of the U.S. market that would determine the future market penetration of SAHP systems. For this study data were collected and tabulated on a single family residential market with emphasis on three aspects of the market place. They are:

-Fundamental data such as the number of houses in each state

- Comparative data such as initial system costs of competing HVAC systems,

-Sales data such as the number of heat pumps sold annually in each state.

Both the efforts on developing engineered systems and the results of the U.S. market study are discussed in detail in the Marketing Section of this report.

Technical studies

The following chapter presents three of the articles published during work on this program. A short technical description of the analytical approaches used precedes the presentation of the papers. 
TECHNICAL PAPERS

\section{INTRODUCTION}

Copies of three of the technical papers prepared during the course of the work on the SAHP program make up this chapter of this report. The following papers were published:

- "A SAHP system Analysis Model". Systems simulation and Economic Analysis for solar Heating and cooling, 175, U.S. DOE (1978).

* - "The Economic Constraints on Solar Energy, Heat pump and Solar Assisted Heat Pump systems". Proc. 1978 Annual Meeting Amer. Sect. Int. Sol. Energy Soc., 2.1. 288, Ed. K.W. Boer and G.E. Franks (1978).

- "SAHP-2: Analytical selection of Marketable SAHP Systems". 3rd Annual solar Heating and Cooling R\&D Contractors' Meeting, U.S. DOE (1978).

- "Analytical Selection of Marketable SAHP Systems". Solar Energy and Conservation Symposium - Workshop, 41, Ed. T.N. Veziroglu, Univ. of Miami (1978) .

* - "Economically Optimum Thermal stoage Size via Marginal Analysis", Proc. 1979 Convention Int. Sol. Energy Soc. (1978).

- "Optimization and Comparison Strategies for Solar Energy Systems", Amer. Soc. Mech. Eng ., Winter Annual Meeting, 79-WA/Sol-26, New York, NY (1979).

- "Analytical Selection of Marketable SAHP Systems" , in Vol. 1. Chap. 6 of Solar Energy and Conservation, Ed. T.N. Veziroglu, Pergamon Press (1980).

- "SAHP-2 Analytical Selection of Marketable SAHP Systems", Proc. Annual DOE Solar Heating and Cooling contractors' Review Meeting, March, 1980, pp. 4-30, U.S. DOE. 
Papers denoted by the asterisks are included in this chapter as Papers 1, 2, and 3.

\section{Areas of Analysis}

Two related, but distinct, analysis efforts are documented by these papers. One, only partially successful, was an attempt to capture temperature, insolation, and collector performance in terse mathematical form from which an understanding of the fundamental relationships that govern the feasibility of solar energy could be derived. Papers 1 and 2 detail the achievements in this area.

The second and more important area of the theoretical work was the development of an analytical model of competing solar energy. SAHP, and conventional space heating systems. This was the major analytical effort. It was successful and it is summarized in the ASME Paper (NO, 3). The other papers published document the progress in developing the various aspects of the model.

The ASME paper derives its conclusions from results obtained from the analysis of the thermal and economic performance of competing systems that are used to provide space heating for a single family residence in the New York City climate. Material presented in the next chapter shows the results of work done after the ASME paper was published to extend these results to four other U.S. cities. 


\section{TECHNICAL PAPER 1}

"The Economic Constraints on Solar Energy, Heat Pump, and Solar Assisted Heat Pump Systems", Proc. 1978 Annual Meeting Amer. Sect. Int. Sol. Energy Soc.. 2.1. 288, Ed. K.W. Boer and G.E. Franks (1978). Franks (1978).
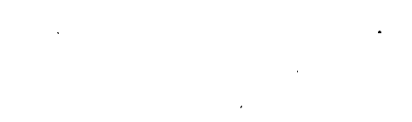
THE ECONOMIC CONSTRAINTS ON SOLAR ENERGY, MEAT PUMP. AND SOLAR ASSISTED HEAT PUMP SYSTEMS

\author{
W. Kahan and R. C. Estes
}

The Singer Company

Corporate Research and Development Laboratory Fatrfield, H.J. 07006

\section{ABSTRACT}

The econonic effectiveness of solar energy systems used for space heating and for heating of domestic hot water are analyzed by comparing the system costs to the present worth of the fuel saving during the systems' Iifetime. Systems between latitudes of $240 \mathrm{~N}$ and $480 \mathrm{~N}$ are considered.

From the analysis, an upper limit for the system cost to the consumer is established as a function of system performance, the cost of money, the escalation rate of fuel costs, and the system's iffetime. The sensitivity of this upper limit cost to changes in economic parameters is demonstrated and discussed.

Similar calculations on the cost effectiveness of heat pump systems in different climatological regions are presented and compared with those of solar energy systems.

Finally, the cost constraints for a solar assisted heat pump system are developed. These constraints are shown to be similar for parallel and for serles configuration; yet, much higher perfomance is required of the solar energy portion in paraliel conffgurations. This suggests that a series solar assisted heat pump system with properly designed components could be most cost effective.

\section{INTRODUCTION}

As part of an overall effort to assess the marketability of solar assisted heat pump systems, we performed an analysis of the price/performance characteristic of basic solar energy systems. The goal of this analysis was to determine the cost effectiveness of these systems by answering the following fundamental question: Under which conditions does the system cost less than the energy it saves over its lifetime?

In the following presentation only two factors are considered in evaluating the financial worth of a solar energy system. They are: (i) the initial system cost, and (2) the value of the energy saved during the system's iffetime. For the generic models discussed here. imprecistion in the knowledge of the detalls of solar energy system cost and of the total quantity of solar energy collected and consumed during the iffe of the system are too iorge to justify the inclusion of such factors as taxes, maintenance costs, and salvage value when comparing costs and iffe cycle benefits of a solor energy systen.

\section{PRESENT VALUE OF SYSTEM ENERGY SAYINGS}

The value of the energy saved by a system in the future is compared to present costs by discounting the future savings using the annual worth of money, $I$, to compute their present value. Thus, if $P_{k}$ is the value of fuel saved during the system's $k$ ' th year, then the present value of that saving is $P_{k} /(i+1)^{k}$ and the present value, $V_{p}$ of the fuel saved during the system's ilfe of $h$ years is

$V_{0}=\frac{P_{1}}{(1+1)}+\frac{P_{2}}{(1+1)^{2}}+\ldots+\frac{P_{N}}{(1+1)^{N}}$

Both $V_{0}$ and $P_{k}$ are expressed in terms of today's dollars and $I^{K}$ is therefore the annual discount rate above inflation. The results of the analysis are then independent of inflation rates.

The quantity $P_{k}$ is related to $P_{0}$, the present value of the fuel saved annually by the solar energy sys. tem, as follows: $P_{k}: P_{0}(1+F)^{k}$ where $F$ is the yearly fuel cost escalation rate above inflation. and where $1 t$ is assumed that no degradation in the system's performance takes place during the system's ilfetime. Using this relation in Eq. (1) and suming the resulting geometric series, the following relation is obtained between $V_{0}$, the present value of the energy saved during the lifetime of the system and $\mathrm{P}_{0}$. the present value of the system's annual energy sovings:

$$
\frac{(1+F)(1+1)^{N}-(1+F)^{N+1}}{(1-F)(1+1)^{N}}
$$$$
V_{0} \cdot P_{0}
$$

where $V_{0}$ can be viewed as the upper limit of the total cost to the end user. of a solar energy system that presently saves $P_{0}$ fuel costs in a single year. In fact, for the system to be warketable on the basis of its economic merits. its total instolled cost must be significantiy below $V_{0}$.

Unfortunately, the quantities, I, N, and $f$ are not well known. The worth of money, $I$, will be comparatively low for an individual home owner with 
IImited investment opportunitfes. In this case reasonable estimates for I may range fron 0.005 to 0.02 (above inflation). If I is estimated for an individual financing a solar energy system with a basic home improvement loan, then reasonable values for I may range from 0.02 to 0.05 or higher, depending upon the slze of the loan and the lending institution. However, reasonable values for 1 . for a business that pays high rates to borrow money or for one that has investment opportunitles with relatively high rates of return on investment, may range from 0.03 to 0.06 .

Sufficlent experience has not been accumulated for precise, estimstes of $\mathrm{N}$, the lifetime of the solar energy system. For the purposes of this analysis. where malntenance costs and degradation ef fects ore onitted, reasonable estimate for $M$ is between 10 and 20 years.

The value for $f$, the fuel escalation rate, in Eq. 2 depends upon future fuel prices which are basically unknown. If "the cost of fuel" is restricted to the cost of electricity to the consumor, then uncertainties in $F$ are reduced, because only about $1 / 3$ of the consumer's electric bill pays for fuel; the remainder pays for labor, capi. tai. taxes and profit, quantities that do not change differently from inflation.

Estimates for $F$, the annual escalation rate of the cost of electricity above Inflation, over a future perlod comparable to system ilfetimes, vary from approximately 0.005 to 0.06 [1] [2] [3]

The results of computing $V_{0}$, using reasonable values of $I, F$, and $N$, are shown in Table $I$.

$\begin{array}{cccc}I & F & H & V_{0} \\ 0.01 & 0.055 & 20 & 32.6 \times P_{0} \\ 0.02 & 0.035 & 15 & 16.9 \times P_{0} \\ 0.04 & 0.025 & 15 & 13.4 \times P_{0} \\ 0.06 & 0.025 & 10 & 8.35 \times P_{0}\end{array}$

Table 1. Yo, the maximum worth of a solar energy system that saves $P_{0}$ in annual fuel cost as a function of $I$, the annual worth of money. $F$, the annual fuel escalation rate, and $N_{1}$ the system iffetime in years.

It Is noteworthy that the spectrum of reasonable values of $I, F$, and $N$ is broad enough to yteld values of maximum system cost that differ by almost a factor of 4. Consequentiy, analyses of the cost effectiveness of a solar energy system can be very atsleading if the economic assumptions used in the analyses are not openly stated.

In the computations that follow, a value of $N=15$ (years) will be used for the system lifetime. On the basis of Reference [3], F=0.035 w1ll be used Por the annual electricity cost escalation rate. Finally, because individual home owners represent the largest solar energy market segment, the appropriate value l-0.02 will be used for the worth of money when evaluating $V_{0}$. This present worth method will be used to evaluate stand alone solar energy systems, stand clone heat pump systems. and SAHP systens that combine solar energy and heat pumps.

\section{SOLAR ENERGY SYSTEM}

Eg. 2 can be used to andyze the cost effectiveness of a generic solor energy system that is used for space heating. In present practice, computer simulations are used to evaluate $P_{0}$ for suecific systems. However, the sallent features of solar energy economics can be elucidated by the following computations.

Using the method of Reference [4], the clear sky Insolation avallable to a unit area of collector over one heating season was calculated for the locatfons listed in Table II, where the length of the heating season was estimated from Reference [5]. Actual insolation values were found by multiplying the clear sky radiation values for the locations listed in Table II by the percentage of clear day insolation received on an average day as given in Reference [6]. P was then calculated assuming that the space heating system utilizes 40 per cent of the avallable insolation and that the value of this energy is $4 \$ / \mathrm{kWh}$ ( $\$ 1.17 /$ therm). Finally, $V_{0}$, the maximum worth of a solar energy system, was calculated with the assumptions stated in the table caption.

For locations in Table II with appreclable heating seasons, $V_{0}$ ranges from $\$ 400 / \mathrm{m}^{2}\left(\$ 37 / \mathrm{ft}^{2}\right)$ to $\$ 160 / \mathrm{m}^{2}$ (\$95/ft 2 ), provided that the solar energy collected throughout the entire heating season is used for space heating. In practice, full utilization of the collected energy for space heating Is only possible in systems that supply signifi. cantly less than the total heating load. Otherwise, not all the energy collected durting the milder portions of the heating season is needed. Consequently, if a large fraction of the heating load is suppited by a solar energy system, its $v_{0}$ will be reduced from the values given in Table il. Typically, the tabulated $V_{0}$ values are appropriate for systems that supply approximately half the lnad; auxillary energy is used to supply the other half. In heat pump terminalogy: these systems have a seasonal perfomance factor (SPF) of 2 and in the locations IIsted in Table II have a median maximum total system price of $\$ 225 / \mathrm{m}^{2}\left(\$ 21 / \mathrm{ft}^{2}\right)$, apportioned over collector area.

Table Il also shows the results of the above methodology applled to solar energy sys tems used for hot water heating. For the citles listed, the median maximum total system price is $\$ 420 / \mathrm{m}^{2}$ $\left(\$ 39 / \mathrm{ft}^{2}\right)$, provided that all the generated hot water is utillzed in all seasons.

The rema Inder of this article extends these economic constraint calculations to stand alone hedt ${ }^{\cdots \cdots}$ pump and to solar assisted heat pump (SAHP) systems for residentlal applications. 


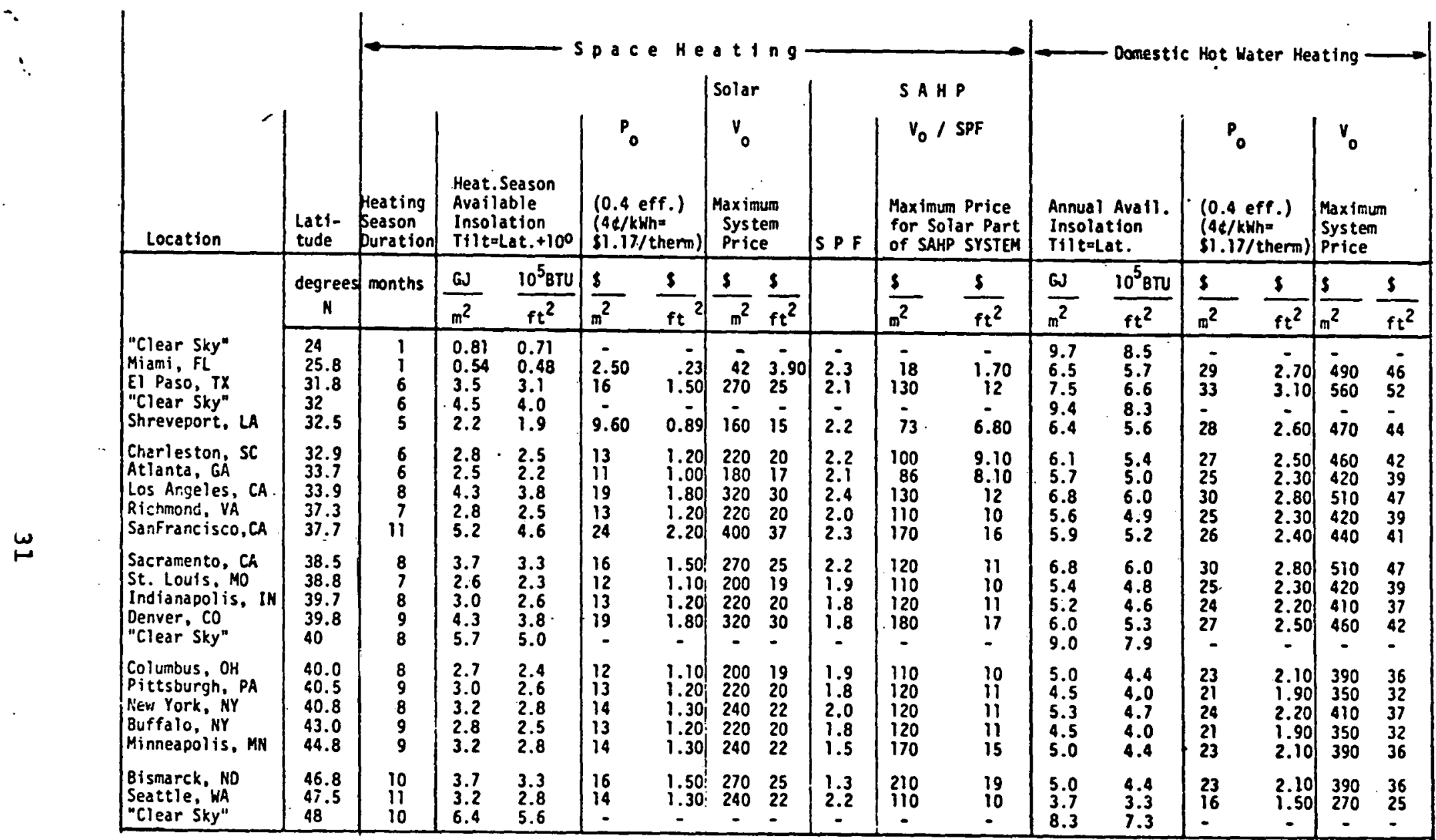

Table II. ECONOMIC CONSTRAINTS ON SOLAR ENERGY AND ON SAHP SYSTEMS.

$V_{0}$ is the maximum worth of an entire solar energy system apportioned over a unit of collector area. Values for space heating systems and domestic hot water systems are shown for different locations. $V_{0} / 5 P F$ is the corresponding quantity for all the solar energy components of a space heating SAHP system where low temperature collectors can be used and where SPF is calculated as described in table 111. Po, the value of energy collected and utilized, is based on a system overall efficiency of 0.4 and a cklkwh (sl. $17 /$ therm) worth of energy. $V_{0}$ is calculated using $\left[=0.02, F=0.035\right.$ and $N=15$ in Eq.2 so that $V_{0}=16.9$ Po. To be , system must be priced significantly below $V_{0}$. 
Degree Days

$\begin{array}{ccc}10^{3}{ }^{\circ} \mathrm{C} \text { Day } & 10^{30} \text { F Day } & \\ 1.1 & 2.0 & \text { Charleston, SC } \\ 1.7 & 3.0 & \text { Atlanta, GA } \\ 2.2 & 4.0 & \text { Richnond, VA } \\ 2.8 & 5.0 & \text { St. Louis, MO } \\ 3.3 & 6.0 & \text { Pittsburgh, PA } \\ 3.9 & 7.0 & \text { Buffalo, NY } \\ 4.4 & 8.0 & \text { Minneannits, AN }\end{array}$

Meating Season Load

$\begin{array}{cc}60 & 10^{6} 87 \\ 39 & 37 \\ 50 & 77 \\ 68 & 64 \\ 80 & 76 \\ 100 & 95 \\ 105 & 100 \\ 130 & 120\end{array}$

SPF

Value of Annual Energy Savings

$(946 / \mathrm{kWh} \cdot \$ 1.17 /$ therm)

$\begin{array}{ll}2.2 & 1240 \\ 2.1 & 290 \\ 2.0 & 380 \\ 1.9 & 420 \\ 1.8 & 490 \\ 1.8 & 520 \\ 1.5 & 470\end{array}$

Table 11I. MEAT PUMP PERFORMANCE IN DIFFERENT CLIMATES

SPF, the seasonal performance factor. and $P_{0}$, the value of energy saved annually by a stand alone heat pump system over electric resistance heating, are shown for a load of $U A=340 \mathrm{~W} /{ }^{\circ} \mathrm{C}$ (650 BTU $n-l$ of -1 ) heated by 3 ton $(10.5 \mathrm{~kJ} / \mathrm{s}$ ) heat pump (singer H-R553036) in different climates.

\section{SAHP SYSTEAS}

4.) Heat Pump. The comblnation of a solar energy system with a heat pump modifies the constraints on the solar energy systen considerabiy. In this case, the performance of a SAHP system is not evaluated in comparison to an electric resistance heater, but rather in comparison to that of a heat pump to determine the value of the solar energy additions. The following discussion of SAHP cost constraints begins with a brief outline of the price/performance characteristics of a heat pump. the basis for the cconomic assessment of SAHP systems.

The heat pump "base" system was developed by calculating the performance of a 3 ton $(10.5 \mathrm{~kJ} / \mathrm{s})$ heat pump (Singer H-R553036) used with a well insulated house (Area $0195 \mathrm{~m}^{2}=2100 \mathrm{ft}^{2}, \mathrm{UA}=$ $340 \mathrm{WOC}^{-1}=650 \mathrm{BTU} h-($ of -1$)$ in 7 different locations having hedting climates ranging from 1100 to $4400{ }^{\circ} \mathrm{C}$ degree days (2000 to 8000 of degree days). ASHRAE data [5] were used to compute, by the $2.8^{\circ} \mathrm{C}(50 \mathrm{~F})$ bin method, the seasonal performance factor (SPF) in each location. Table III above sumartzes the calculation results and shows the annual savings in fuel accrued when using the heat pump instead of electric resistance heating.

The present worth of the (eiectric) energy saved by a heat pump over its lifetime can be evaluated from Eq. 2. Assuming a 10 year $11 \mathrm{fe}, 1=0.02$, and $F=0.035$, the present worth, $V_{0}$, is $10.85 \times$ the annual savings $P_{0}$. and ranges between $\$ 2,600$ and $\$ 5,600$ for the Table III locations. Under the more stringent assumptions of $I=0.05, F=0.015$ and $H=10, V_{0}$ is $8.34 \times P_{0}$ and ranges between $\$ 2,000$ and $\$ 4,300$ for the table III locations.

A 3 ton heat pump costs approximately $\$ 400$ more than a 3 ton air conditioner and is consequently - cost effective substitute for electric heating whenever it replaces an air conditloner. In cases where an air conditioner would not be purchased, the heat pump's installed cost, approximately $\$ 2,000$, is less than the present value of the electric energy it saves over its lifetime and is consequently a cost effective substitute for an electric resistance heater in the locations shown fo Table III.

4.2 SAHP Systems. A heat pump reduces the effective cost of electricity used for space heating by Its SPF so that the effective cost of electricity to the owner of a heat pump is $4 \mathrm{kWWh} / \mathrm{SPF}$, and the resulting maximum worth of the system is $V_{0} / S P F$. Table II lists, $V_{\alpha} S P F$, the price constraints on the solar energy components added to a heat pump to construct a SAHP system. These constraints apply equally to serfes (solar assisted) and to parallel (solar augmented) SAHP systems. Obviously, In efther case the solar energy components must cost less than the solar energy they supply to the load.

Presently, the cost to the consumer of populdrly avallable flat plate collectors, prevalent energy storage subsystems, sensors, controls, and installation prevent solar energy space heating systems, with or without heat pumps, from being more cost effective than stand alone heat pump systems, except perhaps in small clima tological regions that enjoy high insolation during long heating seasons corbined with high or unique electric rates. Furthemore, without drastic increases in the fuel escalation rates. It is difficult to see how the presently popular components can be reduced in price to make solar energy space heating systems economically sound investments in the next decade or two. Volume sales and mass production techniques are not likely to lower solar energy system prices because the system components are already e1 ther mass produced HVAC components, or they are made of mass produced (eg. Sheet) material. Also, - significant fraction of the system's cost is fleld labor an tem not easily amenable to large cost reductions through high sales volumes.

There is, however, a fundamental difference between the series SAHP system and other solar energy sys. tems. The series SAHP system can use collectors and storage systems that operate at low temperatures $\left(100 \mathrm{C}\right.$ to $38^{\circ} \mathrm{C}$; $50^{\circ} \mathrm{F}$ to $\left.100^{\circ} \mathrm{F}\right) ;$ a hed pump trans- 
fors the low temperature solar energy to the load ot a higher temperature $\left(43^{\circ} \mathrm{C} ; 110^{\circ} \mathrm{F}\right)$. Relaxing the requirement of gathering and storing energy at the high temperatures required for comfortable space heating may provide the additional degree of design freedom to reduce the price of SAHP systems and make them economically attractive. Optimum price/performance characteristics of such systems will depend upon the avallability of heat pumps optimized to perform at source temperatures prevalent in such series SAHP systems. This is discussed in the following paper. [7].

Parallel SAHP systems require the same performance (high temperature) of their solar energy components that stand a lone solar energy systems do and they require the same heat pumps that stand alone heat pump systens do. Yet they gather solar energy best when it is worth least, during milder weather when the heat pump has its highest coeffictent of. performance. During the severe part of the heating season, nelther the solar energy components nor the heat pump work at their best. Consequently, parallel SAHP systems are potentially less cost effective than either type of stand alone system.

\section{CONCLUSION}

The value of heat pump ond solar energy systems was investigated by comparing system costs to the value of the energy saved by the system. In comparison to electric resistance heating $(4 \$ / \mathrm{kWh}=\$ 1.17 /$ them $)$, presently avaflable heat pump systems, which also provide cooling, are definitely cost effective in terms of the fuel they save over their iffe cycles.

Solar energy space heating systems (no cooling provided). sized to accomodate approximately half the space heating lood, would be cost effective in meny regions of the $Y . S$. If they could be installed for less than $\$ 225 / a^{2}\left(\$ 21 / f t^{2}\right)$, total system price apportioned over collector area.

A solar energy domestic hot water system is more efficlent in its use of the required capltal investment and, when compared to electric resistance heating. its maximum price yaries from approximately $\$ 330 / \mathrm{m}^{2}\left(\$ 31 / \mathrm{ft}^{2}\right)$ to $\$ 560 / \mathrm{m}^{2}\left(\$ 52 / \mathrm{ft}^{2}\right)$ as the latitude decreases from $480 \mathrm{~N}$ to $240 \mathrm{~N}$.

The solar energy components of parallel and serles SAKP systens would be cost effectlve in many, regfons if they could be priced below $\$ 120 / \mathrm{m}^{2}$ (sili/ft2), as apportioned over collector area. Because a sertes SAHP system does not require the same high performance collector and storage components that parallel SAHP and stand alone solar energy systems do, it has: the potential of being the most cost effective system for space heating and cooling.

\section{ACKNOWL EDGEMENT}

The work reported in this paper was partially. supported by the Department of Energy under Contract Ho. EG-77-C-03-1467.

\section{REFERENCES}

[1] R. F. Messing and H. E. Harris, Comparative Energy Values to 1990, A.D. Little, June. 1977.

(2) SRI International, fuel and Energy Price Forecasts, Vol. I. Electric Power Research Inst1. tute, September. ig77.

[3] E. E. Kappelmani et al. Euel Cost Escalation Study. Naval Weapons Center, China Lake, CA, aprit 1977.

[4] E. A. Farber and C. A. Morrison, "Clear-Day Destgn Values." Applications of Solar Energy for Heating and Cooling of Bulloरings, ASHRAE GRP $17 \%$, $197 \%$

[5] ASHRAE HANDBOOK OF FUNDAMENTALS, $1976 \mathrm{ed} .$, p. 43.11 .

[6] Hortzon Industries, Estimating Solar Energy Avalloble for Collection North Hollywood, CA, 1977.

[7] J. M. Davis, "The Development of Cost Effeceive Solar Assisted Heat Pumps for Heating and Cooling Applications." the following paper. 


\section{TECHNICAL PAPER 2}

"Economically Optimum Thermal storage Size via Marginal Analysis".

Proc. 1979 Convention Int. Sol. Energy Soc. (1979). 
Presented at the 1979 ISES Convention

29 May, Atlanta, Georgia

\title{
ECONOMICALLY OPTIMUM TES SIZE VIA MARGINAL ANALYSIS
}

\author{
W. Kohan and R. C. Estes \\ The Singer Company \\ Corporate Research and Development Laboratory \\ Fairfield, N.J. 07006
}

\section{Introduction}

The size of thermal energy storage (TES) in a solar energy system used for space heating is often determined by one of three methods: simulation, correlation, or rule of thumb. Examples of each method are common. Although these methods are useful for designing systems and are, indeed, indispensable for comparing the performance of competing systems, they do not offer an analytical understanding of how optimum TES size is related to such parameters as local weather persistance, solar energy collection efficiency, component costs, and energy cost.

The analytical relationship between these quantities derived below is corroborated by empirical rule-of-thumb design rules and serves to delineate the arena in which those rules are valid. Furthermore, the relationship can be used to select quickly base TES sizes for simulation studies of diverse solar energy systems.

The discussion presented in this paper proceeds as follows:

\footnotetext{
- A simple Markov chain is used to approximate daily insolation persistence;

- The two resulting independent parameters are used to derive an expression for the number of occurrences of sequences that contain át least $n$ cloudy days within a heating season of given duration;

- the present value of the energy provided to the load by the TES on the n'th , cloudy day during the system's lifetime is evaluated;

- the incremental cost of providing storage for the n'th cloudy day is derived;

- the economically optimum TES size is determined by equating the marginal benefit and the marginal cost of the n'th day of storage; and finally,

- examples are given to illustrate the results of the analysis.
} 


\section{Insolation Persistence Statistics}

In the simplified model of the distribution of insolation intensity used in this discussion each day is catagorized as either "sunny" or "cloudy." The probability of the occurrence of a sunny day, regardless of the state of previous days, is denoted by $P_{s}$. An estimate of this probability $P_{s}$ is abtained from $P_{s}=f_{s} / M$ where $f_{s}$ is the number of sunny days in the heating season whose duration is $M$ days. A similar relation holds for $P_{c}$, the probability of occurrence of cloudy days.

It is here assumed that a day's state of insolation is dependent only upon the previous day's state, i.e., the sequence of sunny and cloudy days forms a first order Markov chain. In addition to the initial probabilities $P_{s}$ and $P_{c^{\prime}}$ four conditional probabilities can then be defined. They are:

$$
P_{\text {ss }} \quad P_{\text {sC }} \quad P_{\text {cs }} \quad P_{\text {cc }}
$$

where, for example, $P_{C s}$ is the conditional prabability that a day will be sunny given that the - previous day was cloudy. Similar definitions hold for the other quantities. The above six probabilities can be used to calculate the probability of obtaining any given $n$ day sequence within the $M$ day season. Thus, for example, the probability that a sequence of five days will consist of three cloudy days sandwiched by sunny days is

$$
P(S C C C S)=P_{s} \times P_{s c} \times P_{c c} \times P_{c c} \times P_{c s}
$$

Note that throughout this discussion, it is assumed that the six probabilities remain essentially constant during the $M$ day interval.

Since a day is either sunny or cloudy, it follows that

$$
\begin{aligned}
& P_{s}+P_{c}=1 \\
& P_{s c}+P_{s s}=1 \\
& P_{c s}+P_{c c}=1
\end{aligned}
$$

and from the probability law that a given probability is equal to the product of the sets of initial and conditional probabilities

$$
P_{s}=P_{s} P_{s s}+P_{c} P_{c s}
$$

or

$$
P_{s}, P_{s c}=P_{c} P_{c s}
$$

Thus, of the six probabilities, only two are independent. In the following, $P_{s}$ and $P_{s s}$ will be used as the independent probabilities. 


\section{Probability of an $\mathbf{n}$ Cloudy Day Sequence}

Let $M R_{c, n}$ denote the number of occurrences, in an $M$ day heating season, of a cloudy day sequence exactly $n$ days long, that is, $n$ consecutive cloudy days bou nded by sunny days. Then

$$
M R_{c, n}=\pi n, M^{P}(S C \cdots C S)
$$

where $\pi_{n, M}$ is the number of $(n+2)$ day sequence in $M$ days. Thus

$$
\left.M R_{c, n}=(M+1)-(n+2)\right] P_{s} \cdot P_{s c} P_{c c}{ }^{n-1} P_{c s}
$$

where

$n \leq M-2 . \quad$ Or, using eqs. (2)

$$
R_{c, n}=\frac{P_{s} \times P_{s}\left(1-P_{s s}\right)^{2}}{1-P_{s}}\left[\frac{1-2 P_{s}+P_{s} P_{s s}}{1-P_{s}}\right]^{n-1} \frac{(M-1)-n}{M}
$$

It follows that $M Q_{c, n}$, the number of cloudy day sequences that are at least $n$ days
long is

$$
M Q_{c, n}=\sum_{i=n}^{M-1} M R_{c, i}
$$

Therefore, (see Appendix A)

$$
Q_{c, n}=U\left[W \frac{C^{n-1}-c^{M-1}}{1-C}-\frac{C^{n-1}(n+C-n C)-c^{M-1}(M+C-M C)}{M(1-C)^{2}}\right]
$$

where

$$
U=\frac{P_{s}^{2}\left(1-P_{s s}\right)^{2}}{\left(1-P_{s}\right)}, \quad W=\frac{M-1}{M}, \quad C=\frac{1-2 P_{s}+P_{s} P_{s s}}{1-P_{s}}
$$

$(6 a, b, c)$ 
For the case of $M \gg n, c^{M}$ is negligible in comparison to $C^{n}$ and

$$
Q_{c, n}=U \frac{C^{n-1}(M-n)-C^{n}(M-n)}{M(1-C)^{2}}
$$

or

$$
Q_{c, n}=P_{s}\left(1-P_{s s}\right) \frac{(M-n)}{M} C^{n-1}
$$

In the absence of insolation persistence, $P_{s s}=P_{s}$ so that $C=P_{c}$ and $Q_{c, n}$ reducés to $P_{s} P_{c} n(M-n) / M$.

Since an $n^{\prime}$ th cloudy day will occur in, and only in, cloudy day sequences at least $n$ days long, the number of $n$ 'th cloudy days (i.e., sequences with at least $n$ cloudy days) in an $M$ day heating season is $M Q_{c, n}$.

\section{Present Value of TES Energy}

In this section there is derived an expression for $B_{n}$, the present value of the benefit accrued (over the system's lifetime) from the capability of the TES to provide sufficient energy to carry the load on the $n$ 'th cloudy day. $B_{n}$ is therefore the incremental benefit of extending TES capability from $n-1$ to $n$ days.

During a single heating season, the average amount of energy, $S_{n}$, that the load would withdraw from TES on the $n$ 'th day of a cloudy day sequence is

$$
S_{n}=D\left[M Q_{c, n}\right]
$$

where $D$ is the average daily energy requirement of the load. If $C_{F}$ denotes the present price of energy, and $f$ the annual fuel escalation rate (above inflation), then $V y, n$, the value of $S_{n}$ in the $y^{\prime}$ th year is

$$
v_{y, n}=S_{n} C_{F}(1+f)^{y}
$$

This future $y^{\prime}$ th year benefit is discounted by (multiplied by) the factor $(1+i)^{-y}$, where $i$ is the annual worth of money above inflation, to obtain the present value of the benefit. The total 
benefit derived over the system lifetime of $N$ years from the $n^{\prime}$ th day TES capability, $B_{n}$ is given by

$$
B_{n}=s_{n} C_{F} \sum_{y=1}^{N}\left(\frac{1+f}{1+i}\right)^{y}
$$

This incremental benefit will be compared to the corresponding incremental system
cost computed in the next section.

\section{Incremental System Cost}

Assume that a system has the capability of collecting and storing sufficient energy to supply a load for $n-1$ consecutive cloudy days. The incremental cost to increase this capability to include the n'th cloudy day is due to two components: (I) the cost of increased storage size, and (2) the cost of increased collector capability. If $D$ is the energy consumed by the load per day, and if the incremental cost of storage per unit
energy is $d$, then the first of the above costs is $d D$.

The incremental collector cost for $n^{\prime}$ th day capability is $\alpha A_{n}$, where $\alpha$ is the price per unit area of installed collector and where $A_{n}$ is the additional collector area required. collected per day per unit area then

$$
A_{n} E P_{s} M=D M Q_{c, n}
$$

where a uniform distribution of cloudy day sequences over the heating season has been assumed. This assumption causes a slight overestimation of TES benefits and it is relatively poor only for large $n$ where TES is usually not economical. The incremental collector system cost is

$$
\text { incremental system cost }=d D+\frac{\propto D Q_{c, n}}{E P_{s}}
$$




\section{Economically Optimum TES Size}

As dictated by the equal marginal principle, the economically optimum TES size is obtained when the marginal benefits, Eq. 10, are equal to the marginal costs, Eq. 12, i.e., when

$$
D Q_{c, n} M C_{F} \sum_{y=1}^{N}\left(\frac{1+f}{1+i}\right)^{y}=d D+\frac{Q_{c, n} \alpha D}{E P_{s}}
$$

Note that this marginal equality is independent of the load size, $D$.

The system size determined as optimum from this expression will, in practice, be oversized because the benefits as calculcted from the left hand side of Eq. 13 are based on a load size $D$ that is assumed to be uniform throughout the heating season. However, the reduction in load experienced by real systems at the beginning and end portions of a heating season results in unused capacity if the system is sized for the average load. Consequently, as discussed below in Section 7.2, the accrued benefits are reduced by approximately 20 per cent.

That the above equality holds at the optimum size can be seen (Ref. 1) by evaluating the TES 'profitability' as a function of $n$, where profitability is defined as the rotal benefit less the total cost. When the profitability is at its maximum, its derivative with respect to $n$ vanishes and consequently the incremental benefit then equals the incremental cost.

Fixed costs are not included in the above analysis. These are the costs to establish a minimum size TES system, one that can provide energy to the load during the night following the:sunny day that immediately preceded the $n$ cloudy days. A minimum value for these fixed costs is $(3 / 4) d D+D \alpha / E$; where the first term is the cost of TEJ for the fraction of a day (approximately 3/4) during which there is no significant collectable insolation, and where the second term is the cost of the collector that collects the load's daily energy requirement. The present value of the benefits derived from this minimum system over its lifetime, $B_{0}$, is

$$
B_{0}=M P_{s}(3 / 4) D C_{F} \sum_{y=1}^{N}\left(\frac{1+f}{1+i}\right)^{y}
$$

Clearly, if B exceeds the fixed costs it is profitable to provide TES even if the marginal profitability of a (larger) $n=1$ TES system is negative. However, even if $B_{0}$ is less than the fixed costs, the marginal benefits may exceed the marginal costs for $n=1$ and a profitable optimum TES size may be found. Numerical examples are given in Section 8. 


\section{Rule of Thumb Corroboration}

7.1 Ratio of Storage to Collector Area. Rules of Thumb are often quoted for $\sigma$, the ratio of storage size to collector area. The above simple Markov chain model can be used to derive a value of $\sigma$ as follows. The TES required for $n$ cloudy days and the $3 / 4$ day preceding them is $D(3 / 4+n)$. The collector area required is the sum of $D / E$ (for the "zeroth" sunny day) and the $A_{j}$ (defined by $E_{q}$. II) for the $n$ cloudy days. Consequently

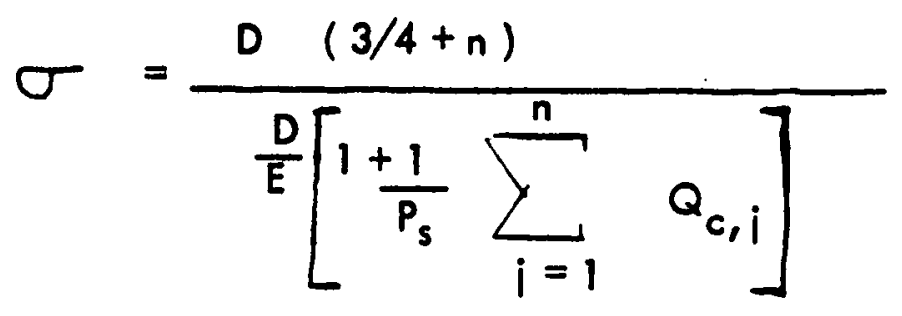

and is independent of the load size D.

For the minimum TES system $(n=0) \sigma=(3 / 4) E=1.35$ gallons of water of storage per $\mathrm{ft}^{2}$ of collector area, where a collector efficiency of $E=750 \mathrm{BTU} /$ day $/ \mathrm{ft}^{2}$ and a storage temperature swing of $50^{\circ} \mathrm{F}$ are assumed. If $P_{s}=0.65$ and $P P_{s s}=0.75$, then for an $n=1$ TES system $\sigma=2.52$ gallons $/ \mathrm{ft}^{2}$. These values are in essential agreement with the rule of thumb $\sigma$ value of approximately 2 gallons $/ \mathrm{ft}^{2}$.

7.2. Fraction of Load Supplied by Solar Energy. If a solar energy system is opt imized by means of the equal marginal principle as stated in Eq. 13, then the ratio of solar energy supplied to the total load energy required can be estimated as follows.

The total system demand is DM, the product of the average daily load and the number of days in a heating season. To determine the system benefit, assume that the load varies sinusoidally over the season. The daily load at day $m$ is then

$$
D_{m}=\frac{D \pi}{2} \sin \left(\frac{m \pi}{M}\right), 0 \leq m \leq M
$$

During the central portion of the heating seoson the load exceeds its-average value. Consequently, alt the energy collected by a system sized, as in the previous section, for the average load, will be of benefit. The benefit derived from the system during the central portion of the heating season is therefore the number of days in the central duration multiplied by D. However, during the end portions of the heating season when the daily load is less than $D_{1}, i, \theta_{0}$, when

$$
\left|\frac{M}{2}-m\right|>\frac{M}{2}-\frac{M}{\pi} \sin ^{-1}\left(\frac{2}{\pi}\right)
$$

the system is not used to full potential. Thus much of the energy collected during this 
period is "wasted" and must be discounted in the determination of actual system benefit.

The ratio of realized to potential benefits, $\gamma$, is then

$$
\gamma=\frac{\pi D\left(1-\cos \sin ^{-1} \frac{2}{\pi}\right)+D\left(\pi-2 \sin ^{-1} \frac{2}{\pi}\right)}{\pi^{D}}
$$

Therefore, the fraction of the load supplied by solar energy, sf, for a system that stores energy for $n$ consecutive cloudy days is

or

$$
s_{s f}=\frac{P_{s} M D+M D \sum_{i=1}^{n} Q_{c, i}}{M D}
$$

If $P_{s}=0.65$ and $P_{s s}=0.72$, then for a mini mum TES system $(n=0), s f=0.51$. If the system capability is extended to $n=1, s f=0.65 ;$ for $n=2, s f=0.71$. These solar fractions are in agreement with the range of optimum values found in practice.

The solar fraction depends upon the system size that is expressed by the parameter $n$ which, in turn, is determined from Eq. 13. Although, as previously discussed, that equation yields' somewhat oversized optima, nevertheless, as examples in the next Section show, these systems rarely exceed sizes corresponding to $n=2$.

\section{Optimum TES - Examples}

Four example systems are considered in this section. The parameters common to all are listed in Table 1. For these examples, $P_{s}$ was selected from inspection of Nashville, TN weather data with a "sunny" day arbitrarily defined as one whose average horizontal insolation exceeded $36 \%$ of the corresponding extraterrestrial value (See Appendix B). Pss for Examples 1, 3, and 4 was similarily obtained. 
In general, the parameter values chosen in Table 1 are meant to be representative of those of a high performance, low cost system. Computer simulation of a system designed in some detail would be necessary to obtain a more accurate value of $E$, the average daily energy collected and stored per unit of collector area.

Table II lists the parameters that were varied in the four examples. The fixed costs listed in this Table (for the $n=0$ sizes) were arbitrarily chosen to be somewhat larger than the incremental costs corresponding to the initial system size. Although these fixed costs do not affect the size of the economically optimum system, they do, of course, affect the total profitability of the optimum system.

In Example 2, $P_{s s}$ was set equal to $P_{s}$ to show the effect of removing insolation persistence. This produced a sharper peak at $n=1$, and larger negotive incremental profits for larger $n$, because the "sunny" days are more uniformly distributed and thus there are fewer occurrences of 2 or more consecutive cloudy days.

Examples 3 and 4 show the pronounced effect on the system economics if the system lifetime is extended from 15 to 20 years. For these cases the optimum system size corresponds to $n=2$. Example 4 uses a collector with a higher incremental cost and consequently the costs and profit are changed proportionately.

Table III summarizes the cost and performance of the four systems. The storage size in this table is based upon a $500 \mathrm{~F}$ temperature swing in a fully mixed water storage tank.

\section{Conclusion}

There has been presented an analytical derivation of the relationship between the economically optimum TES size in a solar energy system and three types of parameters. These are: (1) system parameters such as storage costs, collector cost and collector efficiency; (2) economic parameters such as cost of fuel, fuel escalation rates, and the worth of money; and (3) parameters that describe weather insolation persistence statistics. Because of the approximations inherent in the yalues of these parameters, the results of the derived expression are only approximate. The analysis serves to elucidate how TES size depends upon the above parameters, and to provide a starting point for simulation studies.

\section{Acknowledgments}

The authors wish to thank Professor A. Levine of the Yeshiva University Department of Economics for a helpful discussion of marginal analysis.

This work has been supported in part by the Solar Heating and Cooling Research and Development Branch, Office of Conservation and Solar Application, U.S. Department of Energy, under contract Number EG-77-C-03-1467. 
11. Reference

1. Baumol, William J., Economic Theory and Operations Analysis, 3rd Ed., (Prentice-Hall, Inc., Inglewood Cliffs, N.J., 1972), Chapters 3 and 17.

12. Appendices

12.1 Appendix A: Derivation of Equation 5

Eq. 4 is of the form

$$
Q_{c, n}=U \sum_{i=n}^{M-1}
$$

$$
w c^{i-1}-\frac{u}{M} \sum_{i=n}^{M-1} i c^{i-1}
$$

where $U, W$, and $C$ are defined in Eq. 6.

Since

$$
\sum_{i=n}^{M-1} c^{i-1}=\frac{c^{n-1}-c^{M-1}}{1-c}
$$

and

$$
\begin{aligned}
\sum_{i=n}^{M-1} i c^{i-1} & =\frac{d}{d C}\left[\sum_{i=n}^{M-1} c^{i}\right] \\
& =\frac{d}{d C} \frac{C^{n}-C^{M}}{1-C} \\
& =\frac{C^{n-1}(n+C-n C)-C^{M-1}(M+C-M C}{(1-C)^{2}}
\end{aligned}
$$

it follows that $Q_{c, n}$ is as given in Eq. 5 .

44 


\subsection{Appendix B: Determination of $P_{5}$}

In the examples given in Section 8 , a value of $36 \%$ was arbitrarily adopted for $\beta$, the minimum ratio of terrestrial to extraterrestrial insolation on a "sunny day. This appendix discussed the relation between this cutoff value and system parameters, the latter also being assigned approxima te and arbitrary values.

For the purpose of a solar energy system, a day is sunny if the collect can provide enough solar energy to justify the price of the collector. Assume that for 6 hours in each day of a 200 day heating season a collector that costs $\$ 10 / \mathrm{ft}^{2}$ delivers $1 / 2$ of the available radiation to the load. Furthermore, assume that it is required that the collector annually supply energy worth $\mathrm{I} / 10$ of the collector's price. Then, if the cost of energy is $1 c / 1000$ BTU, the collector must provide $0.5 \mathrm{c}$ of energy per $\mathrm{ft}^{2}$ per day, or $500 \mathrm{BTU}$ in the 6 hour period, or $83 \mathrm{BTU} / \mathrm{ft}^{2}$ hour. The radiation available must therefore be $166 \mathrm{BTU} /$ $\mathrm{ft}^{2} \mathrm{hr}$.

The extraterrestrial insolation intensity (the solar constant) is $430 \mathrm{BTU} / \mathrm{ft}^{2} \mathrm{hr}$. Consequently, a day is "sunny" if the ratio of terrestrial to extraterrestrial insolation is at least $166 / 430=39 \%$.

Unfortunately, there presently does not appear to be any clear cut method of catagorizing a day as sunny or cloudy other than the rather arbitrary approaches discussed above. In the absence of any absolute criterea for determining $\beta$, a value selected on the basis of collector price and performance seems most appropriate. Consequently, under technical and economic conditions that differ considerably from present ones, a different value for $\beta$, and therefore for $P_{s}$ and $P_{s s}$, would be used. 
$P_{s} \quad$ Fraction of doys in heating

0.65 season that are sunny

$M \quad$ Duration of heating season

230 days

$C_{F} \quad$ Present cost of fuel

$10^{-5} \$ / B T U(3.4 c / k W h)$

f Annual fuel escalation rate above inflation

0.035

Annual worth of money above inflation

0.02

d Incremental cost of storage

$0.0017 \$ / B T U$

E System energy collection capability

$700 \mathrm{BTU} / \mathrm{fr}^{2} /$ day

D Load

350000 BTU/day

Table 1. System Parameters for Four Example Cases. These parameters are the same for the four numerical examples discussed in Section 8. 
Parameter

$P_{\text {ss }}$ Conditional probability of sunny day after sunny day

N System lifetime

Cost of minimum $(n=0)$ system

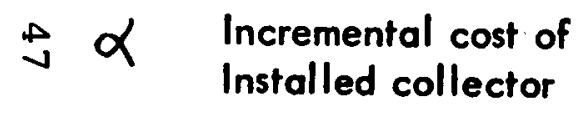

$\stackrel{\leftrightarrow}{ } \alpha \quad \begin{aligned} & \text { Incremental cost of } \\ & \text { Installed collector }\end{aligned}$

\section{Dimension}

$$
\text { Example } 1
$$

Example 2

Example 3

Example 4

$\$ / \mathrm{ft}^{2}$

10

10

10

17

0.72

0.72

0.72

Years

15

15

20

20

$\$$

6000

Table II. Parameters Varied in Four Example Cases. The above parameters were used in the numerical examples discussed in Section 8. 


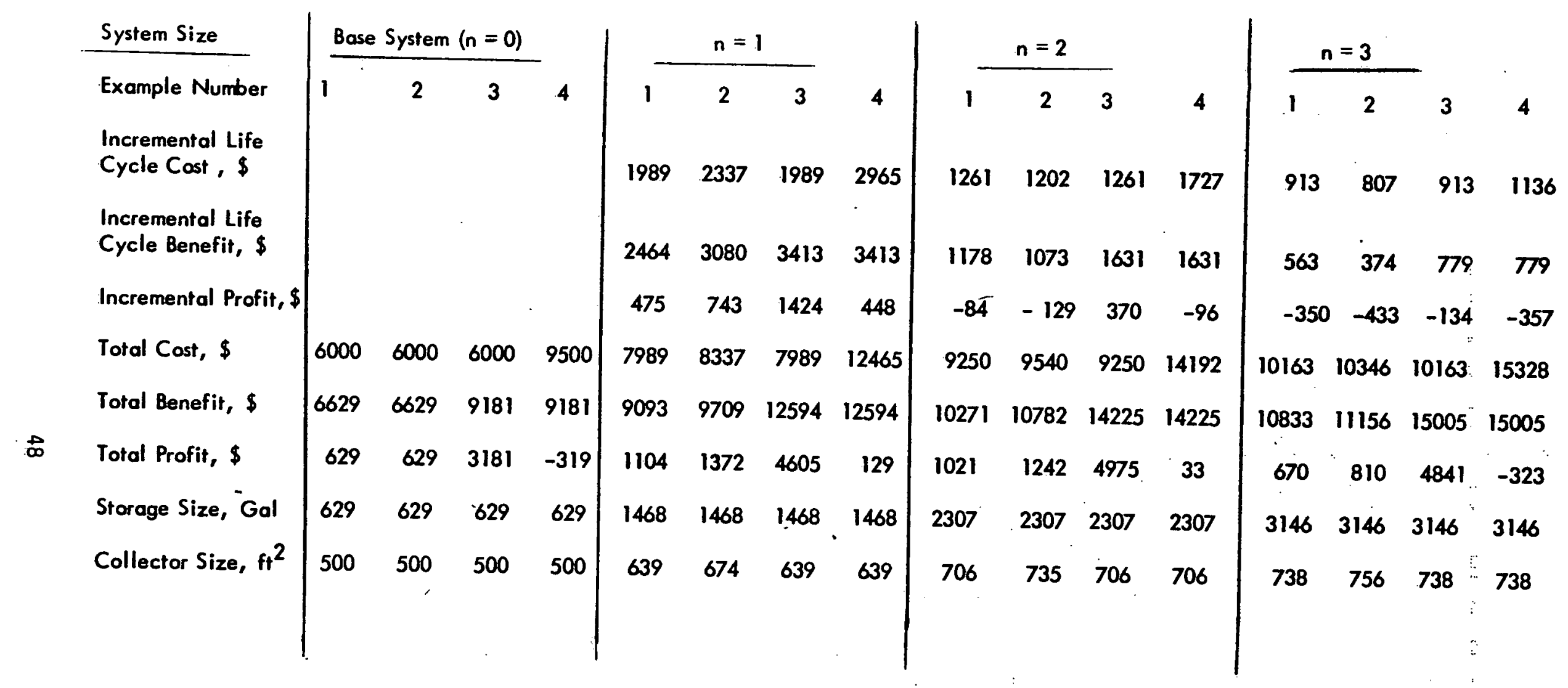

Table III. System Performance as a Function of System Size. The marginal as well as the total costs, benefits, and profits for the systems described in Tables I and II are tobulated for system size that range fram the base system $(n=0)$ that provides energy for 24 hours of a sunny day, to the " $n=3$ system" that provides energy to the load during 3 consecutive cloudy days. Note that the incremental profit is negative for all examples when $n=3$. 


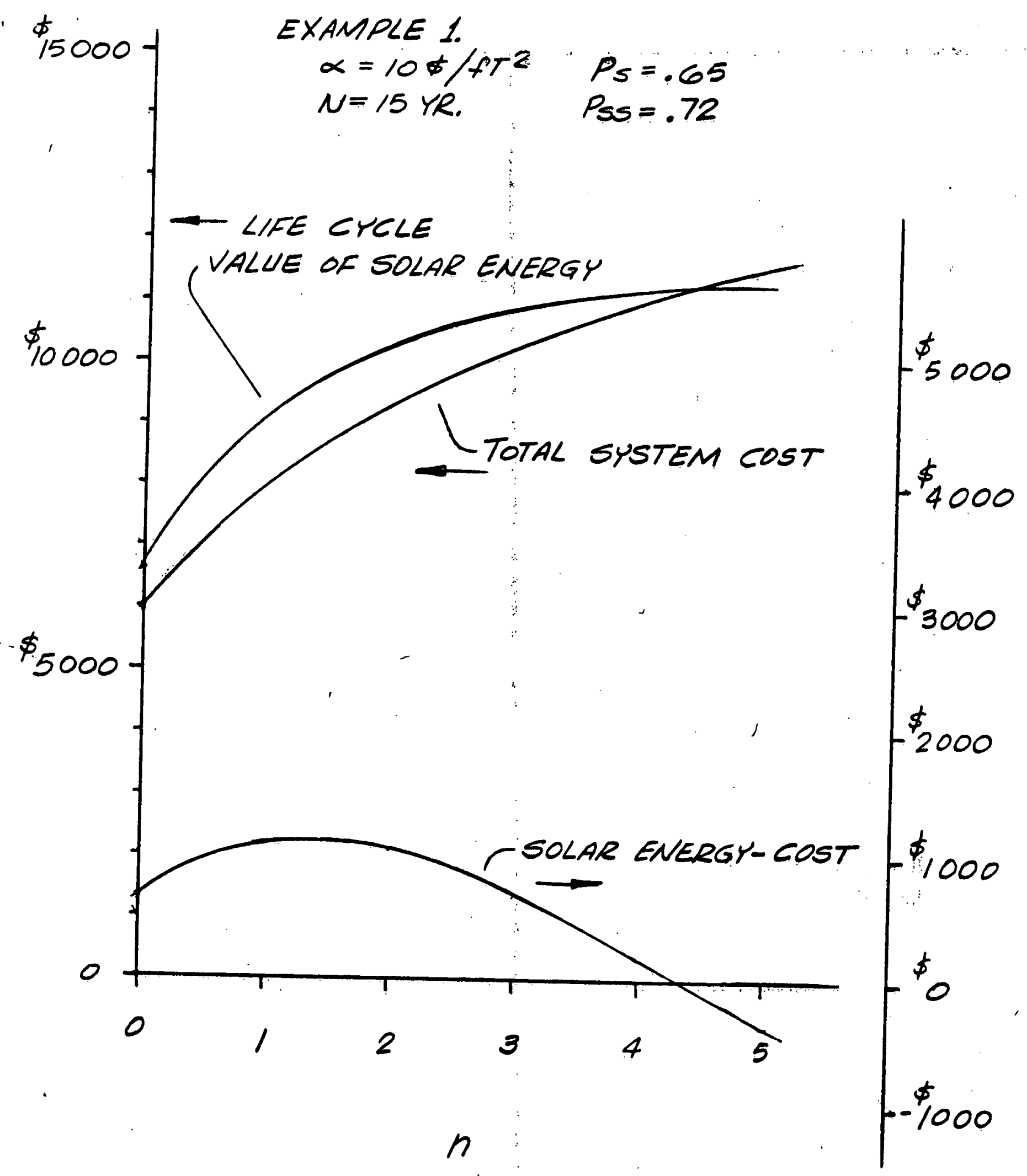

$49:$ 


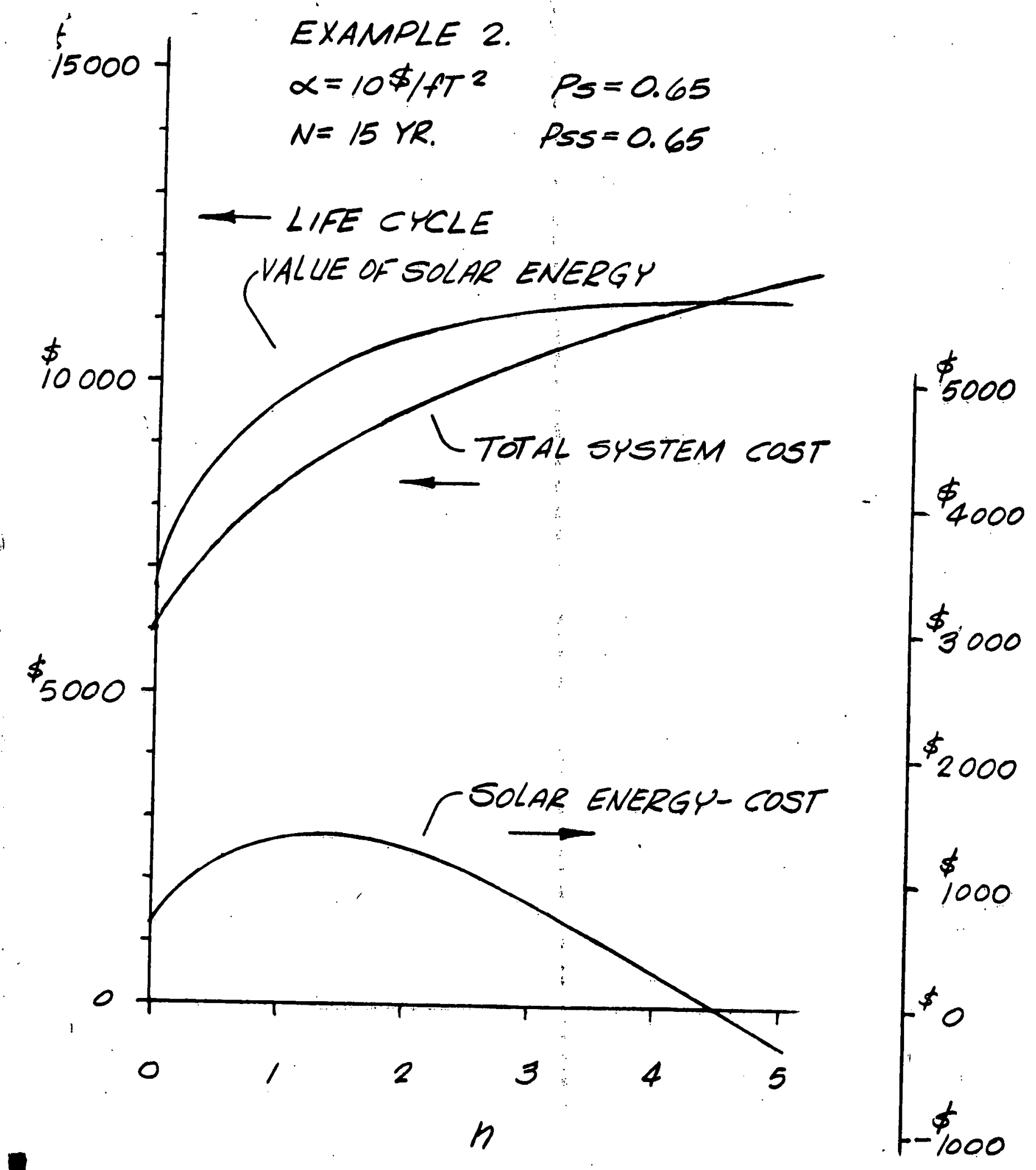

50 


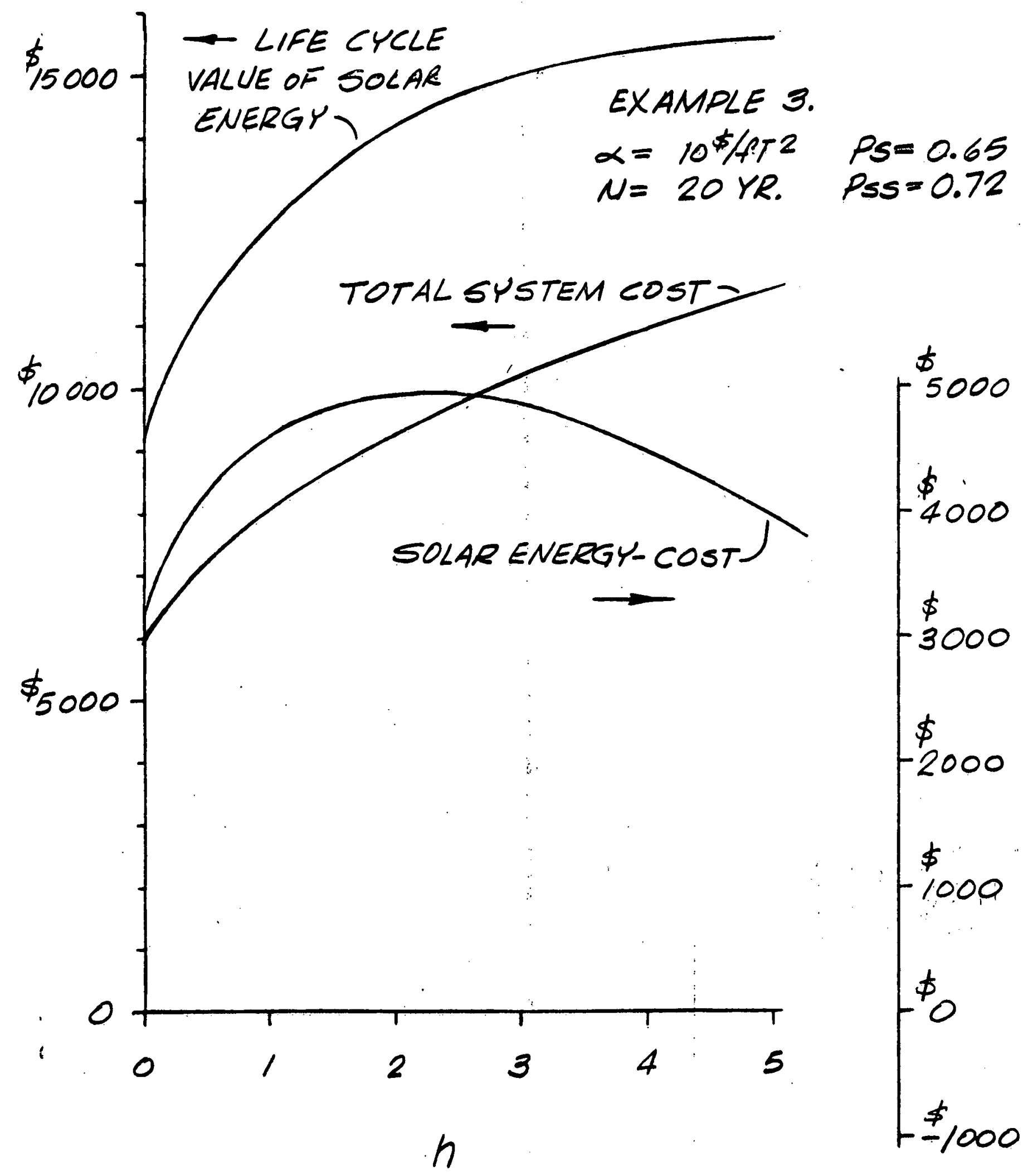

51 


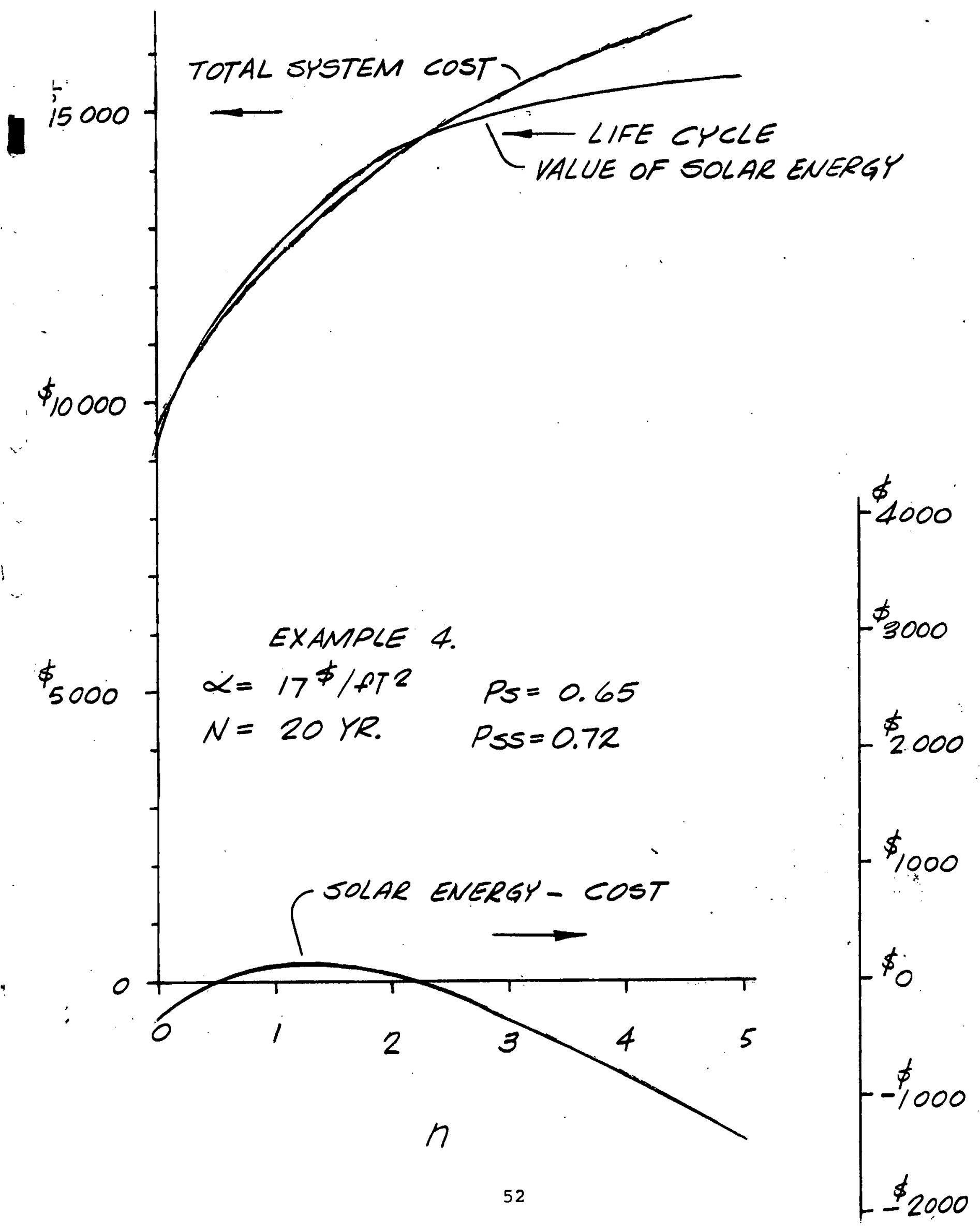


"Optimization and comparison strategies for. Solar Energy Systems", Amer. Soc. Mech. Eng.. Winter Annual Meeting, 79-WA/Sol-26, New York, NY (1979) 


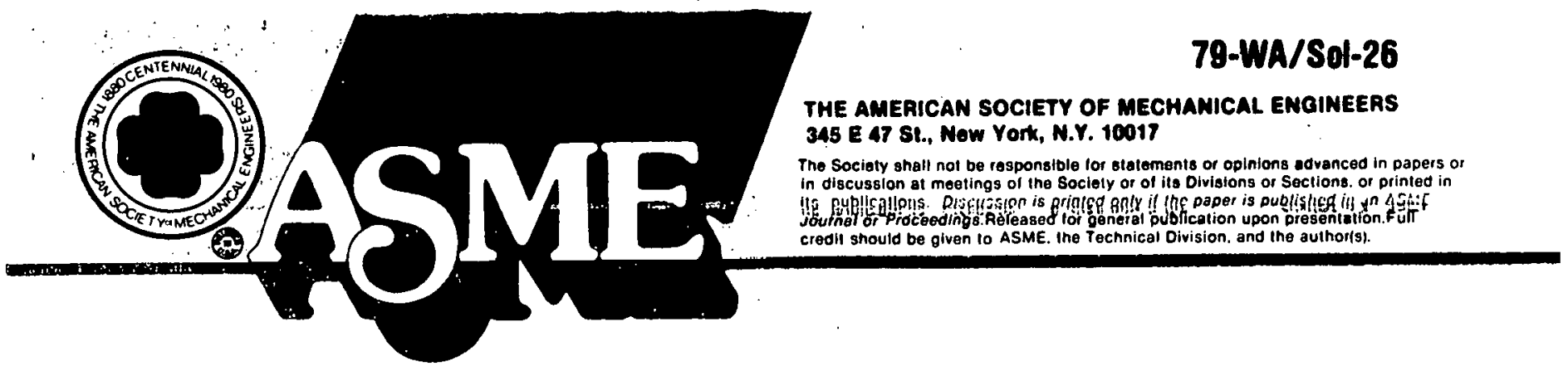

R. C. Estes

W. Kahan

The Singer Company. Corporate Research and Development Lab. Singer Company Fairlield. N.J.

\section{Optimization and Comparison Strategies for Solar Energy Systems}

An analytical model of several simple, generic solur energy systems, with und without heat pumps, is described. The model is augmented by marginal analysis io configure the components of each system rype for an economic optimum and, consequently, for maximum marketability. This model is to be used as a "first-cut" means of identifying the combinations of ranges of system componem parameters and general geographic regions for which each generic configuration is most marketable. Assessment of marketability includes the following considerations: the size of the capital investment, the operating cost savings relative to alternative systems, future cost of energy, and cost of money. The following six sustems types are optimized (where appropriate) and compared: 1) an all electric resistunce heating system, 2) a stand-alone heat puinp system, 3) a stand-alone solar energy system, 4) a series solar assisted heat pump (SAHP) system, 5) a parallel SAHP system, and 6) a dual source SAHP system.

NOMENCLATURE

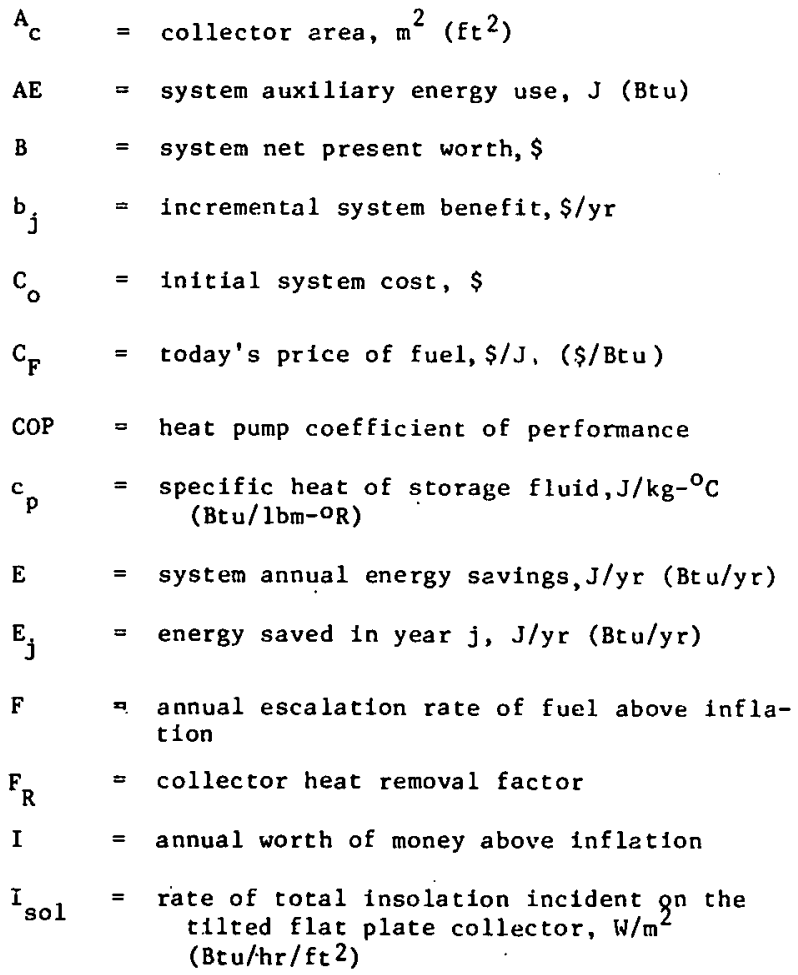

Contributed by the Solar Energy Division of The American Society of Mechanical Engineers for presentation at the Winter Annual Meeting. New York, N.Y., December 2.7, 1979. Manuscript received al ASME Headquarters August 21, i 1979 .

Copies will be available until September I, 1980

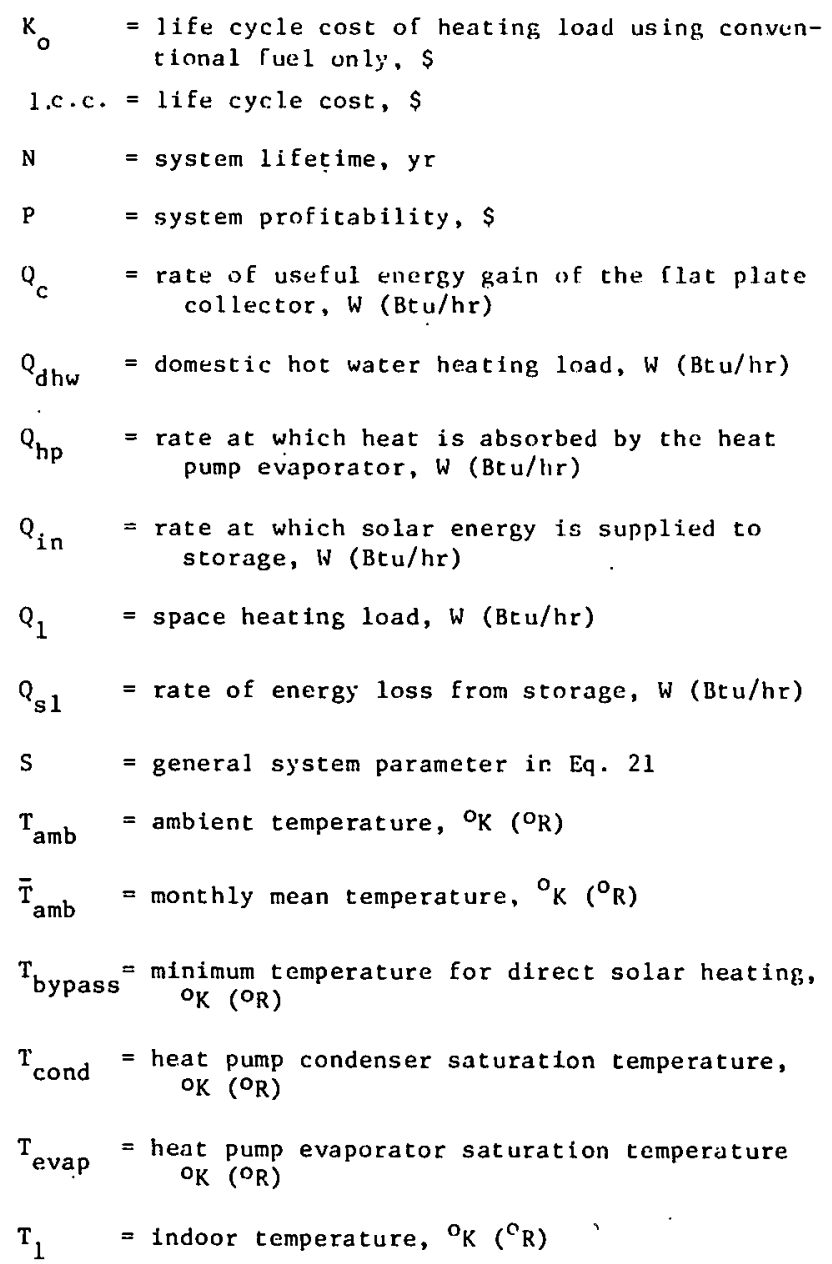




$$
\begin{aligned}
& T_{1}^{\prime}=\text { Indoor temperature reduced to account for in- } \\
& \text { ternal heat generation, } O_{K}(O R) \\
& T_{\max }=\text { maximum allowable storage temperature, }{ }^{\circ}\left({ }^{\circ} R\right) \\
& T_{m i n}=\text { minimum allowable storage temperature, }{ }^{\circ}\left(o_{R}\right) \\
& \mathrm{T}_{\mathrm{r}}=\underset{\mathrm{O}_{\mathrm{K}}\left({ }^{\circ} \mathrm{R}\right)}{\text { temperature }} \text { of the storage surroundings, } \\
& T_{S} \quad=\text { storage temperature, }{ }^{\circ} \mathrm{K}\left({ }^{\circ}\right) \\
& \mathrm{T}_{\mathrm{SW}}=\text { monthly mean temperature swing, } \mathrm{o}_{\mathrm{K}}\left({ }^{\circ} \mathrm{R}\right) \\
& \mathrm{T}_{\infty} \quad=\text { system parameter function in Eq. } 12,{ }^{\circ} \mathrm{K}\left({ }^{\circ} \mathrm{R}\right) \\
& \text { t }=\text { time, } h r \\
& t_{0}=t \text { ime of a system transition, } h r \\
& U_{c} \quad=\text { collector overall energy loss coeffictent, } \\
& \left.\mathrm{W} / \mathrm{m}^{2}-\mathrm{O}_{\mathrm{K}} \text { (Btu/hr-ft } \mathrm{B}^{2}-\mathrm{O}_{\mathrm{R}}\right) \\
& \mathrm{U}_{\mathrm{S}} \quad=\text { storage overall energy loss coefficlent, } \\
& \left.\mathrm{W} / \mathrm{m}^{2}-\mathrm{OK}_{\mathrm{K}} \text { (Btu/hr-ft} \mathrm{B}^{2} \mathrm{O}\right) \\
& \text { (UA) }_{1} \text { = loss coefficlent - area product of the space } \\
& \text { heating load, W/OK (Btu/hr- }{ }^{\circ} \mathrm{R} \text { ) } \\
& \mathrm{v}=\text { storage volume, } \mathrm{m}^{3}\left(\mathrm{ft}^{3}\right) \\
& W_{h p}=\text { auxiliary power used to drive the heat pump } \\
& \text { compressor, J (Btu) } \\
& \Delta \mathrm{T}_{\text {cond }}=\text { constant temperature difference between heat } \\
& \text { pump source and condenser, }{ }^{\circ} K\left(O_{R}\right) \\
& \Delta T_{\text {evap }}=\text { constant temperature } d 1 f \text { ference between heat } \\
& \text { pump evaporator and sink, } \mathrm{O}_{K}\left({ }^{\circ}\right) \text {. } \\
& 2 \text { = heat pump efficiency } \\
& \rho=\text { density of storage fluid, } \mathrm{kg} / \mathrm{m}^{3}\left(1 \mathrm{hm} / \mathrm{ft}^{3}\right) \\
& J=\text { time constant of eq. } 12 \text {, hr } \\
& \overline{\gamma \alpha}=\underset{\text { product }}{\text { collector average transmittance-absorptance }}
\end{aligned}
$$

\section{INTRODUCTION}

For the effective marketing of solar energy systems it is imperative to identify those climaric regions, load profiles, and system characteristics for which such systems are economically promising. For individual systems, load profiles, and regions this identification is normally accomplished through use of computer simulations. However, because the total intersection of the regional, load, and system vartables is so large, It is desirable to develop an efficient and quick means of 1dentifying the most promising combinations and winnowing out the least promising ones.

To accomplish this, an analytical model of a general solar assisted heat pump (SAHP) system which estimates the long term thermal performance of the system and which permits closed form solution has been developed. The system modeled (FIg. 1) contains a flat plate collector which transfer solar heat to a storage tank.
Heating of the residence is accomplished in one of three ways: direct transfer of heat from storage to the residence; tranbfer of heat via a hat pump whose source is the storage tank; or direct electric resistance heating of the residence. The model. is Intended to be used as a "first-cut" method of market identiffcation; thus effects of heat exchangers and subsidiary pumps and fans are neglected and primary system components are modeled by linear first order differential equations. Because of the model simplicity, slight modifications of the model input parameters allow the modeling of an all-electric heating system, a stand-alone heat pump system, a stand-alone solar energy system, a dual source SAHP system, and a paralle1 SAHP system in addition to the series SAHP system. Using the analytical models, an optimum of each of the six systems can be obtained. This is accomplished by tracking, via marginal analysis, the effect of incremental changes in system parameters. At the point where the incremental benefit derived from a change of the parameters equals the Incremental cost of providing those benefits, an optimum system is achieved. By comparing the optimized systems on a life cycle cost basts, the determination of the most economical one is assured. At this point, then, more extensive computer simulation may profitably be called into play. Note, for the purposes of this "sieve" analysis, the system with the best market potential is identifjed as the economically optimum one, l.e., the one with the lowest life cycle cost.

\section{ANALYTICAL MODEL}

Mathemat1cal Model of a Series SAHP System.

A schematic diagram of the series SAHP system that is modeled in this section is shown in Fig. 1 . In this system, solar energy absorbed by the flat plate collector is stored in the form of sensible heat in the storage area. It is transferred from storage to the residential space and hot water heating load efther directly (Valves A open) or via a heat pump (Valves B open).

It is assumed in the model that the storage is fully mixed and characterized by a single temperature $T_{s}$. Thus an energy balance of storage is given by

$$
\int c_{p} v \frac{d T_{s}(t)}{d t}=Q_{1 n}-Q_{\text {out }}
$$

In this equation, the time rate of energy transfer into storage, $Q_{1 n}$, 1s modeled by the following function of $T_{s}$ :

$$
Q_{1 n}=Q_{1 n}\left[t, T_{s}(t)\right]= \begin{cases}0 & , T_{s}>T_{\max } \\ Q_{c}\left[t, T_{s}(t)\right], T_{s} \leq T_{\max }\end{cases}
$$

where $T_{\text {is }}$ is some predetermined maximum (e.g., near the boillixg point of a liquid storage fluid). Also, $Q_{c}$, the rate of useful egergy gain of the flat plate collector is given by [1]

$Q_{c}=A_{c} F_{R}\left\{(\overline{\ell \alpha}) I_{s o l}(t)-U_{c}\left[T_{s}(t)-T_{a m b}(t)\right]\right\}_{(3)}^{+}$ 
The + sign in this equation Indicates that only positive values of the bracketed quantity are used.

The time rate of energy transfer out of storage is also modeled as a function of $T_{s}(t)$ :

$$
\begin{aligned}
& Q_{\text {out }}=Q_{\text {out }}\left[t, T_{s}(t)\right] \\
& = \begin{cases}Q_{1}+Q_{s 1} & , T_{s} \geq T_{\text {bypass }} \\
Q_{h p}+Q_{s 1} & , T_{m i n} \leq T_{s}<T_{\text {bypass }} \\
Q_{s 1} & , T_{s}<T_{\text {min }}\end{cases}
\end{aligned}
$$

Thus, If $T_{\text {f }}$ is above a "byfass" temperature $T_{\text {bypass. }}$ the load is heated directly by stored solar energy and $Q_{\text {out }}$ is fust the sum of $Q_{1}$, the space and domestic hot water heating load, and $Q_{\mathrm{gl}}$, the rate of energy loss from storage, given by

$$
Q_{1}=(\text { UA })_{1}\left\{T_{1}{ }^{\prime}-T_{\text {amb }}(t)\right\}^{+}+Q_{d h w}
$$

and

$$
Q_{s 1}=Q_{s 1}\left[T_{s}(t)\right]=U_{s} v^{2 / 3}\left[T_{s}(t)-T_{r}\right]
$$

where the storage heat loss rate is proportional to the storage surface area which, in turn, is proportional to the two-thirds power of the storage volume. If $\mathrm{T}_{\mathrm{g}}$ decreases below a fredetermined minimum $T_{m i n}$. electric auxiliary energy is used to heat the load and the only energy transferred out of storage is that due to storage losses.

Above the minimum temperature, but below the bypass, stored solar energy is absorbed (at rate $Q_{h p}$ ) in the evaporator of the heat pump, augmented by compressor work, and thence rejected to heat the load. To obtain an expression for $\mathrm{Qhp}$, the coefficient of performance (COP) of the heat pump for heating is modeled as a constant fraction of the COP of a Carnot heat pump:

$\operatorname{cop}=\operatorname{cop}\left[\mathrm{T}_{s}(t)\right]=\eta \frac{\mathrm{T}_{\text {cond }}}{\mathrm{T}_{\text {cond }}-\mathrm{T}_{\text {evap }}}$

where

$$
\begin{aligned}
& T_{\text {cond }}=T_{1}+\Delta T_{\text {cond }} \\
& T_{\text {evap }}=T_{\text {evap }}\left[T_{s}(t)\right]=T_{s}(t)-\Delta T_{\text {evap }}
\end{aligned}
$$

and

$$
Q_{h p}=\left[1-\frac{1}{\operatorname{cop}}\right] Q_{1}
$$

Three curves of COP versus storage ( 1 .e.,source) temperature are shown in FIg. 2: the curve of the "actual" heat pump was obtalned from manufacturer's data on a 3 ton, a1r source heat pump; that of the "model 1 " heat pump was derived from a least square f1t of the heat pump parameters (1.e., $\Delta \mathrm{T}_{\text {evap }}$,

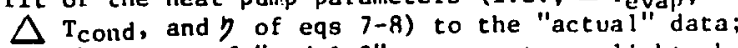
and the curve of "model 2 " represents a slight change in the parameters to depict an improved or second genefat in?!l! lift puing.

With the above assumptions, each of the SAHP components (collector, heat pump, and heating load) is a linear function of $T_{s}$. Thus, the energy balance of Eq. (1) is a linear, first order differential equation with the general form

a $\frac{d T_{S}(t)}{d t}+b(t) T_{s}(t)=c(t)$

If, in this equation, both $b$ and $c$ are constant, a closed form solution existe which has the general form

$$
T_{g}(t)=\frac{c}{b}+\left[T_{s}\left(t_{0}\right)-\frac{c}{b}\right] \exp \left[-\frac{b}{a}\left(t-t_{0}\right)\right]
$$

The time dependence of both these coefficients occurs through their dependence on the weather variables $T_{a m b}(t)$ and $I_{s o l}(t)$. Therefore, In order to gain computational simplicity while retaining some information of weather persistence, the weather variables are represented as rectangular waves. Thus. during each portion of the day in which $\mathrm{T}_{\text {amb }}$ and $I_{\text {sol }}$ are constant, the energy balance equation reduces to a linear first order differential equation with constant coefficients.

The representation of the ambient temperature $\mathrm{T}_{\mathrm{amb}}$ is shown in Fig. 3a. This rectangular wave function is held invariant over the duration of one month and is given by the following function of the monthly mean temperature $\tau_{a m b}$ and mean temperature swing $\mathbf{T}_{\mathrm{SW}}$

$$
\mathrm{T}_{\mathrm{amb}}(t)= \begin{cases}\overline{\mathrm{T}}_{\mathrm{amb}}+.285 \mathrm{~T}_{\mathrm{sw}}, 1030 \mathrm{hrs}<\mathrm{t}<2230 \mathrm{hrs} \\
\overline{\mathrm{T}}_{\mathrm{amb}}-.285 \mathrm{~T}_{\mathrm{sw}}, \begin{array}{l}
0 \text { hrs }<t<1030 \mathrm{hrs}, \\
2230 \text { hrs } \leq t<2400 \text { hrs }
\end{array}\end{cases}
$$

This function can be shown to be a rectangular wave approximation of the sinusoidal function given by Card et al. [2]. Monthly values for $\bar{T}_{a m b}$ and $T_{s w}$ were obtained for the 1958 New York, NY heatins season and for the 1957 Fresno, CA heating season. Heating loads were then calculated from. Eq. 5 using Eq. 11. As can be seen from Table I, the results compare well with loads calculated with actual hourly dry bulb temperature readings using TRNSYS.

To obtain a rectangular wave representation of insolation (Fig. 3b), the total dally insolation on the tilted surface is assumed to be unitormly distributed over $90 \%$ of the daylight hours. At uther times Isol is assumed to be zero. Insolation on the tilted surface is calculated from the dally insolation on a horizontal surface through use of the LIu and Jordan conversion factor for daily radiation [4] and the correlation between daily diffuse and hemispherical insolation derfved in Ref. 5.

Given the mode: of the series SAHP system described above, the atorage temperature at any time $t$ can be shown to be 


$$
T_{s}(t)=T_{\infty}+\left[T_{s}\left(t_{0}\right)-T_{\infty}\right] \exp \left[-\frac{\left(t-t_{0}\right)}{T}\right]
$$

In this equation, $t_{0}$ indicates a time of system transition, for example, a transition from heat pump to direct heating or the dally transtion from daytime to nighttime (zero) insolation; and $T_{\infty}$ and $\mathcal{T}$ are functions of the system parameters which remain constant between system transitions.

The auxilfary energy use of the system between times $t_{0}$ and $t$ is then

$$
\begin{array}{lll}
\operatorname{AE}\left[t, T_{s}(t)\right]=0 & , T_{s}>T_{\text {bypass }} \\
\operatorname{AE}\left[t, T_{s}(t)\right]=W_{h p}\left[t, T_{s}(t)\right], T_{m i n} \leq T_{s} \leq T_{\text {bypass }} \\
\operatorname{AE~}\left[t, T_{s}(t)\right]=Q_{1} \cdot\left(t-t_{o}\right), T_{s}<T_{m 1 n}
\end{array}
$$

where Whp, the auxiliary energy used to drive the heat pump compressor in time $\left(t-t_{0}\right)$ is given by

$$
\begin{aligned}
W_{h p}= & \frac{Q_{1}}{\zeta T_{\text {cond }}}\left\{\left[T_{\text {cond }}+T_{\text {evap }}-T_{\infty}\right]\left(t-t_{o}\right)\right. \\
& \left.+\left[T_{s}(t)-T_{s}(0)\right] \tau\right\} .
\end{aligned}
$$

\section{Mathematical Mode1 of Five Additional Heating systems}

In the preceding section, a mathematical model of a generic series solar assisted heat pump system was described. It is obvious, however, that by fixing certain of the system parameters the modeling of additional systems is accomplished. For example,
if, in Eq. (2)

$$
\mathrm{T}_{\mathrm{min}}=\mathrm{T}_{\text {bypass }}
$$

the solar energy sourced heat pump is always bypassed. If, now, the auxilfary energy requirement of the system is calculated as in Eq. (13c) (1.e., all electric auxillary heating) a simple stand alone solar energy system is modeled. If, however, the auxiliary energy requirement is calculated assuming that the primary auxilfary heating is due to an ambient sourced heat pump, a parallel. SAHP system is modeled. In like manner, an all electric system. $\left(A E \alpha_{Q_{1}}\right)$, a dual source system, and a stand alone heat pump system can be modeled.

\section{Validation of Analytical Model}

Estimates of the energy savings of the modeled systems computed with the above model have been compared with detalled computer simulations (TRNSYS[6]) of the systems. Table I lists the results for systems in a single family residence located near New York, NY and near Fresno. CA. It is evident from these results that the analytical model can correctly assess the performance of these competing systems. Furthermore, it does so with a significant decrease in computational time and effort.

As will be shown in an example. this computation of energy usage by competing HVAC systems forms the basis of the life cycle cost analysis of the systems, which in turn determines their relative marketability, the goal of this program.

\section{ECONOMIC ANALYYSIS}

\section{Life Cycle Cost}

To select an economically" optimum system, a consistent methodology [7] of economic evaluation must be added to the analyses of the rmal performance described above. This is especially critical when comparing systems that have extremely different t.lme profiles of cash flow. For example, an electric resistance heating system has a low inftial cost but a high operating cost. Conversely, a stand alone solar energy system has a high initial cost but a low operating cost. The economic evaluation should select as the desired system the one whose rotal life cycle cost is a minimum.

To compute the present value of the cash flows that make up the life cycle cost, future flows can be compared to inftial ones by discounting future costs and benefits to their present value using the annual worth of money, I. Thus, if a system produces a benefit by in its $j$.'th year of operation and if the system lifetime is $\mathrm{N}$ years, the net present value of the benefits, B, is

$$
B=\sum_{j=1}^{N} \frac{b_{j}}{(1+1)^{j}}
$$

In the discussion in this paper, the annual heating load ( $\mathrm{Eq}$. 5) will be adopted as a base from which to compute $b_{j}$, the annual benefit derived from conserving an amount of energy $E_{j}$ through the use of a heat pump, solar energy, or both. Neglecting system degradation, $E_{j}$ is a constant (thus the $j$ subscript is dropped). However, $b_{j}$ changes because the value of energy escalates at an annual rate of $F$. Therefore, if the value of energy (price of fuel) is Inltially $C_{F}$,

$$
b_{j}=E C_{F}(1 .+F)^{J}
$$

The net present value is therefore

$$
B=E_{F} \sum_{j=1}^{N}\left(\frac{1+F}{1+I}\right)^{j}=E C_{F} \frac{r^{N+1}-r}{r-I}
$$

where

$$
r=\frac{1+F}{1+I}
$$

Unfortunately, the quantities $I, N$, and $F$ are not well known. In the computations of the next section, the values

$$
I=0.02, \quad \mathrm{~F}=0.045, \quad \mathrm{~N}=15 \text { years }
$$

will be used as appropriate for residential systems. Note that $I$ and $F$ are evaluated as rates above inflation so that $B$ will be expressed in terms of real (tcday's) dollars. 
In addition to $B$, the only other life cycle cash flow considered here is $C_{O}$, the intial system cost. Other costs and benefits such as taxes, rebates, malntenance costs, and salvage value w11l be neglected In this analysis since they are generally smaller than the imprecision in the values used for system costs and the approximations used to compute $E$, the annual savings of auxillary energy. Because $B$ is evaluated with respect to $\mathrm{K}_{0}$, the $11 \mathrm{fe}$ cycle fuel cost of a base line system, the total system life cycle cost is

$$
\text { 1.c.c. }=C_{0}+\left(K_{0}-B\right)
$$

The thermal analysis of the preceding section ylelds the E from which B is obtained for each of the competing HVAC systems. Knowing the load requirement, $K_{o}$, and the initial system cost, $C_{o}$ of these systems, one can then select the economically optimum one. However, as discussed below, even without complete knowledge of $C_{o}$ and $K_{o}$, the parameters (e.g. collector area) of a given type of system (e.g. parallel SAHP) can be chosen to make the system the economically optimum one of 1 ts type.

\section{Marginal Analysis}

The cost and benefits derived from solar HVAC systems depend critically on the sizes of their components (e.g. collector area or storage volume). These sizes should therefore be chosen to maximize the "profitability", $P$, of a system, where $P$ is defined as the system benefits less its cost

$$
P=B-C_{0}
$$

so that the configuration with the minimum iffe cycle cost will be the one with the maximum profitability.

Consequently, the optimum cholce of a parameter $S$ w1ll be made when $d P / d S$ vanishes, or approximately when

$$
\frac{\Delta^{B}-\Delta^{C_{o}}}{\Delta s}=0
$$

The quantity $\triangle B$ is the incremental or marginal benefit derived from increasing the parameter size by $\triangle \mathrm{s}$. Similary, $\triangle \mathrm{C}_{\mathrm{o}}$ is the incremental or marginal cost incurred to effect the change $\Delta \mathrm{S}$. The Equal Marginal Principle, Eq. 22, states that the economically optimum system is obtained when the marginal cost is the same as the marginal benefit [8].

If a parameter change $\Delta S$ produces a change $\Delta \mathrm{E}$ in the energy saved annually, then the corresponding $\triangle \mathrm{B}$ can be calculated from Eq. 18a. To calculate $\triangle C_{0}$, only the incremental system cost $\left(\mathrm{e} . \mathrm{g} . \$ 108 / \mathrm{m}^{2}\right.$ $\left(\$ 10 / f^{2}\right)$ of collector) need be known, not the entire initial system cost. Thus marginal analysis enables each type of system to be optimized with respect to its major parameters without complete cost information. An example of marginal analysis system optimization follows.

\section{RESULTS}

In this section, examples of life cycle cost rankIng of the six HVAC systems for New York C1ty, NY and Nashville, TN are given. Two steps are followed in this system ranking: 1) a marginal analysis opt imization of the important system parameters af each of the six systems, and 2) a 11 fe cycle rosting of the optimized systems. The system parameters nptimfzed in the examples are collector area and storage volume. A tabulation of other system parameters is given in Table II.

Marginal Analysis - Economic Optimization of Collector Area and Storage Volume

For clarity, a detafled lllustration of the collector area-stcrage volume optimization is given below for the series SAHP system. In this illustration, incremental costs of $65 \$ / \mathrm{m}^{2}\left(6 \mathrm{~s} / \mathrm{ft}^{2}\right)$ and $212 \mathrm{~s} / \mathrm{m}^{3}$ $\left(6 \$ / \mathrm{ft}^{3}\right)$, respectively, are assumed for the collectur and storage. Results for this and the other systems are given in Table III. Because the energy usages of the al1-electric and heat pump systems are independent of collector area and storage volume, no marginal analysis is performed for these systums.

In Fig. 4a, the annual auxillary energy use of a series SAHP system with a rock storage volume of $4.42 \mathrm{~m}^{3}$ $\left(156 \mathrm{ft}^{3}\right)$ is shown as a function of collector area. Using the analysis of the preceding section, the curve of the incremental benefit minus the incremental. cost of increasinf collector size is determined. The economically optimum collector sizt occurs at the point at which the incremental values are equal, $1 . e$. at which the $\triangle \mathrm{P} / \triangle \mathrm{S}$ curve crosses the abscissa. Thus, If a serles SAHP system located near New York City has a storage volume of $4.42 \mathrm{~m}^{3}\left(156 \mathrm{ft}^{3}\right)$, 1ts optimum collector sizc is approximately $53 \mathrm{~m}^{2}\left(571^{\circ} \mathrm{ft}^{2}\right)$. Using this optimized area, the energy use of the system as a function of changing storage colume is determined (Fig. 4b), and as above, is used to obtain an optimun storage size of $3.28 \mathrm{~m}^{3}\left(116 \mathrm{ft}^{3}\right)$.

\section{Life Cycle Cost of Optimized Systems}

For the purpose of ranking competing systems on the basis of $11 \mathrm{fe}$ cycle costs, initlal system costs must be known. The following assumptions were made for the installation costs of air to air heat pumps and solar energy systems:

Heat Pumps - A 3 ton heat pump of the type sinilar to the "actual" one of Fig. 2 costs approximately $\$ 2000$ to install. The same cost was assumed for the Model I heat pump of that figure. However, an initial cost of $\$ 3000$ was assumed for the "improved" Model 2, as shown in Table II I

Solar Energy - An initial cost of $\$ 4000$ was assumed for plumbing, controls, pumps, and a 11 components other than installed collector and iustalled storage volume. These latter components were priced at $\$ 64.6$ per $\mathrm{m}^{2}\left(\$ 6\right.$ per $\left.\mathrm{ft}^{2}\right)$ and $\$ 212$ per $\mathrm{m}^{3}\left(\$ 6\right.$ per $\left.\mathrm{ft}^{3}\right)$, respectively.

SAHP Systems - The initial system cost, excluding collectors and storage is equal to that of the cost of the heat pump $(\$ 2000$ or $\$ 3000)$ plus the cost of the "Initial" solar energy system (\$4000). An additional $\$ 500$ was charged for the second evaporator heat exchanger in the dual-source configuration.

The "Total Initial System Cost" shown in Table liI for the optinized systems includes the cost of installed collectors and storage in addition to the initial. costs enumerated above. 
In general, the life cycle cost of an HVAC system for a single family residence is a large and, to the layman, an unfamiliar quantity. Consequently, instead of life cycle costs of the competing HVAC systems, Table III shows the corresponding annual uniform cost which is related to the present worth of the life cycle costs by the Uniform Capital Recovery Factor [7], $\left[1(1+I)^{N}\right] /\left[(1+1)^{N}-1\right]$

\section{System Ranking}

The competing systems are ranked in Table III on the basis of their annualized uniform cost (AUC). Even with the low cost, high efflciency collector of Table II, none of the solar energy systems has as low an AUC as does the lowest efficiency, stand-alone atr-toair heat pump in the locations investigated. The stand-alone solar energy system has the highest AUC and thus ranked poorest. Among the SAHP systems, the parallel configuration had the lowest AUC.

It should be noted that for the economic parameters of Eq. 19, the Uniform Capital Recovery Factor is 0.077825 ; thus each $\$ 1000$ of initial cost only adds $\$ 77.84$ to the AUC. Therefore, if the initial cost of the solar energy components, excluding the collector and storage, were reduced from $\$ 4000$ to $\$ 0$, the AuC of the solar energy systems would be reduced by only \$311.30. Even with this extreme assumption none of the optimized solar energy systems would significantly outrank the alr-to-air heat pump.

These results afford a physical understanding of the interaction between the solar energy components and the heat pump in SAHP systems. The series system requires relatively large collector areas because all heat pump source energy must come from the collector. Thus, for the climates investigated, energy that would be supplied free by the atmosphere to a stand-alone air-to-air heat pump is replaced by costly energy from the solar energy components without raising the seasonal performance factor sufficiently to overcome this front end "si.ncharge."

The dual-source SAHP system optimizes to a standalone heat pump (no collector, no storage) under the control strategy that connects the heat pump to the source (storage or ambient air) that provides the larger instantaneous COP. Under these conditions the storage temperature rarely rises to the point where direct heating is possible; rather, the collector energy must pass through the heat pump to reach the load. Consequently, the collector in this case is not cost effective. It should be noted that further research is necessary to determine to what extent more intelligent control algorithms can Improve the performance of the dual source SAHP systems.

The optimum parallel system requires negligible storage volume and little collector area. Here the collector serves to provide large COPs thereby negating the need for heat pump compressor work only during periods of high insolation. At other times the heat pump is operated as a stand-alone unit.

In addition to more optimal control strategies, other component developments, such as coupling storage or the heat pump outdoor coil to the ground, a large reservoir with relative temperature stability, may alter the system ranking.

\section{Sensitivity}

The results presented in the prevlous section are quife sensitivu to input astumpions. Mhree examples serve to illustrate this sensitivity. In the first example, the incremental costs of the collector and storage were reduced to $32 \$ / \mathrm{m}^{2}\left(3 \$ / \mathrm{ft}^{2}\right)$ and $141 \mathrm{~s} / \mathrm{ft}^{3}$ ( $\left.4 \$ / \mathrm{ft}^{3}\right)$, respectively. All other cost and system parameters were maintained at their values shown in Table II. The results are shown in Table IV. Generally, the rankings between the systems are the same although the relative difference between them decreases. If an arbitrary value of $120 \%$ of the AUC of the $\# 1$ ranked system is chosen to qualify a system as economically "competitive", only the parallel system in New York type climates competes with the current generation heat pump at the higher collector and storage costs used to generate Table III. If, as shown in Table IV, these costs are cut approximately in half (something virtually imposstble to achieve with current off-the-shelf technology) all three of the SAHP systems are competitive in this climate. In the warmer Nashville type climates, none of the solar energ; systems compete effectively with the stand alone air sourced heat pump.

In the second example to illustrate the sensitivity to input parameters, the current cost of energy and the annual fuel escalation rate were reduced to $4 \mathrm{c} / \mathrm{kWh}$ and $3.5 \%$ above inflation, respectively. (For brevity, only the stand alone solar energy system was optimized). The results are shown in Table $V$. As expected, as the annual cost of energy decreases, the size of collector and storage required for an economically optimum system are reduced and the relative difference between the AUC's of the heat pumps and the optimized solar system increases.

In the final example, the only farameter that was varied was $C_{F}$, the cost of energy at the $t$ ime of installation. The incremental cost of collectors and storage were maintained at $65 \$ / \mathrm{m}^{2}\left(6 \$ / \mathrm{ft}^{2}\right)$ and 212 $\$ / \mathrm{m}^{3}\left(6 \$ / \mathrm{ft}^{3}\right)$, other parameters were maintained at their values shown in Table II; and only a New York rype climate was investigated. The results are shown in Figure 5. Note that the curves in this figure represent the AUC's for economically optimized systems: that is, the collector area and storage volume vary along each curve as they did in the two previous examples. The figure indicates the cost of energy at which the four solar energy systems become economically competitive with a current generation heat pump. This cost is approximately $15 \mathrm{c} / \mathrm{kWh}$ for the three SAHP systems and $36 \mathrm{c} / \mathrm{kWh}$ for the stand alone solar system. In addition, $F 1 g .5$ shows that for $C_{F}$ greater than $15 \mathrm{c} / \mathrm{kWh}$, where the SAHP systems are economically competitive with the heat pump, the series and dual source SAHP systems outrank the parallel SAHP system. The solar energy system ranks lowest up to energy costs of approximately $36 \mathrm{c} / \mathrm{kWh}$. In the vicinity of this value, the SAHP systems are economically the mnst atractive ones and thus are the stand alone solar energy system's major competition.

\section{CONCLUSION}

A method has been presented to identify solar energy and heat pump systems that are economically optimum in various climatological regions. The method is based upon the use of generic systems that can be modeled by linear first order differential equations 
for which closed form solutions yield results in approximate agreement with those obtained from TRNSYS simulations. This analytical model of the thermal performance of competing HVAC systems has been augmented to include marginal analysis capability. It can therefore optimize the component sizes of each generic system analytically. Of the resulting systems, the one with the lowest life cycle cost is judged best for the climatological region under study, and consequently, the one with the best market potential.

The optimization and comparison procedure is very dependent upon the values assumed for various cost and system parameters. An example was performed for New York, NY and Nashville, TN type climates in which best guesses for the economic paramters and best (i.e., slightly optimistic) estimates of what is possible for solar energy system parameters were assumed. For the two climate types the analysis indicated that, in general, solar energy systems a re not economically competitive with the simple air-to-air heat pump. The sensitivity of the analysis to changes in various economic parameters was also explored and indicated that major changes in the incremental cost of collectors and storage or the cost of energy would be required to make solar energy systems marketable on the basis of their economic performance.

\section{ACKNOWLEDGEMENT}

The authors wish to thank M.C. Lendemer for his dedicated efforts in programming and obtaining the numerical results for this paper.

This work has been supported in part by the Solar Heating and Cooling Research and Development Branch, Office of Conservation and Solar Application, U.S. Department of Energy, under Contract Number EG-77C-03-1467.

\section{REFERENCES}

1. Beckman, W.A., Duffie, J.A., and Klein, S.A., "Simulation of Solar Heat ine Systems". Applicatinns

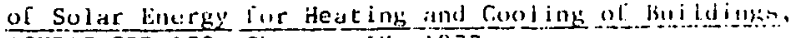
ASHRAE GRP 170 , Chapter IX, 1977.

2. Card, W.H., Ucar, M ., Drucker, E.F., and lakiriaft, J.E., "Generalized Weather Funct ions for Computer Analysis of Solar-Assisted HVAC Systems," ASMF pilper 76-WA/So $1-20$

3. SOLMET-TD 9724 (Hedstrom's Interial SLandard Yoirs Weather Tape), Available irom NOAA (Luvi rommental Data Service), Asheville, NC.

4. LIu, Benjamin Y.H., and Jordan, Kichard $C$, "Avallability of Solar Energy for Flat-Plate Solar Heat Collectors," Applications of Solar Enurgy lur Heating and Cooling of Buildings. ASHRAE (RRP 170 , Chapter V, 1977 .

5. Collares-Pereira, M., and Rabl. A., "The Average Distribution of Solar Radiation-Correlations Retween Diffuse and Hemispherical and Between Daily and Hourly Insolation Values," The Enrico Fermi Institute. University of Chicago. June, 1978.

6. Klein, S.A., et al., "IRNSYS - A Transient Similation Program,"' ASHRAF Trans., Vol. 82, Part 1, 1976.

7. Ruegg, R.T., Solar Heating and Coul ing in Buildings: Methods of Economic Evaluation, National Bureau of Standards, NBSLR 75-712, July, 1975.

8. Báumol, W.J. Economic Theory and Operations Analysts, 3rd. Ed., (Prentice-Hal1, Inc.,1972), Chap. 3. 
Table I. Validation of Analytical Model

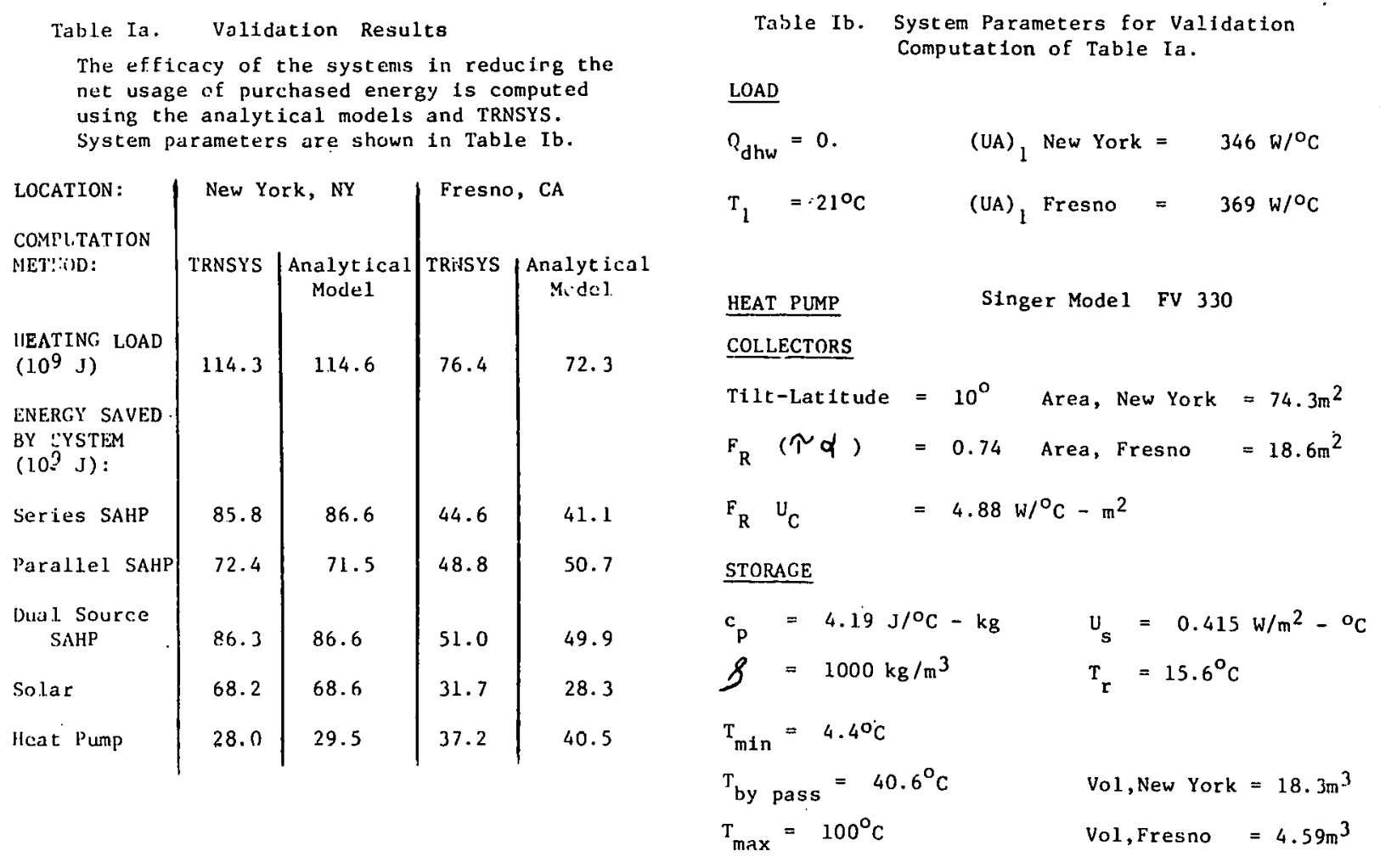

Table II. System Parameters for Tables III and IV

$\underline{\text { LOAD }}$

$$
\begin{array}{llll}
\left.{ }^{(\mathrm{UA})}\right)_{1} & =346 \mathrm{~W} /{ }^{\circ} \mathrm{C} & (656 & \text { BTU } \left./ \mathrm{hr}-{ }^{\circ} \mathrm{F}\right) \\
{ }_{\mathrm{dhw}} & =0 & \\
\mathrm{~T}_{1}^{\prime} & =21{ }^{\circ} \mathrm{C} & \left(70^{\circ} \mathrm{F}\right) \\
\mathrm{T}_{1} & =21^{\circ} \mathrm{C} & \left(70^{\circ} \mathrm{F}\right)
\end{array}
$$

IIEAT PUPQ Shown in Fig. 2. (Models 1 and 2)

COLLECTORS

$$
\begin{array}{ll}
\text { Tilt }- \text { Latitude }= & 10^{\circ} \\
F_{R}(\tau \alpha)= & 0.62 \\
F_{R} U_{L} & =\begin{array}{l}
5.68 \mathrm{~W} / \mathrm{m}^{2}-{ }^{\circ} \mathrm{C} \\
\end{array}
\end{array}
$$

STORAGE Rock

$$
\begin{aligned}
& =0.879 \mathrm{~J} /{ }^{\circ} \mathrm{C}-\mathrm{kg}\left(0.21 \mathrm{BTU} / 1 \mathrm{~b} \mathrm{~m} \mathrm{~m}^{\circ} \mathrm{F}\right) \\
& \rho=1530 \mathrm{~kg} / \mathrm{m}^{3}\left(95.71 \mathrm{~b} \mathrm{~m} / \mathrm{ft}^{3}\right) \\
& \mathrm{u}_{\mathrm{s}}=0.415 \mathrm{w} / \mathrm{m}^{2}-{ }^{\circ} \mathrm{C}\left(0.073 \mathrm{BTU} / \mathrm{hr}-{ }^{\mathrm{o}}{\mathrm{F}-\mathrm{ft}^{2}}^{2}\right. \\
& \mathrm{T}_{\mathrm{r}}=15.6^{\circ} \mathrm{C} \quad\left(60^{\circ} \mathrm{F}\right) \\
& \mathrm{T}_{\min }=-23^{\circ} \mathrm{C} \quad\left(-10^{\circ} \mathrm{F}\right) \\
& \mathrm{T}_{\text {by pass }}=40.6^{\circ} \mathrm{C} \quad\left(105^{\circ} \mathrm{F}\right) \\
& \mathrm{T}_{\text {max }}=100^{\circ} \mathrm{C} \quad\left(212^{\circ} \mathrm{F}\right) \\
& \text { FUEL } \operatorname{cosT} \quad 1.39 \times 10^{-8} \$ / \mathrm{J} \quad\left(0.1465 \times 10^{-4} \text { \$/BTU }\right) \\
& (=5 \mathrm{c} / \mathrm{kWh})
\end{aligned}
$$


Table III. Comparison of Systems with $65 \$ / \mathrm{m}^{2}\left(6 \$ / \mathrm{ft}^{2}\right)$ Collectors and $211 \$ / \mathrm{m}^{2}\left(6 \$ / \mathrm{ft}^{3}\right) \mathrm{storage}$. The cost and performance of air-to-air heat pumps are compared to those of optimized all-air SAHP and solar energy systems. See Table II for general system parameters.

IIIa. Comparison of Systems in New York, NY

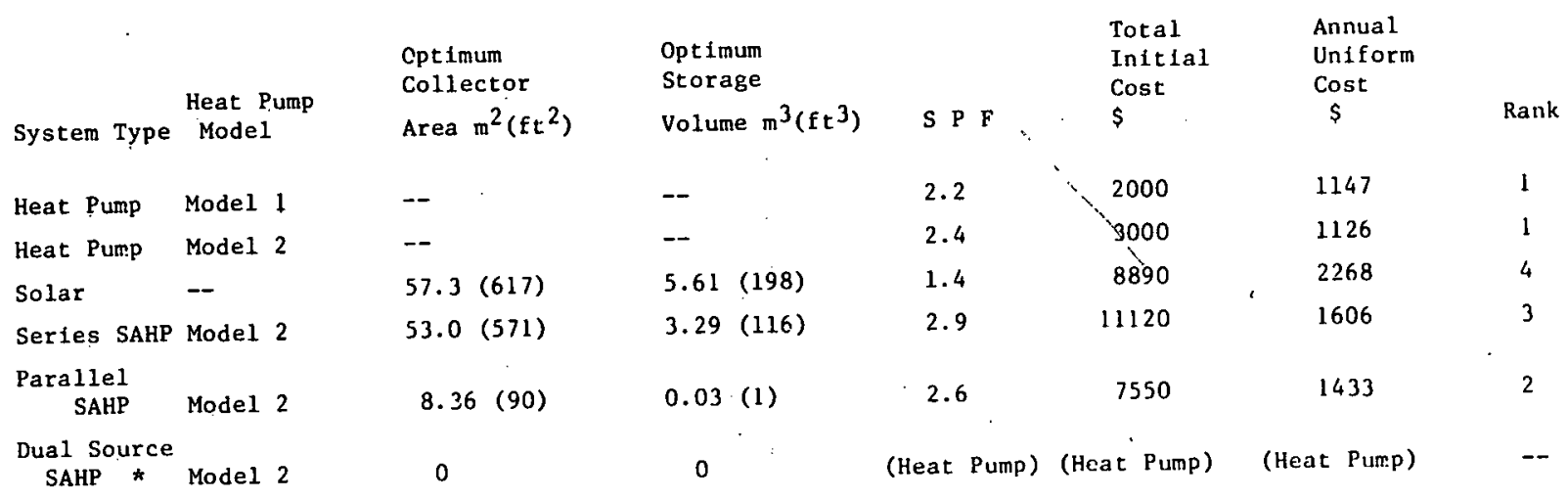

IIIb. Comparison of Systems in Nashville, TN

\begin{tabular}{|c|c|c|c|c|c|c|c|}
\hline System Type & $\begin{array}{l}\text { Heat Pump } \\
\text { Mode1 }\end{array}$ & $\begin{array}{l}\text { Optimum } \\
\text { Collector } \\
\text { Area } m^{2}\left(\mathrm{ft}^{2}\right)\end{array}$ & $\begin{array}{l}\text { Optimum } \\
\text { Storage } \\
\text { Volume } \mathrm{m}^{3}\left(\mathrm{ft}^{3}\right)\end{array}$ & $S P F$ & $\$$ & $\$$ & Rank \\
\hline Heat Pump & Mode1 1 & -- & -- & 2.4 & 2000 & 786 & 1 \\
\hline Heat Pump & Mode1 2 & -- & -- & 2.6 & 3000 & 828 & 1 \\
\hline Solar & -- & $44.6(430)$ & $4.67(165)$ & 1.5 & 7870 & 1628 & 4 \\
\hline Sertes SAHP & Model 2 & $37.2(400)$ & $2.27(80)$ & 3.1 & 9880 & 1267 & 3 \\
\hline Parallel SAHP & Model 2 & $11.6(125)$ & $0.71 \quad(25)$ & 2.9 & 7900 & 1140 & 2 \\
\hline $\begin{array}{l}\text { Dual Source } \\
\text { SAHP * }\end{array}$ & Model 2 & 0 & 0 & eat Pump) & (Heat Pump) & (Heat Pump) & - \\
\hline
\end{tabular}

\footnotetext{
* The optimum dual source SAHP system reduces to a stand alone heat pump and 18, therefore, not ranked separately.
} 
Table IV Comparison of Systems with $32 \$ / \mathrm{m}^{2}\left(3 \$ / \mathrm{ft}^{2}\right)$ Collectors and $141 \$ / \mathrm{m}^{2}\left(4 \$ / \mathrm{ft}^{3}\right)$ storage.

The cost and performance of air-to-air heat pumps are compared to those of optimized all-alr SAhip and solar energy systems. See Table II for general system parameters.

IV a. - Comparison of Systems in New York, NY

\begin{tabular}{|c|c|c|c|c|c|c|c|}
\hline System Type & $\begin{array}{l}\text { Heat Punp } \\
\text { Model }\end{array}$ & $\begin{array}{l}\text { Optimum } \\
\text { Collector } \\
\text { Area } \\
\mathrm{m}^{2}\left(\mathrm{ft}^{2}\right)\end{array}$ & $\begin{array}{l}\text { Optimum } \\
\text { Storage } \\
\text { Volume } \\
\mathrm{m}^{3}\left(\mathrm{ft}^{3}\right)\end{array}$ & $S P F$ & $\begin{array}{l}\text { Total } \\
\text { Initial } \\
\text { Cost } \\
\quad \$\end{array}$ & $\begin{array}{l}\text { Annua } 1 \\
\text { Unif orm } \\
\text { Cost } \\
\$\end{array}$ & Rank \\
\hline Heat Pump & Model 1 & -- & -- & 2.2 & 2000 & 1147 & 1 \\
\hline Keat Puinı & Mode1 2 & -- & - & 2.4 & 3000 & 1126 & 1 \\
\hline Solar & -- & $144.0(1550)$ & $16.6(585)$ & 1.9 & 10990 & 1.980 & 5 \\
\hline Series SAHP & Model 2 & $82.7(890)$ & $5.7(200)$ & 3.6 & 10470 & 1423 & 3 \\
\hline Parallel SAHP & Mode1 2 & $20.9(225)$ & $0(0)$ & 2.7 & 7680 & 1398 & 2 \\
\hline $\begin{array}{l}\text { Dual Source } \\
\text { SAHP } \star\end{array}$ & Mode 12 & $34.4(370)$ & $0(0)$ & 2.8 & 8614 & 1439 & 4 \\
\hline
\end{tabular}

IV b. Comparison of Systems in Nashville. TN

\begin{tabular}{|c|c|c|c|c|c|c|c|}
\hline & Heat Pump & $\begin{array}{l}\text { Optimum } \\
\text { Collector } \\
\text { A rea }\end{array}$ & $\begin{array}{l}\text { Optimuin } \\
\text { Storage } \\
\text { Volume }\end{array}$ & & $\begin{array}{l}\text { Total } \\
\text { Initial } \\
\text { Cost }\end{array}$ & $\begin{array}{l}\text { Annual } \\
\text { Uni form } \\
\text { Cost }\end{array}$ & \\
\hline System Type & Model & $m^{2}\left(f t^{2}\right)$ & $m^{3}\left(f^{3}\right)$ & $S P F$ & $\$$ & $\$$ & Rank \\
\hline Heat Pump & Model 1 & -- & -- & 2.4 & 2000 & 786 & 1 \\
\hline Heat Pump & Mode 12 & -- & -- & 2.6 & 3000 & 828 & 1 \\
\hline Solar & -- & $93.8(1010)$ & $11.3(400)$ & 2.1 & 8630 & 1415 & 5 \\
\hline Series SAHP & Model 2 & $62.7(675)$ & $4.2(150)$ & 4.0 & 9625. & 1333 & 4 \\
\hline Paralle1 SAHP & Model 2 & $24.2(260)$ & $1.3(45)$ & 3.2 & 7960 & 1096 & 2 \\
\hline SAHP * & Mode1 2 & $32.5(350)$ & $1.3(45)$ & 3.3 & 8730 & 1147 & 3 \\
\hline
\end{tabular}

* The optimum dual source SAHP system reduces to a stand alone heat fump and is, therefore, not ranked separately. 
Table V. Sensitivity of Results to Fuel Cost

Today's Cost of Fuel

Annual Fuel Escalation Rate

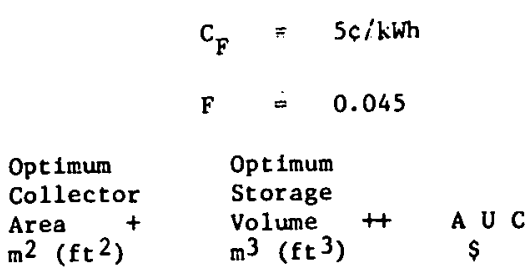

$$
\begin{aligned}
& C_{F}=45 / \mathrm{k} / \mathrm{h} \\
& F=0.035
\end{aligned}
$$

Opt1mum

Storage

volume

$\mathrm{m}^{3}$ ( $\mathrm{ft}^{3}$ )

Area +

$\mathrm{m}^{2}\left(\mathrm{ft} \mathrm{t}^{2}\right)$

A U C

$\$$

\begin{tabular}{|c|c|c|c|c|c|c|}
\hline Heat Pump, Model 1 & -- & -- & 1147 & -- & -- & 887 \\
\hline Heat Pump, Model 2 & -- & -- & 1126 & -- & -- & 892 \\
\hline Solar & $57.3(617)$ & $5.61(198)$ & 2268 & $43.7(470)$ & $3.83(135)$ & 1838 \\
\hline \multicolumn{7}{|c|}{ System: * (Nashville) } \\
\hline Heat Pump, Model 1 & -- & -- & 786 & -- & -- & 621 \\
\hline Heat Pump, Model 2 & - & -- & 828 & -- & -- & 672 \\
\hline Solar & $44.6(480)$ & $4.67(165)$ & 1628 & $32.5(350)$ & $2.41 \quad(85)$ & 1342 \\
\hline
\end{tabular}

\section{System: * ( New York)}

* General System Parameters are given in Table II.

+ Incremental Collector Cost $=65 \$ / \mathrm{m}^{2}\left(6 \$ / \mathrm{ft}^{2}\right)$

+ Incremental Storage Cost $=211 \$ / \mathrm{m}^{3}\left(6 \$ / \mathrm{ft}^{3}\right)$ 


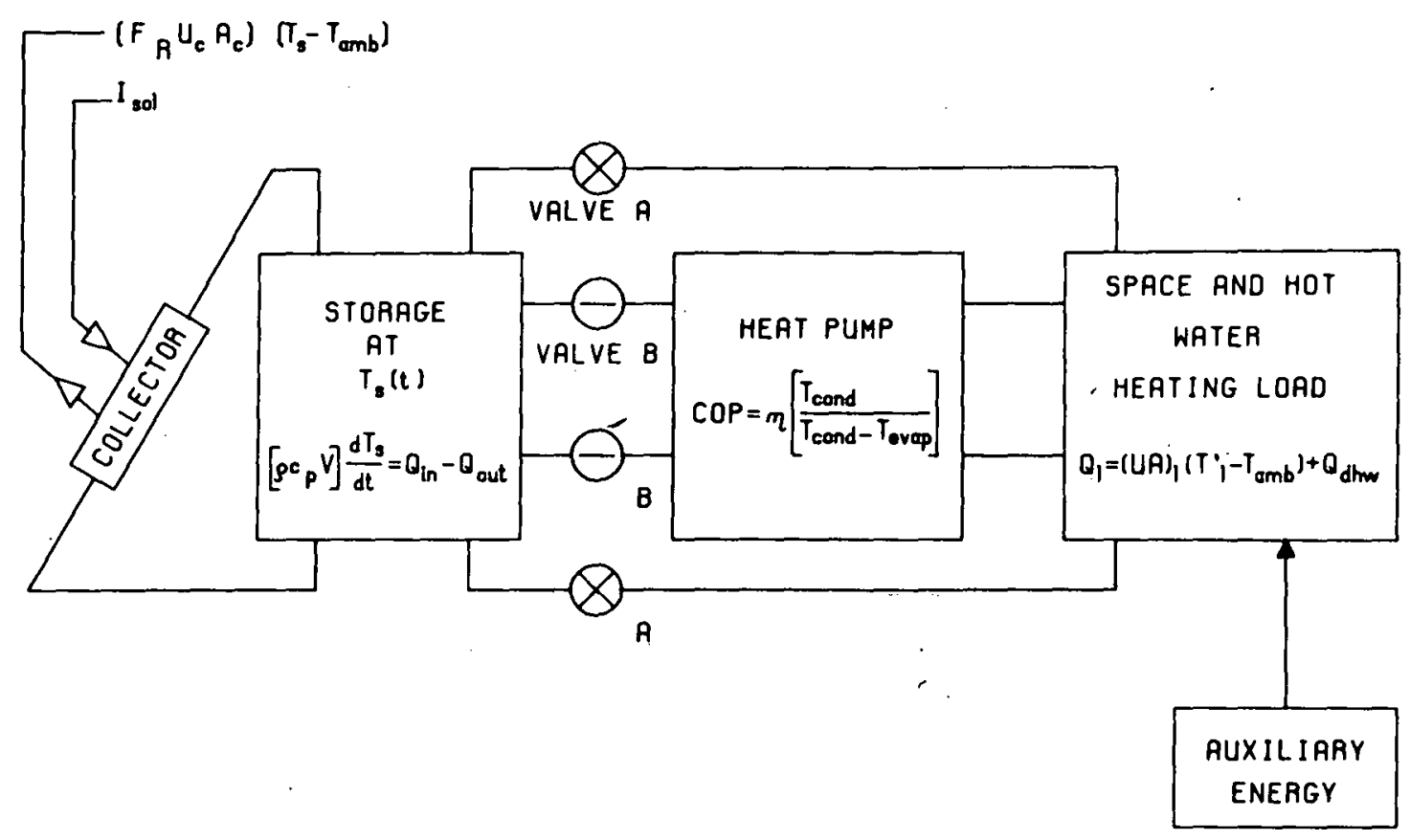

FIGURE 1. A SOLAR ASSISTED HEAT PUMP (SAHP) SYSTEM.

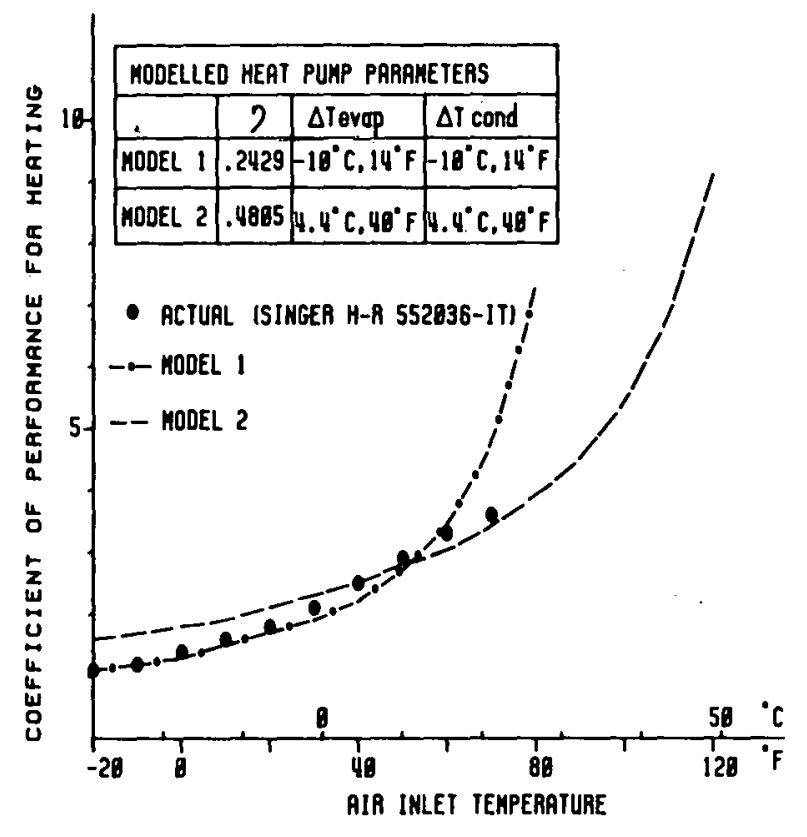

FI6. 2. COMPARISON OF COP VS. SOURCE TEMPERATURE FOR ACTUAL AND MODEL HEAT PUMPS

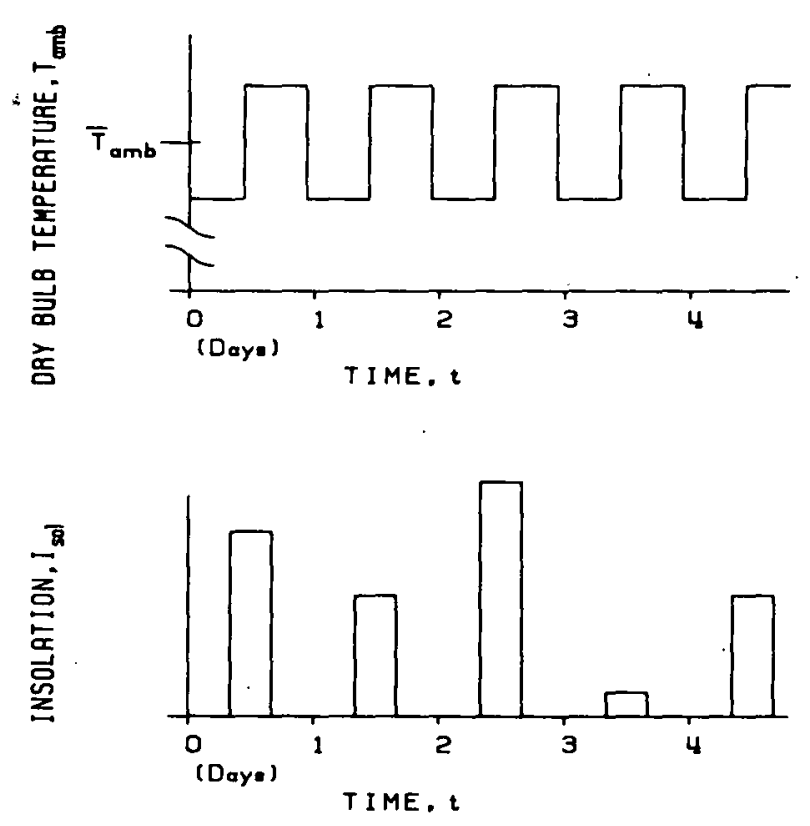

FIGURE 3. WEATHER VARIABLES RECTANGULAR WAVE FOAM REPAESENTATION 


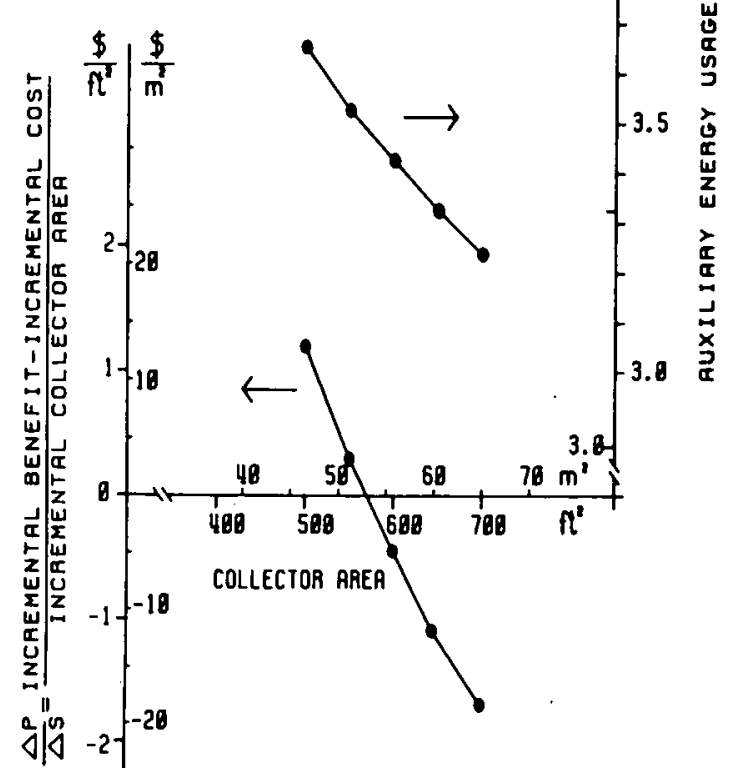

FIG. 4Q. COLLECTOR ARER OPTIMIZATION. PERFORMED HITH STORAGE VOLUME $=4.42 \mathrm{~m}^{\circ}\left(156 \mathrm{ft}^{2}\right)$

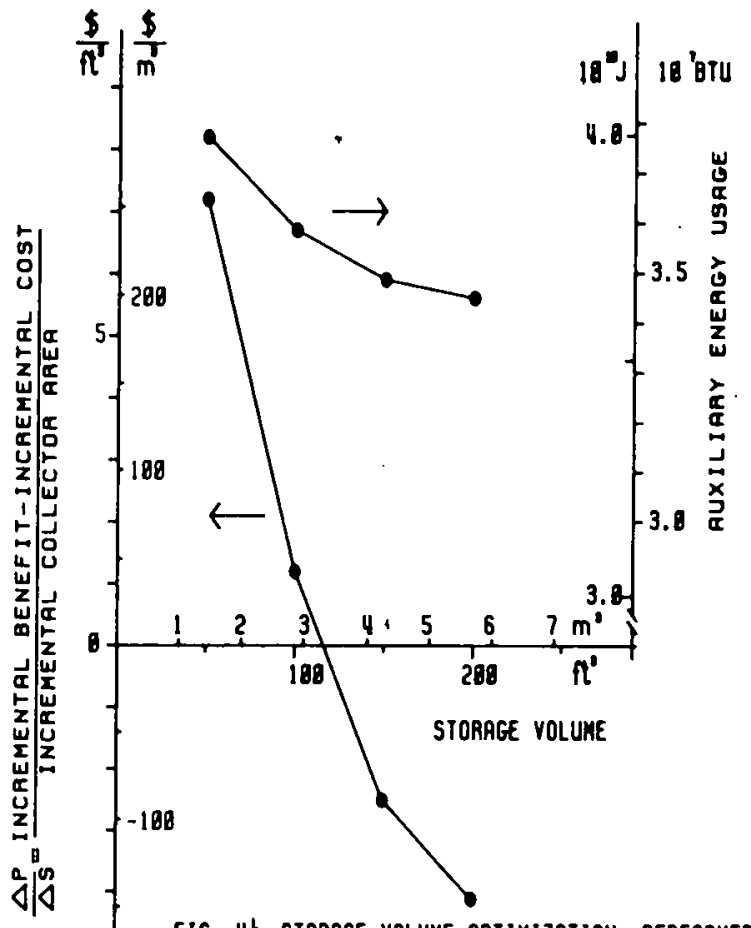

FIG. Ub. STORRGE VOLUME OPIIMIZATION. PERFORMED WITH COLLECTOR AREA $=53.85 \mathrm{~m}^{\prime}\left(571 \mathrm{f}^{2}\right)$

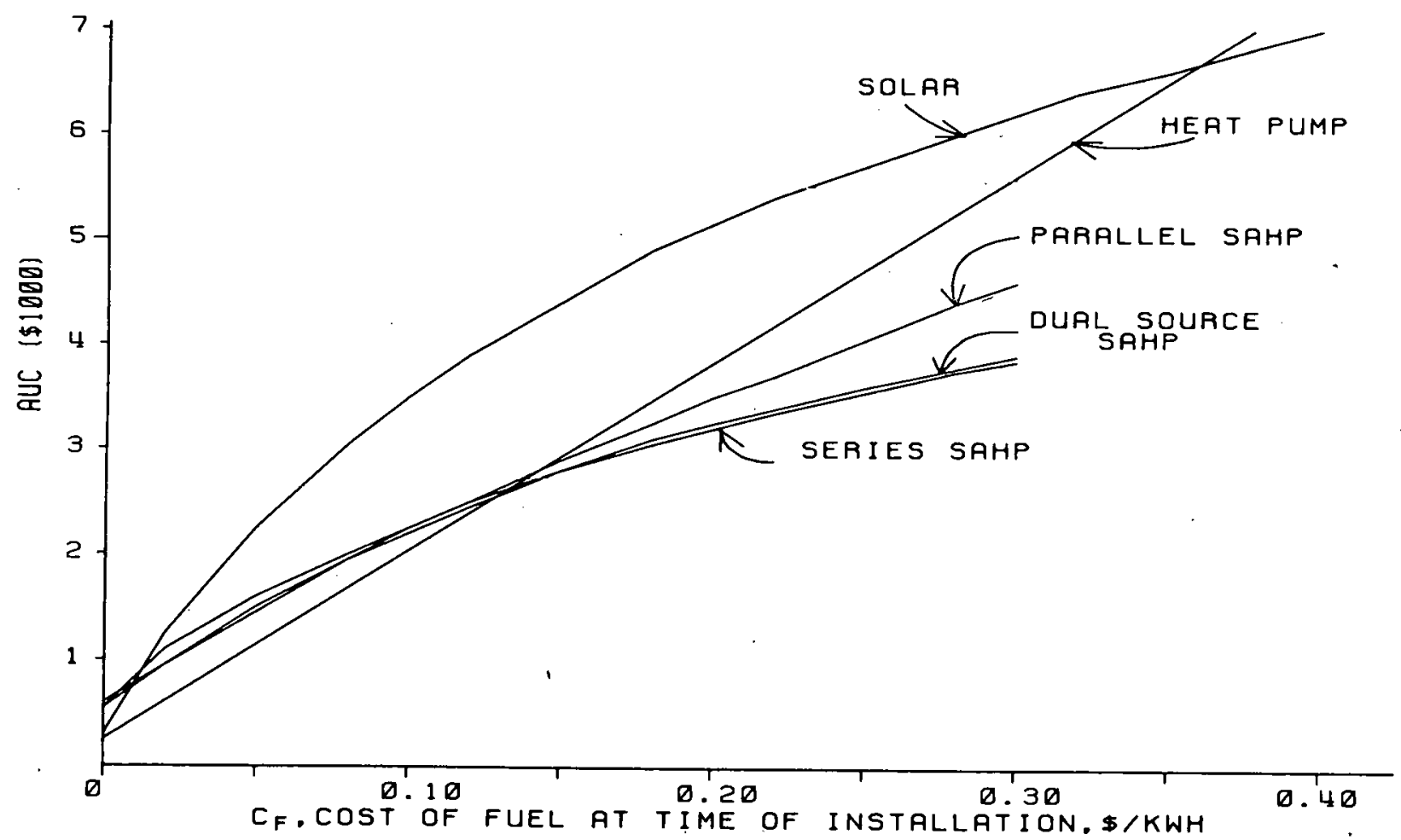

FIG. 5. SENSITIVITY OF OPTIMIZATION PROCEDURE TO COST OF FUEL 
CHAPTER T-3

CONCLUS IONS

\section{INTRODUCTION}

This chapter presents the conclusions of the Technical section. Also included are results ootained from the Analytical Model after publication of Paper No. 3 of the Technical section ("ASME Paper"). That paper compared the cost of owing and operating competing solar and conventional space heating systems in a single family house in the New York city climate. This cost comparison is extended here to four other U.S. cities: Charleston, SC, Nashville, TN, Madison, WI, and Santa Maria, CA.

In addition to performing the thermal and economic analysis for these four ocher climate regions, the method of presenting the performance and operating costs of the stand-alone heat pump has been modified here and the cost and performance of gas (or oil) fired systems that have seasonal efficiencies of $50 \%$ have been added.

\section{Heat Pump cost and Performance}

Figure 2 of the ASME Paper shows the COP of a 3 ton singer heat pump and of two "model" heat piumps as a function of air inlet temperature. Model 2 of this figure has $a$ better cop for the air inlet temperature range encDuntered in SAHD system speration and was, therefore, used in the Analytical Model program to analyze SAHP systems. It was also used in the ASME Paper to predict the performance of the stand-alone heat pimp system shown in Figure 5 of that paper. Note that the Analytical Model does not account for defrost losses, nor does it model the finite capacity of an actual heat pump. Rather, the heat pump is assumed to jperate as a fraction of a carnot heat pump with infinite capacity and thus does not account for the real world need for supplementary electric resistance heat. Although these drawbacks are not to significant in analyzing series SAHP systems, they are suostantial in the prediction of stand-aloine heat pimp performance.

To overcome the principal effects of these drawbacks, the analytical model heat pump curve of Figure 5 of the ASME Paper has been replaced here with a series of curves that show the performance of normal, stand-alone heat pumps whose seasonal performance factors 
(SPF) range from 1.75 to 2.25 . However, the $\$ 3,000$ installation price was returned in the calculations even though this value is approximately $\$ 1,000$ higher than estimates obtained from contractors for the installation of a 3 ton split system heat pump in a single family house. As explained in the ASME paper, this $\$ 1,000$ "overcharge" slightly favors solar energy systems and causes an error in the annual uniform cost (AUC) of only $\$ 78$, a negligible quantity when compared to the total AUC.

This change in the characteristics of the stand-alone heat pump in the comparison analysis resulted in a discernable change in the cost of fuel at which the SAHP and heat pump systems have equal life cycle costs. For example, in Figure 5 of paper 3, this cost in New York City is approximately 13\%/KWh, while T3.1 of this chapter it is approximately $7 \mathrm{k} / \mathrm{kwh}$. In either case, the SAHP system LCC is not significantly lower than the heat pump LCC unless the fuel cost (in 1979 asllars) at the time the system is installed is considerably above its present average national value.

Fuel

The results presented here also show the AUC of a $100 \%$ efficient electric resistance heating system and of a $50 \%$ seasonally efficient gas (or oil) heating system as a function of $C_{F}$, the cost of fuel when the system is installed. We have assumed that all fuels escalate at the same rate above general inflation, 4.5 percent per year.

\section{Results}

Figures T3.1 through T3.5 show the results of the thermal and economic analysis for five U.S. cities. As discussed in the AsME Paper, each active solar energy system, in each city, at each value of $C_{F}$, is sized with the collector area and storaje volume which yield the economically optimam system. The thermal and economic parameters assumed in the analysis are given in Table II of the ASME Paper. The UA values indicated in the figures for each city are typical of single family houses in that part of the country. Furthermore, as in the ASME Paper, the following assumptions were made:

- fuliy installed collector cost of $\$ 6 / \mathrm{ft}^{2}$

- storage cost of $\$ 5.93 / \mathrm{ft}^{3}$ 
- system lifetime of 15 years

- worth of money above inflation of 2 percent per year

- fuel escalation rate above inflation of 4.5 percent per year

Lower fuel escalation rates, as commonly predicted for electricity, would favor conventional over solar energy systems. Such lowex rates ivere, in fact, used in the LCC analysis of Chapter M-5 of this report. Similarly, higher values for the worth of miney, corresponding to past consumer buying preferences, would also favor conventional over solar energy systems.

As a test of the sensitivity. of the results to changes in economic parameters, the AUC's of series SAHP and heat p:amp systems inere calculated for two values of annuál fuel escalation rates: 0.045 and 0.025 . The other parameters were not changed. Figure T3.6 shows the results of the calculations. As would be expected, 'at the lower escalation rate, the SAH? and heat pimp systems have equal LCC's at a higher "crossover" value of the cost of electricity at the time the systems are installed. The change in escalation rate from 0.045 to 0.025 raises this zrossover value from. $3 \xi / \mathrm{kw}$ l to $10 \xi / \mathrm{kwh}$, where a SPF of 2 is assumed for the heat pump.

In general, the analyses of Figures T3.1 - T3.5 were performed to assess the marketability of SAit? systems to oe developed in the future. Accordingly, it was assumed that the moderately efficient collector used in the analysis could be acquired, fully installed, for an appreciably lower price than is currently possible. In addition, high efficiency heat pumps were used in the SAHP systems analyzed. Nevertheless, these improved active solar energy systems do not become clearly competitive with existing haat pump systems on a LCC basis until the cost of electricity bacomes mach higher than its present average national value.

For a SAHP system, which has a high.up front cost, to be more marketable than a heat pump system which has a low initial cost, the SAHP LCC mast be significantly lower than that of the heat pump. The resilts of the analyses showed that this oocurs if the cost of electricity (in 1979 constant dollars) at the time the system is installed is appreciably higher than $7 \mathrm{c} / \mathrm{kwh}$. This may 
take many years. For example, an increase to only $10 \mathrm{c} / \mathrm{kwh}$ (in 1979 constant dollars) from the 7\%/kwh electricity rates currently prevalent in some regions would take 8 years at an annual fuel escalation rate of 0.045 (above inflation); and 14 years at a 0.025 rate. The lower escalation rate of 0.025 will produce equal LCC for SAHP and heat pump systems at approximately $10 \mathrm{c} / \mathrm{kwh}$. Therefore, not only is equality of LCC between SAHP and heat pump systems 14 years into the future at the assumed rate of 0.025 , but also it would be many years after that before SAHP would achieve a significant LCC advantage.

\section{Conclusions}

1. It is clear that if gas is available at an equivalent cost of less than $1 \% / k w h$, then even systems with a $50 \%$ utilization efficiency are far mare cost efféctive than any of the competing systems. In effect, Government gas price regulations provide a strong disincentive for the marketability of any of the energy conserving systems.

2. At current electricity prices, the air-to-air heat pump, when compared to any of the solar systems analyzed, is the most cost effective space heating system in all the climate regions considered. This is true even where cooling is not required and the heat pump cost is antirely "absorbed" by the space heating system.

3. At electricity costs of 2 or more times their present national average, the series SAHP system has the lowest AuC. Since its up-front costs are much higher than those of a stand-alone heat pump, consumers will have to becone more sensitive to life cycle costs in order for SAHP systems to penetrate the market deeply.

4. Finally, the results show that stand-alone solar energy systems will not be cost competitive until electricity costs rise enormously. When and if this should nappen, it is more likely that significant life style changes will occur than that a typical U.S. family will be able to spend the equivalent of $\$ 5,000$ of today's dollars annually for space heating.

5. SAHP systems become competitive with air-to-air heat pumps 
at electricity costs in the neighborhood of $7 \mathrm{k} / \mathrm{kwh}$ (1979 constant dollars) only if all the following are true:

a) the hypothetical collector doas indeed become available at $\$ 6 / \mathrm{ft}^{2}$, fully installed;

b) the consumer bases his buying decision totally on LCC rather than on up-front costs; and

c) more efficient heat pimpis do not become available, even at $\$ 3,000$ (1979 constant dollars).

\section{Suggested Topics for Future Efforts}

The work doile in the course of the present program and the conclusions drawn from that work suggest three topics that warrant further study.

Topic 1. Collector Parameter stúdy

Results of the present program showed that active solar energy systems becone competitive with air-to-air heat pumps (on a life cyale cost basis) when electricity costs zre significantly higher than their present U.S. average value in 1979 constant dollars. Thes@ results were based on the availability of a moderately efticient collector that could se acquired for $\$ 6$ per square fost, fully installed.

A suggested project for further study is to evaluate the consequences of the availability of collectors with both improved as well as inferior performance at boch lower and higher costs. This study would be done most efficiently with the Analytical Model Program. For each collector type and for each system of interest the program could siza collector area zad storage volume so that the resulting system will have a minimim life cycle cost. These optimized systems should be designed for a numier of values of the present cost of fuel so that the stuly yields a sense of how soon the marketability of the associated system is feasible.

The overall goal of this suggested project would be to provide information that will help identify and select collector derelopment projects that can significantly accelerate the market penetration of solar energy systems. 
Topic 2. Dua I Source SAHP Control Algorithm

The present program showed that when the cost of energy was hig'h enough to justify aciive solar energy systems, the series SAHP system's life cycle cost was lower than that of the dual source SAitP system. Furthermore, the difference was larger than the $\$ 500$ assumed for the cost of the adiltional evaporator of the dual source system. Since the dual source system can operate as a series system, the deficiency in its performance mist be die to the simplistic algorithm used to control the real-time selection of which of its two evaporators is to be operative.

A suggested project for further study is to use a slightly revised form of the Analytical Model program to aid in assessing and formulating superior algorithms for selecting which of the two evaporators will be used at any time.

This decision will be based on the goal of providing the most efficient operation over the total heating season. For maximum effectiveness, the algorithms should be designed to use forecast values of insolation and ambient temperature as bases for their decisions. The best-algorithms thus devised should be used to control evaporator selection; the resulting system performanae will then give a good indication of the inherent capabilities of dual source SAHP systems ampared to the other SAHP configurations.

The overall goal of this suggested project is to provide information necessary for planners and policy makers who wish to encourage the development of promising S.AHP systems.

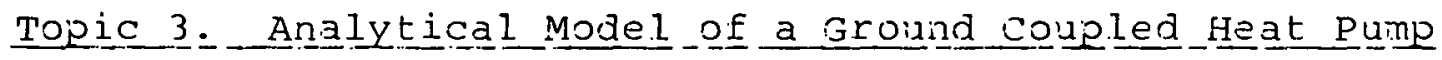

The present program showed the series SAHP system to je more pronising than the other active solar energy systems. It is natural to wonder if its expensive front-end energy gathering system could not be replaced by one substantially cheaper. Since the heat pump does not require high grade energy as its source, it is possible that an efficient system could de designed in which the evaporator is coupled to the ground.

Simulations of such a ground-coupled heat pidip involve lengthy and costly compiter runs. Consequently, they cannot be used easily to gain sufficient insight into system operation to determine the operation strategy that optimizes the seasonal energy extraction 
of a grodid-coupled heat piump.

A suggested project is to devise an Analytical Model of a groundcoupled heat pump that represents the thermal parameters coupled capacitors and that has an appropriate nonlinear element to represent the heat pump. Heat flows of interest will be given by the transient solution of the electrical analogue. This solution can be ootained from the closed form solution of two coupled linear differential equations.

The goal of this suggested project is to understand:

- the capability of the ground to provide short term and long term storage, and

- the interaction between the near and far field of the ground.

The study will also make feasible the development of control strategies that optimize system performance. 


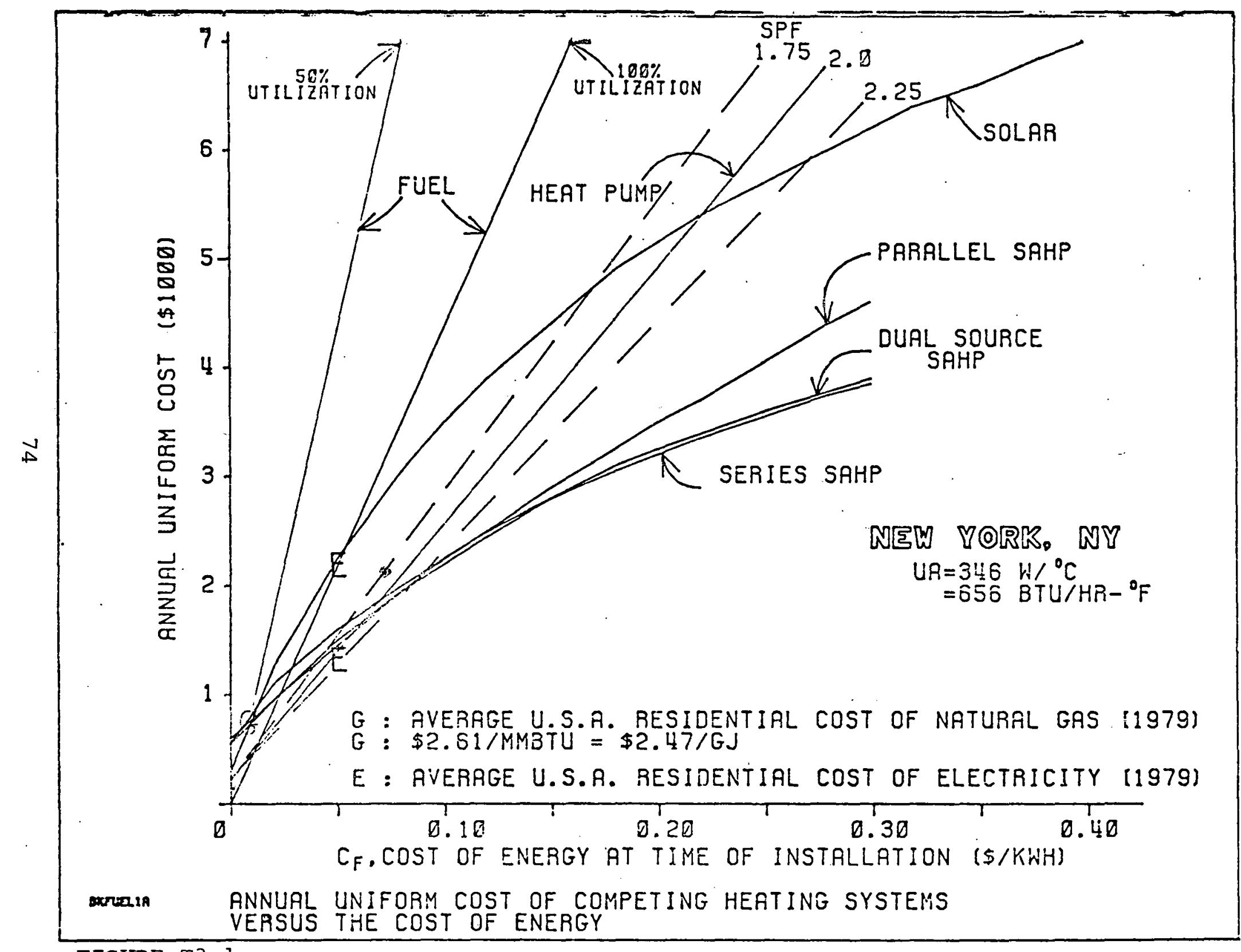

FIGURE T3.I 


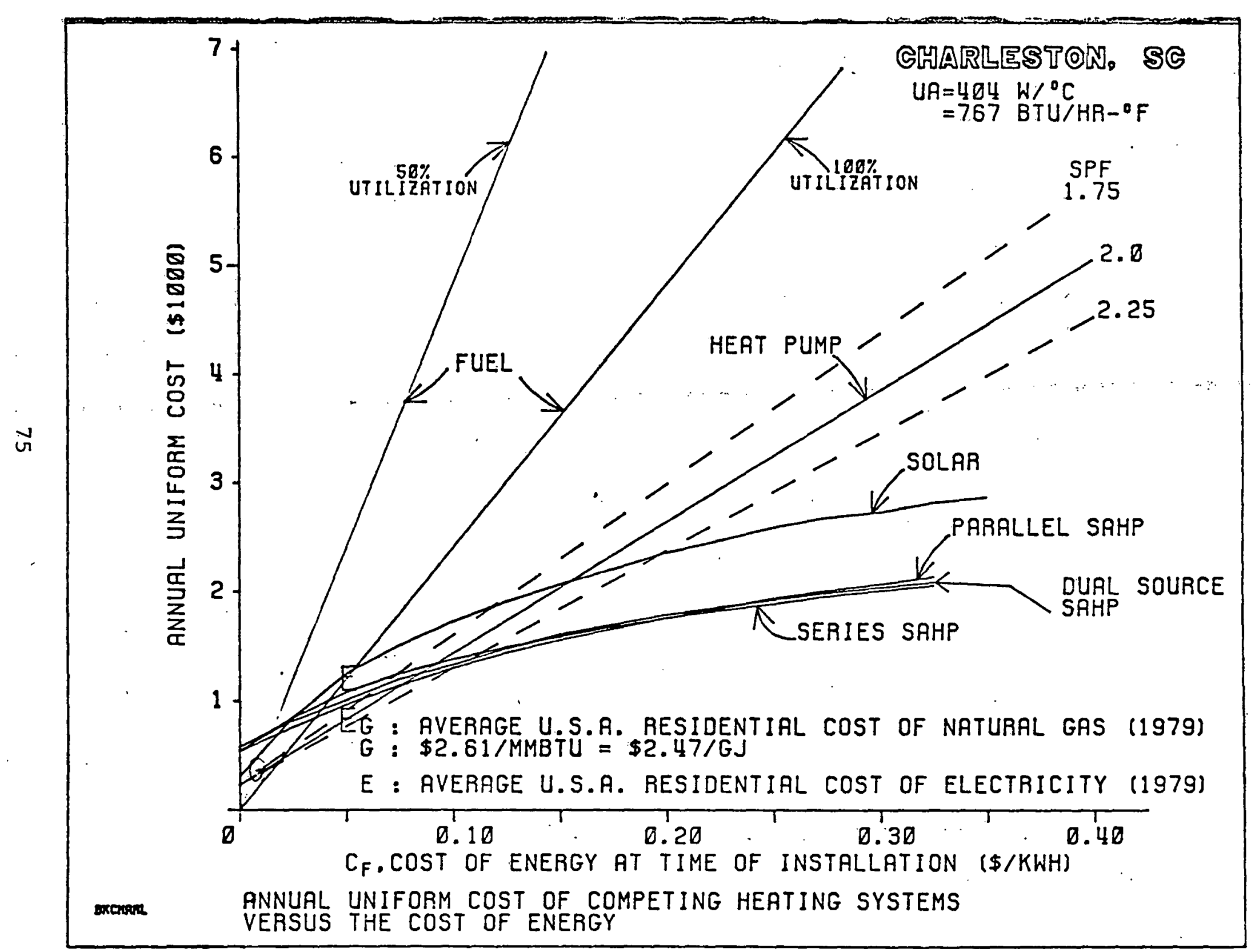

FIGURE T3.2 


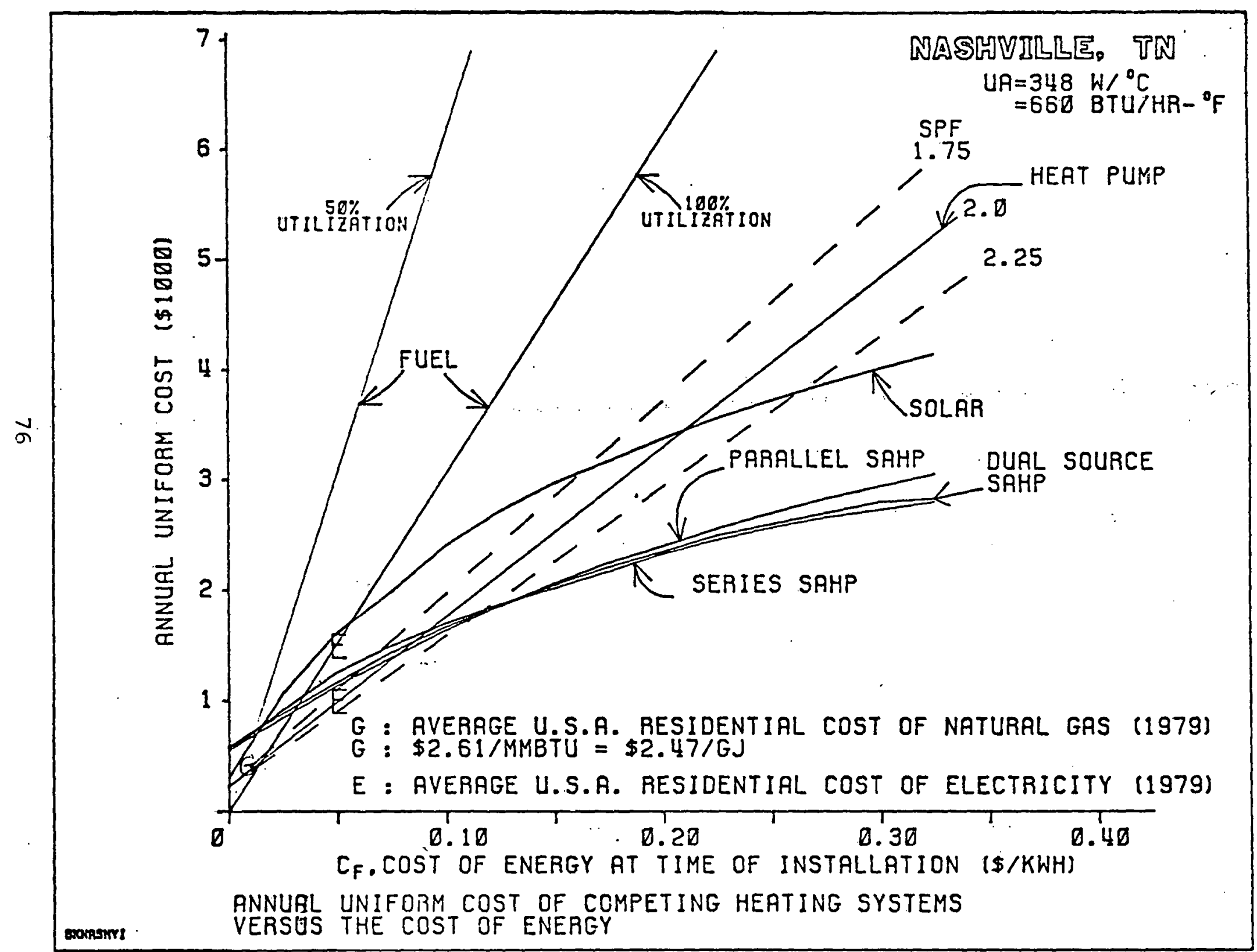

FIGURE T3.3 


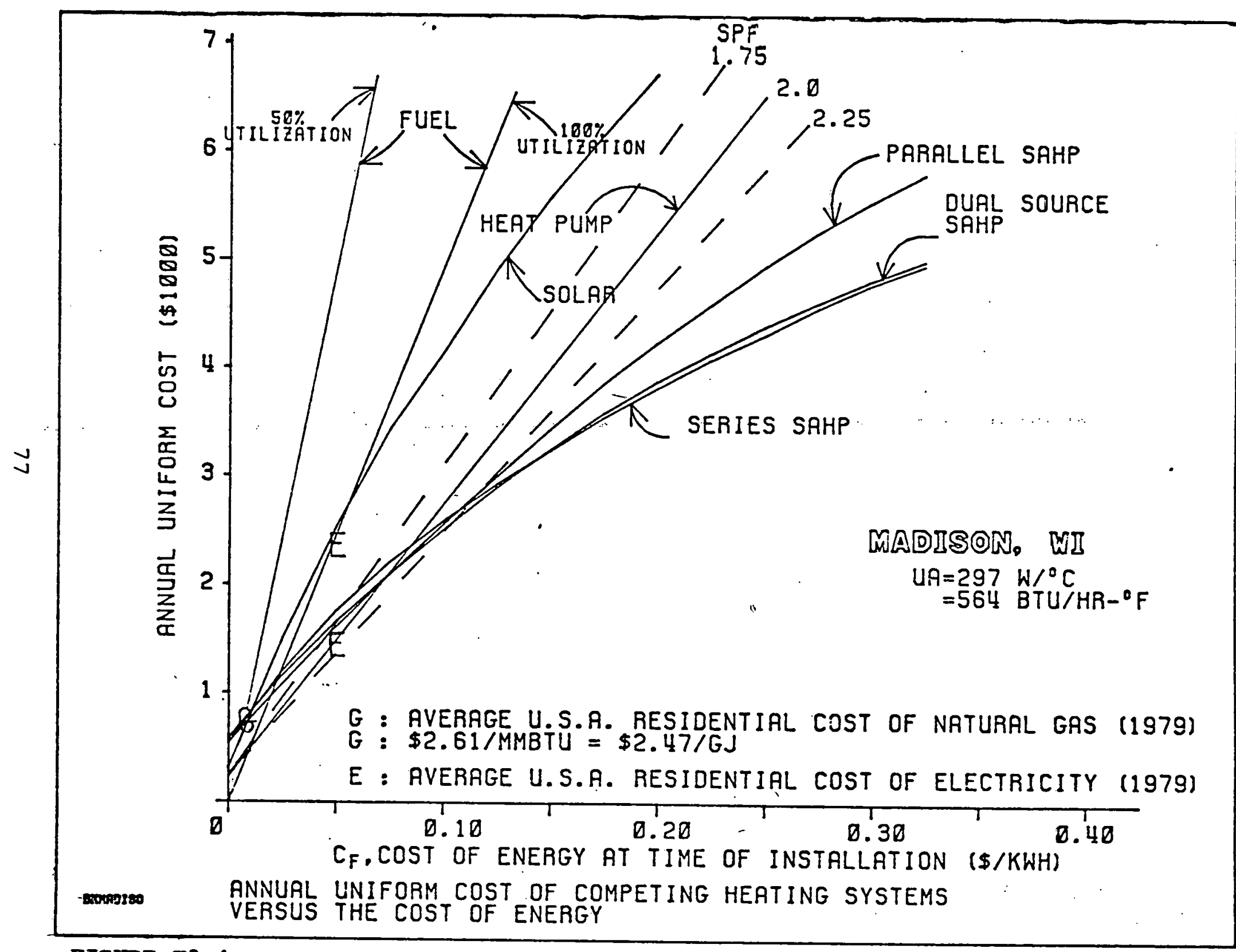

FIGURE T3.4 


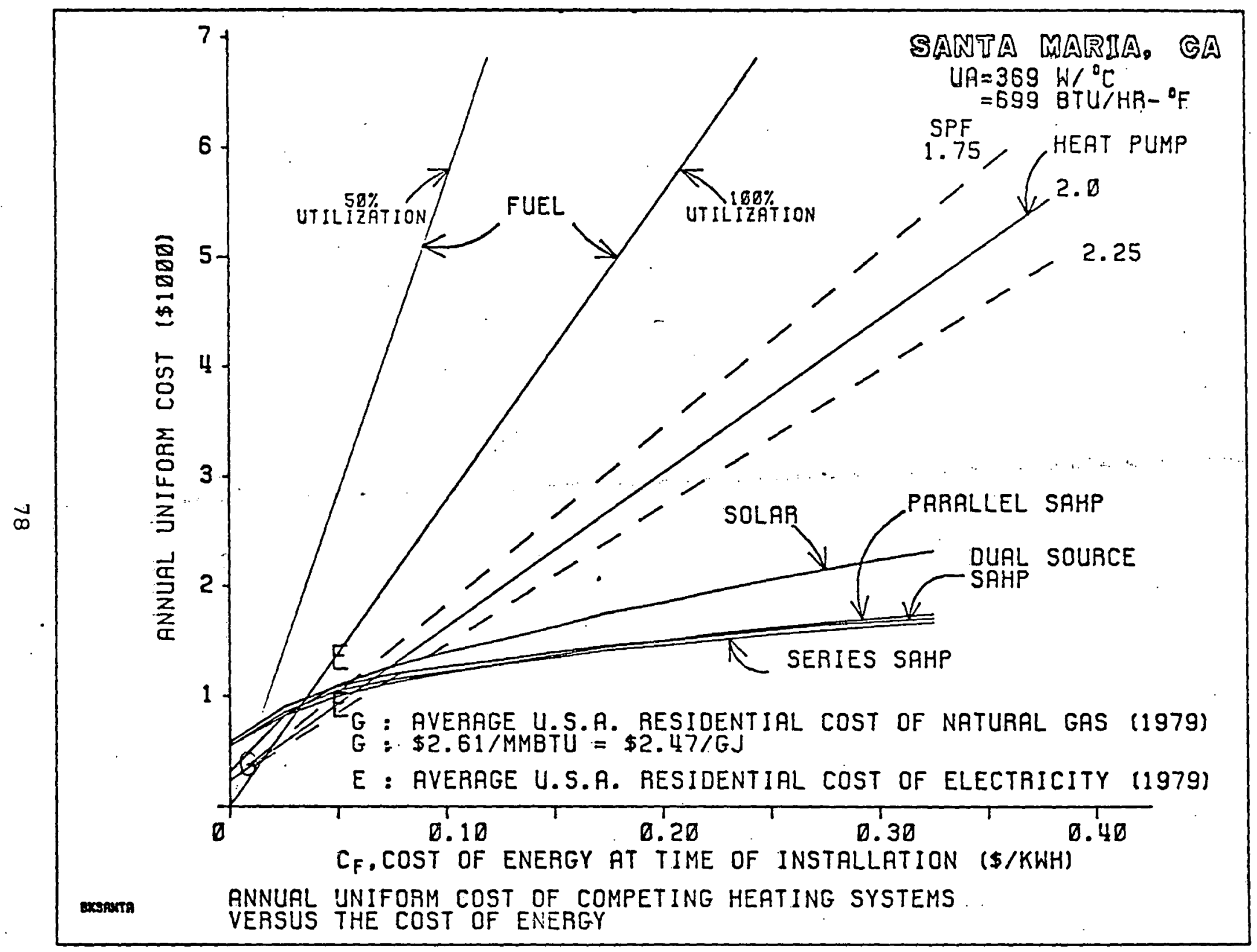

FIGURE T3.5 


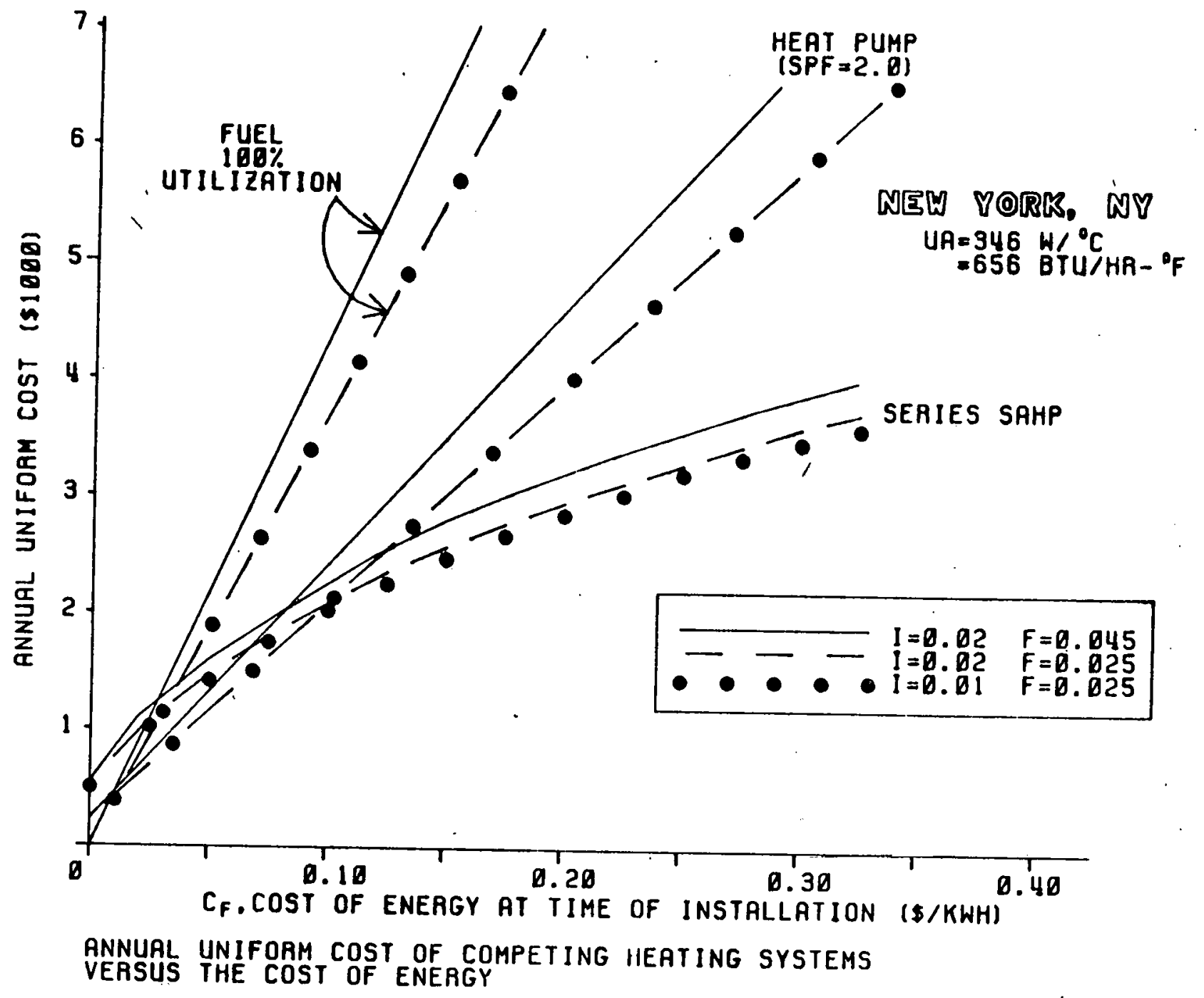

Figure T3.6 Sensitivity of AUC to

$-F$, Annual Fuel Escalation Rate

-I, Annual Worth of Money

Three sets of curves depict the Annual Uniform cost of owning and operating three types of heating systems:

- 100\% efficient, conventionally fueled systems

- heat pump systems with $\mathrm{SPF}=2$

- series SAHP systems

versus $C_{F}$, the cost of fuel at the time the systems are installed. All systems are used to heat a single family house in a New York city type climate. For all curves, the system lifetime is 15 years and the values of $F$ and $I$ are above inflation. 


\section{CHAPTER $\quad M-1$ \\ MARKETING SECTION INTRODUCTION}

The work of the Marketing study was carried out in parallel with the work of the Technical study, under common supervision and with appropriate coordination at key points. This section of the report describes the work and results of the Marketing study.

This study was based on the premise that a SAHP system would be marketable in a region only if its total life cycle cost (LCC) was competitive with the LCC's of the primary conventional HVAC systems of that region. Accordingly, the major work of this study deals with the collection and collation of system and energy cost and distribution data. However, in order to obtain realistic SAHP data for the LCC comparisons, it was necessary also to expend some work to design several SAHP systems in sufficient detail that their component costs could be ootained and that extensive computer simulations of them could be performed so that their energy costs could be ascertained. One important result of the preliminary life cycle cost analyses was that factors other than life cycle cost influence the marketability of systems which have low life cycle costs but high initial costs, such as the SAHP and heat pump. Consequently, a portion of this Marketing section describes efforts to determine what some of these factors are.

The Marketing section contains the following chapters:

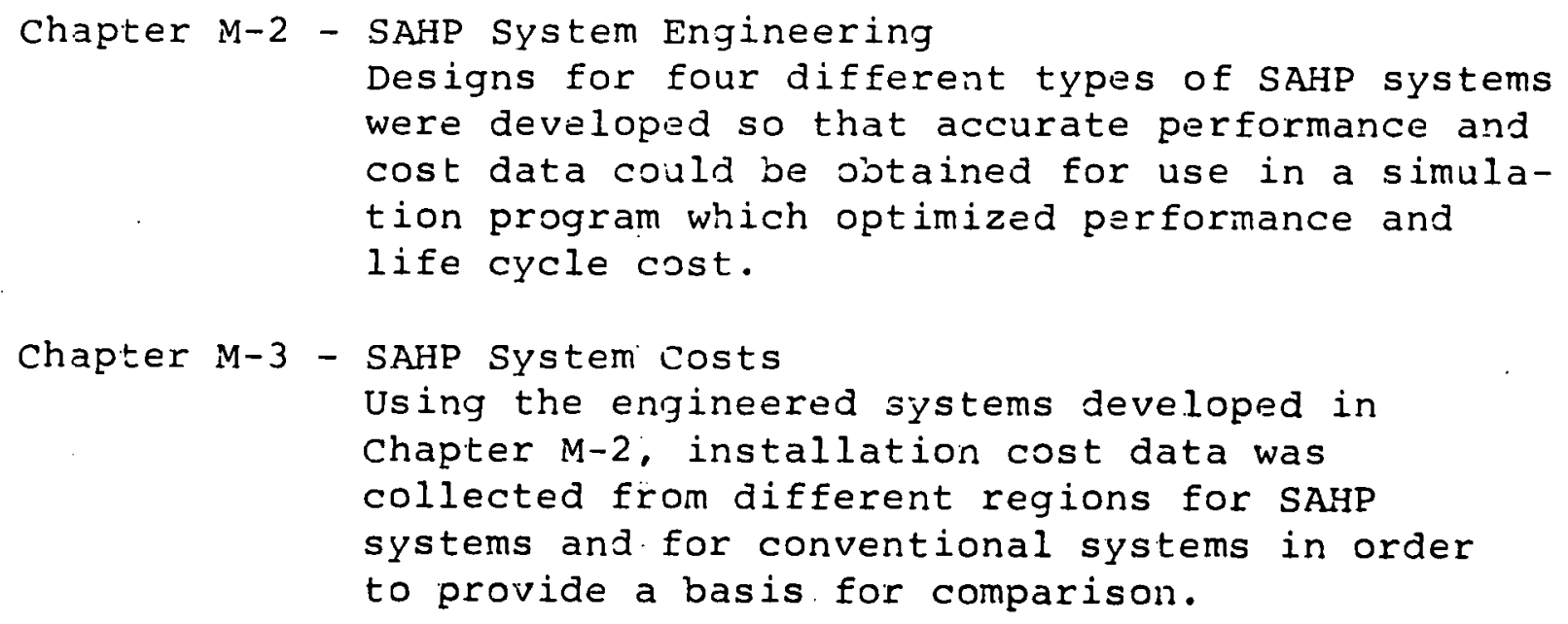




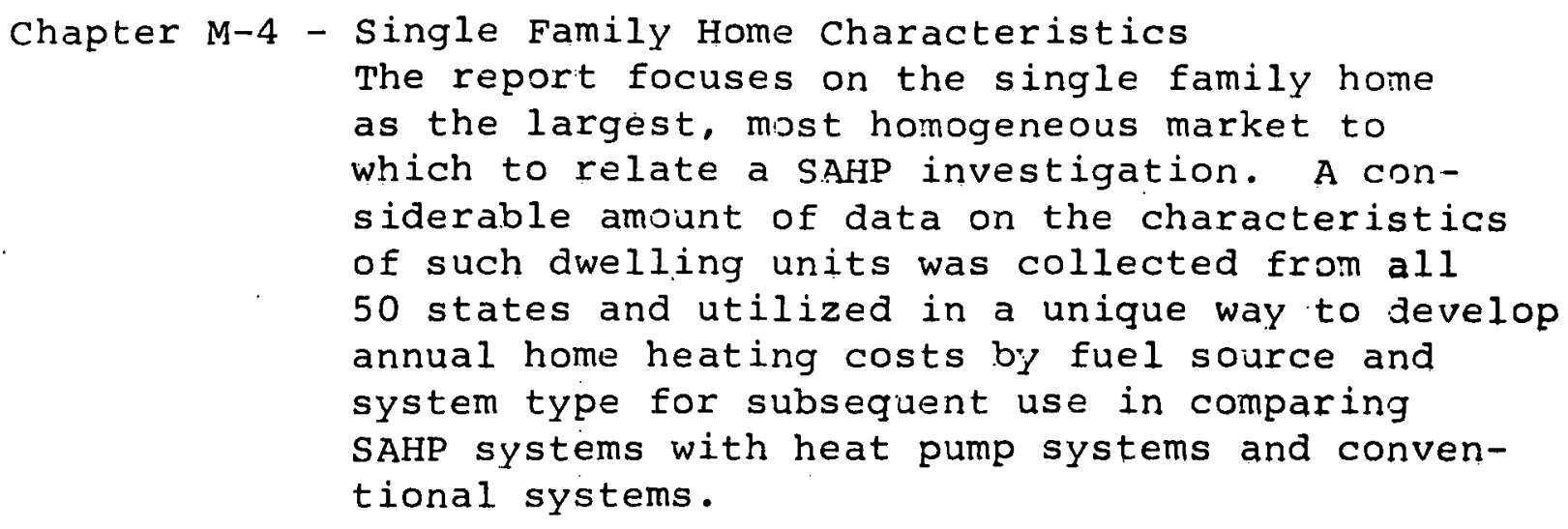

Chapter M-5 - Life Cycle costs

Life.cycle costs were prepared for conventional systems in typical cities.

Chapter M-6 - Correlation Analysis Correlation of heat pump sales with conventional systems on the basis of each of several factors failed to produce significant correlation. However, when several key factors were combined, a high correlation resulted. 
CHAPTER $M-2$

ENG INEERING OF SELECTED SAHP SYSTEMS

Introduction

One of the basic tasks of the SAHP marketability study was to identify, if possible, the SAHP system configurations that would have life cycle costs competitive with those of conventional heating systems. Since there are a myriad of climatic regions in the U.S." this identification was to take place for the major climatic and/or HVAC marketing regions. In this study, this identification was broken into two phases:

1) the development and use of an analytical model to quickly delineate the most probable combinations of climatic regions and system configurations, and

2) the design and simulation of detailed engineered SAHP systems to assess the actual performance and cost characteristics of the systems designated by the Analytical Model.

The development and use of the Analytical Model is discussed in the previous section. The design of four engineered systems began in parallel with the development of the Analytical Model and is discussed in this chapter. Sufficient flexibility was designed into each of the four systems so that modifications suggested by the Analytical Model, or by insights acquired during the simulation studies of the systems, could be made readily.

\section{System Selection Criteria}

Many existing and proposed SAHP systems were studied to determine the features that are desirable in SAHP systems. Using engineering judgment and compromises to eliminate cost ineffective characteristics, these features were combined into four basic designs. These SAHP system designs are shown in Figures M2.1 - M2.4.

Several assumptions were made prior to the design of the four SAHP systems. These assumptions concern the installed costs and efficiencies of the systems since the primary criterion for the marketability of a SAHP system is that its total life cycle cost 
must be equal to or lower than that of existing HVAC systems. The first two major assumptions are that (1) only low cost collectors can be used economically and (2) the total area of the collectors must be restricted due to both economics and existing building characteristics (i.e., size).

These assumptions led to the choice of a series rather than a parallel SAHP configuration for the four designs. In the parallel system both the air-to-air heat pump and the collectors must "stand alone"; that is, be able to operate independently for direct space heating. However, during periods of low outside temperature, when the majority of heating energy is consumed, both the heat pump and the high temperature collector required by the parallel system are relatively inefficient. The low cost, low temperature collector used:in the series system, however, operates at relatively high efficiencies at these temperatures and therefore collects more solar energy per square foot than the high temperature collector of the parallel system. This energy is used (in the series system) to raise the fluid.temperature entering the evaporator of the heat pump and thus to raise the heat pump efficiency.

It is noteworthy that the choice of a series SAHP system was corroborated by later work done with the Analytical Model. As discussed in detail in Paper 3 and chapter $\mathrm{T}-3$ of the Technical section of this report, it was found that of the four active solar energy systems, the series SAHP is the most cost effective one for the space heating of a single family residence in the climatic regions of New York, NY, Charleston, SC, Nashville, TN, Madison, WI, and santa Maria, CA.

The assumption of the use of only restricted area, low cost collectors led also to the omission of the capability for direct solar heating in the four system designs. In the spring and Autumn, when sufficient insolation and low enough loads exist to allow the collector temperature to rise above the minimum required for direct heating, the total amount of energy saved. by direct heating will be too low to justify economically the additional equipment and installation costs required to provide direct solar heating.

A method of accessing outside air has been incorporated into the four selected SAHP system designs. When the heat pump discharge 
air temperature drops below the outside temperature, outside air is brought into the system. This air may be routed through the collector, through storage, directly to the heat pump, or any combination of the three so that all available sources of energy are utilized. Thus, a simultaneous dual source capability is provided.

Because it was assumed that existing off-the-shelf heat pumps would be used for the selected SAHP designs, design considerations were taken to insure proper and realistic operation of the systems, including the avoidance of high and low heat pump condenser and evaporator temperatures. These adverse temperature conditions are prevented in the four selected designs by a recirculating loop that mixes the heat pump discharge with the supply air to approach an optimum entering temperature for maximum COP.

Design considerations such as zone heating were not considered in the systems because existing heat pumps cannot tolerate drastic evaporator or condenser load variations. Sophisticated and expensive equipment and controls would be required to enable an existing heat pump to adapt to large load variations. A variable capacity compressor would solve this problem; however, detailed engineering would be required for each installation. Marketing criteria preclude SAHP systems with zoning because of their technical and economic characteristics.

All four systems are based on modern, off-the-shelf equipment and could be readily constructed at the present time.

Description of selected systems

All four selected SAHP systems have the same basic control algorithms and ability to take advantage of the maximum energy available to the system to provide the maximum SPF. These algorithms, described below, are summarized in the notes that follow the - Figures M2.1 - M2.4.

The systems and controls were reviewed by engineers of The Singer Company's Climate control Division, ITC/Solar and BNL. In addition, all systems were simulated successfully on TRNSYS (Reference 1). In an independent DOE solar contract, zia corporation of colorado used at least one of these systems for TRNSYS simulation as an aid in its system design. 
system 1. Figure M2.1 shows system 1, an all-air SAHP system. this figure, the heat pump "Main Unit" is considered to be the portion of the heat pump that would normally be outdoors; i.e.. the evaporator in the heating mode and the condenser in the cooling mode.

The only sources of heat to the house are the heat pump and the auxiliary heater. The auxiliary heater is not shown in this system and is used only when the heat pump is not capable of maintaining the desired house temperature. During operation of the heat pump (in the heating mode), the control logic of system 1 is designed to supply the maximum usable energy to the heat pump at all times. Generally, the maximum usable energy source would be the highest temperature air available to the heat pump evaporator. However, since existing off-the-shelf air-to-air heat pumps typically display a maximum instantaneous COP at evaporator temperatures of $70^{\circ} \mathrm{F}$, the optimum source for this system is defined to be either: (1) the highest temperature air available to the heat pump - if this air is below $70^{\circ} \mathrm{F}$; or (2) the available air modulated to $70^{\circ} \mathrm{F}$ - if the available air is above $70^{\circ}$. Note that $70^{\circ} \mathrm{F}$ is a typical rather than an absolute value and can be changed to coincide with the maximum $C O P$ of the particular heat pump used.

The heat source for the air-to-air heat pump of system 1 can be outside air, heat from the solar collector or from the rock storage, or any combination of the three. Dampers $D_{4} \cdot 5 \cdot 6$ of Figure 2.1 operate so as to prevent the minimum system temperature from dropping below the ambient. (Thus, if $\mathrm{T}_{4}$ is below $\mathrm{T}_{\mathrm{OS}}, \mathrm{D}_{4}$ closes and $D_{5}$ and $D_{6}$ open to discharge. the colder air and replace it with warmer outdoor air.)

Dampers $D_{2} \cdot 3$ allow the system air to flow through the collector. when there is a solar gain and to bypass them otherwise. Dampers $D_{7}$ and $D_{8}$ modulate to maintain $T_{7}$ at $70^{\circ} \mathrm{F}$ by mixing storage air at temperature $\mathrm{T}_{1}$ with the solar heated air. If, however, $\mathrm{T}_{7}$ does go above $70^{\circ} \mathrm{F}$, damper $\mathrm{D}_{1}$ modulates open, allowing the cold discharge air to recirculate and $\mathrm{mix}$ with the hot air at $\mathrm{T}_{7} ;$ thus, the air entering the heat pump at $\mathrm{T}_{5}$ is maintained at a $70 \mathrm{~F}$ maximum.

When the house thermostat does not call for heat but insolation is available, the system will put solar heat into storage. The heat pump's centrifugal blower is controlled independently of the 
compressor to provide blower operation during this "storage cycle". An independent blower can also be used for this purpose. When the collector air temperature $\mathrm{T}_{2}$ is greater than the storage air temperature $\mathrm{T}_{1}$, the heat pump blower circulates air first through the collector and then through storage. If the outside air is warmer than the storage air, dampers $D_{4}-D_{6}$ will position to allow outside air to heat storage.

In the cooling mode, dampers $\mathrm{D}_{2} \cdot 3$ always bypass the collector. When the room thermostat calls for cooling, the heat sink for the heat pump is storage, outside air, or both. When the heat pump discharge air temperature $\mathrm{T}_{4}$ is greater than the outside air temperature $\mathrm{T}_{\mathrm{OS}}$, dampers $\mathrm{D}_{4}-\mathrm{D}_{6}$ are positioned to allow the hotter $\mathrm{T}_{4}$ air to be rejected to the outside and replaced by the cooler outside air. Dampers $D_{7}$ and $D_{8}$ are positioned to allow system

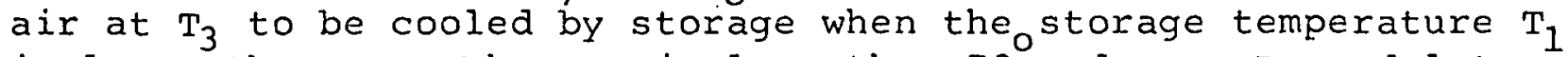
is lower than $T_{3}$. When $T_{7}$ is less than $70^{\circ}$, damper $D_{1}$ modulates open to recirculate and mix the warmer heat pump discharge air with the cold system supply air at $T_{7}$. Thus, the heat gump entering air temperature $\mathrm{T}_{5}$ is maintained at a minimum of $70 \mathrm{~F}$. (The $70 \mathrm{~F}$ temperature was chosen to provide an optimum "source" temperature for a typical, off-the-shelf air-to-air heat pump to prevent cooling capacity reduction).

In the cooling mode when the room thermostat does not call for cooling (the heat pump compressor is not running) storage will be cooled if the storage temperature $T_{1}$ is higher than the outside air temperature ToS. During this" "storage cooling cycle", which usually occurs at night, the heat pump blower in the Main Unit operates and dampers $D_{4}-D_{8}$ position to allow the cooler outside air to circulate through storage.

In summary, the typical operation of this system in the cooling mode allows storage to cool the entering condenser air and thereby to raise the efficiency of the heat pump. At night, when both the cooling load and outside ambient temperature are low, storage is cooled by outside air to prepare it for the next day's use.

The advantages of system 1 include the use of air collectors which have no freeze-up or high temperature problems and the use of an air-to-air heat pump which does not require an additional heat exchanger to sink and source outside air. 
System 2. Figure M2.2 shows system 2, one with an air collector, water storage, and a water-to-air heat pump. The major difference between this system and system 1 is the water-to-air heat exchanger. This heat exchanger is required to transfer heat from the outside air and/or collector to the storage and/or heat pump. The advantages of System 2 include the use of air collectors which have no freeze-up or over-heating problems; the use of water pipes rather than air ducts between the roof and basement areas (these generally have lower installation costs); and the use of water storage which does not have the fungus and deterioration problems of rock storage.

System 3. System 3 shown in Figure M2.3 is similar to system 1 except that it is an all-water rather than all-air system. To protect against collector freeze up, either a glycol or a arain down system (as shown) can be used. The ancillary components, such as the air vents and expansion tank shown in Figure M2.3, represent what might be required in an actual installation. The water-to-air heat exchanger transfers heat between the system ano outside air. The advantages of this system include the elimination of the water-to-air heat exchanger between the collector, storage, and heat pump which is required in system 2 (this exchanger normally causes the collector to operate at high temperatures and thus lower efficiency); the use of the higher efficiency water collector; and the use of water pipes instead of air ducts.

System 4. System 4 of Figure M2.4 has a water collector, water storage, and an air-to-air heat pump. The advantages of this system are its use of the higher efficiency water collectors; the air-to-air heat pump (capable of operation at low temperature); and water pipes instead of ducts between the roof and basement areas.

\section{Conclusions}

Four SAHP systems, with their appropriate control algorithms, were engineered with sufficient flexibility to provide reasonably high operating efficiencies in the various climatic regions in the U.S. It was originally intended that the Analytical Model would indicate the specific climatic regions where SAHP has a marketable LCC. In addition, it was to provide collector and storage sizes for initial TRNSYS simulation of the engineered systems. subsequent simulations of the engineered systems were, then, to 
yield desired system modifications and detailed SAHP cost and performance data for real world LCC determination. It was these additional simulations, together with modifications dictated by engineering judgment and local construction codes, that were to allow final optimization of the systems.

The results of the LCC analyses performed by the Analytical Model showed that, in the climatic regions investigated, SAHP LCC's were higher than those of the heat pump in the near future, that is, the future of interest to strategic planners in HVAC companies. In the present context this shows that SAHP systems are not marketable. Therefore, the engineered SAHP systems were never used in any LCC analysis. 


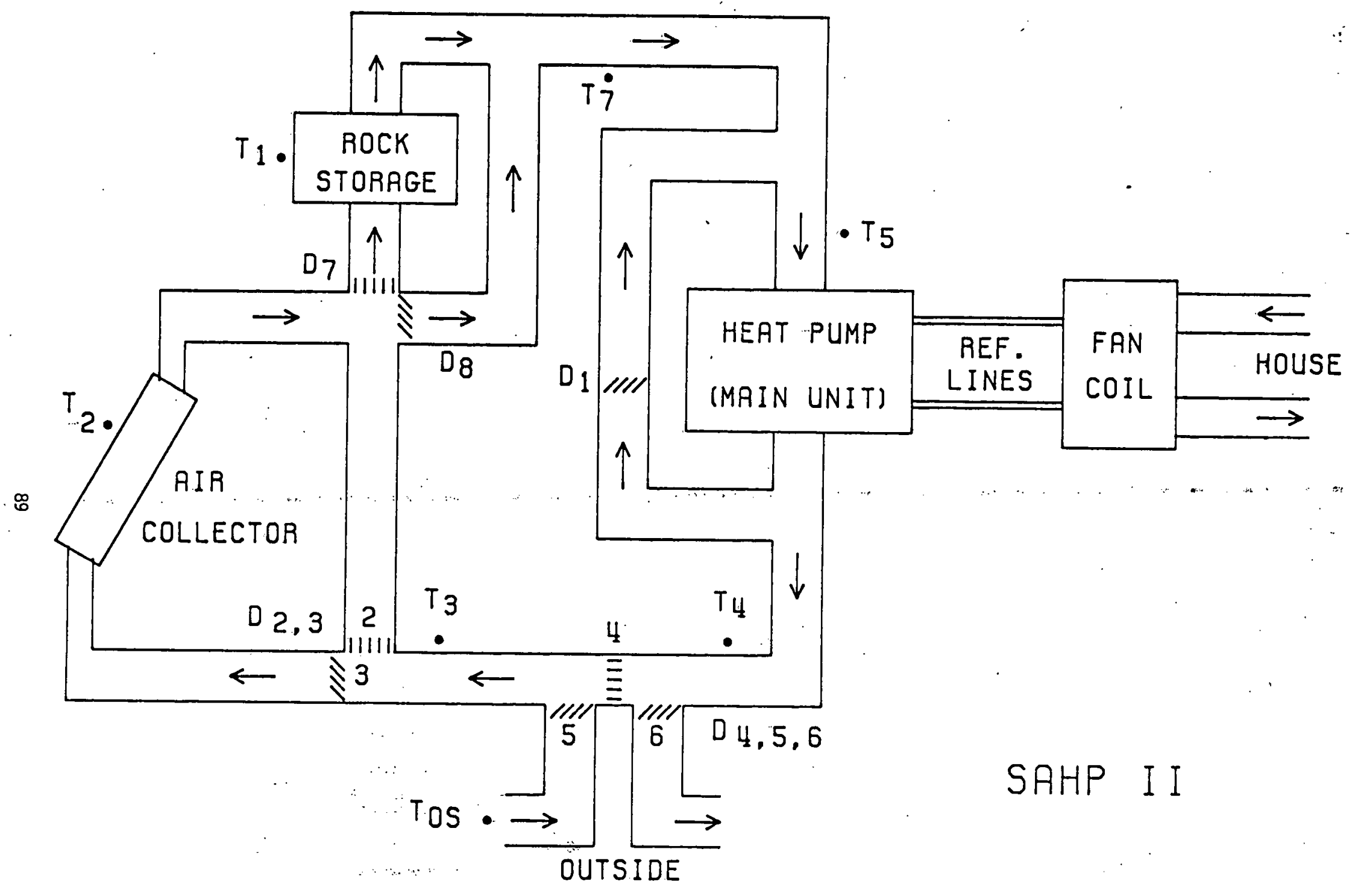

FIG. M2.1 - SYSTEM 1 AÍR TO RIR SOLAR. ASSISTED HERT PUMP WITH STORAGE 
I. Heating Mode

A. In general:

Dampers $\mathrm{D}_{2,3}$
$\mathrm{T}_{2}>\mathrm{T}_{3}$
$\mathrm{D}_{3}$ open, D2 closed
$\mathrm{T}_{3} \geq \mathrm{T}_{2}$
$D_{2}$ open, $D_{3}$ closed

Dampers $D_{4,5,6}$
$\mathrm{T}_{4}>\mathrm{T}_{\mathrm{Og}}$
$\mathrm{D}_{4}$ open, $\mathrm{D}_{5,6}$ closed
$\mathrm{T}_{\mathrm{OS}} \geq \mathrm{T}_{4}$
$\mathrm{D}_{5,6}$ open, $\mathrm{D}_{4}$ closed

B. When the house thermostat calls for heat:

Damper $\mathrm{D}_{1}$, (modulating)

$$
\begin{array}{ll}
\mathrm{T}_{5}>70^{\circ} \mathrm{F}+2^{\circ} \mathrm{F} & \mathrm{D}_{1} \text { opens } \\
\mathrm{T}_{5} \leqq 70^{\circ} \mathrm{F} & \mathrm{D}_{1} \text { closes }
\end{array}
$$

Dampers $D_{7,8}$ (modulating)

$\left(\mathrm{T}_{2}>\mathrm{T}_{1}+2^{\circ} \mathrm{F}\right)$ and $\left(\mathrm{T}_{7}<70^{\circ} \mathrm{F}\right) \quad \mathrm{D}_{7}$ closes, $\mathrm{D}_{8}$ opens

$\left(\mathrm{T}_{2}>\mathrm{T}_{1}+2^{\circ} \mathrm{F}\right)$ and $\left(\mathrm{T}_{7}>70^{\circ}+2^{\circ} \mathrm{F}\right) \mathrm{D}_{7}$ opens, $\mathrm{D}_{8}$ closes

$\left(\mathrm{T}_{1}>\mathrm{T}_{2}\right)$ and $\left(\mathrm{T}_{7}>70^{\circ} \mathrm{F}+2^{\circ} \mathrm{F}\right) \quad \mathrm{D}_{7}$ closes, $\mathrm{D}_{8}$ opens

$\left(\mathrm{T}_{1}>\mathrm{T}_{2}\right)$ and $\left(\mathrm{T}_{7}<70^{\circ} \mathrm{F}\right) \quad \mathrm{D}_{7}$ opens, $\mathrm{D}_{8}$ closes

C. When the house thermostat is not calling for heat:

Damper $\mathrm{D}_{1}$ closes

Damper $\mathrm{D}_{8}$ closes and Damper $\mathrm{D}_{7}$ opens

Main Unit Fan
$\mathrm{T}_{2}>\mathrm{T}_{1}+5^{\circ} \mathrm{F}$
Fan turns on
$\mathrm{T}_{\underline{1} .} \geq \mathrm{T}_{2}$
Fan turns off 


\section{System 1}

II. Cooling Mode

A. In general:

Damper $D_{2}$ open and Damper $D_{3}$ closed

Dampers $\mathrm{D}_{4,5,6}$

$$
\begin{array}{ll}
\mathrm{T}_{4} \geq \mathrm{T}_{\text {os }} & \mathrm{D}_{4} \text { closed, } \mathrm{D}_{5,6} \text { open } \\
\mathrm{T}_{4}<\mathrm{T}_{\mathrm{OS}} & \mathrm{D}_{5,6} \text { closed, } \mathrm{D}_{4} \text { open }
\end{array}
$$

B. When the house thermostat calls for cooling:

Dampers $D_{7,8}$

$\mathrm{T}_{1}>\mathrm{T}_{3}+2^{\circ}$

$\mathrm{T}_{3}>\mathrm{T}_{1}$

Damper $D_{1}$

$\mathrm{T}_{5}<-70^{\circ}$

$\mathrm{T}_{5} \geqq 70^{\circ}$
D7 closes, D8 opens

$\mathrm{D}_{7}$ opens, $\mathrm{D}_{8}$ closes

C. When the house thermostat is not całling for cooling:

Damper $D_{1}$ closed

Damper $\mathrm{D}_{7}$ open and $\mathrm{D}_{8}$ closed

Main Unit Fan

$\begin{array}{ll}\mathrm{T}_{1}>\mathrm{T}_{\mathrm{OS}} & \text { Fan turns on } \\ \mathrm{T}_{\mathrm{OS}} \geq \mathrm{T}_{1} & \text { Fan turns off }\end{array}$




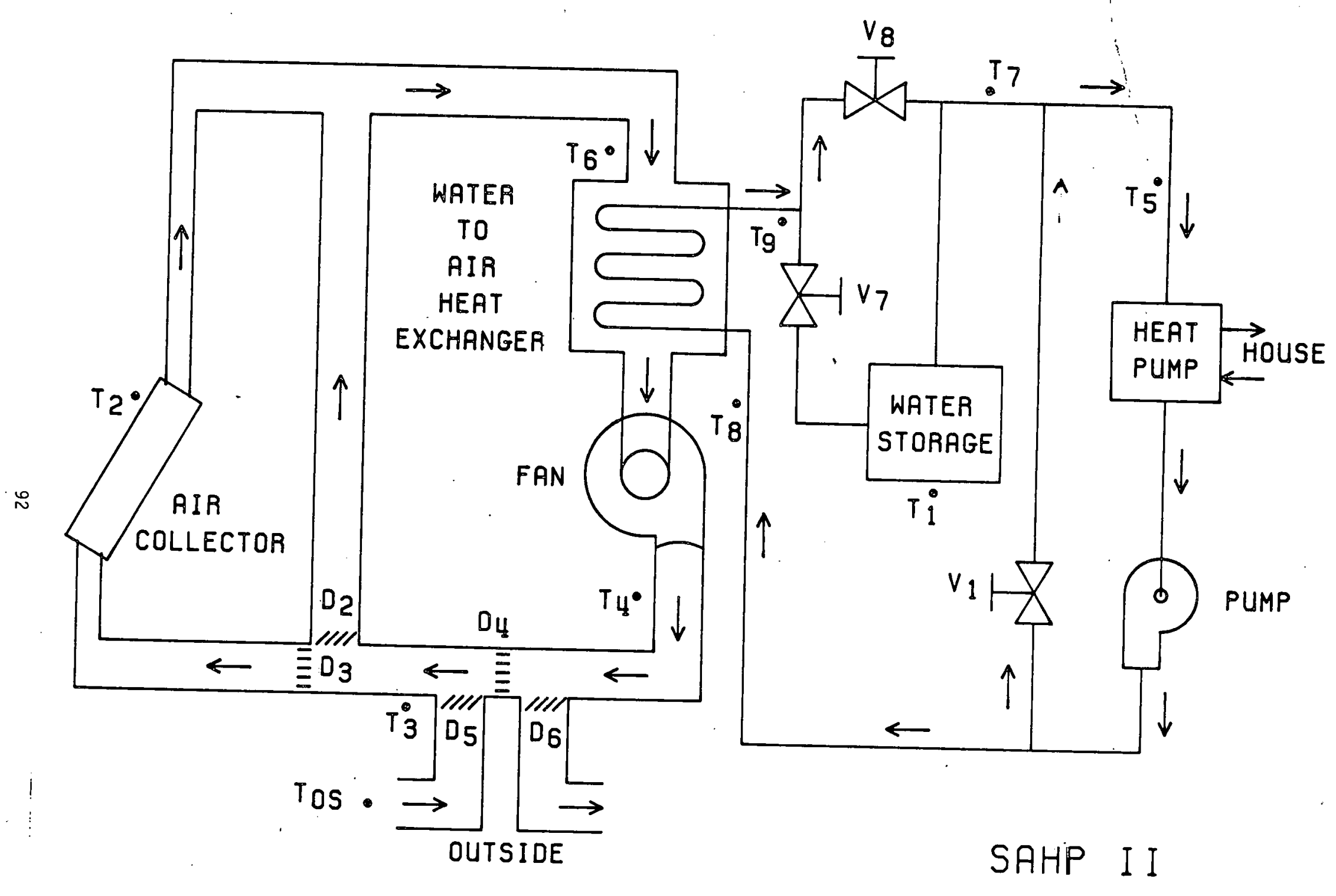

FIG M2.2 - SYSTEM:2 AIR COLLECTOR, WATER STORAGE.

WATER TO AIR HEAT PUMP 
I. Heating Mode

A. In general:
Dampers $\mathrm{D}_{2} \cdot 3$
$D_{3}$ open, $D_{2}$ closed
Pump (water)
Heat Pump on
Pump on
Fan on
Pump on
Dampers $\mathrm{D}_{4} \cdot 5 \cdot 6$

$$
\mathrm{T}_{\mathrm{OS}}>\mathrm{T}_{4}+2^{\circ} \mathrm{F}
$$
$\mathrm{D}_{5} \cdot 6$ open, $\mathrm{D}_{4}$ closed
$\mathrm{T}_{4} \geqq \mathrm{~T}_{\text {OS }}$
$\mathrm{D}_{4}$ open, $\mathrm{D}_{5} \cdot 6$ closed

B. When the house thermostat calls for heat:

Valve $v_{1}$ (modulating)

$$
\begin{array}{ll}
\mathrm{T}_{5}>70^{\circ} \mathrm{F}+2^{\circ} \mathrm{F} & \mathrm{V}_{1} \text { opens } \\
\mathrm{T}_{5}<70^{\circ} \mathrm{F} & \mathrm{V}_{1} \text { closes }
\end{array}
$$

Valves $\mathrm{V}_{7 \cdot 8}$ (modulating)

$$
\begin{array}{ll}
\left(\mathrm{T}_{9}>\mathrm{T}_{1}+2^{\circ} \mathrm{F}\right) \text { and }\left(\mathrm{T}_{7}>70^{\circ} \mathrm{F}+2^{\circ} \mathrm{F}\right) & \mathrm{V}_{7} \text { opens, } \mathrm{V}_{8} \text { closes } \\
\left(\mathrm{T}_{9}>\mathrm{T}_{1}+2^{\mathrm{O}} \mathrm{F}\right) \text { and }\left(\mathrm{T}_{7}<70^{\circ} \mathrm{F}\right) & \mathrm{V}_{8} \text { opens, } \mathrm{V}_{7} \text { closes } \\
\left(\mathrm{T}_{9}<\mathrm{T}_{1}\right) \text { and }\left(\mathrm{T}_{7}>70^{\circ} \mathrm{F}+2^{\circ} \mathrm{F}\right) & \mathrm{V}_{7} \text { closes, } \mathrm{V}_{8} \text { opens } \\
\left(\mathrm{T}_{9}<\mathrm{T}_{1}\right) \text { and }\left(\mathrm{T}_{7}<70^{\circ} \mathrm{F}\right) & \mathrm{V}_{7} \text { opens, } \mathrm{V}_{8} \text { closes }
\end{array}
$$

Fan

$$
\begin{array}{ll}
\mathrm{T}_{2}>\mathrm{T}_{8}+2{ }^{\mathrm{O}} \mathrm{F} & \text { Fan turns on } \\
\mathrm{T}_{8} \geqq \mathrm{~T}_{2} & \text { Fan turns off }
\end{array}
$$


c. When the house thermostat is not calling for heat:

Fan

$\mathrm{T}_{2}>\mathrm{T}_{1}+5^{\circ} \mathrm{F}$

$T_{1:} \geq T_{2}$
Fan turns on

Fan turns off 
II. Cooling Mode

A. In general:

Dampers $D_{3}, D_{4}$ closed and Dampers $D_{2}, D_{5}, D_{6}$ open Pump (water)

Heat Pump on

Pump on

Fan on

Pump on

B. When the house thermostat calls for cooling:

Fan

$$
\begin{array}{ll}
\mathrm{T}_{8}>\mathrm{T}_{\mathrm{OS}}+2^{\mathrm{O}} \mathrm{F} & \text { Fan turns on } \\
\mathrm{T}_{\mathrm{OS}} \geqslant \mathrm{T}_{8} & \text { Fan turns off }
\end{array}
$$

Valves $\mathrm{V}_{7,8}$

$\mathrm{T}_{1}>\mathrm{T}_{9}+2^{\mathrm{O}} \mathrm{F} \quad \mathrm{V}_{7}$ closes, $\mathrm{V}_{8}$ opens

$\mathrm{T}_{9}>\mathrm{T}_{1}$

$\mathrm{V}_{8}$ closes, $\mathrm{V}_{7}$ opens

Valve $v_{1}$ (modulating)

$$
\begin{array}{ll}
\mathrm{T}_{5}<68^{\circ} \mathrm{F} & \mathrm{V}_{1} \text { opens } \\
\mathrm{T}_{5} \geqq 70^{\circ} \mathrm{F} & \mathrm{V}_{1} \text { closes }
\end{array}
$$

C. When house thermostat is not calling for cooling:

Fan

$$
\begin{aligned}
& \mathrm{T}_{1}>\mathrm{T}_{\mathrm{OS}}+2^{\circ} \mathrm{F} \\
& \mathrm{T}_{\text {os }} \geq \mathrm{T}_{1} \\
& \text { Valves } V_{1,7,8}
\end{aligned}
$$




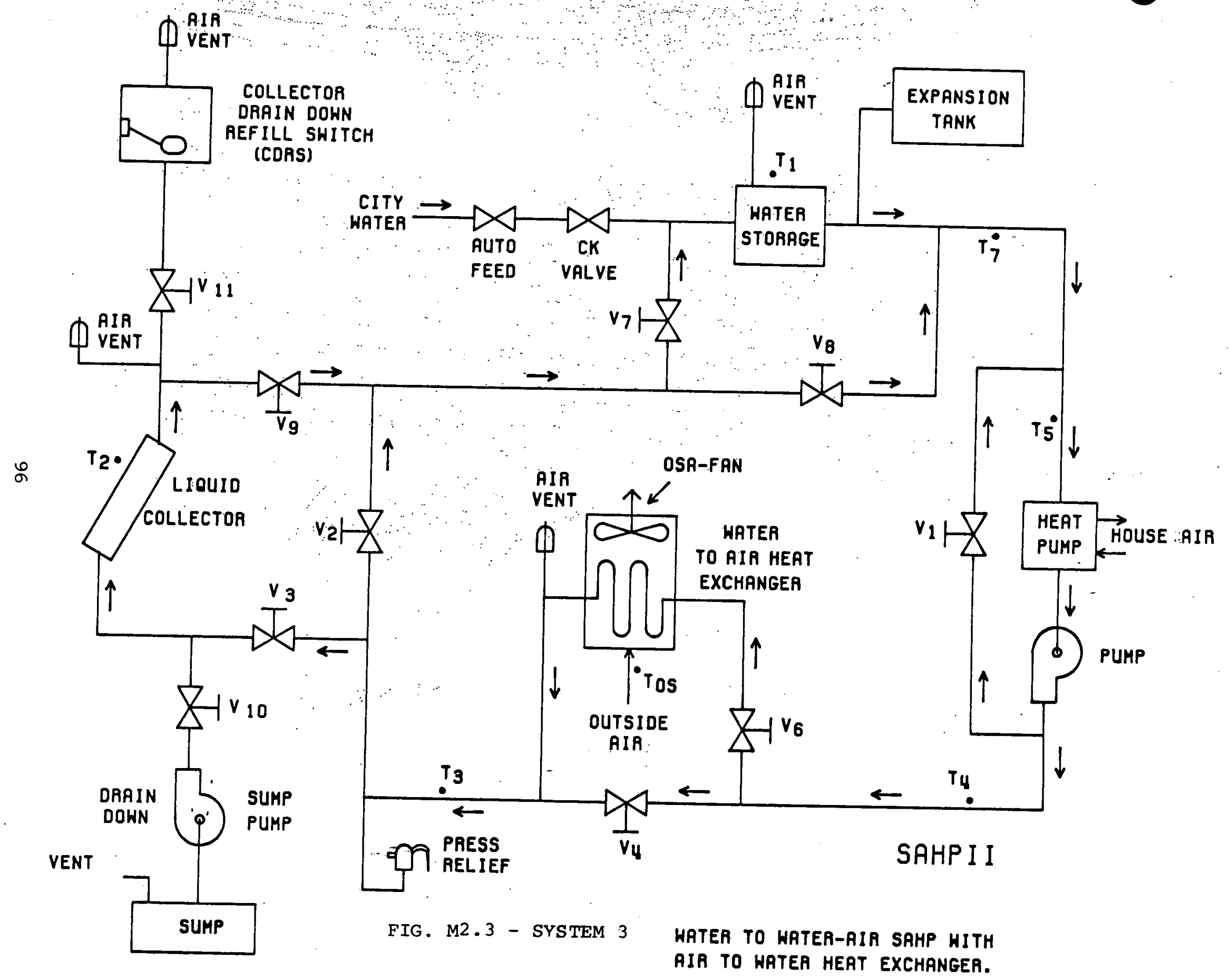




\section{Heating Mode}

A. In General:

When the house thermostat goes into the heating mode at the start of the heating season, Valves $V_{10}, 11$ open and the sump pump turns on until the CDRS switch trips and closes $\mathrm{V}_{10}, 11$ and turns off the sump pump.

Pump (Water)

Heat Pump on Pump on

OSA Fan

$V_{6}$ open and Pump on OSA Fan turns on Valves $V_{2}, 3$

Pump on and $\mathrm{T}_{2} \rightarrow \mathrm{T}_{3}+3^{\circ} \mathrm{F}$. $V_{3}$ opens, $V_{2}$ clos es

Pump on and $\mathrm{T}_{3} \cong \mathrm{T}_{2}$ $V_{2}$ opens, $V_{3}$ closes Valves $V_{4}, 6$

Pump on and $\mathrm{T}_{4} \geqslant \mathrm{~T}_{\text {os }}$ $\mathrm{V}_{4}$ opens, $\mathrm{V}_{6}$ closes

Pump on and $\mathrm{T}_{\mathrm{OS}} \geqq \mathrm{T}_{4}$ $\mathrm{V}_{6}$ opens, $\mathrm{V}_{4}$ closes

B. When the house thermostat is calling for heat:

Valve $\mathrm{V}_{1}$ (modulating)

$$
\begin{array}{ll}
\mathrm{T}_{5}>70^{\circ} \mathrm{F}+2^{\circ} \mathrm{F} & \mathrm{V}_{1} \text { opens } \\
\mathrm{T}_{5} \& 70^{\circ} \mathrm{F}(-) 2^{\circ} \mathrm{F}, & \mathrm{V}_{1} \text { opens }
\end{array}
$$

Valves $\mathrm{V}_{7,8}$ (modulating)

$$
\begin{array}{lll}
\left(\mathrm{T}_{2}>\mathrm{T}_{1}+2^{\circ} \mathrm{F}\right) & \text { and }\left(\mathrm{T}_{7}<70^{\circ} \mathrm{F}\right) & \mathrm{V}_{7} \text { closes, } \mathrm{V}_{8} \text { opens } \\
\left(\mathrm{T}_{2}>\mathrm{T}_{1}+2^{\circ} \mathrm{F}\right) \text { and }\left(\mathrm{T}_{7}>70^{\circ} \mathrm{F}+2^{\circ} \mathrm{F}\right) & \mathrm{V}_{7} \text { opens, } \mathrm{V}_{8} \text { closes }
\end{array}
$$


.II. Cooling Mode

A. In General:

When the house thermostat goes into the cooling mode, $\mathrm{V}_{2}, 11$ close and $\mathrm{V}_{10}$ opens to perform collector drain down. Ifre adation; $V_{2}$ opens and $V_{3}$ closes.

Pump (Water)

Heat Pump on Pump on

OSA-Fan

$\mathrm{V}_{6}$ open and Pump on OSA - Fan turns on Valves $V_{4}, 6$
$\mathrm{T}_{4}>\mathrm{T}_{\mathrm{OS}}+2^{\circ} \mathrm{F}$
$\mathrm{V}_{4}$ closes, $\mathrm{V}_{6}$ opens
$\mathrm{T}_{4} \leqq \mathrm{~T}_{\mathrm{OS}}$
$\mathrm{V}_{6}$ closes, $\mathrm{V}_{4}$ opens

B. When the house thermostat is calling for cooling:
Valve $\mathrm{V}_{1}$ (modulating)
$\mathrm{T}_{5} \odot 70^{\circ} \mathrm{F}(-) 2^{\circ} \mathrm{F}$
$\mathrm{V}_{1}$ opens
$\mathrm{T}_{5}>70^{\circ} \mathrm{F}+2^{\circ} \mathrm{F}$
$\mathrm{V}_{1}$ closes
Valves $V_{7,8}$
$\mathrm{T}_{1}>\mathrm{T}_{3}+2^{\circ} \mathrm{F}$
$\mathrm{V}_{7}$ closes, $\mathrm{V}_{8}$ opens
$\mathrm{T}_{3}>\mathrm{T}_{1}$
- $\mathrm{V}_{7}$ opens, $\mathrm{V}_{8}$ closes

C. When the house thermostat is not calling or cooling:

Pump (Water)
$\mathrm{T}_{1}>\mathrm{T}_{\text {OS }}+2^{\circ} \mathrm{F}$
Pump turns on
$T_{\text {os }} \geq T_{1}, 7,8$
$v_{1,8}$ closes, $v_{7}$ opened 


$$
\begin{array}{ll}
\left(\mathrm{T}_{1}>\mathrm{T}_{2}\right) \text { and }\left(\mathrm{T}_{7}>70^{\circ} \mathrm{F}+2^{\circ} \mathrm{F}\right) & \mathrm{V}_{7} \text { closes, } \mathrm{V}_{8} \text { opens } \\
\left(\mathrm{T}_{1}>\mathrm{T}_{2}\right) \text { and }\left(\mathrm{T}_{7}<70^{\circ} \mathrm{F}\right) & \mathrm{V}_{7} \text { opens, } \mathrm{V}_{8} \text { closes }
\end{array}
$$

C. When the house thermostat is not calling for heat;

$$
\begin{aligned}
\text { Pump (Water) } & \\
\mathrm{T}_{2}>\mathrm{T}_{1}+5^{\circ} \mathrm{F} & \text { Pump turns on } \\
\mathrm{T}_{1} \cong \mathrm{T}_{2} & \text { Pump turns off } \\
\text { Valves } \mathrm{V}_{1}, 7,8 & \mathrm{~V}_{1,8} \text { closes, } \mathrm{V}_{7} \text { opened }
\end{aligned}
$$




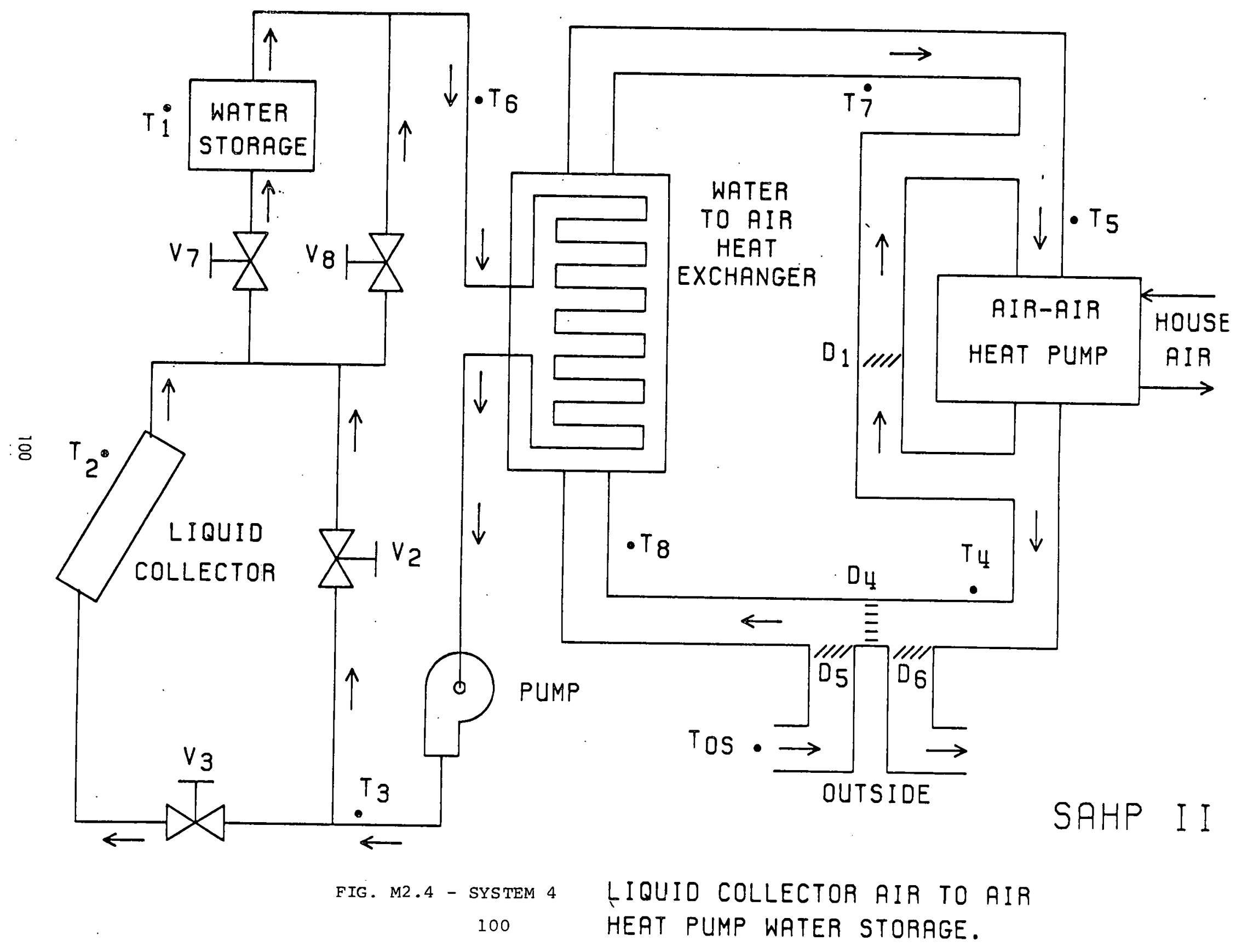


I. Heating Mode

A. When the house thermostat is calling for heat:

Pump (water)

$\left(\mathrm{T}_{1}>\mathrm{T}_{8}+2^{\circ} \mathrm{F}\right)$ or $\left(\mathrm{T}_{2}>\mathrm{T}_{8}+2^{\circ} \mathrm{F}\right) \quad$ Pump turns on

$\mathrm{T}_{8}>\mathrm{T}_{6}$

Pump turns off

Valves $V_{7}, 8$ (nodulating)

$\left(\mathrm{T}_{2}>\mathrm{T}_{1}+2^{\circ} \mathrm{F}\right)$ and $\left(\mathrm{T}_{7}<70^{\circ} \mathrm{F}\right) \quad \mathrm{V}_{7}$ closes, $\mathrm{V}_{8}$ opens

$\left(\mathrm{T}_{2}>\mathrm{T}_{1}+2^{\circ} \mathrm{F}\right)$ and $\left(\mathrm{T}_{7}>70^{\circ} \mathrm{F}+2^{\circ} \mathrm{F}\right) \quad \mathrm{V}_{7}$ opens, $\mathrm{V}_{8}$ closes

$\left(\mathrm{T}_{1}>\mathrm{T}_{2}\right)$ and $\left(\mathrm{T}_{7}>70^{\circ} \mathrm{F}+2^{\circ} \mathrm{F}\right) \quad \mathrm{V}_{7}$ closes, $\mathrm{V}_{8}$ opens

$\left(\mathrm{T}_{1}>\mathrm{T}_{2}\right)$ and $\left(\mathrm{T}_{7}>70^{\circ} \mathrm{F}\right) \quad \mathrm{V}_{7}$ opens, $\mathrm{V}_{8}$ closes

Dampers $D_{4,5,6}$

$$
\begin{array}{ll}
\mathrm{T}_{\mathrm{os}}>\mathrm{T}_{4}+2^{\mathrm{O}} \mathrm{F} & \mathrm{D}_{4} \text { closes, } \mathrm{D}_{5,6} \text { opens } \\
\mathrm{T}_{4}>\mathrm{T}_{\mathrm{OS}} & \mathrm{D}_{5,6 \text { closes, } \mathrm{D}_{4} \text { opens }}
\end{array}
$$

Dampers $D_{1}$ (modulating)

$$
\begin{array}{ll}
\mathrm{T}_{5}>70^{\circ} \mathrm{F}+2^{\circ} \mathrm{F} & \mathrm{D}_{1} \text { opens } \\
\mathrm{T}_{5}<70^{\circ} \mathrm{F}-2^{\mathrm{O}} \mathrm{F} & \mathrm{D}_{1} \text { closed }
\end{array}
$$

B. When house thermostat is not calling for heat:

Valves $V_{7}$ open and $V_{8}$ closed and Damper $D_{1}$ closed Pump (water)
$\mathrm{T}_{2}>\mathrm{T}_{1}+2^{\circ} \mathrm{F}$
Pump turns on
$\mathrm{T}_{1} \geq \mathrm{T}_{2}$
Pump turns off 
Dampers $D_{4}, 5,6$ and Fan

$$
\mathrm{T}_{\mathrm{os}}>\mathrm{T}_{1}+2^{\mathrm{O}} \mathrm{F} \quad \mathrm{D}_{5}, 6 \text { open, } \mathrm{D}_{4} \text { closes, Fan turns on }
$$

$\mathrm{T}_{1} \geq \mathrm{T}_{\text {os }}$

$D_{5}, 6$ close, $D_{4}$ opens, Fan turns off

Valves $V_{2}, 3$

$\left(\mathrm{T}_{2}>\mathrm{T}_{3}+2^{\circ} \mathrm{F}\right)$ and Pump on $\mathrm{V}_{3}$ opens, $\mathrm{V}_{2}$ closes

$\left(\mathrm{T}_{3}>\mathrm{T}_{2}\right)$ and Pump on $\quad \mathrm{V}_{2}$ opens, $\mathrm{V}_{3}$ closes 
II. Cooling Mode

A. In General:

$$
\begin{gathered}
\text { Valves } \mathrm{V}_{2}, 3,7,8 \\
\text { Dampers } \mathrm{D}_{4}, 5,6 \\
\mathrm{~T}_{4}>\mathrm{T}_{\mathrm{OS}}+2^{\circ} \mathrm{F} \\
\mathrm{T}_{\mathrm{OS}}>\mathrm{T}_{4}
\end{gathered}
$$$$
\mathrm{V}_{3,8} \text { closed, } \mathrm{V}_{2,7} \text { opened }
$$$$
\mathrm{D}_{5}, 6 \text { open, } \mathrm{D}_{4} \text { closed }
$$$$
D_{5}, 6 \text { closed, } D_{4} \text { open }
$$

B. When the house thermostat calls for cooling:

$$
\text { Pump (water) }
$$

$$
\begin{array}{rlrl}
\mathrm{T}_{8} & >\mathrm{T}_{1}+2^{\circ} \mathrm{F} & \text { Pump turns on } \\
\mathrm{T}_{1} & \stackrel{\geqslant}{\mathrm{T}_{8}} & \text { Pump turns off } \\
\text { Damper } \mathrm{D}_{1} \text { (modulating) } &
\end{array}
$$

$$
\begin{array}{ll}
\mathrm{T}_{5}<70^{\circ} \mathrm{F}-2^{\circ} \mathrm{F} & \mathrm{D}_{1} \text { opens } \\
\mathrm{T}_{5}>70^{\circ} \mathrm{F}+2^{\circ} \mathrm{F} & \mathrm{D}_{1} \text { closes }
\end{array}
$$

C. When the house thermostat is not calling for cooling:

Pump and Fan

$$
\begin{array}{cl}
\mathrm{T}_{1}>\mathrm{T}_{\mathrm{OS}}+2^{\circ} \mathrm{F} & \text { Pump, Fan turn on } \\
\mathrm{T}_{\mathrm{OS}} \geq \mathrm{T}_{1} & \text { Pump, Fan turn off } \\
\text { Damper } \mathrm{D}_{1} \text { closed } &
\end{array}
$$


CHAPTER $M-3$

HVAC SYSTEM COMPONENT AND INSTALLATION COSTS

\section{Introduction}

An early requirement of the economic system optimization scheme of the Analytical Model was cost and performance information for the SAHP system's components. Accordingly, cost and performance data were compiled for the major components of the four SAHP systems of chapter $M-2$. In addition, in order that life cycle cost comparisons of the various types of systems could be made, costs and performance data of conventional heating systems were compiled.

The results of these cost and performance collection activities are presented in this chapter in four sections. In the first section, total system costs, including installation, are discussed for both SAHP and conventional HVAC systems. The next three sections then discuss in more detail the cost and performance characteristics of the three major components of the SAHP system: the collector, the heat pump, and the thermal energy storage.

\section{System costs}

The two primary vehicles of solar energy collection in SAHP systems are air and liquid. Initial component and installation costs for an air-sourced, single family residential SAHP system which contains a three ton heat pump are shown in Table M3.1. The heat pump's component and installation costs are grouped in this table for easy comparison with the total SAHP system costs and were obtained from References 2-8. The results of a similar cost study performed by an independent source are shown in Table M3.2 and are in reasonable agreement with the figures of Table M3.1.

Two estimates of component and installation costs for a liquid solar energy system sized for residential use are shown in Table M3.3. These estimates are for a stand-alone solar heating system, that is, one with no heat pump; because costs for liquid SAHP systems were available only for relatively large commercial applications, they were omitted from this study. As indicated in Table M3.3, the estimates yielded an installed system cost of $\$ 39.10$ per square foot of collector area. 
In addition to the above solar energy system costs, installed costs of conventional HVAC systems were collected for a number of U.S. cities. These are shown in Tables 1 and 2 of Appendix 2. Unlike the solar energy system costs of Tables M3.2 and M3.3, the conventional system costs are based on installation in new single family housing and include the costs of all duct work and electrical wiring. The cost of retrofit conventional HVAC systems, where duct work exists, may be appreciably lower than these. In general, HVAC system costs are reasonably consistent across the U.S.. although differences do occur between individual house construction and large volume tract construction. Typically, heat pump and oil are the most expensive systems while electric resistance. is always the least expensive.

\section{Collector study}

The collectors are the most costly component of a SAHP system and their cost effectiveness is crucial to successful SAHP marketability. To compare different manufacturers' collector costs and cost effectiveness, a collector cost analysis was performed. In addition, comparisons were made between collector retail and installation costs and between site-assembled and factory-assembled collector costs.

In Figure M3.1, the collector efficiency per unit installed cost of six single glazed collectors arranged in $400 \mathrm{ft}^{2}$ arrays is plotted against $\Delta \mathrm{T} / \mathrm{I}$ (Reference 9). The $\Delta \mathrm{T} / \mathrm{I}$ is the temperature difference between the collector inlet and outside ambient divided by the insolation. The figure shows that the lowest price collector (Solaris) has the highest efficiency per unit installed cost at the lower $\Delta \mathrm{T} / \mathrm{I}$ range. Therefore, at the low temperatures used by the series SAHP system, the Solaris collector would have the highest efficiency installed cost.

The retail and installed costs for the collectors of Figure M3.1 are listed in Table M3.4. The $\$ 6.00$ installed cost of the site-assembled Solaris collector is approximately one-half that of the cheapest factory assembled collector. Additional prices of factory assembled collectors are listed in Table M3.5 and are in reasonable agreement with those of Table M3.4.

Heat pumps

Heat pumps are a major component of, and the primary competitor 
to, SAHP systems. Therefore, heat pump cost data must be available for the marketing analysis. In addition to the air-to-air heat pump costs listed in Tables M3.1 - M3.2, further heat pump cost data were collected and are shown in Table M3.6 and Figure M3.2. Table M3.6 lists the budget prices (50-60 percent of list price) of three residential-sized water-to-air heat pumps by unit cost and cost per ton.

The price versus the cooling capacity of residential air-to-air heat pumps is plotted in Figure M3.2. In this figure, the retail price is taken to be 75 percent of the list price.

\section{Thermal Energy Storage}

Thermal energy storage is a major component of the SAHP system and its cost effectiveness may affect SAHP marketability. Thermal energy storage (TES) costs and cost effectiveness were reviewed (Reference 9) by ITC/Solar. An important conclusion reached is that, for a series SAHP system, most of the phase change materials (PCM) developed for solar applications would give a lower system performance than would water storage.

A cost comparison of PCM and sensible storage systems is dependent on the selection of arbitrary parameters. One parameter that must be carefully considered is the allowable or usable temperature range of the sensible storage system. A large temperature range effectively reduces the required size of the sensible storage system. Proponents of latent heat systems (PCM) generally assume a range of $30^{\circ} \mathrm{F}$ to $40^{\circ} \mathrm{F}$ in their comparisons. However, sensible heat storage systems are presently available which utilize very large temperature ranges. An extreme example is the Megatherm system which utilizes a temperature variation of water from $160^{\circ} \mathrm{F}$ to $280^{\circ} \mathrm{F}$

A sensible heat storage unit used in conjunction with a liquid-toair or dixal source heat pump could also be utilized over a very wide temperature range. For instance, an unpressurized storage tank could be utilized from $50^{\circ} \mathrm{F}$ to $180^{\circ} \mathrm{F}$. Thus almost 300,000 BTU's could be contained in a liquid storage tank of 275 gallons.. the standard size of a fuel oil storage tank.

Cost data for Iiquid and for air thermal energy storage systems are given in Tables M3.1 - M3.3. 


\section{Conclusions}

The costs and performance data described in this chapter were used in the Analytical Model to compare the life cycle costs of SAHP and heat pump systems. However, the results of the Analytical Model show that the installed cost of active solar energy system components, excluding collectors and storage, plays an insignifiicant role in determining the total life cycle cost of the system, especially when fuel costs are high enough to make active solar energy systems cost effective. Paper 3 of the Technical section discusses this point in more detail. The collection of data was extended into the conventional HVAC system market as described in the following chapter. 


\section{TABLE M3.1 - SAHP SYSTEM COST BREAKDOWN}

\section{(All Air system)}

\section{COMPONENT}

Heat Pump - (3 ton air-to-air package unit)

Electric Auxiliary Heater

Ducts - to an existing forced air heating system and outside air,

Ducts - without an existing forced air heating system

Solar collectors

Rock storage

Ducts - to Solar collectors and Rock storage

Dampers and Motors - to Solar Collectors and Rock Storage

Blower - for Solar Package (if needed)

Control System - for Solar Package $\cos T \cdot(\$)$

COMPONENT

INSTALLED

$\begin{array}{ll}1039.00 & 1808.00 \\ 109.00 & 1500.00 \\ 800.00 & 20.00 / \mathrm{ft}^{2} \\ 14.50 / \mathrm{ft}^{2} & 25.00 / \mathrm{ton}^{2} \\ 81.00 / \mathrm{ton}^{2} & 125 \\ 300.00 & 600.00 \\ 480.00 & 880.00 \\ 150.00 & 250.00 \\ 320.00 & 600.00\end{array}$


TABLE M3.2 - SOLAR SYSTEM COST BREAKDOWN

$$
\text { (Air Systems) }
$$

Item

Collectors

Rock Storage

Primary Fan (collector)

Primary Ductwork (collector)

Secondary Fan (House)

Secondary Ductwork (House)

Backdraft Dampers

Heat Pump

Controls
Installed cost (\$)

$14.20 / \mathrm{ft}^{2}$
$2.25 / \mathrm{ft}^{2}$ of collector
$2.00 / \mathrm{ft}^{2}$ of collector
$3.00 / \mathrm{ft}^{2}$ of collector
350
900
50
$625 / \mathrm{ton}$
190

$2.25 / \mathrm{ft}^{2}$ of collector

$2.00 / \mathrm{ft}^{2}$ of collector

$3.00 / \mathrm{ft}^{2}$ of collector

(n)




\section{TABLE M 3.3 - SOLAR SYYSTEM COST BREAKDOWN}

\section{(Liquid Systems)}

\section{Installed cost $\left(s / \underline{f} t^{2}\right.$ of Collector Area)}

Item

General Conditions

Site Work

Collector supports

Tank Supports and Pit

Plumbing

Collectors

Pumps

Insulated Storage Tank

Piping and Misc. Plumbing

Electrical

Bond

Total
ITC/Solar Telex OTA (ExC O\& P)* Estimate

$$
2.80
$$

N.A

.07

0.09
4.72
N.A.
2.65
N.A.

14.63

$7.21-13.00$

1.20

.23

1.88

N.A.

8.75

.83

(Field only)

$\begin{array}{rr}2.10 & .19 \\ --.30 & \text { N.A. }\end{array}$

$\$ 39.10 / \mathrm{ft}^{2}$

* Cost estimates, excluding overhead and profit, obtained from Application of Solar Technology to Today's Energy Needs. Office of Technology Assessment, June, 1977. 
TABLE M3.4 - COLLECTOR COSTS FOR A

RES IDENTIAL SIZED SOLAR ARRAY

\section{Cullector}

"Solaris" *

Reynolds Aluminum

ITC/Solar-Black Paint ${ }^{+}$

ITC/Solar-Black Chrome ${ }^{+}$

Sunworks

Revere
Suggested Retail, $s / \mathrm{ft}^{2}$ Installed Costs, $s / \mathrm{ft}{ }^{2}$

$$
6.00
$$

6.00

9.58

11.90

11.40

13.76

14.24

16.60

14.49

17.95

14.71

18.54

* Site-assembled collector

+ Internally manifolded collector

Source: Reference 9 
Supplier

Sunworks

Revere

Solar Energy

Products

Gainesville, FL

Solaron

(Enersol)
Type

Liquid, copper single glazed

Liquid, copper double glazed

Iiquid, aluminum single glazed

Air, steel
Unit Selling Price

( $s / s q$. ft. $)$

$12.00-14.00$

11.50

$10.00-12.00$

12.05

SOURCE: Fay Friedlander, Solar Engineering Magazine,

"Are Price Reductions in Sight", May, 1977. 


\title{
TABLE M3.6 - WATER-TO-AIR HEAT PUMP COSTS \\ (Budget Prices)
}

\author{
Rated Heating Capacity \\ $1000 \mathrm{BTU} / \mathrm{hr}$ \\ Cost (s) \\ 910 \\ 933 \\ 1336 \\ 22 (1.8 Tons) \\ 33 (2.75 Tons) \\ 45 (3.75 Tons) \\ cost (s) \\ Cost Per Ton ( $S 2$ \\ 496 \\ 361 \\ 356 \\ SOURCE: Over-the-phone quote by York Dealer.
}




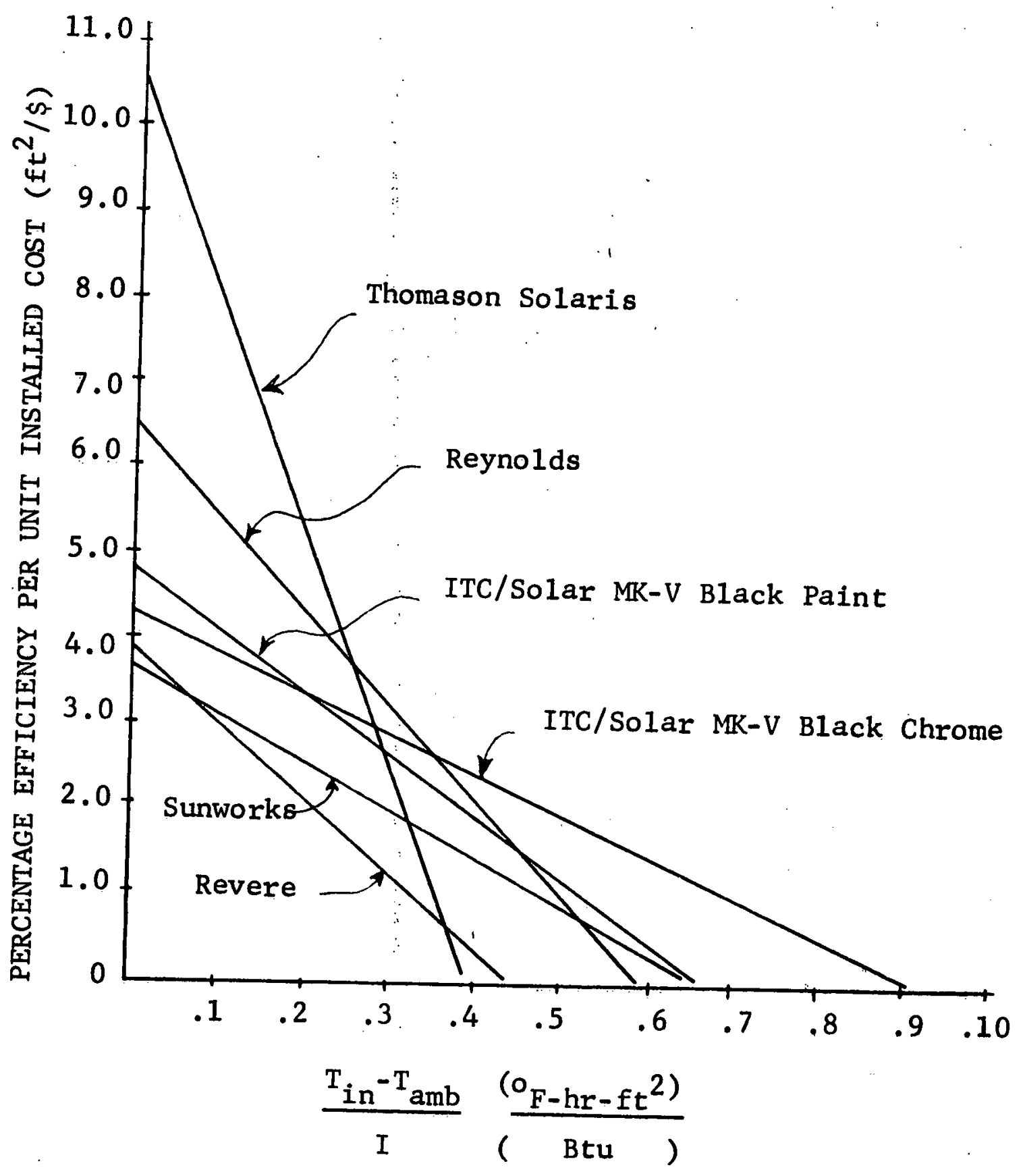

Figure M3.1 Comparison of the Collector Efficiency Per Unit Installed Cost of Six Manufacturers' Single Glazed Collectors.

(All collectors were tested in equivalent $400 \mathrm{ft}^{2}$ arrays.)

Source: Reference 9 


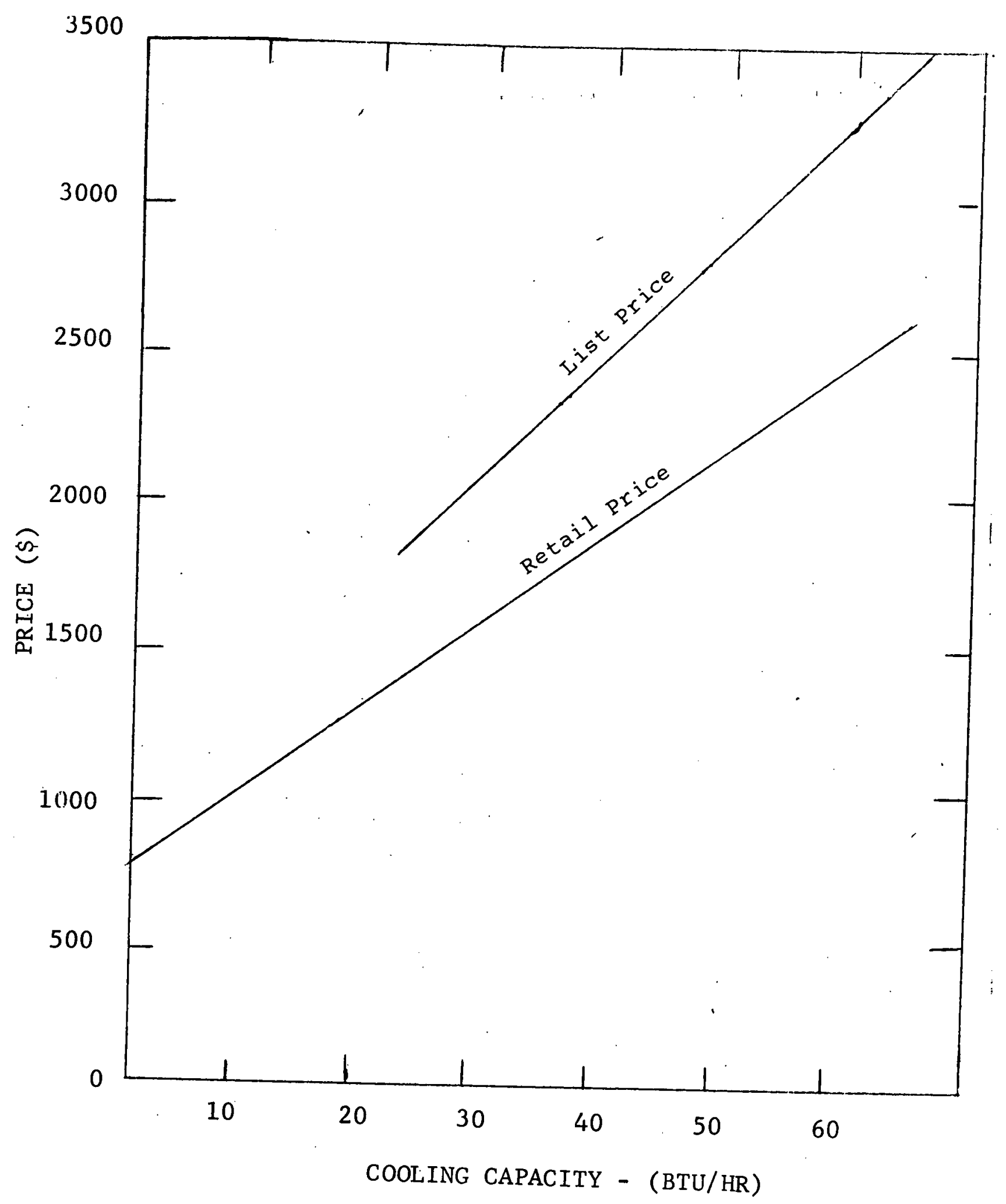

Figure M3.2: Air-to-air Heat pump. Price Versus cooling Capacity (Westinghouse - Fa11, 1975 data)

Source : "Residential Heat Pump Sizing Practices for Northern Climates," T. J. Fagan, Proceedings of the Second Annual Heat Pump Technology Conference, Oklahoma State University, October 18-19, 1976 
CHAPTER M-4

SINGLE FAMILY HVAC MARKET CHARACTERISTICS

\section{Introduction}

Single family housing represents the major future SAHP market. As a base from which to assess this market's potential, data that describe pertinent aspects of it as it exists today were accumulated and analyzed.

The New Single Family Home (NSFH) market was selected as the principal focus of the study. This choice was based on a review of the total U.S. Building construction activity which is shown, for 1978, in Table M4.1.

A SAHP system, by definition, incorporates a heat pump, and a heat pump, as normally defined and typically applied, is primarily an air conditioner which can be "reversed" to provide efficiently a portion of the required heating function. Therefore, the prime market potential would be found among buildings in which there is a high incidence of air conditioning. Table M4.1 shows that Manufacturing, Warehouses, Garages and Service stations are low-incidence users of air conditioning; they constitute only $13 \%$ of the toial floor space awarded, and would constitute only about $5 \%$ of all air conditioned space.

In examining the $87 \%$ of the buildings where there is a high incidence of air conditioning, it is seen that about one third of the total consists of Multi-Family Residential, commercial, and Institutional buildings. However, this group of buildings constitutes an extremely broad spectrum of...

... structure-types -- ranging from spread-out low-rise to urban high-rise

... usage-types -- stores, offices, hospitals, schools, theaters, hotels

... hours of occupancy -- from low-hours schools to continuous-occupancy hotels and hospitals

... heating load characteristics -. all commercial building types generate some portion of their winter heating 
TABLE M4.I

1978 CONSTRUCTION CONTRACT AWARDS

Building Type

Awards

MM Sq.Ft. \% to Total

High-Incidence Air Conditioning- $60 \%$ or More

Residential - Single Family

Residential - Multi Family

Commercial

Institutional

Total High-Incidence
2245

512

584

215

3556
$55 \%$

$13 \%$

$14 \%$

$5 \%$

$87 \%$

Low-Incidence Air Conditioning-30\% or Less

Manufacturing

Warehouses

Garages and Service Stations

GRAND TOTAL

\begin{tabular}{rr}
209 & $5 \%$ \\
251 & $6 \%$ \\
57 & $1 \%$ \\
\hline 4073 & $100 \%$
\end{tabular}

(1)

Totals may not add due to rounding

SOURCE: MCGraw-Hill Information Systems Company,

F.W. Dodge Division, "Dodge Construction Potentials", December, 1978 
requirements because of denser lighting, occupancy, and machinery/appliances; but some buildings, such as office buildings with large core areas, supermarkets with reclamation of heat rejected by refrigeration equipment. classrooms with high-density occupancy can generate a large portion of these requirements especially if heat is reclaimed

... architectural treatment ranging from "fortress" style to "large glass area" style

... and so on

As a result, efforts to delve deeply into these building-types become unproductive because of the over-specialization required to deal with the variabilities of most of the building types or because of the unrepresentativeness that results from successive sieves of narrowing norms which successfully fewer buildings fit.

By contrast, the New Single Family Home (NSFH) market is...

... very large -- constituting about $2 / 3$ of high-incidence air conditioning building types and $55 \%$ of all building types

... relatively homogeneous -- variations tend to occur within fairly narrow ranges, such as size, number of stories, basement versus basementless, which in turn affect heating/cooling capacity within equally narrow ranges and operating characteristics very little

Thus, SAHP systems and equipment evaluated for the NSFH market would be more likely to have universal application, with its attendant economies of mass production manufacture and contractor skills acquisition. In another sense, it might be said that SAHP must first prove viable in the NSFH market where its acceptance would be advanced by these economies of universal application.

The commercial market, on the other hand, requires a greater degree of individual design and specialized equipment because of its greater variability which would tend to exacerbate first cost consideration for a SAHP system. Given that commercial and institutional buildings require relatively less heat, and pay less per unit of energy for that heat, it follows that the greater 
first cost of a SAHP system would have to be amortized over relatively fewer BTU's at a smaller absolute saving per BTU.

Thus, the NSFH market was chosen as the focus of this study.

\title{
Classes of Data
}

Three classes of data were judged necessary to characterize today's single family HVAC market:

\author{
- Fundamental Data \\ - Comparative Data and \\ - Sales Data
}

This chapter explains what these data classes are and which data are included in them. The data that were collected and derived are presented in Table M4.2 at the end of the chapter. The methodology used to obtain these data is described in Appendix 1. Finally, the last section of this chapter outlines the use of the data in the SAHP market evaluation and draws several conclusions about the residential market.

\section{Fundamental Data}

"Fundamental HVAC Market Data" includes stable, non-changing market characteristics such as the number of existing houses in each state, the average state degree days (DD), the UA of an average house, average house heat loads, annual heating to cooling load ratios, and heat pump seasonal performance factors (SPF). These data were collected for the 50 states and the District of columbia, and are tabulated in Columns A-G of Table M4.2.

The number of existing houses shown in column A of Table M4.2 shows the distribution of detached single family residences in the U.S. as of the last census (Reference 10). This represents the potential residential market size.

The average state degree day (DD) values (Column B) are weight averaged on the population distribution throughout the state. A conventional approach was used to calculate these values (Appendix 1). However, they may not be representative of actual 
heating requirements because of the spring and Fall "carry over". That is, little heating or cooling is required when days are warm and nights are cool because the thermal mass of the house averages the internal temperature during these times. Therefore, actual heating and cooling requirements can differ from those predicted by the simple DD approach (DD $\times$ UA $\times 24$ ).

The average house UA values (column $c$ ) are based on fossil fuel heated houses and are regionally, rather than state, averaged values. The UA is the heat loss rate of a house per degree temperature difference between the inside and outside. Basically, these values were calculated from utility company statistical data on the heating fuel consumed per region (References 10-11). (See Appendix 1 for more details). It was assumed in the calculations that the house temperature was $70^{\circ} \mathrm{F}$ and that the internal heat load of the house provides 100 percent of the heat above $65^{\circ} \mathrm{F}$. No consideration was made for lower thermostat settings, for night set back, or for zoning. Therefore, the UA values listed are not only those dictated by, the house construction parameters but also represent the actual heat loss values as governed by occupancy schedules and average house temperatures.

Average house heat load values were calculated for both fossil fuel (Column D) and all-electric (Column E) heated houses on a state-by-state basis. Typical single family housing heat load data for existing houses are not directly available. A common method used to generate these data is to calculate the heat load of a model house with a fixed UA value in the various degree day regions of the country. However, this technique ignores the differences that exist in regional building characteristics. The data collected for this study show that in warmer climates houses tend to be larger and/or more poorly insulated and thus to have higher UA values.

To account for these regional building characteristics, the heat loads of Columns $D$ and $E$ were derived from two items: (1) the annual amount of fuel consumed for space heating; and (2) an estimate of the heating system's seasonal efficiency (See Appendix 1 for details). Data on natural gas consumed for space heating (References 10-11) yielded the annual amount of space heating fuel consumed, on the average, by a single family residence in each state. The seasonal efficiency or annual fuel utilization coefficient, $U_{C}$, of a gas fired heating system was assumed 
to be 0.5 (Reference 12). Typically, present gas heating systems are not significantly more than 50 percent efficient because only approximately half the combustion heat is used by the house; almost half goes up the chimney and is wasted. In contradistinction, electric resistance heating systems have $U_{C}$ values of 1.0 .

Data on oil consumption for space heating of single family houses was difficult to obtain because fuel oil is distributed by many small private dealers. Therefore, it was assumed that the annual heat load for oil heated houses is the same as that for gas heated houses. This assumption is corroborated by the large number of houses that:easily switch from one of these fuels to the other. Furthermore, while electrically heated houses usually have a unique insulation characteristic, no such feature commonly differentiates between gas and oil heated houses.

Data on space heating electricity consumption for all-electric houses were obtained from Reference 13. These data indicate that all-electric houses have lower heat loads than gas heated houses. Improved building practices in all-electric houses account for a substantial amount of this decreased heat load. In addition, individual room zone control may contribute to the reduced heat load. Such reduced heat load building characteristics are indicative of future residential building designs as shown in ASHRAE standard 90-75 and may be a significant factor in SAHP design and marketability.

The annual heating to cooling load ratios of column F were obtained directly from Reference 7; no verification of their accuracy exists. This ratio describes the general relationship between heating and cooling requirements and provides a means for calculating approximate cooling loads.

The seasonal performance factors (SPF) listed in column $G$ for the heat pump are population weighted averages calculated by the ASHRAE bin method using DD values and a three ton singer Model H-R553086 air-to-air heat pump. As previously discussed, the heating $D D$ values in the Spring and Fall do not necessarily agree with actual heating requirements. Thus, the bin calculation may assume that the heat pump operates during more hours of moderate weather than it actually does and, consequently, may yield somewhat high SPF values. In addition, because the SPF values calculated by the bin method do not reflect the effects of defrost or 
of cycling losses, they are somewhat inflated.

Comparative Data

"Comparative Data" includes data that delineate the total cost of owning and operating the various conventional HJAC systems. These data are divided into two categories: (1) the initial cost of purchasing and installing the systems and (2) the annual costs of heating with the systems.

Since initial system costs do not vary much across the U.S., they are not included in Table M4.2. Instead, they were collected from HVAC contractors and home builders in five U.S. cities and are presented for gas, oil, electric resistance, the heat pump systems in Tables $M 1$ and M2 of Appendix 2. These system costs reflect the HVAC costs for houses built boch individually and for development tracts. In general, HVAC system costs are generally lower in tract construction than in individual construction. Thus, it is important to state the origin of system costs in all life cycle cost analyses. All cost data in this study, with the exception of the Fort Worth and Dallas data, are based on individual construction.

HVAC operating costs are a function of the heat load, the system efficiency, and the cost of fuel. The latter two quantities are combined (Columns $H-K$ ) to give the "utilized cost of fuel". This is the price the consumer pays for the heat content of the fuel that enters the conditioned space and is obtained by dividing the cost of the fuel by the heating system's efficiency, $U_{C}$. (Recall that for gas and oil systems, $U_{C}=0.5$; for all-electric systems, $U_{C}-1.0$; and for heat pump systems, $\left.U_{C}=S P F.\right)$

The annual cost of heating with the various systems (Columns $L-O$ ) can now be calculated as the product of the utilized fuel cost and the annual heat load. It should be noted that the heat pump operating costs of column $N$ are based on heat loads of fossil fuel heated houses and thus cannot be compared to the annual operating costs of electrically heated houses which usually have smaller heat loads.

\section{Sales Data}

"Sales Data" includes the actual volume of sales of HVAC systems, 
a quantity which results from the interaction of the fundamental and comparative characteristics. In this study, these data are presented in two forms, the distribution of existing conventional HVAC systems (Columns $P-R$ ) and the sales of central heat pump and air conditioning systems sold for residential use (Columns S-T).

The latter data represent the market where air conditioning is required and non-fossil fuel heating is accepted and thus the most likely SAHP market. They are limited to the sales of split system air-to-air air conditioners $(A / C)$ and heat pumps (HP) (References 14-15) under five ton cooling capacity because these units comprise the bulk of systems sold in the residential market.

\section{Summary}

HVAC marketing data were collected for the 50 states to establish a base from which to assess the SAHP system's market potential. The data base includes the heat pump as well as conventional gas, oil, and all-electric heating systems because, in many areas of the country, heat pumps are competitive with the other systems and, in fact, are increasingly considered "conventional" by the HVAC industry in these areas. In addition, the heat pump is $a$ particularly appropriate standard to which SAHP systems can be compared because: (1) it is included, by definition, in the...: SAHP system and thus serves as a means of determining the cost increment associated with the solar assist, and (2) both systems are "fueled" by electricity and thus the sensitivity of a cost comparison of the systems to assumptions of future fuel costs is reduced.

The data base, coupled with calculation methods described above are used in a unique way to generate the single family residential market information used throughout this study. For example, the average house UA values used in the Analytical Model were taken from Table M4.2. In addition, eleven of the data types of this table were used in an analysis, described in Chapter $M-6$, to determine the key factors affecting heat pump sales. Data which were not used in this marketing study (primarily the distribution of heating systems throughout the U.S.) are included in Table M4.2 for their archival valve.

Generally, the data of Table M4.2 show favorable gas heating costs, supporting the popular usage of this type of system. 
High heat pump sales are shown, however, not to correlate to low heat pump energy costs. This latter fact is accentuated by the results of the next chapter. 
TABLE M 4.2a - SINGLE FAMILY DETACHED RES IDENCE CHARACTER IST ICS (1977)

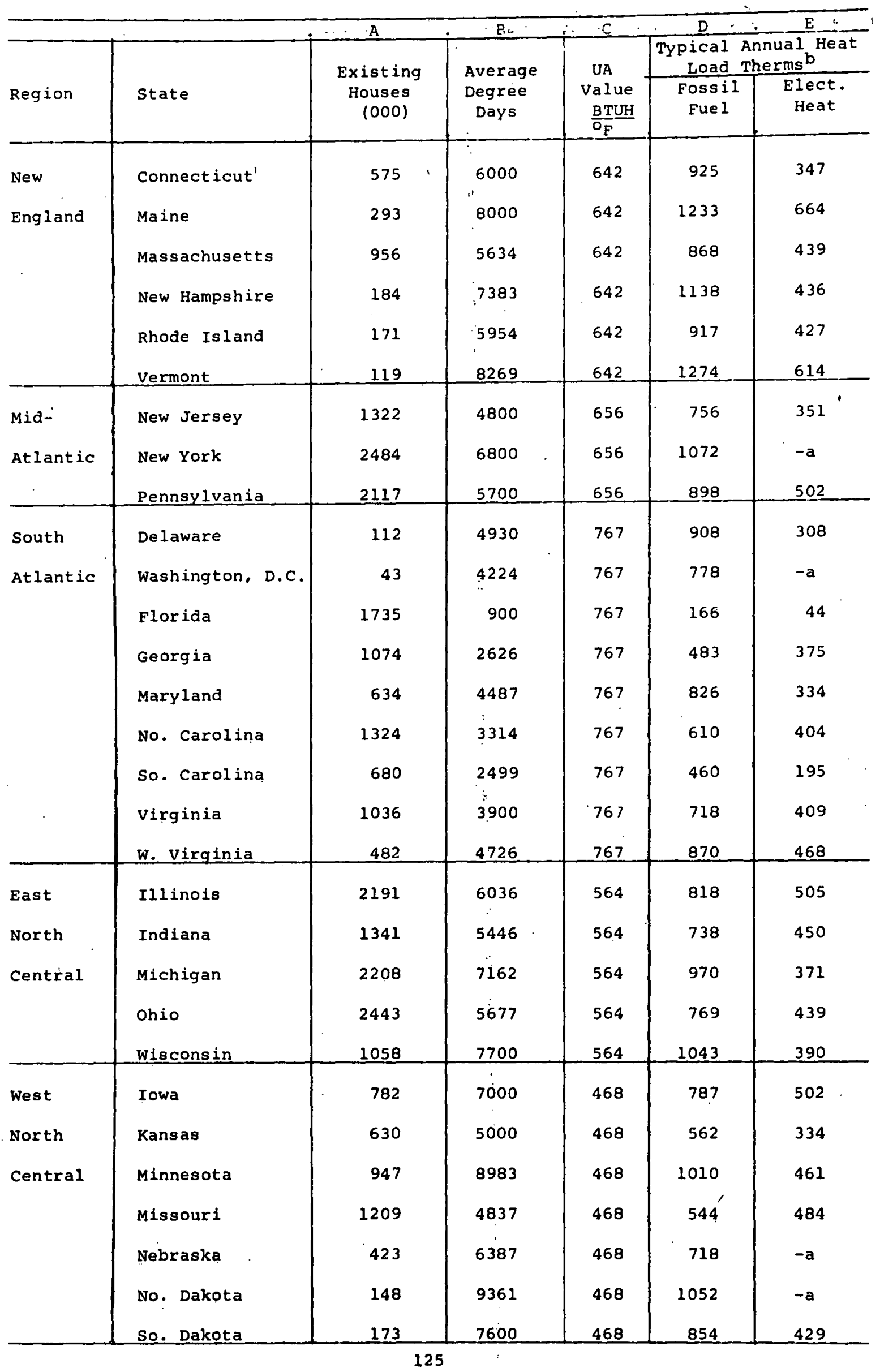


TABLE M 4.2a - SINGLE FAMILY DETACHED RES IDENCE CHARACTERISTICS (1977)

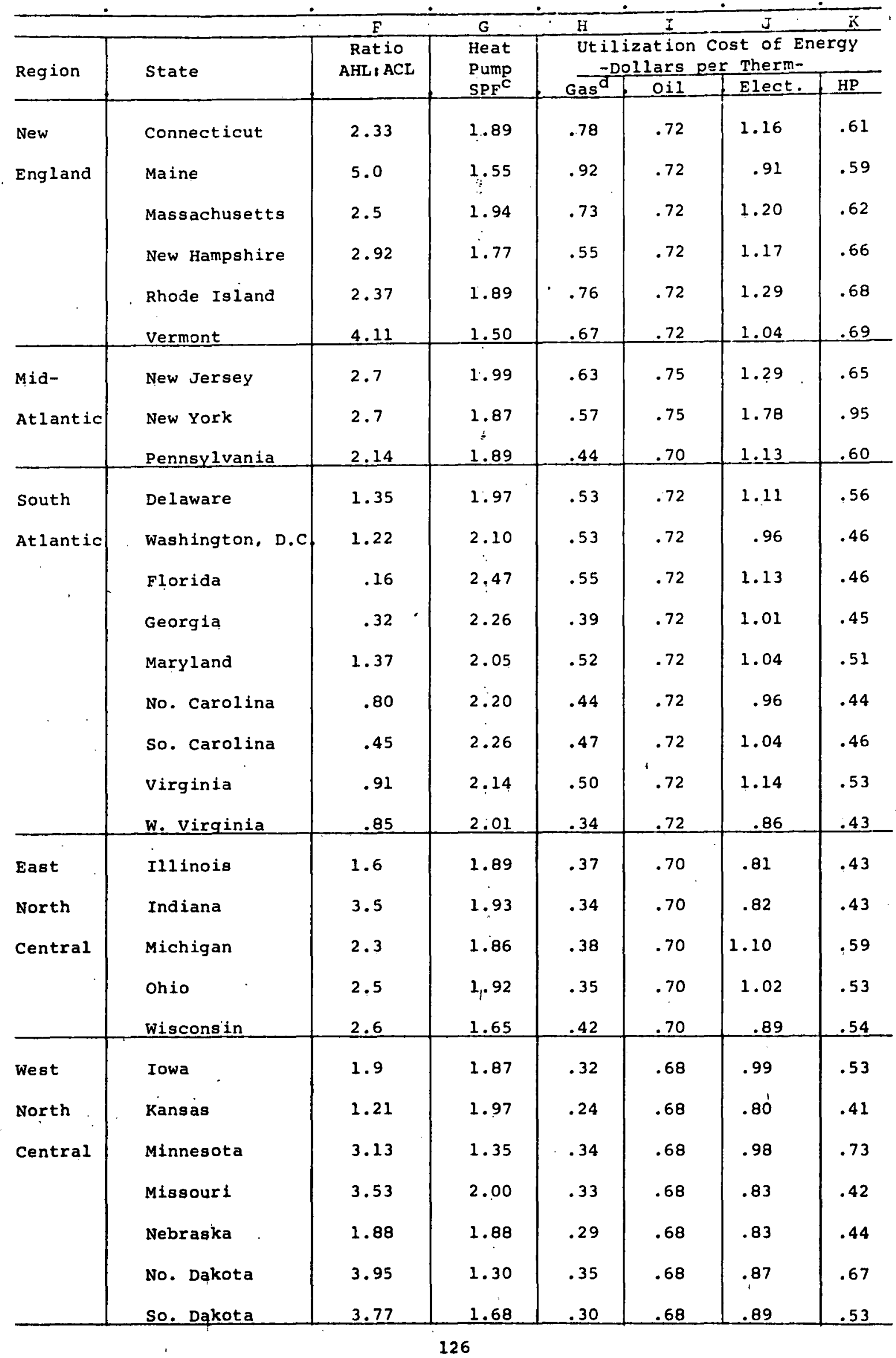


TABLE M4.2a - SINGLE FAMILY DETACHED RES IDENCE CHARACTERISTICS (1977)

\begin{tabular}{|c|c|c|c|c|c|}
\hline & & L & $M$ & N & 0 \\
\hline \multirow[t]{2}{*}{ Region } & \multirow[t]{2}{*}{ State } & \multicolumn{4}{|c|}{$\begin{array}{c}\text { Average Annual Heating cost } \\
\text {-Dollars- }\end{array}$} \\
\hline & & Gas $^{\mathrm{E}}$ & $0 i 1^{e}$ & $\mathrm{HP}^{\mathrm{E}}$ & Elec. ${ }^{\mathrm{t}}$ \\
\hline New & Connecticut & 722 & 666 & 564 & 403 \\
\hline \multirow[t]{5}{*}{ England } & Maine & 1134 & 888 & 728 & 405 \\
\hline & Massachusetts & 626 & 618 & 532 & 527 \\
\hline & New Hampshire & 626 & 819 & 751 & 510 \\
\hline & Rhode Island & 697 & 660 & 624 &, 551 \\
\hline & Vermont & 854 & 917 & 879 & 639 \\
\hline Mid- & New Jersey & 476 & 567 & 491 & 453 \\
\hline \multirow[t]{2}{*}{ Atlantic } & New York & 611 & 804 & 1018 & $-a$ \\
\hline & Pennsylvania & 395 & 629 & 539 & 567 \\
\hline South & Delaware & 481 & 654 & 508 & 342 \\
\hline \multirow[t]{8}{*}{ Atlantic } & , washington, D.C. & 412 & 560 & 358 & $-a$ \\
\hline & Florida & 91 & 120 & 76 & 50 \\
\hline & Georgia & 188 & 348 & 217 & 379 \\
\hline & Maryland & 430 & 595 & 421 & 347 \\
\hline & No. Carolina & 268 & 439 & 268 & 388 \\
\hline & so. Carolina & 216 & 331 & 212 & 203 \\
\hline & Virginia & 359 & 517 & 381 & 466 \\
\hline & w. Virqinia & 296 & 626 & 374 & 402 \\
\hline East & Illinois & 303 & 573 & 352 & 409 \\
\hline North & Indiana & 251 & 517 & 317 & 369 \\
\hline \multirow[t]{3}{*}{ Central } & Michigan & 369 & 679 & 572 & 408 \\
\hline & Ohio & 269 & 538 & 408 & 470 \\
\hline & wiscons in & 438 & 730 & 563 & 347 \\
\hline West & Iowa & 252 & 535 & 417 & 497 \\
\hline North & Kansas & 135 & 482 & 230 & 267 \\
\hline \multirow[t]{5}{*}{ Central } & Minnesota & 343 & 687 & 737 & 452 \\
\hline & Missouri & 180 & 370 & 228 & 402 \\
\hline & Nebraska & 208 & 488 & 316 & $-a$ \\
\hline & No. Dakota & 368 & 715 & 705 & $-a$ \\
\hline & So. Dakota & 256 & 581 & 453 & 382 \\
\hline
\end{tabular}




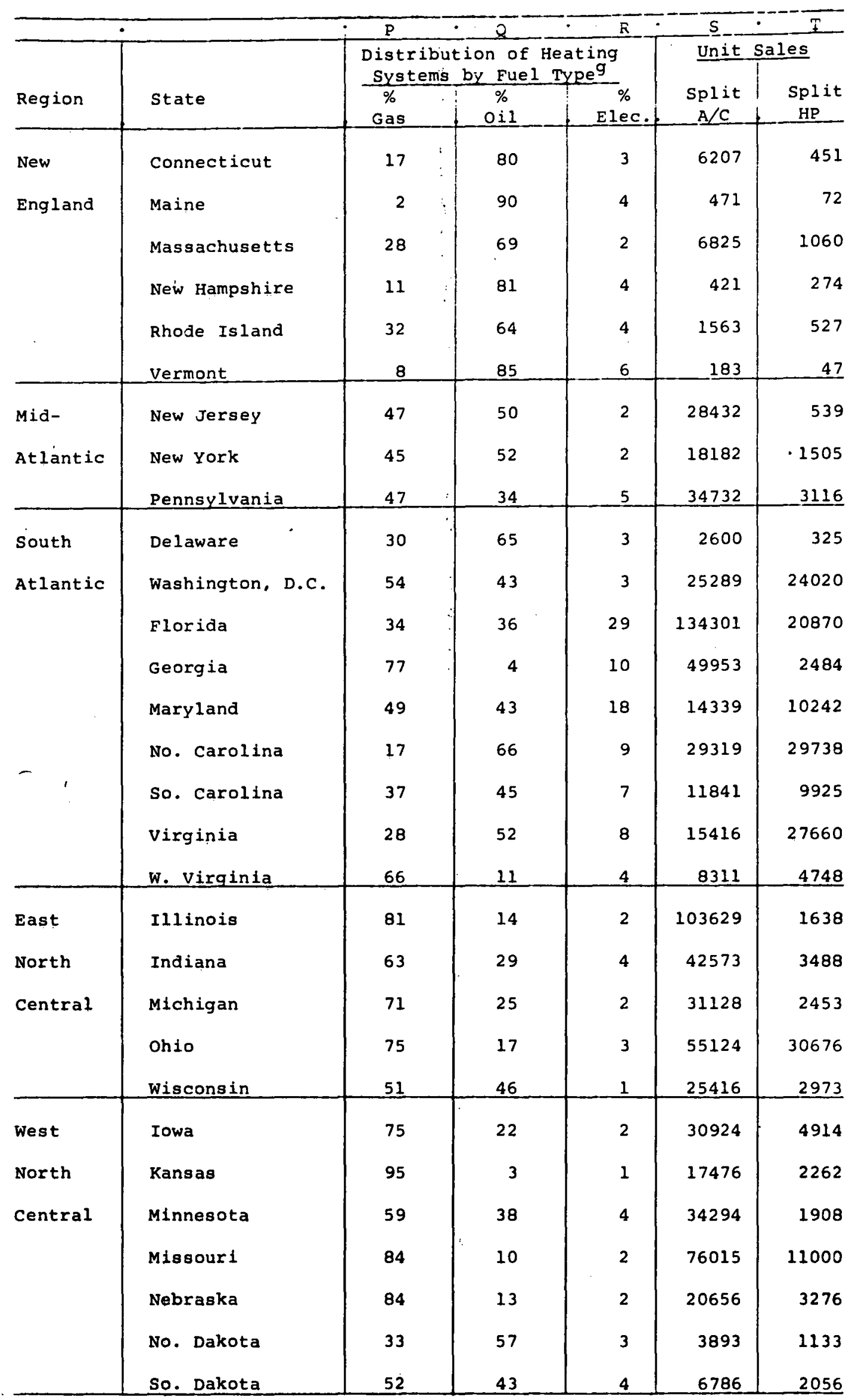


'PABLE M4.2b - SINGLE FAMILY DETACHED RES IDENCE CHARACTERISTICS (1977)

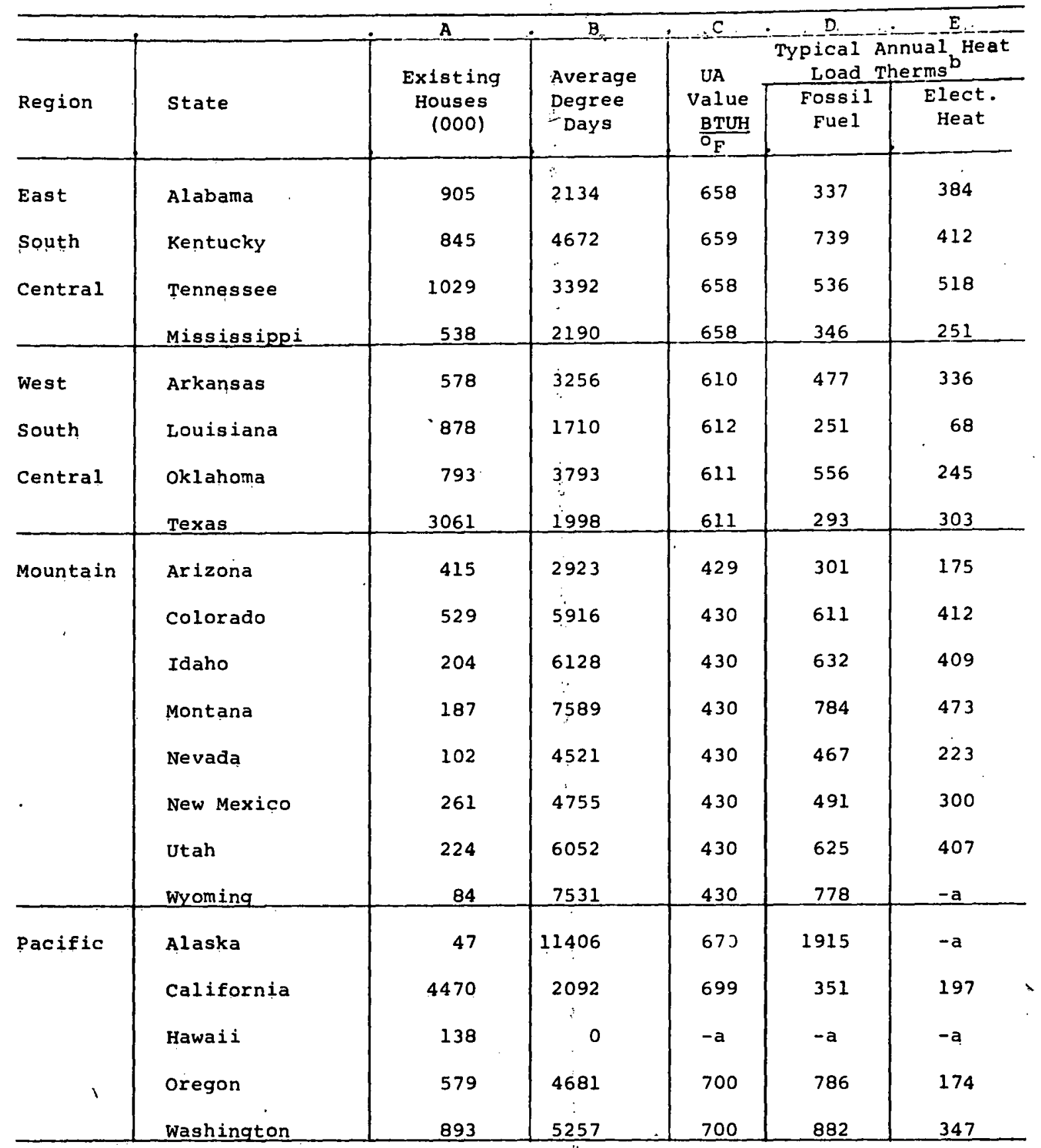




\begin{tabular}{|c|c|c|c|c|c|c|c|}
\hline & \multirow{3}{*}{ state } & & \multirow{3}{*}{$\begin{array}{l}\text { Heat } \\
\text { Pump } \\
\text { SPPF }\end{array}$} & $H$ & $I$ & $I$ & $\mathrm{~K}$ \\
\hline \multirow[t]{2}{*}{ Region } & & \multirow[t]{2}{*}{$\begin{array}{c}\text { Rat io } \\
\text { AHL : ACL }\end{array}$} & & \multicolumn{4}{|c|}{$\begin{array}{l}\text { Utilization Cost of Energy } \\
\text {-Dollars per Therm }\end{array}$} \\
\hline & & & & $\mathrm{Gas}^{\mathrm{a}}$ & 으느 & Elec. & HP \\
\hline East & Alabama & .46 & 2.27 & .38 & .69 & .92 & .41 \\
\hline South & Kentucky & 1.08 & 2.03 & .30 & .69 & .71 & .35 \\
\hline \multirow[t]{2}{*}{ Central } & Tennessee & .60 & 2.20 & .30 & .69 & .66 & .30 \\
\hline & Mississippi & .40 & 2.27 & .33 & .69 & 1.00 & .44 \\
\hline West & Arkansas & .56 & 2.20 & .25 & .65 & .81 & .37 \\
\hline South & Louisiana & .38 & 2.30 & .30 & .65 & .84 & .37 \\
\hline \multirow[t]{2}{*}{ Central } & oklahoma & .75 & 2.16 & .29 & .65 & .84 & .39 \\
\hline & Texas & 1.4 & 2.29 & .40 & .65 & .96 & .42 \\
\hline \multirow[t]{8}{*}{ Mountain } & Arizona & 1.20 & 2.24 & .43 & .69 & 1.20 & .54 \\
\hline & colorado & 5.1 & 1.89 & .26 & .69 & .87 & .46 \\
\hline & Idaho & 4.5 & 1.89 & .54 & .69 & .52 & .28 \\
\hline & Montana & 4.4 & 1.69 & .30 & .69 & .57 & .34 \\
\hline & Nevada & 2.5 & 2.05 & .35 & .69 & .92 & .45 \\
\hline & New Mexico & 1.91 & 2.01 & .32 & .69 & .95 & .47 \\
\hline & Utah & 3.25 & 1.89 & .29 & .69 & .69 & .37 \\
\hline & Wyoming & 7.52 & 1.70 & .25 & .69 & .62 & .36 \\
\hline \multirow[t]{5}{*}{ Pacific } & Alaska & $-a$ & $-a$ & .33 & .74 & .78 & $-a$ \\
\hline & California & 1.00 & 2.28 & .34 & .74 & .99 & .43 \\
\hline & Hawaii & $-a$ & $-a$ & 1.61 & .74 & 1.30 & $-a$ \\
\hline & oregon & 4.95 & 2.02 & .58 & .74 & .66 & .33 \\
\hline & washington & 8.4 & 1.95 & .52 & .74 & .33 & .17 \\
\hline
\end{tabular}




\begin{tabular}{|c|c|c|c|c|c|}
\hline \multirow{3}{*}{ Region } & \multirow{3}{*}{ State } & L & M. & $\underline{N}$ & 0 \\
\hline & & \multicolumn{4}{|c|}{$\begin{array}{c}L \text { Average Annual Heat ing Cost } \\
\text {-Dollars- } \\
\text { - }\end{array}$} \\
\hline & & $\mathrm{Gas}^{\mathrm{e}}$ & o ${ }^{i} 1^{e}$ & & Elec. $\mathrm{f}$ \\
\hline East & Alabama & 128 & 233 & 138 & 353 \\
\hline South & Kentucky & 222 & 510 & 259 & 293 \\
\hline \multirow[t]{2}{*}{ Central } & Tennessee & 161 & 370 & 161 & 342 \\
\hline & Mississippi ' & 114 & 239 & $1 \frac{52}{52}$ & 251 \\
\hline West & Arkansas & 119 & 310 & 176 & 272 \\
\hline South & Louisiana & 75 & 163 & 93 & 57 \\
\hline \multirow[t]{2}{*}{ Central } & Oklahoma & 161 & 361 & 217 & $-a$ \\
\hline & Texas & 117 & 190 & 123 & 260 \\
\hline \multirow[t]{8}{*}{ Mountain } & Arizona & 129 & 208 & 163 & 210 \\
\hline & Colorado & 159 & 422 & 281 & 358 \\
\hline & Idaho & 341 & 436 & 177 & 213 \\
\hline & Montana & 235 & 541 & 267 & 270 \\
\hline & Nevada & 163 & 322 & 210 & 205 \\
\hline & New Mexico & 157 & 339 & 231 & 337 \\
\hline & Utah & 181 & 431 & 231 & 232 \\
\hline & Wyoming & 195 & 537 & 280 & $-\mathrm{a}$ \\
\hline \multirow[t]{5}{*}{ Pacific } & Alaska & 1494 & 1417 & $-a$ & $-a$ \\
\hline & California & 119 & 260 & 151 & 195 \\
\hline & Hawa i $i$ & $-a$ & $-a$ & $-a$ & $-a$ \\
\hline & Oregon & 456 & 512 & 259 & 115 \\
\hline & Washington & 459 & 653 & 150 & 115 \\
\hline
\end{tabular}




\begin{tabular}{|c|c|c|c|c|c|c|}
\hline & \multirow[b]{3}{*}{ State } & $P$ & 8 & $R$ & $\mathrm{~S}$ & $T$ \\
\hline \multirow[b]{2}{*}{ Region } & & \multicolumn{3}{|c|}{$\begin{array}{l}\text { Distribution of Heating } \\
\text { systems by Fuel Type }\end{array}$} & \multicolumn{2}{|c|}{ Unit Sales } \\
\hline & & $\begin{array}{c}\% \\
\text { Gas } \\
\end{array}$ & $\begin{array}{r}\% \\
0 \text { il } \\
\end{array}$ & $\begin{array}{c}\% \\
\text { Elesc }\end{array}$ & $\begin{array}{l}\text { Split } \\
\mathrm{A} / \mathrm{C}\end{array}$ & $\begin{array}{c}\text { Split } \\
\text { HP }\end{array}$ \\
\hline East & Alabama & 74 & 1 & 12 & 37576 & 15199 \\
\hline South & Kentucky & 64 & 9 & 8 & 19958 & 18089 \\
\hline \multirow[t]{2}{*}{ central } & Tennessee & 36 & 6 & 41 & 28354 & 16823 \\
\hline & Mississippi & 77 & -a & 12. & $114 \underline{523}$ & $2 \underline{8} 6 \underline{6}$ \\
\hline West & Arkansas & 85 & 1 & 4 & 23044 & 5570 \\
\hline South & Louisiana & 94 & $-a$ & 4 & 66952 & 4376 \\
\hline \multirow[t]{2}{*}{ Central } & oklahoma & 94 & $-a$ & 3 & 41835 & 5033 \\
\hline & Texas & 94 & -a․ & 5 & 274176 & _1 97709 \\
\hline \multirow[t]{8}{*}{ Mountain } & Arizona & 87 & $-a$ & 9 & 9606 & 2424 \\
\hline & colorado & 94 & 2 & 1 & 7200 & 1616 \\
\hline & Idaho & 27 & 47 & 8 & 3327 & 2121 \\
\hline & Montana & 79 & 17 & 1 & 1905 & 379 \\
\hline & Nevada & 54 & 15 & 30 & 3562 & 624 \\
\hline & New Mexico & 89 & 2 & 3 & 2274 & 458 \\
\hline & Utah & 88 & 4 & 1 & 7958 & 646 \\
\hline & Wyoming & 91 & 3 & 1 & 386 & 7 \\
\hline \multirow[t]{5}{*}{ Pacific } & Alaska & 15 & 69 & 5 & $-a$ & $-a$ \\
\hline & California & 93 & 1 & 5 & 134205 & 11115 \\
\hline & Hawaii & 22 & $-a$ & 56 & $-a$ & $-a$ \\
\hline & oregon & 28 & 41 & 25 & 4902 & 6635 \\
\hline & washington & 27 & 45 & 25 & 6359 & 3622 \\
\hline
\end{tabular}


a. Data not available

b. 1 Therm $=10^{5}$ BTU

C. SPF values are based on the performance of the Singer Model \# H-R553036 air-to-air heat pump.

d. Values for gas utilization cost are based or 1976 data.

e. Annual. Heating cost is based on the heat load of a fossil fuel heated house (Column D).

f. Annual Heating cost is based on the heat load of an electric resistance heated house (Column E).

9. The distribution of heating systems by fuel type is based on existing houses. Approximately $49 \%$ of these systems are forced air systems. The remaining $51 \%$ deliver energy via water or electric baseboard heaters. 


\title{
CHAPTER M-5
}

\author{
LCC ANALYSIS IN SELECTED CITIES
}

\section{Introduction}

An underlying assumption in the assessment of system marketability is that an energy conserving system that has high up front costs such as the solar assisted heat pump (SAHP) will be marketable only if its life cycle costs (LCC) are less than those of competing HVAC systems. The primary LCC analyses and comparisons of this study were obtained from the Analytical Model program; to retain generality, these analyses used the regional data of Chapters $M-3$ and $M-4$. The results of the Analytical Model are based upon the thermal and economic performance of very simple "generic" systems that are amenable to simple and rapid mathematical analysis.

The rather general results of the Analytical Model are complemented by results derived in this shapter from data collected on the cost and performance characteristics of actual systems in specific locations. Actual system data offer an opportunity to check the correlation between life cycle cost and marketability. This correlation is crucial to the assessment of the future marketability of SAHP systems.

Two classes of actual systems were studied in this program. In the first of these, detailed LCC data were collected for newly constructed houses in three U.S. cities - Fort worth, TX, Dallas, TX, and Madison, WI - for gas, oil, electric resistance, and heat pump heating systems. Each of the systems' life cycle costs was then calculated and compared to its unit sales volume in the specific cities. In the second class studied, life cycle costs were calculated for a heat pump system that cooled as well as heated, a mode of operation not considered in the Analytical Model Program.

In general, the house heating and cooling loads used in the LCC analyses of this chapter are based on well insulated, all-electric houses. (The one exception is Madison, WI, for which loads of all-electric houses were unavailable.) Since loads of all-electric houses are typically lower than those of fossil fiel heated houses, the LCC results presented here for the fossil fuel houses might be low. However, insulation levels in new houses, and thus 
heating and cooling loads, are similar in both fossil fuel and ali-electric houses. Therefore, the load difference has been ignored in this study.

Localized Data - 3 cities

City LCC data, rather than statewide averages, are required to determine the relationship between 1 ife cycle costs and sales volumes of competing HVAC systems. The use of statewide average LCC and sales data could distort the results of the analyses since factors that influence HVAC performance and cost, such as fuel cost and availability, vary significantly within a state. These variations will influence the sales distribution. When the ICC's of competing heating systems are compared, however, with the HVAC sales in a single city where the HVAC market characteristics can be closely observed, the results become meaningful.

The data required to calculate the I.CC of conventional HVAC systems were obtained using the methodology outlined in Appendix 2 . Using this medhodology, telephone surveys were conducted in the cities of Dallas, TX, Fort Worth, TX, and Madison, WI. The data resulting from these surveys are shown in Table M-1 of Appendix 2. The neighboring cities of Fort worth and Dallas were chosen because they delineate the effects of the fuel cost difference within a state. Although these two cities share the same climate and initial system costs. the difference in the costs of gas and electricity between them results in a significant difference in heating system sales.

Appendix 2 also contains the methodology used to calculate the life cycle costs of the primary heating systems used in new single family housing (NSFH) in each of the three cities. These life cycle costs are expressed in terms of their present values. The present value of the LCC is the amount of money required at the beginning of a system's operation which, if invested at the discount rate, would pay for all costs of purchasing and operating the system throughout its lifetime:

In the LCC computations, the initial system costs are based on HVAC contractor's estimates and do not reflect the additional building costs of chimneys when fossil fuel heating systemis are used and the higher insulation levels when electric heating systems are used. In addition, salvage values are not considered in the analyses because HVAC components depreciate in a complex 
and uncertain manner. Note, however, that because the salvage value is accrued at the end of the system lifetime, it contrib-utes only insignificantly to the present value of the system's life cycle cost. Omitting salvage values tends to favor solar over conventional systems because the latter have a larger fraction of costly long-lived components.

The results for the major HVAC systems in each of the three cities surveyed are shown in Tables M5.1-M5.3. In Fort worth, the results of the HVAC LCC calculations (Table M5.1) reflect the effects of the relatively low cost of electricity compared to that of natural gas. Consequently, the ranking of systems by LCC places the HP first (lowest LCC), followed oy electric resistance heat $\left(I^{2} \mathrm{R}\right)$, and then by gas. (Note, irtually no iNSFH are built with oil heat in this area.) The sales data show that, in Fort Worth, electric resistance heat dominated the NSFH space heating market in 1977 and 1978. However, some of the major builders indicate that the HP will take a significant share of the market in 1979. Thus, in Fort worth, the conventional systems to which SAHP systems must be compared will be the $A P$ and $I^{2} R$. Both systems should be considered because, while HP's have the lower LCC $I^{2} \mathrm{R}$ represents nearly the entirely existing HVAC market.

The HVAC LCC calculations in Dallas, as shown in Table M5.2, rank gas first (lowest LCC), followed by the HP and electric cesistance. It is noteworthy that, although the first ranked system (gas) did dominate the HVAC market as hypothesized, more electric resistance heaters were sold than heat pumps. This may indicate that consumer and builder preferences are presently guided more by initial cost than by LCC.

In the third area considered, Marison, WI, the LCC calculation summarized in Table M5.3, ranks gas first (lowest LCC), followed by HP, oil, and finally $I^{2} \mathrm{R}$. The HVACmarket in 1977 and 1978 for NSFH was predominately gas. However, as in the Texas cities, fewer HP's were sold than the lower LCC ranked oil and electri= re-sistance heating systems.

\section{Correlation Between LCC and Sale}

As noted above, the results of the LCC analyses were not entirely consisient with the assumption that HVAC systems with the lowest LCC have the highest probability of success in the marketplace. 
Although the HVAC systems with the lowest LCC usially had the highest sales volume, the remaining HVAC systems sales volume were not related to LCC ranking. In particular, HP sales did not seem to be directly related to LCC. A study to determine what factors do influence HP sales is discussed in the following chapter.

\section{Life Cycle costs - Heat Pumps}

A second LCC study, analyzing life cycle costs which include the cooling as well as heating costs of conventional heat pump systems, was carried out to complement the work of the Analytical Model. Basic data were collected and tabulated for three cities (Madison, WI, Nashville, TN, and New York, NY) that represent major market areas. Those data are tabulated in Appendix 2. The results of the heat pump study are given in Table M5.4.

\section{Cooling Load Data}

The life cycle cost analys is presented here is sensitive to the method used in calculating cooling loads. One conventional method is the Degree Day Method which involves miltiplying the house UA value* by the cooling Degree Days. However, cooling degree days cannot be used independently in cooling load calculations because the cooling load is a function of the enthalpy, which is dependent on humidity - as well as on temperature. In addition, in the spring and Fall, when days are warm and nights cool, the thermal mass of the house averages the internal temperature. producing a cooling load lower than that predicted by the Degree Day Method.

Another method of obtaining cooling loads is to use utility company statistical data; this method was used in this analysis. To convert utility data into cooling loads and electrical usage, the seasonal EER (SEER) must be available (Appendix 2). Since utility companies would not normally maintain data on SEER values for their areas, and did not in the case of those surveyed reasonable SEER's were estimated for each city.

One shortcoming of deriving cooling loads from dtility data is the

*The UA valve is the heat loss rate from a house per degree temperature difference between the inside and outside. 
inherent inaccuracy of basing present and future cooling load calculations on past air conditioning usage patterns. The residential HVAC market is cost sensitive; when energy was generally cheap, little regard was shown for wasted energy and residential consumers habitually maintained excessive comfort levels. However, as the cost of energy has grown, so has interest in such energy saving techniques as setback thermostate, insulation, and more conservative comfort conditions. The relationships of residential air conditioning use to electricity costs is not vlearly known. It is, therefore, difficult to determine the annual cooling loads from utility data.

\section{$\underline{\text { Results }}$}

The results of the heat pump LCC calculations for the three locations are shown in Table M5.4. Although the Analytical Model used a statewide average UA value for existing fossil fuel houses for its LCC calculations, it is of interest to compare the LCC's derived from it to these resilts. In all cases, the Analytical Model predicted a higher present value of the LCC for space heating (New York: $\$ 24,666$; Nashville: $\$ 10,560$; Madison: $\$ 17,430$ ) because the average UA values used in it are higher than the values encountered in the present study, which was limited to new and, hence, better insulated housing. Also, the present calculations used as recommended in Reference $17,0.025$ as the annual fuel escalation rate, $F$, and 0.01 as the annual worth of money, $I$ instead of 0.045 and 0.02 , respectively, used in the Analytical Model analyses. In general, at these low rates the LCC is dependent on the difference between $F$ and $I$. The lower values of LCC calculated in this chapter are due in part to the 0.01 reduction in the difference between $F$ and $I$.

An important point regarding the LCC and marketability of heat pumps should be borne in mind. Heat pumps provide cooling; thus their effective LCC for heating should be reduced becaise a part of the system cost can be apportioned to cooling, a function not provided by stand-alone solar, gas, or electric resistance heating. Therefore, the effective heating system cost of a heat pump system in a climate requiring air conditioning would be the heat pump cost less the cost of a comparable central air conditioner.

\section{Summary}

Two ancillary LCC analyses were performed and are presented in 
this chapter. Both used HVAC cost and performance data collected for specific locations so that distortions caused by the use of broad averages could be eliminated. One of the analyses; performed strictly to complement: the results of the Analytical Model, developed LCC's which included the cooling as well as the heating costs of a stand-alone heat pump. One. important conclusion of this analysis is that a large difference can exist between LCC's calculated on the basis of regionally averaged, fossil fuel heated, existing housing data (the Analytical Model) and locally averaged, electric resistance heated, new housing data (the present study). Thus, both the data base and the future destination of the HVAC system (i.e., retrofit or new house market) must be clearly stated in all LCC studies.

The results of the other LCC analysis indicate that the sales of HVAC systems, and in particular the sales of HP systems, are not directly related to the ICC of these systems. This is explored more fully in the following chapter which presents the results of a correlation analysis between HP sales and selected marketing data. 


\begin{tabular}{|c|c|c|c|c|}
\hline & \multicolumn{4}{|c|}{ Method of Heating } \\
\hline & Gas & $\mathrm{I}^{2} \mathrm{R}$ Electric & Heat Pump & Oil \\
\hline $\begin{array}{c}\text { Initial System } \\
\text { Cost }\end{array}$ & $\$ 1875$ & $\$ 1675$ & $\$ 2375$ & $\mathrm{NA}$ \\
\hline Cost of Fuel ${ }^{2}$ & $0.266 c / C F$ & $2 c / k w h$ & $2 c / k w h$ & NA \\
\hline $\begin{array}{c}\text { Annual Heating } \\
\text { Cost }\end{array}$ & $\$ 238$ & $\$ 262$ & $\$ 125$ & NA \\
\hline $\begin{array}{c}\text { LCC }^{3} \\
\text { (Present Value) }\end{array}$ & $\$ 7906$ & $\$ 7263$ & $\$ 6119$ & NA \\
\hline $\begin{array}{r}\text { Volume of Sales }{ }^{4}-1977 \\
1978\end{array}$ & $\begin{array}{l}68 \\
44\end{array}$ & $\begin{array}{r}687 \\
1631\end{array}$ & $\begin{array}{l}41 \\
89\end{array}$ & $\begin{array}{l}0 \\
0\end{array}$ \\
\hline
\end{tabular}

Notes :

1. Includes the cost of central air conditioning.

2. The cost of fuel is averaged over the typical heating load.

3. Economic parameters used are given in Appendix 2 .

4. Values represent the 1977-1978 sales to new single family housing construction.

5. Virtually no oil heated houses are built in Fort worth. 


\begin{tabular}{|c|c|c|c|c|}
\hline & Gas & $\begin{array}{r}\text { Method } \\
\mathrm{L}^{2} \mathrm{R} \quad \text { El ectric } \\
\end{array}$ & $\begin{array}{l}\text { Heating } \\
\text { Heat Pump }\end{array}$ & Oil \\
\hline $\begin{array}{c}\text { Initial System } \\
\text { Cost }\end{array}$ & $\$ 1875$ & $\$ 1675$ & $\$ 2375$ & $\mathrm{NA}$ \\
\hline Cost of Fue ${ }^{2}$ & $0.182 c / C F$ & $3.69 \mathrm{c} / \mathrm{kwh}$ & $3.69 \mathrm{c} / \mathrm{kwh}$ & NA \\
\hline $\begin{array}{l}\text { Annual Heating } \\
\text { Cost }\end{array}$ & $\$ 163$ & $\$ 485$ & $\$ 231$ & $\mathrm{NA}$ \\
\hline $\begin{array}{c}\text { LCC }^{3} \\
\text { (Present Value) }\end{array}$ & $\$ 6413$ & $\$ 11034$ & $\$ 7916$ & $\mathrm{NA}$ \\
\hline $\begin{array}{r}\text { Volume of Sales }{ }^{4}-1977 \\
1978\end{array}$ & $\begin{array}{l}2105 \\
2523\end{array}$ & $\begin{array}{l}245 \\
617\end{array}$ & $\begin{array}{r}30 \\
\times \quad 39\end{array}$ & $\begin{array}{l}\dot{N} A \\
N A\end{array}$ \\
\hline
\end{tabular}

\section{Notes :}

1. Includes the cost of central air conditioning.

2. The cost of fuel is averaged over the typical heating.load.

3. Economic parameters used are given in Appendix 2.

4. Values represent the 1977-1978 sales to new single family housing construction.

5. Virtually no oil heated houses are built in Dallas. 


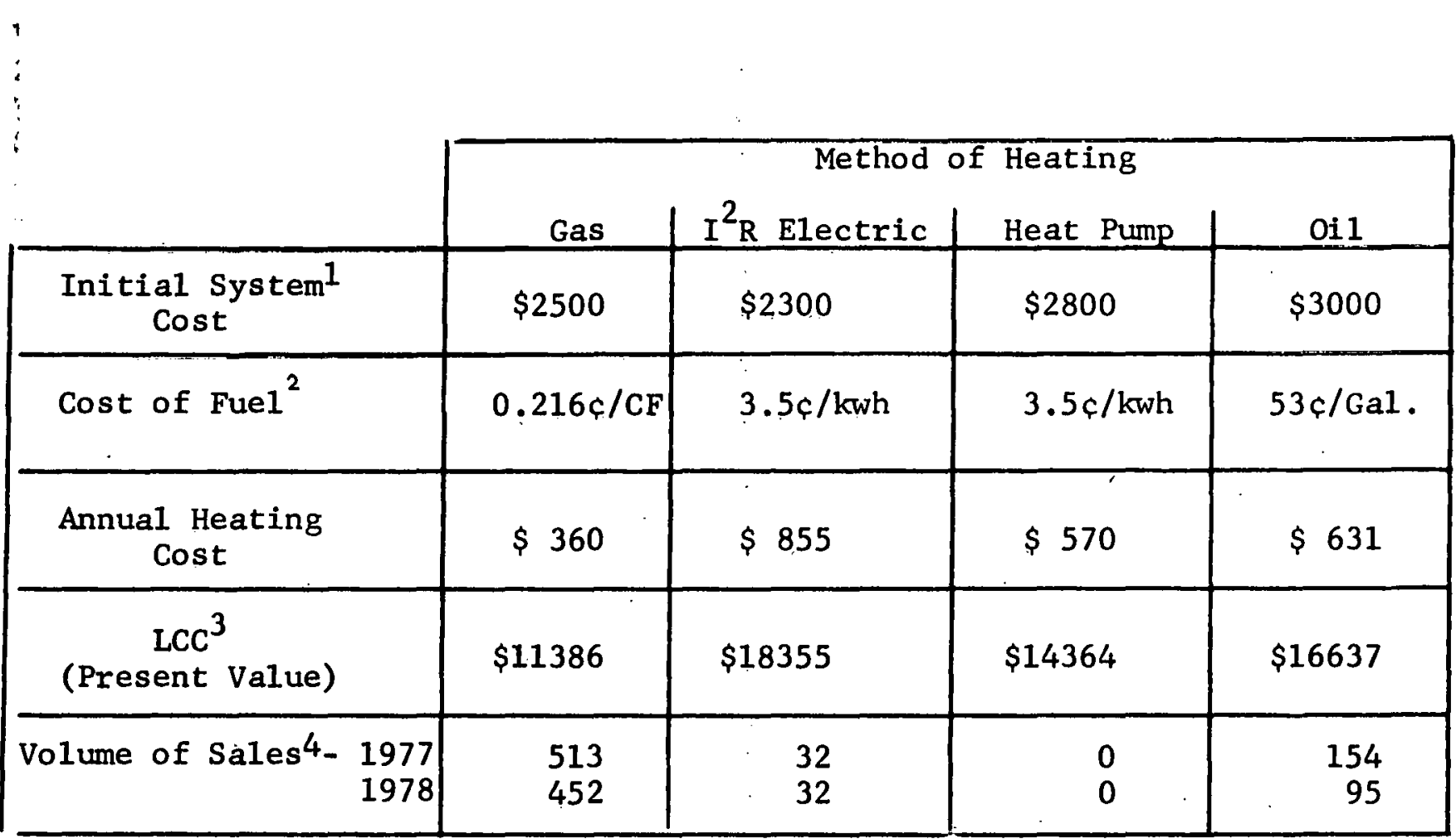

Notes :

1. Includes the cost of central air conditioning.'

2. The cost of fuel is averaged over the typical heating load.

3. Economic parameters used are given in Appendix 2.

4. Values represent the 1977-1978 sales to new single family housing construction. 
TABLE M5.4 - LIFE CYCLE COSTS FOR HEATING AND COOLING IN THREE CITIES

The present values (PV) of owning and operating a heat pump in the three locations are tabulated along with loads and the current (May, 1979) cost of electricity.

\begin{tabular}{|c|c|c|c|}
\hline CITY & NEW YORK, NY & N̦AS HVILLE, TN & MADISON, WI \\
\hline FIRST $\cos T(\$)$ & 3100 & 2888 & 2800 \\
\hline $\begin{array}{l}\text { PV OF } 15 \text { YEARS } \\
\text { FUEL } \operatorname{COST}(\$)\end{array}$ & 9419 & 4532 & 11516 \\
\hline $\begin{array}{l}\text { PV OF } 15 \text { YEARS } \\
\text { MAINTENANCE COST (\$) }\end{array}$ & 2128 & 1982 & 1922 \\
\hline PV OF LCC (\$) & 14647 & 9402 & 16238 \\
\hline $\begin{array}{l}\text { WINTER } \\
\text { ELECTRICITY COST } \\
(c / k w h)\end{array}$ & 7.05 & 3.20 & 3.50 \\
\hline $\begin{array}{l}\text { ANNUAL HEATING LOAD } \\
\text { (THERMS) }\end{array}$ & 369 & 461 & 834 \\
\hline $\begin{array}{c}\text { SUMMER } \\
\text { ELECTRICITY COST } \\
(c / \text { kwh })\end{array}$ & 8.82 & 3.20 & 4.89 \\
\hline $\begin{array}{l}\text { ANNUAL COOLING LOAD } \\
\text { (THERMS) }\end{array}$ & 133 & .154 & 234 \\
\hline
\end{tabular}

NOTE: 1 THERM $=10^{5} \mathrm{BTU}$ 
CHAPTER $M-6$

\section{CORRELATION ANALYSIS}

\section{Introduction}

The life cycle cost analysis of Chapter M-5 shows that the expected relationship between the low LCC's and high sales volumes of heat pumps (HP) does not always hold. It is evident, then, that factors other than life cycle costs influence HP sales. Since the same factors that govern HP sales will probably strongly influence SAHP sales, an attempt was made to aiscover these factors. This attempt took the form of a correlation analys is between HP sales and selected HVAC market data of Chapter $M-4$.

The analysis performed in this study was not intended to indisate trends in heat pump sales but to indicate the factors which influence these sales. Thus, for example, the goal was not to determine how an increase in oil prices in one year contributes to an increase in HP sales the next, but rather to determine if heat pumps sell better in areas where oil prices are high than they do in areas where these prices are low. The correlation analysis showed that no one factor has a significant influence on HP sales in the U.S. Rather, an interrelationship of several factors was found to corcelate highly with these sales.

\section{Simple correlation}

The first step in the correlation analysis was an attempt to find a simple correlation between heat pump sales and selected data from Table M4.2. Marketing judgment was used to select the following data as that having the most probable effect on HP sales:

I. the ratio of the annual heating load to cosling load, which gives weight to the degree to which the heat pump's basic function of cooling will be utilized;

II. air conditioning sales. which is a:other means of giving weight to the degree to which the heat pump's cooling function will be utilized;

III. the annual costs of heating with oil, gas, or heat pump systems, which gives weight to the degree of 
advantage (or disadvantage) a heat pump system has over competing heating systems due to energy costs;

IV. the difference in the utilized cost of fuels* between the heat pump and oil or gas, which is another means of giving weight to the degree of advantage or disadvantage of heat pump versus competing heating systems due to energy costs; and

V. the number of existing houses, which gives weight to the potential retrofit market.

Each data type was plotted on a scatter diagram with heat pump sales as the dependent variable and the selected marketing data as the independent variable. (Each state represents one data point). A least-square fit line was drawn through the points and a "correlation coefficient" was calculated for each of the diagrams. The correlation coefficient describes the degree of relationship, or correlation, between the dependent and independent variables; its value ranges from 0 to 1 . with zero indicating no relationship and $l$ indicating a perfect linear relationship between the two variables.

An example of a simple correlation is shown in Figure M6.1. In this example, the independent variable is the difference in utilized fuel cost between oil and heat pump systems. This variable describes the regions where fuel cost creates an economic advantage (or disadvantage) for heat pumps over oil heat. For this example, the correlation analysis yielded a low correlation coefficient $(0.32)$, indicating a poor dependence of heat pump sales on fuel cost difference.

Similarly, low correlation coefficients were found for each of the individual data types analyzed. Coefficients ranged from 0.27 when the independent variable was the annual cost of heating with gas to 0.40 when the independent variable was air conditioning sales. These results indicate that simple relationships between HP sales and the various types of selected market

*The utilized cost of fuels is obtained by dividing the unit fuel cost by the efficiency of the heating system. It represents the actual price the consumer pays for the heat content of the fuel that enters the conditioned space. 
data are very weak.

Multiple Correlation Analysis

To determine if a complex relationship exists between heat pump sales and the various classes of market data, a multiple correlation analysis was performed. This analysis correlates several marketing variables simultaneously with heat pump sales. The analysis was performed with the Forecasting and Analysis system Program (Reference 16) available on the Singer Time-sharing System.

On the basis of several runs of the Forecasting and inalysis System program, two new classes of data were added to the correlation analysis:

I. single family housing starts, which gives weight to the potential new installation market, and

II. new gas heating services, which gives weight to the availability of gas as a heating fuel.

The state-by-state data for these two classes are tabulated in Table M6.1. In addition, since the data or the utilizod cost of fuel are encompassed in the annual heating data, this variable was omitted in the multiple correlation analysis.

The multiple correlation analysis yielded a multipl.e correlation coefficient of 0.85 , indicating a high degree of correlation between heat pump sales and the eight selected marketing variables.

\section{Conclusion}

Heat pum? sales are correlated to market data in a complex manner and simple, individual correlations cannot be used for heat pimp sales prediction. However, it was shown that heat pump salas are highly correlated to the following eight marketing variables simultaneously: the ratio of the heating to cooling load; air conditioning sales; the annual cost of heating with oil, gas, and heat pump systems; the number of existing single family houses; the number of new single family housing starts; and the number of new gas heating services. 
Further trials of the Multiple correlation Analysis to determine if there are other factors that significantly correlate with heat pump sales, and/or to establish a weighting for each of the factors might be useful in knowing where and how to more effectively market such systems. 


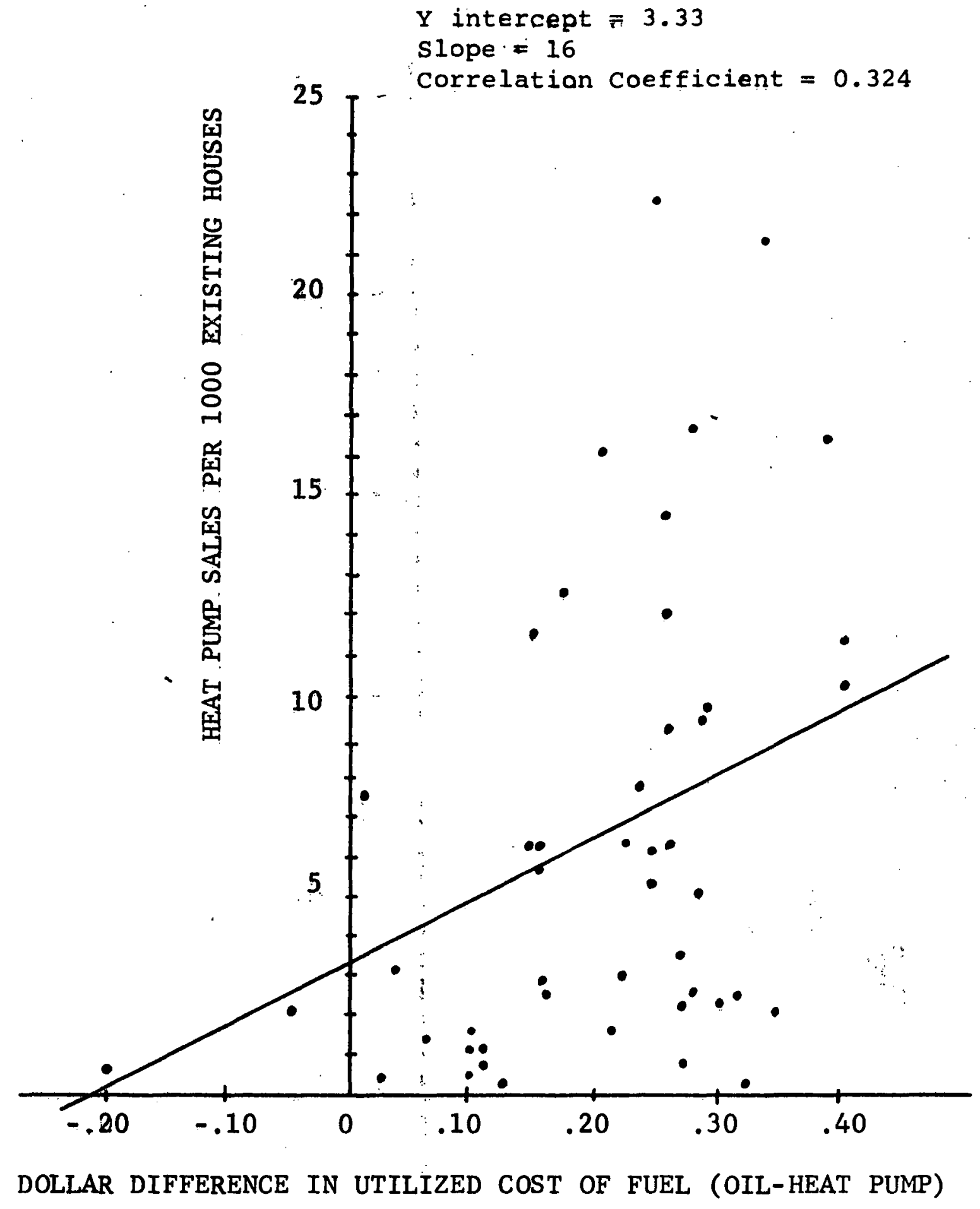

Figure M6.1 - Sample correlation of heat pump sales to the difference in the utilized cost of fuel between oil and heat pump systems. 
TABLE M6.1 a - ADDITIONAL CORRELATION DATA

\begin{tabular}{|c|c|c|c|}
\hline Region & State & $\begin{array}{l}\text { Single Family } \\
\text { Housing Starts }\end{array}$ & $\begin{array}{c}\text { New Gas Heating } \\
\text { Services } \\
\times 10^{3} \\
\end{array}$ \\
\hline New England & $\begin{array}{l}\text { Connecticut } \\
\text { Maine } \\
\text { Massachusetts } \\
\text { New Hampshire } \\
\text { Rhode Island } \\
\text { Vermont }\end{array}$ & $\begin{array}{r}11,999 \\
5,931 \\
20,963 \\
6,655 \\
3,332 \\
3,212\end{array}$ & $\begin{array}{l}3.7 \\
* \\
8.2 \\
0.4 \\
1.7 \\
*\end{array}$ \\
\hline Mid-Atlantic & $\begin{array}{l}\text { New Jersey } \\
\text { New York (Up State) } \\
\text { Pennsylvania }\end{array}$ & $\begin{array}{l}26,669 \\
29,231 \\
47,008\end{array}$ & $\begin{array}{r}8.1 \\
10.7 \\
9.5\end{array}$ \\
\hline South Atlantic & $\begin{array}{l}\text { Delaware } \\
\text { District of Columbia } \\
\text { Florida } \\
\text { Georgia } \\
\text { Maryland } \\
\text { North Carolina } \\
\text { South Carolina } \\
\text { Virginia } \\
\text { West Virginia }\end{array}$ & $\begin{array}{r}2,793 \\
885 \\
96,695 \\
37,077 \\
25,406 \\
49,603 \\
21,801 \\
48,927 \\
4,619\end{array}$ & $\begin{array}{r}* \\
1.4 \\
10.7 \\
28.3 \\
3.6 \\
6.4 \\
2.4 \\
0.9 \\
0.5\end{array}$ \\
\hline $\begin{array}{l}\text { East } \\
\text { North } \\
\text { Central }\end{array}$ & $\begin{array}{l}\text { Illinois } \\
\text { Indiana } \\
\text { Michigan } \\
\text { Ohio } \\
\text { Wisconsin }\end{array}$ & $\begin{array}{l}59,378 \\
30,269 \\
45,755 \\
47,964 \\
30,412\end{array}$ & $\begin{array}{c}84.5 \\
* \\
45.8 \\
0.3 \\
32.0\end{array}$ \\
\hline $\begin{array}{l}\text { West North } \\
\text { Central }\end{array}$ & $\begin{array}{l}\text { Iowa } \\
\text { Kansas } \\
\text { Minnesota } \\
\text { Missouri } \\
\text { Nebraska } \\
\text { North Dakota } \\
\text { South Dakota }\end{array}$ & $\begin{array}{r}21,203 \\
15,262 \\
29,593 \\
31,442 \\
11,743 \\
6,734 \\
7,240\end{array}$ & $\begin{array}{r}11.3 \\
11.1 \\
18.9 \\
15.5 \\
8.7 \\
2.4 \\
3.3\end{array}$ \\
\hline
\end{tabular}




\section{TABLE M6.1b - ADDITIONAL CORRELATION DATA}

\begin{tabular}{|c|c|c|c|c|}
\hline Region & State & $\therefore$ & $\begin{array}{l}\text { Single Family } \\
\text { Housing Starts }\end{array}$ & $\begin{array}{c}\text { New Gas Heating } \\
\text { Services } \\
\mathrm{x} 10^{3}\end{array}$ \\
\hline $\begin{array}{l}\text { East } \\
\text { South } \\
\text { Central }\end{array}$ & $\begin{array}{l}\text { Alabama } \\
\text { Kentucky } \\
\text { Tennessee } \\
\text { Mississippi } \\
\end{array}$ & : & $\begin{array}{l}33,004 \\
23,253 \\
30,773 \\
14,962\end{array}$ & $\begin{array}{l}8.9 \\
0.0 \\
3.8 \\
3.6\end{array}$ \\
\hline $\begin{array}{l}\text { West } \\
\text { South } \\
\text { Central }\end{array}$ & $\begin{array}{l}\text { Arkansas } \\
\text { Louisiana } \\
\text { Oklahoma } \\
\text { Texas }\end{array}$ & $\begin{array}{l}\vdots \\
\vdots \\
\vdots \\
\vdots\end{array}$ & $\begin{array}{r}19,167 \\
31,951 \\
26,996 \\
119,608\end{array}$ & $\begin{array}{l}* \\
11.3 \\
16.6 \\
61.6\end{array}$ \\
\hline Mountain & $\begin{array}{l}\text { Arizona } \\
\text { Colorado } \\
\text { Idaho } \\
\text { Montana } \\
\text { Nevada } \\
\text { New Mexico } \\
\text { Utah } \\
\text { Wyoming }\end{array}$ & $\begin{array}{l} \\
\vdots \\
\vdots \\
\vdots\end{array}$ & $\begin{array}{r}34,253 \\
28,360 \\
11,965 \\
7,334 \\
11,256 \\
7,428 \\
16,824 \\
6,378\end{array}$ & $\begin{array}{r}5.3 \\
21.9 \\
* \\
* \\
9.0 \\
9.3 \\
26.0 \\
4.2\end{array}$ \\
\hline Pacific & $\begin{array}{l}\text { Alaska } \\
\text { California } \\
\text { Hawaii } \\
\text { Oregon } \\
\text { Washington }\end{array}$ & $\vdots$ & $\begin{array}{r}9,300 \\
166,742 \\
4,437 \\
27,713 \\
38,010\end{array}$ & $\begin{array}{r}* \\
201.5 \\
0.0 \\
9.7 \\
*\end{array}$ \\
\hline
\end{tabular}

* Data Not Available 


\section{References}

1. Klein, S.A., et al.." "TRNSYS Manual A Transient Simulation Program", Report No. 38, University of Wisconsin Engineering Experiment Station, Madison, Wisconsin, October, 1977.

2. Singer Co.. "List Prices 1977-1978", Catalog-HR5530, The Singer Co., Climate Control Division, Cateret, NJ, 1977.

3. Sears, "Customer Prices-Residential", February, 1978.

4. InterTechnology Corporation, "Solar System cost Breakdown", ITC, June, 1977.

5. Golay, Michael W.. "End Use Space Conditioning Equipment Cost Data", MIT, DAAK02-74-C-0308, MaY, 1977.

6. Singer Co., "List Prices Solar Supplement Apparatus", Catalog-ECS12-10, The Singer Co., Climate Control Division, Carteret, NJ, 1977.

7. Jardine, D.M. and Jones D.W., "Phoenix City of Colorado Springs Solar Assisted Heat Pump Project", Technical Report, DOE Contract No. EG-77-C-02-4351, October, 1977.

8. Ottaviano Technical Services, Inc.. Solar Energy. Chapter VI, 1977.

9. ITC/Solar, "Technical Status Report", DOE Contract EG-77-C-03-1467, september, 1978.

10. Heddleson, Fred A., "Fuels Used for Single-Family Detached Residential Heating in the United States", ORNL-TM-4690, 1975

11. The American Gas Association, Gas Facts-1976 Data, American Gas Association, Arlington, VA, 1977.

12. E.C. Hise and A.S. Holman, "Heat Balance and Efficiency Measurements of Central, Forced Air, Residential Gas Furnaces", ORNL/NSF/EP-88, 1975. 
13. DOE/EIA "All Electric Homes", Energy Data Report DOE/EIA0009/1, January, 1978.

14. ARI, "ARI Unitary Heating and cooling sections Report of Trading - Area Sales of Split Heat Pumps", Form UHP-5-SA, 1977.

15. ARI, "Unitary Heating and Cooling Section's Report of Split Systems Air Conditioning Condensing Units only", Form USST-5-SA, 1977.

16. IBM System/360/Scientific Subroutine Package, Version III, 360A-CM-03X GH20-0205,-4, Fifth Edition, August, 1970

17. Davis, J. Michael, "Economic Parameters for Life Cycle Cost (LCC) Analysis, "DOE Memorandum, Feb. 26, 1979. 
APPENDIX 1

SINGLE FAMILY HVAC MARKETING CHARACTERISTICS METHODOLOGY

The following methodology was used to generate Table M4.2:

1) Column $A$

The number of occupied housing units per state was obtained from U.S. Bureau of Census data.

2) Column B

Each state's average Degree Days, DD, was weight averaged by population:

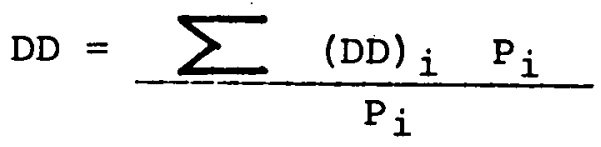

Where $\mathrm{P}_{i}=$ the population of the $i$ th major city of the state.

$(D D)_{i}=$ the annual degree days of that city.

3) Column $\mathrm{C}$

The UA was calculated for each region (e.g.. the Mid-Atlantic region) from fuel consumption data obtained from the AGA:

$$
\mathrm{UA}=\frac{\mathrm{FC} \times \mathrm{U}_{\mathrm{C}}}{24 \times \mathrm{DD}_{\mathrm{reg}}}
$$

Where $F C=$ regionally averaged annual fuel consumption (in BTU's), of residential fossil fuel heating systems.

$\mathrm{DD}_{\text {reg }} \quad$ regionally averaged Degree Days (weight averaged by state population).

$$
U_{C}=0.5 \text { (fossil fuels). }
$$

4) Column D

Each state's annual heat load for fossil fuel heated houses was calculated from:

Annual Heat Load $=$ UA $\times$ DD $\times 24$ 
For all-electric houses, each state's typical residential annual heat load was weight averaged by population and calculated from:

$$
\text { Annual Heat Load }=\frac{\sum\left((k w h)_{i} \times N_{i}\right)}{\sum N_{i}}
$$

Where $(\mathrm{kwh})_{i}=$ the annual amount of electricity used for space heating by the average residential customer as reported by the ith utility company (data obtained from DOE).

$$
\begin{aligned}
\mathrm{N}_{i}= & \text { the total number of electric heat } \\
& \text { customers serviced by the ith utility } \\
& \text { company (data obtained from DOE). }
\end{aligned}
$$

6) Column F

The ratio of the annual heating load, AHL, to the annual cooling load, ACL, was obtained from D.M. Jardine, "Phoenix City of Colorado springs", SAHP Project Report, DOE EG-77-C-02-4351 (1977).

7) Column G

For each state the SPF, the seasonal performance factor or heating efficiency of a heat pump, was obtained from the DD of that state. This was done by calculating the SPF of a 3-ton heat pump for 8 cities, using the ASHRAE bin method and appropriate weather data of those cities. These cities span a degree day range from $1000 \mathrm{DD}$ to $8000 \mathrm{DD}$ in approximately $1000 \mathrm{DD}$ increments. The SPF's for these cities were then correlated against the $\mathrm{DD}$ of each city. This correlation was used to predict the SPF of a location whose DD value was given.

Table III of Paper 1 in Chapter T-2 of the Technical section of this report lists the eight cities and the data used for the above correlation.

8) Columns $\mathrm{H}-\mathrm{K}$

The utilization cost of a heating fuel in each state was 
obtained by dividing the actual fuel cost by the heating system's utilization coefficient, $U_{C}$. Fuel costs were obtained from $A G A$ and DOE. Values of $U_{C}$ used
are:

$$
\begin{aligned}
& \text { gas and o.il, } U_{C}=0.5 ; \\
& \text { all-electric, } U_{C}=1.0 ; \\
& \text { heat pump, } U_{C}=S P F .
\end{aligned}
$$

9) Columns L-O

The typical annual home heating (fuel) cost for each state was obtained by multiplying the fuel utilization cost (Columns H-K) by the annual heat load (Columns D-E).

10) Columns $P-R$

The distribution of heating fuel types in each state was obtained from U.S. Bureau of Census data.

11) Columns S-T

Split system air conditioner (A/C) and heat pump (HP) sales for 1977 were obtained from ARI data. 


\section{APPENDIX 2}

\section{LIFE CYCLE COST DATA COLLECTION AND CALCULATION METHODOLOGY}

I. Methodology of HVAC Life Cycle cost Data collection

The following 'methodology was used to collect the data required for the life cycle cost analysis of chapter $M-5$.

1) Contact local gas and electric companies of each city for:

-rate schedules

- number of new single family houses (NSFH) completed by heat fuel type

-data or sources of data on instrumented (annual) tests in similar NSFH with central air, forced air, gas and electric heat, and heat pump systems

-typical NSFH heating and cooling loads

-electric power consumption of NSFH for all-electric and fossil fuel heated houses in the heating and cooling season (on a 6 month breakdown)

2) Contact oil company for fuel oil price.

3) Contact local Department of Building for:

-building code difference, if any, between NSFH heated with electric and fossil fuels

-average living area $\left(\mathrm{ft}^{2}\right)$ of $\mathrm{NSFH}$

$-U$ or UA of average $\mathrm{NSFH}$

4) Contact three local HVAC sales and service contractors in each city for:

-complete installation cost in NSFH of gas, oil, and electric furnaces with central $\mathrm{A} / \mathrm{C}$ and of $\mathrm{HP}$

-annual cost of service contract on each of the above HVAC systems and determine if the rate is fixed annually.

5) Contact three local building contractors for: 
-the portion of the selling price of the house that the HVAC system contributes for gas, oil, and electric furnaces with central $\mathrm{A} / \mathrm{C}$, and for $\mathrm{HP}$ -the heating and cooling loads of NSFH

-average living area $\left(\mathrm{ft}^{2}\right.$ ) of NSFH

-UA of NSFH

6) Contact (as a backup for Step 3) the National Association of Home Builders for:

-average living area ( $\mathrm{ft}^{2}$ ) of NSFH in particular areas -average $U$ or $U A$ values of NSFH

-differences in building construction (U) of NSFH with electric heat versus fossil fuel heat. 
TABLE Ia - 1979 HVAC MARKET CHARACTERISTICS - FORT WORTH, TX

A. Utility Rate structure (Heating Season Rate)

1. Lone Star Gas Company

$\begin{array}{cccc}\begin{array}{c}\text { First } \\ 1000 \mathrm{CF}\end{array} & \begin{array}{c}\text { Each Additional } \\ 1000 \mathrm{CF}\end{array} & \begin{array}{c}\text { Average Fuel } \\ \text { Adjustment Rate } \\ \text { Each } 1000 \mathrm{CF}\end{array} & \begin{array}{c}\text { Average } \\ \text { Cost }\end{array} \\ \$ 3.01 & \$ 2.5051 & \$ 0.10 & 0.266 \mathrm{CF} / \mathrm{CF}\end{array}$

2. Texas Electric Service company

\begin{tabular}{|c|c|c|c|c|}
\hline $\begin{array}{l}\text { First } \\
25 \mathrm{kwh}\end{array}$ & Each & $\begin{array}{l}\text { Additional } \\
\text { kwh }\end{array}$ & $\begin{array}{c}\text { Average Fuel } \\
\text { Adjustment Rate } \\
\text { Each kwh } \\
\end{array}$ & $\begin{array}{c}\text { Average } \\
\text { Cost } \\
\end{array}$ \\
\hline$\$ 6.00$ & & $0.75 \%$ & $1.0 \phi$ & $2.0 \xi / \mathrm{kw}$ \\
\hline
\end{tabular}

B. Average (1650 $\mathrm{ft}^{2}$ ) New Single Family All-Electric House: Heat Load $398.2 \times 10^{5} \mathrm{BTU}$, Cool Load $436.6 \times 10^{5} \mathrm{BTU}$.

c. Annual Heating cost $1874 \mathrm{ft}^{2}$, New single Family House: Heat Pump $\$ 125, \quad$ Electric Resistance $\$ 262$, Gas $\$ 238$.

D. HVAC Forced Air System Installed costs in Sample (1874 $\mathrm{ft}^{2}$ ) New Single Family House (Heating $\mathrm{UA}=494 \mathrm{BTU} / \mathrm{hr}{ }^{\circ} \mathrm{F}$; cooling UA $=1294 \mathrm{BTU} / \mathrm{hr}{ }^{\circ} \mathrm{F}$ ):

Heat Pump $\$ 2375$, Gas with $\dot{A} / C$ \$1875, Resistance (Elect) with $A / C \$ 1675$.

E. HVAC Sales in New Single Family Housing:

\begin{tabular}{|c|c|c|c|c|}
\hline \multirow{2}{*}{ Year } & \multirow{2}{*}{$\begin{array}{c}\text { NSFH } \\
\text { Completed }\end{array}$} & \multicolumn{3}{|c|}{ Heating Type } \\
\cline { 3 - 5 } & Gas & $\mathrm{I}^{2} \mathrm{R}$ & $\mathrm{HP}$ \\
\hline 1977 & 796 & 68 & 687 & 41 \\
1978 & 1764 & 44 & 1631 & 89 \\
\hline
\end{tabular}

Note: All NSFH had forced air heat and $\mathrm{A} / \mathrm{C}$. 
TABLE $1 \mathrm{~b}=1979$ HVAC MARKET CHARACTERISTICS - DALLAS TX

A. Utility Rate structure (Heating season Rate)

1. Lone star Gas Company

\begin{tabular}{|c|c|c|c|}
\hline & & Average Fuel & \\
\hline First & Each Additional & Adjustment Rate & Average \\
\hline $1000 \mathrm{CF}$ & $-1000 \mathrm{CF}$ & Each 1000 CF & Cost \\
\hline$\$ 2$ & $\$ 1.79$ & $0.663 c$ & 0.182 \\
\hline
\end{tabular}

2. Dallas Power and Light Company

\begin{tabular}{|c|c|c|c|}
\hline & & Average Fuel & \\
\hline $\begin{array}{l}\text { First } \\
20 \mathrm{kwh}\end{array}$ & $\begin{array}{c}\text { Each Additional } \\
1000 \mathrm{kwh} \\
\end{array}$ & $\begin{array}{l}\text { Adjustment Rate } \\
\text { Each kwh } \\
\end{array}$ & $\begin{array}{l}\text { Average } \\
\text { Cost }\end{array}$ \\
\hline$\$ 4.50$ & 2.334 & $1.2 \phi$ & $3.7 \xi / \mathrm{kwh}$ \\
\hline
\end{tabular}

B. Average $\left(1650^{2} \mathrm{ft}\right)$ New Single Family All-Electric Houses : Heating Load $398.2 \times 10^{5}$ BTU; Cooling Load $436.6 \times 10^{5} \mathrm{BTU}$.

C. Annual Heating cost in $1874 \mathrm{ft}^{2}$ New Single Family House:

Heat Pump $\$ 231, \quad$ Electric Resistance $\$ 485$, Gas $\$ 163$.

D. HVAC Forced Air system Installed Costs in Sample (1874 $\mathrm{ft}^{2}$ ) New Single Family House (Heating UA=794 BTU/hr ${ }^{\circ}$; Cooling $\mathrm{UA}=1294 \mathrm{BTU} / \mathrm{hr} \mathrm{O}_{\mathrm{F}}$ ) :

Heat Pump \$2375, Gas with A/C \$1875, Resistance (Elect) with $A / C \quad \$ 1675$.

E. HVAC Sales in New Single Family House (NSFH):

\begin{tabular}{|c|c|c|c|c|}
\hline \multirow{2}{*}{ Year } & $\begin{array}{c}\text { NS FH } \\
\text { Completed }\end{array}$ & Gas & $1^{2} \mathrm{R}$ & HP \\
\cline { 3 - 5 } 1977 & 2500 & 2105 & 245 & 30 \\
1978 & 3291 & 2523 & 617 & 39 \\
\hline
\end{tabular}


TABLE IC - 1979 HVAC MARKET CHARACTERISTICS - MADISON WI

A. Utility Rate structure: (Heating Season)

1. Madison Gas and Electric Company (Electric)

$\begin{array}{llccc}\text { Base } & \begin{array}{c}\text { First } \\ 1000 \mathrm{kwh}\end{array} & \begin{array}{c}\text { Each Additional } \\ \mathrm{kwh}\end{array} & \begin{array}{c}\text { Fuel } \\ \text { Adjustment }\end{array} & \begin{array}{c}\text { Average } \\ \text { Cost }\end{array} \\ \$ 2.00 & 3.36 \% / \mathrm{kwh} & 2.75 \% & .33608 \% / \mathrm{kwh} & 3.5 \% / \mathrm{kwh}\end{array}$

2. Madison Gas and Electric Company (Gas)

$\begin{array}{lccc}\text { Base } & \begin{array}{c}\text { First } \\ 1000 \mathrm{CF}\end{array} & \begin{array}{c}\text { Each Additional } \\ \mathrm{CF}\end{array} & \begin{array}{c}\text { Average } \\ \text { Cost }\end{array} \\ \$ 2.00 & \$ 2.27 & .206 \% & .216 \mathrm{C} / \mathrm{CF}\end{array}$

3. Fuel Heating oil (\#2.) 53c/gallon

B. Average $\left(1400^{2} \mathrm{ft}\right)$ New Single Family Gas Heated House: Heat Load $834 \times 10^{5} \mathrm{BTU} ;$ Heating UA $=588 \mathrm{BTU} / \mathrm{hr}{ }^{\circ} \mathrm{F}$.

C. Average Annual Heating Cost in New Single Family House: Heat Pump $\$ 570, \quad$ Oil $\$ 631, \quad$ Gas $\$ 360$.

D. HVAC Forced Air system (includes A/C) Installed costs in Sample (1400 $\mathrm{ft}^{2}$ ) New Single Family House:

Heat Pump $\$ 2800, \quad$ Gas $\$ 2500, \quad$ Oil $\$ 3000$.

E. HVAC Sales in New Single Family Housing:

\begin{tabular}{|c|c|c|c|c|r|}
\hline & \multirow{2}{*}{$\begin{array}{c}\text { NS FH } \\
\text { Year }\end{array}$} & \multicolumn{3}{|c|}{ Heating Type } \\
\hline & & Gas & $I^{2} \mathrm{R}$ & HP & OII \\
\hline 1977 & 699 & 513 & 32 & 0 & 154 \\
1978 & 579 & 452 & 32 & 0 & 95 \\
\hline
\end{tabular}




\section{TABLE 1 - NOTES}

Table 1 shows the HVAC market characteristics separated into the following groups of data:

1) The utility rate structures obtained from the utility companies are calculated for the heat load to provide the average cost of a single unit of fuel.

2) Surveys of builders, realtors and the Department of Building have yielded the size and heat/cool load of the average new single family house (NSFH).

3) Annual heating fuel costs were calculated on the sample house (described in D) and will be used with HVAC system costs in the LCC analysis.

4) Survey of builders and HVAC contractors yielded the HVAC system installed costs in the sample new single family house. The sample house size, load, and cost data were obtained by using popular house sizes, closest to the average NSFH, that builders and contractors could provide reliable data on. The HVAC system installed costs in Fort Worth and Dallas, TX are for tract home construction.

5) HVAC sales data in NSFH were obtained by surveying utility companies to determine the number of NSFH completed by heating fuel type. 
TABLE 2a

HP MARKET CHARACTERISTICS NEW YORK, NY

A. Utility Rate structure

\begin{tabular}{|c|c|c|c|c|c|c|}
\hline & First & Additional & Additional & $\begin{array}{l}\text { Fuel Adj. } \\
\text { Rate/kwh }\end{array}$ & $\begin{array}{c}\text { Extra } \\
\text { Charges }\end{array}$ & $\begin{array}{c}\text { Average } \\
\text { Cost }\end{array}$ \\
\hline winter & $\begin{array}{l}10 \mathrm{kwh} \\
3.53 \% / \mathrm{kwh}\end{array}$ & $\begin{array}{l}770 \mathrm{kwh} \\
7.387 \mathrm{k} / \mathrm{kwh}\end{array}$ & $\begin{array}{l}\text { over } 770 \mathrm{kwh} \\
4.76 \mathrm{k} / \mathrm{kwh}\end{array}$ & $.05794 / \mathrm{kwh}$ & & $7.05 \mathrm{c} / \mathrm{kwh}$ \\
\hline Summer & $\begin{array}{l}10 \mathrm{kwh} \\
3.33 \xi / \mathrm{kwh}\end{array}$ & $\begin{array}{l}1500 \mathrm{kwh} \\
7.387 \mathrm{k} / \mathrm{kwh}\end{array}$ & $\begin{array}{l}\text { over } 1500 \mathrm{kwh} \\
7.15 \dot{\mathrm{k}} / \mathrm{kwh}\end{array}$ & $.0579 \mathrm{c} / \mathrm{kwh}$ & $1.5 \mathrm{c} / \mathrm{kwh}$ & $8.82 c / k w h$ \\
\hline
\end{tabular}

B. Average Annual Load (NSFH):

Heat $10800 \mathrm{kwh}$; Cool $3900 \mathrm{kwh}$; Total $14700 \mathrm{kwh}$.

C. Average amount of electricity used:

Heat $(S P F=2) 5400 \mathrm{kwh}$; COOI $($ SEER $=6.7) 2000 \mathrm{kwh}$; Total $7400 \mathrm{kwh}$.

D. Average seasonal electric cost: Heat $\$ 381$; cool $\$ 176 ;$ Total $\$ 557$.

E. Heat Pump (HP) installed cost: $\$ 3100$ average in NSFH.

F. HVAC Sales in NSFH (almost no HP's sold)

\begin{tabular}{|c|c|c|c|}
\hline \multirow{2}{*}{ Year } & \multirow{2}{*}{ NSFH } & Heating Type \\
\hline & HP & other \\
1977 & NA & 0 & NA \\
1978 & NA & 0 & NA \\
\hline
\end{tabular}




\section{HP MARKET CHARACTERISTICS - NaShVille, TN}

A. Utility Rate structure

\begin{tabular}{|c|c|c|c|c|}
\hline & $\begin{array}{l}\text { First } \\
\text { kwh }\end{array}$ & $\begin{array}{l}\text { Additional } \\
\text { kwh }\end{array}$ & $\begin{array}{c}\text { Fuel Adj. } \\
\text { Rate }\end{array}$ & $\begin{array}{l}\text { Average } \\
\text { Cost }\end{array}$ \\
\hline $\begin{array}{l}\text { Winter } \\
\text { Summer }\end{array}$ & $\begin{array}{l}3.2 \xi / k w h \\
3.2 \xi / k w h\end{array}$ & $\begin{array}{l}3.2 \xi / k w h \\
3.2 \xi / k w h\end{array}$ & $\begin{array}{l}\text { NA } \\
\text { NA }\end{array}$ & $\begin{array}{l}3.2 \mathrm{k} / \mathrm{kwh} \\
3.2 \xi / \mathrm{kwh}\end{array}$ \\
\hline
\end{tabular}

B. Average annual load NSFH:

Heat 13,500 kwh; Cool $4500 \mathrm{kwh}$; Total $18000 \mathrm{kwh}$.

C. Average amount of electricity:

Heat $(S P F=2.2) 6136 \mathrm{kwh} ; \operatorname{COOl}(\operatorname{SEER}=6.8) 2250 \mathrm{kwh}$; Total $8386 \mathrm{kwh}$.

D. Average seasonal electricity cost:

Heat $\$ 196 ;$ Cool $\$ 72 ;$ Total $\$ 268$.

E. HP installed cost:

$\$ 2888$ average in NSFH

F. HVAC sales in NSFH:

\begin{tabular}{|c|c|c|c|}
\hline & & \multicolumn{2}{|c|}{ Heating Type } \\
Year & NSFH & Electric & Other \\
\hline & & & \\
1977 & 3387 & 2756 & 631 \\
1978 & 4213 & 3659 & 554 \\
\hline
\end{tabular}


TABLE 2C

1979 HP MARKET CHARACTERISTICS - MADISON, WI

A. Utility Rate structure

\begin{tabular}{|c|c|c|c|c|c|}
\hline & $\begin{array}{c}\text { First } \\
1000 \mathrm{kwh}\end{array}$ & $\begin{array}{c}\text { Additional } \\
\text { kwh }\end{array}$ & Fuel Adj. & Base & $\begin{array}{l}\text { Average } \\
\text { cost }\end{array}$ \\
\hline $\begin{array}{l}\text { Winter } \\
\text { Summer }\end{array}$ & $\begin{array}{l}\$ 3.36 / \mathrm{kwh} \\
\$ 4.2 / \mathrm{kwh}\end{array}$ & $\begin{array}{l}\$ 2.75 / k w h \\
\$ 4.2 / k w h\end{array}$ & $\begin{array}{l}\xi .33608 / \mathrm{kwh} \\
\xi .33608 / \mathrm{kwh}\end{array}$ & $\begin{array}{l}\$ 2.00 \\
\$ 2.00\end{array}$ & $\begin{array}{l}\$ 3.5 / \mathrm{kwh} \\
\$ 4.89 / \mathrm{kwh}\end{array}$ \\
\hline
\end{tabular}

B. Average annual load NSFH:

Heat 24,436 kwh; Cool $6856 \mathrm{kwh}$; Total $31292 \mathrm{kwh}$.

C. Average amount of electricity used:

Heat $(\operatorname{SPF}=1.65) 14,810 \mathrm{kwh} ; \operatorname{Cool}(\operatorname{SEER}=7) 3,343 \mathrm{kwh} ;$ Total 18,153 kwh.

D: Average seasonal electricity cost:

Heat $\$ 518$; Cool $\$ 163$; Total $\$ 681$.

E. HP installed cost: $\$ 2800$ average in NSFH.

F. HVAC sales in NSFH:

\begin{tabular}{|c|r|r|r|r|r|}
\hline & & \multicolumn{5}{|c|}{ Heating Type } \\
Year & NSFH & Gas & $I^{2}$ R & HP & OiI \\
\hline 1977 & 699 & 513 & 32 & 0 & 154 \\
1978 & 579 & 452 & 32 & 0 & 95 \\
\hline
\end{tabular}




\title{
TABLE 2 - NOTES
}

\author{
NSFH $=$ New Single Family House \\ NA $=$ Not Available
}

LCC data for conventional HP systems for single family residences are tabulated.

SPF values were calculated by the ASHRAE Bin method. Reasonable values for SEER were chosen.

Heat pump installed cost represents complete installation cost in a new single family house (NSFH) including equipment, duct work, plumbing, and electrical wiring. 
II. Life cycle cost calculation

The following methodology was used to determine the life cycle costs of Chapter $M-5$. An example of its use follows:

1) Calculate the average annual heating and/or cooling load from utility companies' data and/or new single family housing (NSFH) characteristics:

a) Heat Load $=\left(\frac{\text { BTUH loss }}{\Delta T}\right) \times$ (Seasonal Heating DD $X 24$ )

Where (BTUH loss $/ \Delta \mathrm{T}$ ) is the heat loss at a specified inside and outside temperature difference (in ${ }^{\circ} F$ ), and the Seasonal Heating Degree Days (DD) is obtained from Reference 11 .

(Note: Seasonal Heating DD differ from DD in that they are tabulated from data collected over the heating and/or cooling season only - not over the entire year.)

b) Cooling loads are calculated from available utility companies' statistical data: e.g., cool capacity $\mathrm{X}$ operating hours.

2) Calculate $E$, the annual amount of fuel used for heating or cooling:

$E=\frac{\text { Heating or cooling Load }}{\text { heat content per unit of fuel } \times U_{C}}$

Where $U_{C}$ is the annual efficiency of the heating or cooling system. For gas and oil, $U_{C}=0.5$; for $I^{2} R, U_{C}=1.0$; for $H P$, $\mathrm{U}_{\mathrm{C}}=\mathrm{SPF}$; and, for $\mathrm{A} / \mathrm{C}, \mathrm{U}_{\mathrm{C}}=\operatorname{Seer} / 3.413$.

3) Calculate $\mathrm{C}_{\mathrm{F}}$, the cost of a unit of fuel averaged over the typical month in the heating and/or cooling season:

Monthly fuel consumption

$C_{F}=\frac{\left.i \sum_{1}(\text { (cost increment } i / B T) \times B T U_{i}\right)+ \text { Base cost }}{E / 6}$

A six (6) month heating/cooling season is assumed. 
Annual Average $C_{F}=\frac{\left(C_{F} \times k w h\right)_{\text {winter }}+\left(C_{F} \times k w h\right)_{\text {summer }}}{(k w h) \text { winter }+(k w h) \text { summer }}$

4) Use the following values (Reference 17) in the life cycle cost analysis.

\begin{tabular}{|l|l|c|}
\hline IC & First cost & Initial System Cost \\
\hline$q$ & Maintenance Cost & .05 IC $_{\mathrm{p}}$ \\
\hline $\mathrm{i}$ & $\begin{array}{l}\text { Discount Rate } \\
\text { (Above Inflation) }\end{array}$ & .01 \\
\hline$g$ & $\begin{array}{l}\text { Inflation Rate } \\
\mathrm{f}\end{array}$ & $\begin{array}{c}\text { Fuel Escalation Rate } \\
\text { (Above Inflation) }\end{array}$ \\
\hline $\mathrm{N}$ & Life of Unit (years) & .025 (electricity) \\
\hline
\end{tabular}

5) Calculate PV, the present value of the system's total life cycle cost:

$P V=I C_{p}+E \times C_{F} \times \frac{r\left(r^{N}-1\right)}{(r-1)}+q \times \frac{L\left(L^{N}-1\right)}{(L-1)}$

Where: $r=\frac{1+f}{1+i}$ and $L=\frac{1}{1+i}$ 
An example of the LCC calculation of an air-to-air heat pump system in Madison, Wisconsin follows:

1) Heating and cooling Loads

a) Calculate heating load:

(Heat load data supplied by Midwest Heating and Air Conditioning, Madison, Wisconsin.)

$$
\begin{aligned}
\text { Heat Load } & =\frac{\text { BTUh loss }}{\Delta \mathrm{T}} \times \text { Seasonal DD } \times 24 \\
& =\frac{5000 \text { BTUh }}{\left(70^{\circ} \mathrm{F}-\left(-15^{\circ} \mathrm{F}\right)\right)} \times 5940 \text { DD } \times 24 \\
& =834 \text { therms }
\end{aligned}
$$

b) Calculate cooling load.

(Cooling load data supplied by Madison Gas and Electric.)

Test on 100 All-Electric Houses average operating hours $=650$ hours average cooling capacity $=36,000 \mathrm{BTU}$

Cooling Load $=36,000$ BTU X $650=234$ therms

2) Calculate $E$, the annual amount of fuel used for heating and cooling.

(Assume $\mathrm{SPF}=1.65$ and $\mathrm{SEER}=7.0$ )

$$
\begin{gathered}
\mathrm{E} \text { heat }=\frac{834 \text { therms }}{3.413 \mathrm{BTU} / \mathrm{kw} \times 1.65}=14810 \mathrm{kwh} \\
\mathrm{E} \text { cool }=\frac{234 \text { therms }}{3413 \mathrm{BTUkw} \times(7 / 3.413}=3343 \mathrm{kwh} \\
\mathrm{E} \text { annual }=\mathrm{E}_{\text {Heat }}+\mathrm{E}_{\mathrm{CoOl}}
\end{gathered}
$$$$
\mathrm{E} \text { annual }=14810 \mathrm{kwh}+3343=18153 \mathrm{kwh}
$$ 
3) Calculate $C_{F}$, the cost of a unit of fuel averaged over the typical heating/cooling season month.

(Assume six month heating/cooling season.)

$$
\begin{aligned}
14810 \mathrm{kwh} / 6 & =2468 \mathrm{kwh} / \text { heating month } \\
3343 \mathrm{kwh} / 6 & =557 \mathrm{kwh} / \text { cooling month }
\end{aligned}
$$

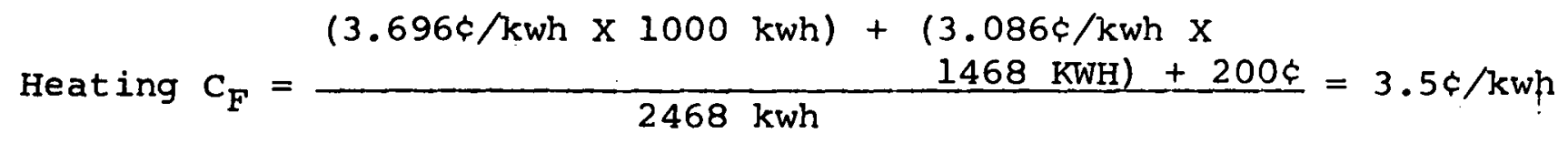

cooling $C_{F}=\frac{(4.536 \mathrm{k} / \mathrm{kwh} \times 557 \mathrm{kwh})+200 \mathrm{c}}{557 \mathrm{kwh}}=4.89 \mathrm{k} / \mathrm{kwh}$

$$
\text { (3.5\% kwh X } 14810 \mathrm{kwh})
$$

Annual Average $C_{F}=\frac{+(4.89 \mathrm{c} / \mathrm{kwh} \times 3343 \mathrm{kwh})}{18153 \mathrm{kwh}}=3.76 \mathrm{k} / \mathrm{kwh}$

4) The initial cost of the system, IC , was obtained from Midwest Heating and Air Conditioning, Madison, Wisconsin.

$$
I C_{p}=\$ 2800 \text {. }
$$

5) Calculate PV, the present value of the system's total Iife cycle cost.

$$
\begin{aligned}
& \mathrm{q}=0.05 \times \$ 2800=\$ 140 \quad \text { (Annual Maintenance cost) } \\
& \mathrm{r}=\frac{1+0.025}{1+0.01}=1.0149 \\
& \mathrm{~L}=\frac{1}{1+0.01}=0.99 \\
& \mathrm{PV}=\$ 2800+18153 \mathrm{kwh} \times 3.76 \mathrm{k} / \mathrm{kwh} \times \frac{1.0149\left(1.0149^{15}-1\right)}{1.0149-1} \\
& \quad+\$ 140 \times \frac{0.99\left(0.99^{15}-1\right)}{0.99-1}=\$ 16238
\end{aligned}
$$




\section{ADDENDUM \\ DOMESTIC HOT WATER HEATING SYSTEMS}

Domestic hot water heating systems are energy-conserving solar energy systems which, in contradistinction to the space heating systems discussed in the main body of this report, may be economically viable in many parts of the U.S. today. 1 A major factor affecting both the energy savings and initial costs of these systems is the angle at which the solar collectors are tilted. For optimum solar collection on a year-round basis, this angle should equal the latitude of the system's location.

In most cases, existing houses do not have surfaces tilted at the latitude angle and extra trussing would be required to provide them. Because of the expense, it is reasonable to question whether such trussing is economically justifiable. To answer this question, the Analytical Model Program was modified to include monthly city water temperatures and to generate from them the life cycle costs of optimized domestic hot water (DHW) heating systems.

Because monthly city water temperatures were not readily available, a survey was conducted by $R$. Shapess to obtain them for the major cities covered by the Analytical Model program (TMY cities). The form letter sent to each of the cities and the responses received are attached to this addendum.

The purpose of the modifications to the Analytical Model program was to determine the economic savings incurred by mounting the collectors at a tilt equal to the latitude as opposed to mounting them in a vertical (90 degree) plane. A vertical surface was assumed to be the surface which is most readily available for direct mounting of the collector array and which is least attractive from an energy collection standpoint. The economic savings were obtained by optimizing, for each city, the collector area and storage volume at both tilts and noting the difference between the total life cycle costs for each tilt. This difference represents the maximum amount which can be spent on trussing before the value of the energy saved by mounting at the optimum tilt is negated.

1. Paper No. 2 of the Technical section of the report. 
The analysis was run for two cities. New York, NY and Fort Worth, TX, selected because only their monthly city water supply temperatures were available at the time the analyses were run. In each case, the hot water heating load was determined as a function of: the average monthly water supply temperature; a minimum acceptable tap temperature of $140^{\circ} \mathrm{F}$; and a daily hot water usage factor of $50 \mathrm{gal} / \mathrm{day}$, as recommended by the ASHRAE Handbook of Fundamentals. In addition, the following cost factors were assumed: incremental costs of $\$ 6.00 / \mathrm{sq}$. ft. for the collector and $\$ 5.98 / \mathrm{cu}$. ft. for the storage volume; an energy cost of $\$ 0.05 / \mathrm{kwh}$ escalating at an annual rate of $4.5 \%$ (above inflation); an annual discount rate of $2 \%$ above inflation; a system lifetime of. 15 years; and an initial system cost (less collectors and storage) of $\$ 1500$.

The results, as shown in Tables $I$ and II, indicate that the value in the energy savings realized by varying the tilt from vertical to optimum was:

$\$ 720$ in New York, NY

$\$ 380$ in Fort worth, TX

This equates to a maximum add-on incremental cost per sq. ft. of collector of approximately $\$ 7$ in New York and $\$ 4$ in Fort worth. clearly, the value of changing the tilt from that of a common roof slope to the optimum one for solar energy collection is considerably less than the above values.

In conclusion, designers and architects should perform this type of rather simple calculation to determine if collector trussing is economically justified. 
TABLE I. OPTIMIZATION OF A DOMESTIC HOT WATER SYSTEM IN NEW YORK, NY

\begin{tabular}{|c|c|c|c|c|}
\hline $\begin{array}{l}\text { Collector } \\
\text { Tilt } \\
\text { (Degrees) } \\
\end{array}$ & $\begin{array}{c}\text { Optimum Collector } \\
\text { Area } \\
(\mathrm{Sq} \cdot \mathrm{Ft} .)\end{array}$ & $\begin{array}{c}\text { Optimum Storage } \\
\text { Volume } \\
\text { (Cu.Ft.) } \\
\end{array}$ & $\begin{array}{c}\text { Annual Energy } \\
\text { Usage } \\
\left(10^{6} \text { BTU }\right) \\
\end{array}$ & $\begin{array}{c}\text { Total Life } \\
\text { Cycle Cost } \\
(\$) \\
\end{array}$ \\
\hline 90 & 125 & 40 & 8.88 & 4870 \\
\hline 40.8 & 100 & 45 & 6.66 & 4150 \\
\hline Annual Energy Savings & & & 2.22 & \\
\hline Total Life Cycle Cost & t Savings & & & 720 \\
\hline
\end{tabular}

NOTE: Annual domestic hot water heating load was $13.73 \times 10^{6}$ BTU. 
TABLE II. OPTIMIZATION OF A DOMESTIC HOT WATER SYSTEM IN FORT WORTH, TX

\begin{tabular}{|c|c|c|c|c|}
\hline $\begin{array}{l}\text { Collector } \\
\text { Tilt } \\
\text { (Degrees) } \\
\end{array}$ & $\begin{array}{c}\text { Optimum Collector } \\
\text { Area } \\
(\mathrm{Sq} . \mathrm{Ft} .) \\
\end{array}$ & $\begin{array}{c}\text { Optimum Storage } \\
\text { Volume } \\
\text { (Cu.Ft.) } \\
\end{array}$ & $\begin{array}{c}\text { Annual Energy } \\
\text { Usage } \\
\left(10^{6} \text { BTU }\right) \\
\end{array}$ & $\begin{array}{c}\text { Total Life } \\
\text { Cycle Cost } \\
(\$) \\
\end{array}$ \\
\hline 90 & 100 & 45 & 3.88 & 3405 . \\
\hline 32.8 & 95 & 45 & 2.55 & 3020 . \\
\hline
\end{tabular}

Total Energy Savings

1.33

Total Life Cycle Cost Savings

385 .

NOTE: Annual domestic hot water heating load was $11.34 \times 10^{6}$ BTU. 
August 27, 1979

TO: Chief Administrator of the Water Department

\section{Dear Sir:}

We are collecting data for a solar heating research project for the Department of Energy and require certoin information that you may have avallable. To determine the cost/effectiveness oi particular soiar systems, It is necessary to know the average city water temperature, on a monthly, basis, that enters the individual (residential and commercial) water meters.

Any data or information you can contribute on this subject will be appreciated.

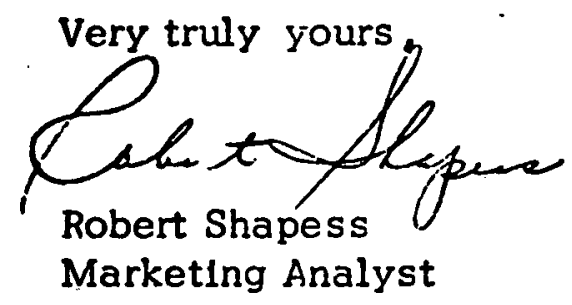

RS:dw

$$
\begin{aligned}
& \text { Anerage } T^{\circ}=45^{\circ} \mathrm{F} \\
& \text { High } T^{\circ}=71^{\circ} \mathrm{F} \\
& \text { Low } T^{\circ}=33^{\circ} \mathrm{F} \\
& \text { Gruat Folle, montana, } 59403
\end{aligned}
$$


RICHARD FULTON, MAYOR

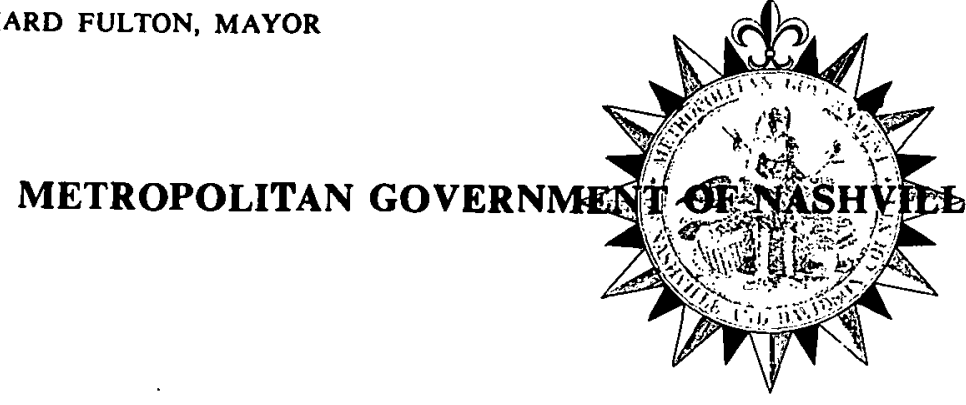

September 10, 1979

DEPARTMENT OF WATER AND BEWERAGE gERVICES WATER TREATMENT PLANT OMOHUNDRO DRIVE

NASHVILLE, TENNESSEE 97210

Mr. Robert Shapess

Marketing Analyst

Singer Company

Climate Control Division

1300 Federal Blvd.

Carteret, New Jersey 07008

Dear Mr. Shapess:

We have compiled the following data on water temperatures in the distribution system. The values represent an average of approximately 150 sample location throughout the system taken on a weekly basis.

$\begin{array}{llll}\text { July, } 1978 & 79^{\circ} \mathrm{F} & \text { January, } 1979 & 46^{\circ} \mathrm{F} \\ \text { August } & 79^{\circ} \mathrm{F} & \text { February } & 47^{\circ} \mathrm{F} \\ \text { September } & 78^{\circ} \mathrm{F} & \text { March } & 53^{\circ} \mathrm{F} \\ \text { October } & 70^{\circ} \mathrm{F} & \text { April } & 59^{\circ} \mathrm{F} \\ \text { November } & 64^{\circ} \mathrm{F} & \text { May } & 63^{\circ} \mathrm{F} \\ \text { December } & 55^{\circ} \mathrm{F} & \text { June } & 70^{\circ} \mathrm{F}\end{array}$

If we can be of any further assistance, please feel free to contact us.

$L L W / j d b$

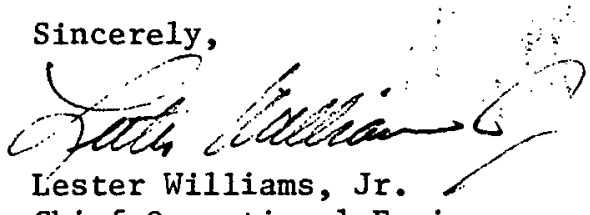

cc: Mr. K. R. Harrington

Director - Water \& Sewerage Services

Mr. W. F. Brock, Jr.

Assistant Director - Water \& Sewerage Services

Mr. J. Michael Patterson

Chief Utility Accountant 
The City of Phoenix water supply is a combination of surface water from the Salt and Verde Rivers and ground water developed by deep wells.

The primary source of supply is surface water from the Salt and Verde Rivers. This water is processed in four water treatment plants operated by the City of Phoenix. The Deer Valley and Squaw Peak Plants are located on the Arizona Canal, the Val Vista Plant on the Southern Canal, while the Verde Plant is located at the confluence of the Salt and Verde Rivers. An additional source of surface water is derived from the operation of an infiltration gallery and 13 shallow wells along the Verde River channel.

The ground water is developed by approximately 100 deep wells in Deer Valley, Paradise Valley, and the Salt River Valley.

The water chemistry data secured from representative sample points throughout the distribution grid is tabulated below. This data was secured from the 75 representative sampling points of the Phoenix water system grid. The range shown reflects the varying chemical make-up as influenced by the percentage of surface and ground water at varlous points in the grid and the varying chemical make-up of ground water aquifiers. The actual analysis constantly varies as dependent on the ratio of surface and ground water being utilized and seasonal variations of surface water chemistry.

Annual Distribution System Chemical Analysis

Samples taken during July 1977 - June 1978

Concentration in parts per million

Average 1

$\begin{array}{lc}\mathrm{pH} & 8.1 \\ \text { Chloride } & 149 \\ \text { Alkalinity(Total) } & 157 \\ \text { Hardness } & 225 \\ \text { Total Solids } & 551 \\ \text { Fluoride* } & 0.41 \\ \text { Iron } & 0.02 \\ \text { Nitrate as (N) } & 2.1 \\ \text { Sodium } & 61 \\ \text { Sulfate } & 65\end{array}$

Range

$\begin{array}{ccc}7.7 & - & 8.6 \\ 17 & - & 458 \\ 94 & - & 216 \\ 94 & - & 440 \\ 238 & - & 1150 \\ 0.22 & - & 0.79 \\ 0 & - & 0.15 \\ 0.2 & - & 13.8 \\ 17 & - & 215 \\ 6 & - & 152\end{array}$

* Naturally occurring fluorides with no additional fluorides added. 


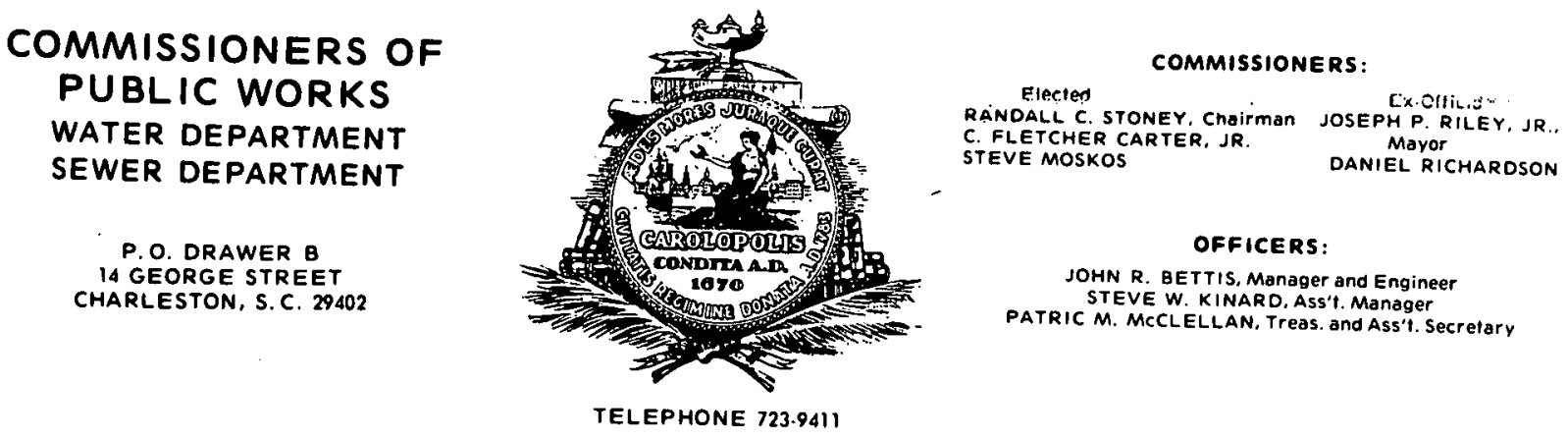

1978

\begin{tabular}{|c|c|}
\hline JANUARY $=--44$ & Low - - 40 \\
\hline FEBRUARY ---44 & Low --- 39 \\
\hline \multicolumn{2}{|l|}{ MARCH-- ---56 } \\
\hline APRIL & 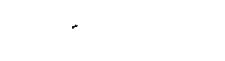 \\
\hline \multicolumn{2}{|l|}{ MAY - - - - -- 69} \\
\hline JUNE - - - - & High - - 85 \\
\hline JULY $\ldots-\cdots-85$ & High---- 88 \\
\hline \multicolumn{2}{|l|}{ AUGUST -----83} \\
\hline \multicolumn{2}{|l|}{ SEPTEMBER --80} \\
\hline \multicolumn{2}{|l|}{ OCTOBER----70 } \\
\hline NOVEMBER--- 65 & \\
\hline DECEMBER---55 & \\
\hline
\end{tabular}



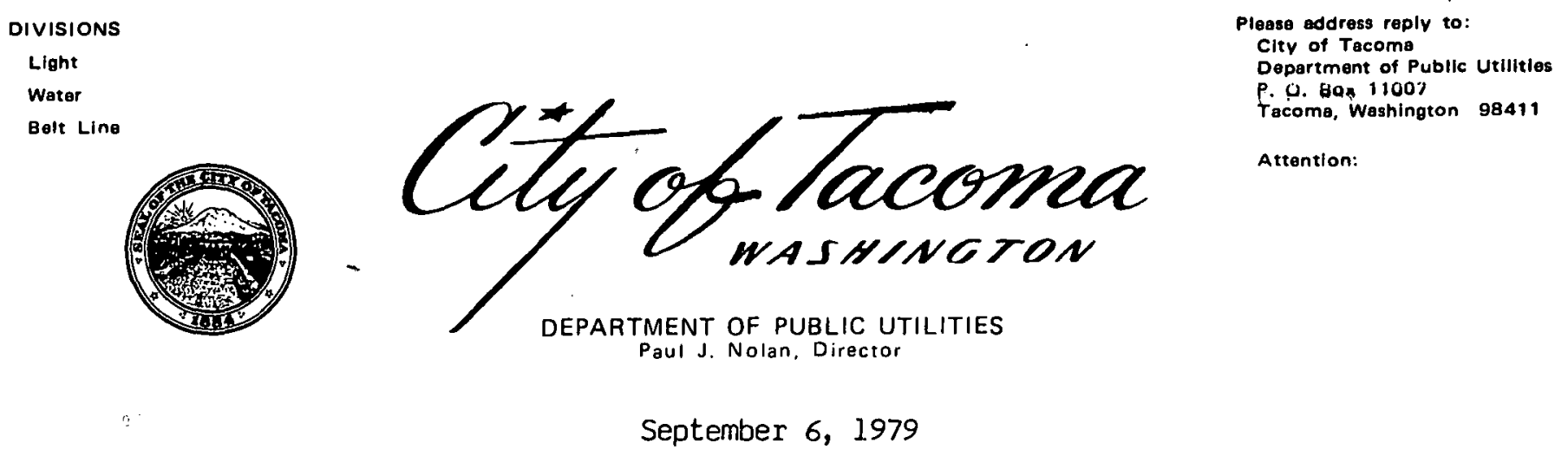

Mr. Robert Shapess

Marketing Analyst

The Singer Company

Climate Control Division

1300 Federal Blvd.

Carteret, New Jersey 07008

Dear Mr. Shapess:

In response to your letter of August 27, 1979, we routinely monitor water temperature in our water system at the planit of one of our large industrial users. Average water temperatures at that point for the period of August 1977 through August 1978 are as follows:

$\begin{array}{llll}\text { Aug. } 1977 & 61.3^{\circ} \mathrm{F} . & \text { Mar. } 1978 & 43.7^{\circ} \mathrm{F} . \\ \text { Sept. } 1977 & 60.0^{\circ} \mathrm{F} . & \text { Apr. } 1978 & 47.2^{\circ} \mathrm{F} . \\ \text { Oct. } 1977 & 53.8^{\circ} \mathrm{F} . & \text { May } 1978 & 50.3^{\circ} \mathrm{F} . \\ \text { Nov. } 1977 & 48.1^{\circ} \mathrm{F} . & \text { June } 1978 & 55.8^{\circ} \mathrm{F} \\ \text { Dec. } 1977 & 48.4^{\circ} \mathrm{F} . & \text { July } 1978 & 60.6^{\circ} \mathrm{F} . \\ \text { Jan. } 1978 & 42.4^{\circ} \mathrm{F} . & \text { Aug. } 1978 & 64.0^{\circ} \mathrm{F} . \\ \text { Feb. } 1978 & 42.0^{\circ} \mathrm{F} . & & \end{array}$
advise.

If we can be of further service in this regard, please

Very truly yours,

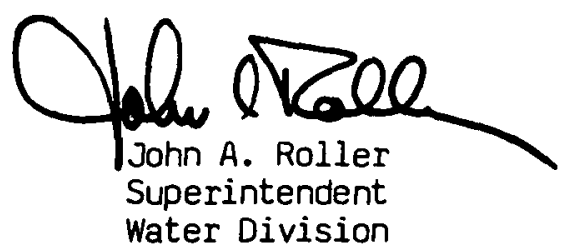

JAR:RLP/SMC 


\section{SEATTLE, WASHINGTON}

CEDAR DISTRIBUTION TEMPERATURE ${ }^{\circ}$

(AVERAGE OF RANGES)

\begin{tabular}{|c|c|c|c|c|c|c|c|c|c|c|c|c|c|c|c|}
\hline Month & $\begin{array}{c}13 \text { Years } \\
\text { Monthly } \\
\text { Average Mean }\end{array}$ & 1989 & 1988 & 1987 & 1986 & 1985 & 1984 & 1983 & 1982 & 1981 & 1980 & 1979 & 1978 & 1977 & 1976 \\
\hline January & 42.9 & & & & & & & & & & & 38.3 & 44.2 & 45.5 & 45.5 \\
\hline February & 43.1 & & & & & & & & & & & 40.1 & 44.6 & 46.2 & 43.7 \\
\hline March & 45.7 & & & & & & & & & & & 42.8 & 45.5 & 46.4 & 42.4 \\
\hline Apri1 & 50.1 & & & & & & & & & & & 47.3 & 50.9 & 51.8 & 49.9 \\
\hline Ma: & 54.8 & & & & & & & & & & & 56.3 & 56.5 & 55.8 & 56.8 \\
\hline June & 60.2 & & & & & & & & & & & 61.7 & 63.5 & 62.4 & 59.5 \\
\hline July & 63.5 & & & & & & & & & & 67.1 & 65.9 & 68.7 & 62.6 \\
\hline August & 64.8 & & & & & & & & & & & 68 & 66.7 & 68.5 & 63.5 \\
\hline September & 62.1 & & & & & & & & & & & & 61.9 & 63.5 & 6.26 \\
\hline October & 57.8 & & & & & & & & & & & & 58.6 & 56.7 & 58.7 \\
\hline November & 51.4 & & & & & & & & & & & & 50.9 & 50 & 54.9 \\
\hline December & 44.5 & & & & & & & & & & & & 42.8 & 46.4 & 47.8 \\
\hline
\end{tabular}


T A B L E L 6

AVERAGE WEEKLY TEMPERATURES OF NEW YORK CITY WATER SUPPLIES

$Y$ E A R 1978-DEGREES FARENHEIT

Week Ending

Jan. $\frac{1978}{7}$

Catskili-Delaware 、 Croton

$\begin{array}{r}14 \\ 21 \\ 28 \\ \hline \text { Feb. } \\ 11 \\ 18 \\ 18 \\ 25 \\ \hline\end{array}$

\begin{tabular}{lll}
\hline Mar. & 4 \\
11 & 38 \\
& 18
\end{tabular}

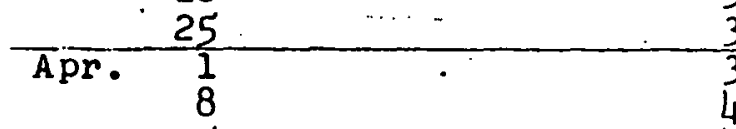

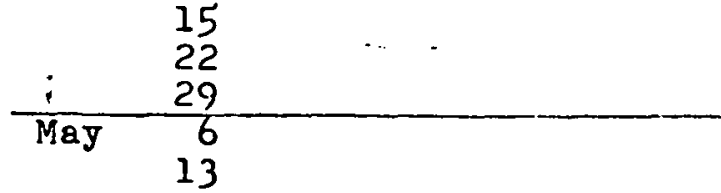

\begin{tabular}{r}
20 \\
27 \\
\hline June \\
10
\end{tabular}

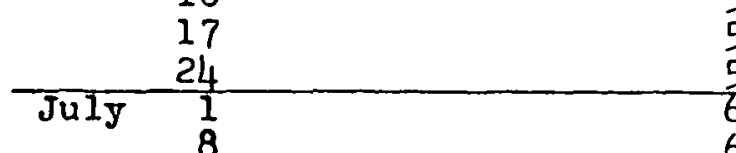

$\begin{array}{r}15 \\ 22 \\ : \quad 29 \\ \hline\end{array}$

\begin{tabular}{cr}
29 \\
\hline Aug & 5 \\
12 \\
19 \\
26 \\
\hline
\end{tabular}

sept.

26

9
16
23
30

- 1
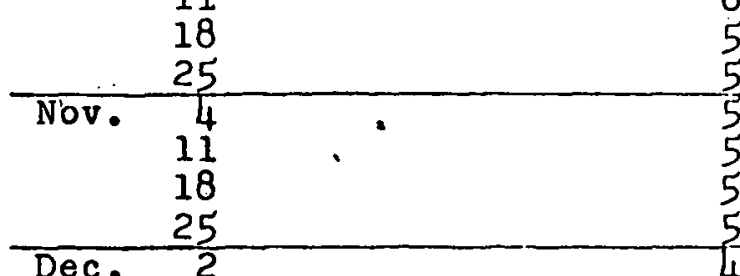

Dec. 2

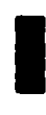
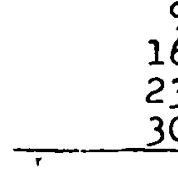

23

30

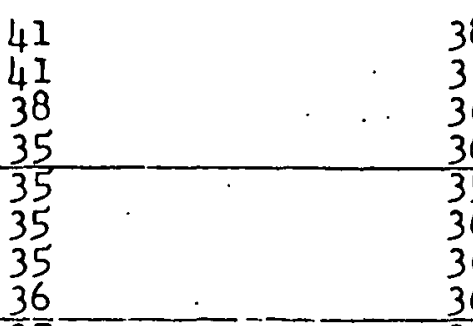

36

37

38

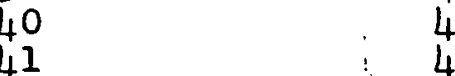

$42 \quad \therefore \quad 45$
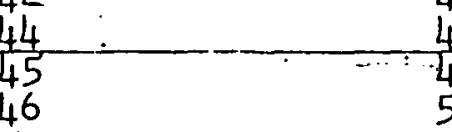

51.52

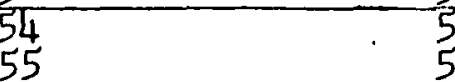

56
58

60

59

61

$61-61$

$63 \quad 64$

63

$63 \quad 69$

6470

63
62
60

$60-\frac{69}{67}$

$\begin{array}{ll}60 & 67\end{array}$

$58 \quad 65$

$57+62$

$54 \quad 58$

$\begin{array}{r}53 \\ 51 \\ \hline\end{array}$

$47 \quad 48$

4474

$43 \quad 43$

40

50

32
8 RECAPITULATI ON

$\begin{array}{lll}\text { Weekly } & 50 & 52 \\ \text { Minimum } & 35 & 35\end{array}$

(Mean)

Daily

Minimum $\quad 34 \quad 34$

Wookly

Maximum

(Mean)

$64 \quad 70$

Daily

Maximum 64

71

(n) 


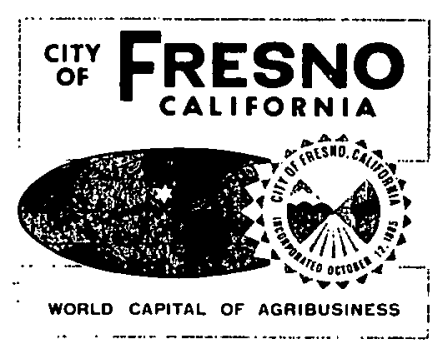

\section{PUBLIC WORKS DEPARTMENT}

WATER DIVISION
1910 E. UNIVERSITY, FRESNO, CALIFORNIA 93703 PHONE (209) 488-1412

September 12,1979

The Singer Company

1300 Federal Blvd.

Carteret, New Jersey 07008

Attention: Robert Shapess, Marketing Analyst

Gentlemen:

We are in receipt of your letter inquiring about our well water temperature. Our average well water temperature is between 69 and 72 degrees.

$\approx$

If we can be of further assistance, please do not hesitate to contact our office.

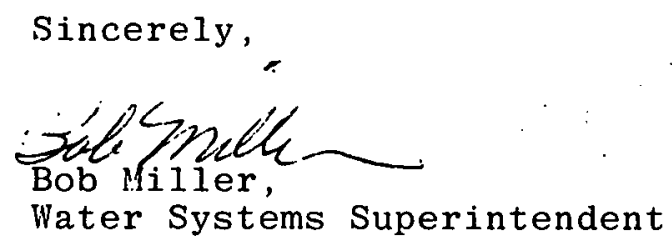

BWM : ss 
MIAMI-DADE WATER AND SEWER AUTHORITY

P. O. $80 \times 330316$

MIAMI. FLORIOA 33133
Main Office

3575 S. Le Jeune Road Telephone 665.7471

\author{
September 26, 1979
}

The Singer Company

1300 Federa1 Boulevard

Carteret, New Jersey 07008

Attention: Mr. Robert Shapess

$\mathrm{RE}$ : Solar Heating Research Project

Gent lemen:

Your letter requesting information for the subject project has been referred to me for reply.

The Authority obtains its raw water supply from underground supply wells. Consequently, our system water temperature remain constant throughout the year at $78^{\circ} \mathrm{F}$.

Should you have further question, call or write me.

Sincerely yours,

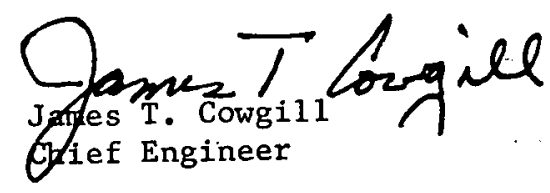

$\mathrm{JTC} / \mathrm{tn}$

cc: File 
ANALYSIS OF WATER DELIVERED TO MAINS

(MQ/I UNLESS OTHERWISTE NOTED)

\section{FLORENCE PLANT}

1978

\section{(CONT.)}

OHMAHA, NERR.

\begin{tabular}{|c|c|c|c|c|c|c|c|c|c|c|c|c|c|c|}
\hline \multicolumn{8}{|c|}{ * CCE-M (MINI SAMPLER) } & \multicolumn{7}{|c|}{$\Sigma=$ LESS THAN } \\
\hline & JAN & FEBR. & MAR. & APR. & MAY & JUtie & JULY & AUE & SEPT & OCT & nOV & DEC & AVSRACE & $\begin{array}{c}\text { U.S.E.P.A. } \\
\text { M.C.L. }\end{array}$ \\
\hline Awuixuy (AI) & $<0.03$ & $<0.03$ & 0.06 & 0.12 & 0.05 & 0.13 & 0.10 & 0.03 & 0.07 & 0.15 & 0.05 & 0.04 & 0.07 & \\
\hline CAOMUUM (CO) & & & $k n, 001$ & & & & & & & 50.001 & & & $k 0.001$ & 0.01 \\
\hline BARIUM (Ba) & & & $<0.25$ & & & & & & & $<0.25$ & & & $<0.25$ & 1.0 \\
\hline mencurr (Mo) un $/ 1$ & & & & & $<0,5$ & & & & & $1<0.5$ & & & $1<0.5$ & 2.0 \\
\hline \multicolumn{15}{|c|}{ RADIONUCLIDES $(p \mathrm{Ci} / \mathrm{I})$} \\
\hline ONOSSALPHA & 5 & & 2 & & 4 & & 3 & & & 3 & & & 3 & 15 \\
\hline GROSS BETA, & 10 & 11 & 10 & 10 & 11 & 10 & 10 & 12 & 10 & 10 & 10 & 10 & 10 & \\
\hline STRONTUU - so: & $<0.5$ & & $<0.3$ & & $<0.3$ & & $\leq 0.4$ & & & $\leq 0.6$ & & & $\leqslant 0.4$ & \\
\hline RADIUU-228 : & $<1.0$ & & $<1.0$ & & $<1.0$ & & $1<1.0$ & & & $<1.0$ & & & $<1.0$ & 5.0 \\
\hline 1001NE-131 $\quad \because \cdots$ & $<0.4$ & & & & & & $<0.3$ & & & & & & $<0.4$ & \\
\hline TRITIUN & $<2000$ & & $<2,000$ & & $<2,000$ & & $<2000$ & & & $<2000$ & & & $<2,000$ & 20,000 \\
\hline \multicolumn{15}{|c|}{ ORGANICS $(\mathrm{ug} / 1)$} \\
\hline ENORIN & & N.D. & & &. & & & & & & & & N.D. & 0.2 \\
\hline LIMOAME & & N.D. & & & & & & & & & & & $N \cdot D$. & 4.0 \\
\hline METHEXYEHLOR & & N.D. & & & & & & & & & & & N.D. & 100 \\
\hline TOXAPHENE & & N.D. & & & & & & & & & & & N.D. & 5.0 \\
\hline $2,4-0$ & & & & & & N.D. & & & & & & & N.D. & 100 \\
\hline $2.9 .8-18$ & & & & & & 0.17 & & & & & & & 0.17 & 10.0 \\
\hline $\begin{array}{l}\text { CARE SN CHUROFOAN } \\
\text { ETRACT }\end{array}$ & 489 & 393 & 670 & 61.6 & 515 & 563 & 440 & 553 & 450 & 427 & 9.78 & $\therefore 58$ & 407 & \\
\hline EATER TLGPSRATURE O $\mathrm{C}$ & 0.2 & 0.4 & 1.7 & 8.8 & 15.7 & 21.5 & 25.3 & 24.8 & 21.6 & 14.1 & 6.8 & 0.6 & 11.8 & \\
\hline
\end{tabular}


EL PASO, TEXAS

AVERAGE MONTHLY TEMPERAIURES

WATER TREATHENT PLANT EFFLUENT

$\begin{array}{ll}\text { August } 1978 & 78^{\circ} \mathrm{F} \\ \text { September } 1978 & 76^{\circ} \mathrm{F} \\ \text { October } 1978 & 71^{\circ} \mathrm{F} \\ \text { November } 1978 & 70^{\circ} \mathrm{F} \\ \text { December } 1978 & 70^{\circ} \mathrm{F} \\ \text { January } 1979 & 70^{\circ} \mathrm{F} \\ \text { February } 1979 & 70^{\circ} \mathrm{F} \\ \text { March } 1979 & 68^{\circ} \mathrm{F} \\ \text { April } 1979 & 70^{\circ} \mathrm{F} \\ \text { May } 139 & 73^{\circ} \mathrm{F} \\ \text { June } 1979 & 75^{\circ} \mathrm{F} \\ \text { July } 1979 & 79^{\circ} \mathrm{F} \\ \text { August } 1979 & 78^{\circ} \mathrm{F}\end{array}$

